\title{
Organizational culture, leadership and performance in context : trust and rationality in organizations
}

Citation for published version (APA):

Koene, B. A. S. (1996). Organizational culture, leadership and performance in context : trust and rationality in organizations. [Doctoral Thesis, Maastricht University]. Rijksuniversiteit Limburg. https://doi.org/10.26481/dis.19960913bk

Document status and date:

Published: 01/01/1996

DOI:

10.26481/dis.19960913bk

Document Version:

Publisher's PDF, also known as Version of record

\section{Please check the document version of this publication:}

- A submitted manuscript is the version of the article upon submission and before peer-review. There can be important differences between the submitted version and the official published version of record. People interested in the research are advised to contact the author for the final version of the publication, or visit the DOI to the publisher's website.

- The final author version and the galley proof are versions of the publication after peer review.

- The final published version features the final layout of the paper including the volume, issue and page numbers.

Link to publication

\footnotetext{
General rights rights.

- You may freely distribute the URL identifying the publication in the public portal. please follow below link for the End User Agreement:

www.umlib.nl/taverne-license

Take down policy

If you believe that this document breaches copyright please contact us at:

repository@maastrichtuniversity.nl

providing details and we will investigate your claim.
}

Copyright and moral rights for the publications made accessible in the public portal are retained by the authors and/or other copyright owners and it is a condition of accessing publications that users recognise and abide by the legal requirements associated with these

- Users may download and print one copy of any publication from the public portal for the purpose of private study or research.

- You may not further distribute the material or use it for any profit-making activity or commercial gain

If the publication is distributed under the terms of Article $25 \mathrm{fa}$ of the Dutch Copyright Act, indicated by the "Taverne" license above, 
Organizational Culture, Leadership and Performance in Context

Trust and Rationality in Organizations 


\title{
Organizational Culture, Leadership and Performance in Context
}

\author{
Trust and Rationality in Organizations
}

\section{PROEFSCHRIFT}

\author{
ter verkrijging van de graad van doctor \\ aan de Rijksuniversiteit Limburg te Maastricht, \\ op gezag van de Rector Magnificus, Prof. Mr M.J. Cohen, \\ volgens het besluit van het College van Dekanen, \\ in het openbaar te verdedigen op \\ vrijdag13 september 1996 om 14.00 uur \\ door
}

Bastiaan Anton Simon Koene 


\section{Promotor:}

Prof. dr A.M. Sorge (Humboldt Universität zu Berlin / Rijksuniversiteit Limburg)

\section{Copromotoren:}

Prof. dr J.L. Soeters (Koninklijke Militaire Academie)

Dr A.L.W. Vogelaar (Koninklijke Militaire Academie)

Beoordelingscommissie:

Prof. dr A. Van Witteloostuijn (voorzitter)

Prof. dr S.J.M. Maijoor

Prof. dr C. Wilderom (Katholieke Universiteit Brabant)

Koene, Bastiaan Anton Simon

Organizational Culture, Leadership and Performance in Context:

Trust and Rationality in Organizations

\section{(c) 1996 B.A.S. Koene}

Proefschrift Rijksuniversiteit Limburg Maastricht

Treiw : organisatiecultuur / leiderschap / management control / bedrijfsresultaat / organisatieleer ISBN $90-9009734-1$

Cover: M.E. Döderlein de Win / Art de Triomphe Maastricht Production: Datawyse Maastricht / Krips Repro Meppel 


\section{ACKNOWLEDGEMENTS}

Writing a dissertation is actually a quite unfair description of the actual process that leads to the completion of a Ph.D. It conveys a sense of loneliness, of performance of an utterly individual task. In practice, however, the largest leaps forward in the process of creating this dissertation were made in periods of intensive communication, discussion and argumentation with others. The 'technology of foolishness' (March, 1984) applies: often chaos, conflicting understandings, pieces of the puzzle that do not fit and deadlines increase production and are the source of the most creative solutions. Support, guidance and feedback of others are indispensable aspects of this process. Many people have helped me on my way, sometimes they didn't even know it, sometimes I didn't notice it until later. It is impossible to identify all who have contributed and I apologize to those who are inevitably, but unintentionally omitted here. Still, I would like to take the opportunity to thank some of them. First of all, this dissertation has greatly benefited from the comments of Sjo Soeters, Ad Vogelaar, and Arndt Sorge. I am grateful for their personal support and genuine concern for me as their student. Also I would like to thank Arjen van Witteloostuijn, Steven Maijoor and Celeste Wilderom for judging the final version of the manuscript and providing useful comments.

A word of thanks also goes to the many people who have given so generously of their time at the supermarket company that supported my research and where my field research took place. I would especially like to thank Paul, Patty, Wim, Geert and Herma. I have benefitted greatly from our discussions about the goals and later the outcomes of our research project. I also would like to thank Hein Schreuder and Hans Pennings for their support and guidance in starting my dissertation and steering it in the general direction of its accomplishment.

Furthermore, I would like to thank my collegues at the University of Limburg. Many of them have, at one time or another, had an impact on this dissertation. I benefited more from their comments, off the wall remarks, and true insights than I care to admit. I am especially indebted to Christophe Boone for his methodological insight; Bas van Diepen, Marielle Heijltjes and René Olie for their companionship; Anne-Wil Harzing for the office-space she gave me; Arjen van Witteloostuijn for his trust; and Piet Eichholtz. Steven Maijoor, and Hanno Roberts for stretching the scope of my intellectual reality. Marielle deserves a special word of thanks, as we shared an office for almost five years. She brought colour to our office, has been a most useful intellectual sparring partner and a source of truly dutch gepassioneerde nuchterheid.

Even more, I would like to thank my parents for instilling me with a curious and questioning mind and for their consistent support; my brother and sister for their friendship; my mother-in-law for the care she has given to our family; Hans Schenk for showing me the way to the world of academia and Business administration; the members of Chaupiques for Nino Rota and their comradeship; Frank Smulders for his insight. I must also thank Marc Straat for his loyal friendship. His never ceasing optimism and (intellectual) support when I learned to change diapers leave me greatly indebted. 
Most of all, however, I would like to thank the two people I love most. Marlène shares my life and does this with great dedication and commitment. In many ways she shows me the joys of living. Her support in the past years has been a great source of comfort and motivation. Berend is our common product, although by now he is developing into a truly independent member of our team. His love and trust are endearing. He never stops to amaze me. I dedicate this book to them. 


\section{CONTENTS}

1

\section{Introduction}

2 Organizational culture and leadership

The history of organizational culture

Roots in management theory

Definition of organizational culture

The impact of organizational culture

Organizational culture in context

Organizational culture and leadership

\section{Empirical studles of organizatlonal culture}

3.1 Organizational culture and climate

3.2 Organizational culture, climate and performance

The measurement of organizational culture and climate

Organizational culture, climate and performance

What can the studies tell us?

Further research

3.3 Context and culture formation

Two reviews: organizational climate as a dependent variable

Recent studies: organizational culture as a dependent variable

Determinants of organizational culture

Work satisfaction

Summary

Further research

\subsection{Conclusion}

\section{$4 \quad$ Leadership}

4.1 Management and leadership

4.2 Trends in leadership theory and research

Present foci for leadership research

4.3 Leadership as a relational concept: structuring and consideration

A theoretical basis: Performance and Maintenance

Initiating structure and consideration in the Netherlands

The impact of consideration and initiating structure

The situational dependence of leadership effectiveness

Summary

4.4 Extension of the leadership style research: charismatic leadership 
Personality differences between leaders and managers

The impact of charismatic leadership

Empirical research on charisma

Transactional and transformational leadership

Transformational leadership and performance

\subsection{Conclusion}

\section{Research questlons and research design}

5.1 Research questions

The operationalization of organizational culture and leadership

The influence of the organizational context

The impact of culture, climate and leadership on organizational performance Summary

5.2 The empirical setting

5.3 The research design

Sample

Data collection

Survey response

5.4 Procedure for data analysis

6 Varlable description

6.1 The questionnaire variables

The questionnaire data

Scale evaluation and variable construction: factor analyses

Evaluating scale reliability

Validating aggregation: within-store agreement

Descriptive statistics and correlations

Dimensions of organizational culture, climate and leadership

6.2 Performance variables

Performance indicators for supermarkel stores

Calculation of the performance variables

Selection of the performance variables

Performance development since 1989

Correlations between the performance variables

6.3 The context variables

Descriptive statistics and correlations

7 The organizational context

7.1 Organizational context and organizational performance

Multivariate analyses using LISREL

Organizationai context and performance 
Performance development

Summary: the impact of context on performance

7.2 Organizational context and the social variables

Multivariate analyses using LISREL

Two models relating context and social variables

7.3 Concluding remarks

8 The soclal variables and organizational performance

8.1 The social variables and organizational performance

8.2 Two models explaining the influence of the social variables on organizational performance

Store performance and the social variables

Store performance development and the social variables

Summary: impact of the social variables on organizational performance

8.3 Discussion

Leadership and organizational performance

Organizational culture, climate, satisfaction and performance

Performance development in the recent past

8.4 Concluding remarks, revisiting the research questions

9 Conclusion

9.1 Summary of the findings

9.2 Discussion of the findings: trust and rationality in organizations

9.3 Limitations of this study

9.4 Further research

9.5 Implications for management practice

\section{Literature}

\section{Summary in Dutch}

\section{Curriculum Vitae}

\section{List of abbreviations}




\section{CHAPTER 1}

\section{INTRODUCTION}

This book describes the outcomes of a study investigating the influence of organizational culture and leadership on organizational effectiveness. It was inspired by the genuine puzzlement of the management of a Dutch supermarket. chain by the practical significance of organizational culture for the performance of their supermarket stores. The chain's top management was reanalyzing the position and role of its store management. Studying store performance, they saw variations in performance that could not be explained by economic differences such as economies of scale, differences in the technical system reflected in variations in the stores' productivity standards, or market differences reflected in market potential for the specific stores. Rather, they felt these variations might be caused by differences in organizational culture. In general, the chain's management argued, there were differences in work attitudes and work atmosphere between the stores that every experienced store executive noticed upon entering a store. Besides they noted that store managers seemed to 'take their own culture along' as they moved from store to store.

What makes organizations effective? This central question has guided management researchers in their quest for understanding the functioning and impact of organizations in all forms and sizes. Management scholars have studied, for example, the organizational structure, employee behavior in organizations, and the relationship of the organization with its external environment. The cumulative results of these investigations are discussed in contemporary management textbooks (e.g. Daft, 1992; Johnson and Scholes, 1993; Robbins, 1996). In the past decade a 'new' aspect of organization has been added to the toolbox of organizational architects: the concept of organizational culture. By now the concept of organizational culture has been established as an important aspect of organizations. Parallel to the rise of interest in organizational culture, attention for leadership in organizations has increased, as leadership is considered important for building and sustaining an organizational culture. This book presents the results of an empirical study of the impact of organizational culture and leadership on organizational effectiveness.

\section{Purpose of this study}

In the past decade organizational culture has been established as an important organization variable. Yet, often the concept is used in a very general way. This study was initiated on the basis of three considerations regarding the present knowledge about organizational culture.

First, the importance of organizational culture for organizational performance needs reconsideration at the moment. In the past decade organizational culture has been propagated as a panacea for the problems facing modern organizations. It was 
established as an important, if not the most important, aspect of successful contemporary organizations. Several authors proposed that with the increasing complexity and dynamism of the business environment organizations should exhibit flexibility and adaptability, but also a consistent and focused identity (e.g. Handy, 1989; Mills, 1991). The 'simultaneous loose-tight properties' that Peters and Waterman attributed to 'their' excellent companies (Peters and Waterman, 1982) seemed to be the answer for companies trying to escape from bureaucracy, whilst maintaining their organizational identity. Organizational culture also seemed the answer to the call for a qualitatively different mechanism for coordinating and controlling the activities of organization members, whose changed attitudes to work and life in general made them ill at ease with the traditional organizational structures. In the past five years, however, with the increasing familiarity of the concept of organizational culture, the importance of other aspects of organizations is revaluated. In 1990 Elliott Jaques, a pioneer of the study of organizational culture in organizations (Jaques, 1951), published an article titled 'In Praise of hierarchy' (Jaques, 1990). In this article Jaques argued that the disfunctioning of the hierarchical model of organization was not caused by inherent shortcomings of the model, but by a lack of understanding of its functioning. Hierarchy in organizations remains important. Recently, other writers have also pointed to the increasing importance of the hierarchical mode of control in a number of very successful organizations (Ritzer, 1993). These developments make the evaluation of the impact of organizational culture and its role in the determination of organizational performance vis à vis other determinants of organizational performance important.

The second consideration for this study is related to the kind of organizational culture usually measured in quantitative empirical research. In practice, studies of organizational culture have not focused on differences in organizational culture between comparable organizations, but on differences caused by the type of work done in organizations. Most quantitative empirical studies of organizational culture identified differences in culture between organizations with completely different production technologies, thus focusing mainly on the impact of industry differences on organizational culture (Hofstede et al., 1990). Recent research has indicated that the dimensions describing organizational culture most currently in use reflect differences between industries being significantly more homogenous within industries (Chatman and Jehn, 1994). To study the impact of organization-specific differences in organizational culture the appropriate focus would thus be identifying differences in culture between organizations using identical technologies (operating in the same industry). Barney (1986) argued that this focus on differences in culture purely based on differences between comparable organizations is extremely important for management, because these are the differences that can provide a company with a competitive advantage over its direct competitors. This resource-based theory of the firm is interesting, but still rarely studied quantitatively (see for example Maijoor and van Witteloostuyn, 1996.) What aspects of organizational culture differ between organizations and influence organizational performance when technology is kept constant is one of the central questions addressed in the description of the outcomes of the empirical study presented in this book. 
The third and final consideration for this study was the fairly small amount of quantitative empirical research on the impact of organizational culture on organizational performance. Much of the empirical work on organizational culture has been qualitative in nature, often based in an anthropological research tradition (e.g. Frost et al., 1985; Trice and Beyer, 1993). Quantitative comparative research on organizational climate has a relatively long tradition (Payne and Pugh, 1976; Hellriegel and Slocum, 1974), and much of the early comparative studies of organizational culture used measures of organizational climate as approximations for organizational culture. Only a few studies, however, investigated the influence of organizational culture on the financial performance of organizations (e.g. Denison, 1990; Gordon and DiTomaso, 1992). In the empirical study presented in this book organizational culture, climate and leadership are studied quantitatively. The concepts are related to quantitative measures of organizational performance to verify their meaning for the effective functioning of organizations.

\section{Outline}

Figure 1.1 summarizes the issues studied in this dissertation and refers to the relevant chapters in this book. This dissertation contains nine chapters. In chapter 2 organizational culture is defined and put into a historical and theoretical context. It broadly explains my interest in organizational culture and the focus of study chosen in this dissertation.

Chapter 3 discusses the empirical literature on organizational culture and climate. It is argued that, although organizational culture and climate research are closely related concepts, there is a clear difference in focus. However, if well-interpreted, results from organizational climate research can help advance our understanding of the impact of organizational culture in organizations.

The influence of leadership in organizations is discussed in chapter 4. Leadership is mostly seen as an important determinant of organizational culture (e.g. Schein, 1992). Chapter 4 starts with a general discussion of the leadership concept, reviews the results of empirical leadership research in the past four decades, and argues for empirical research on the influence of leadership on organizational

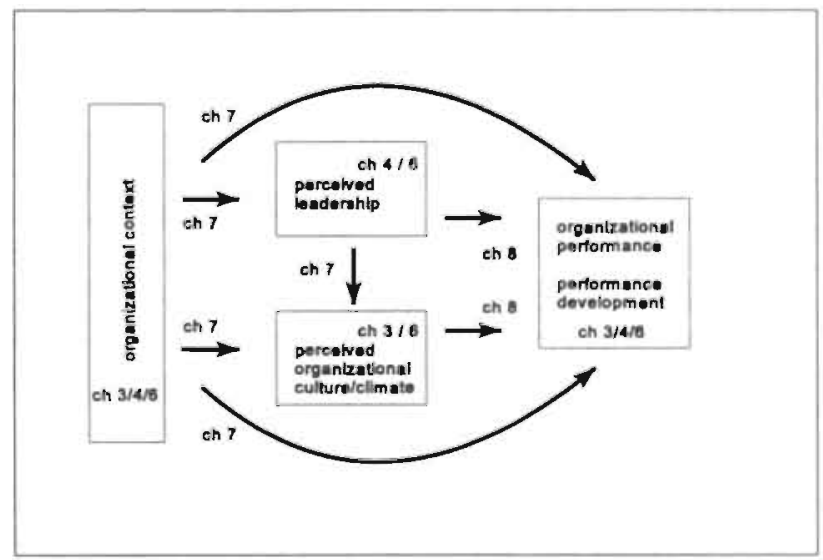

Figure 1.1 Chapter outline performance and its relationship with organizational culture. 
Chapter 5 concludes our theoretical discussion of organizational culture and leadership. Six research questions are formulated that summarize the conclusions of chapters 3 and 4 . These research questions guide the empirical investigation of the influence of organizational culture and leadership on organizational performance presented in chapters 6,7 , and 8 . Chapter 5 further describes the research design and the empirical setting of the field research.

The last four chapters describe and discuss the outcomes of the empirical research. Chapter 6 describes the empirical operationalizations of the variables used in this study and provides us with an evaluation of the quality of the data. Chapter 7 focuses on the influence of the formal organizational context on organizational performance and the social variables measuring leadership, organizational culture and organizational climate. Chapter 8 focuses on our central research question. It describes the influence of leadership, organizational culture and organizational climate on organizational performance. Finally, chapter 9 reviews the outcomes of chapter 7 and 8 and explores what the findings mean for our understanding of the impact of organizational culture and leadership in organizations. 


\section{CHAPTER 2}

\section{ORGANIZATIONAL CULTURE AND LEADERSHIP}

The understanding that organizational culture is an important factor for the success of business organizations has conquered the business world by storm in the first half of the 1980s. The recognition of the issue seems best exemplified by the enormous success of Peters and Waterman's book 'In search of excellence' (Peters and Waterman, 1982) of which by 1985 some 2.5 million copies had been sold (Freeman. 1985). Along with 'In search of excellence' a number of other very popular books were published focusing on the importance of what might be called the 'behavioral side of management and organization' (Denison, 1990). The interest in the concept of organizational culture can be explained partly by the Western curiosity about the success of Japanese enterprises (e.g. Ouchi, 1981; Pascale and Athos, 1981) that were rapidly becoming major players in the international business environment near the end of the seventies (Ohmae, 1985). Partly also, the emergence of the concept can be put into an historical perspective, showing that its present visibility can be understood from the changing view of organizations in the past decade (Sorge, 1989; Pfeffer, 1982). This chapter discusses the concept of organizational culture. First, its emergence will be put in a wider historical context. Then, the meaning of the concept will be discussed relating it to organization theory. Earlier contributions to organization theory have addressed a similar issue and can aid our understanding of the meaning of culture in organizations. After putting the concept in perspective organizational culture will be defined more precisely and our specific interest in the influence of organizational culture on organizational performance will be clarified.

\section{The history of organizational culture}

Taking a historical perspective, the past decades seem to show three broad stages in the development of management thought. From a preoccupation with productivity and growth, to an interest in the influence of organizations on people, and finally towards the recognition of the importance of people for organizational performance. Pfeffer (1982) described the first two stages. To begin, the 1950s and 1960 s showed a preoccupation with industrial growth reflected in the development of the bureaucratic mode of control, emphasizing organizational structure and formal control. Then the late 1960 s and 1970s, showed a different societal agenda resulting in a different focus in management studies:

'First, there was less respect for authority, in general, and work organization authority in particular. Work organizations could no longer be justified solely in terms of productivity, or profits; rather, new emphases came to be placed on their effects on the total human experience; emphasis grew on the quality of working life and, finally, the role of the workplace as a kind of substitute for other forms of affiliation such as families and communities (Ouchi and Jaeger, 1978). Second, with the increasing focus on politics in society came renewed 
attention to issues of power and politics in organizations' (Pfeffer, 1982: 30-31).

Consistent with these developments the beginning of the 1970 s witnessed an increased emphasis on the study of work climate and worker satisfaction in organizations (Hellriegel and Slocum, 1974; Payne and Pugh, 1976). Studies of work climate and satisfaction focused on the impact of the organization on the individual employee, consistent with the increased emphasis on the effects of work organizations on the total human experience and the issues of power and politics in organizations (Pfeffer, 1982). Employees were viewed as stakeholders in the organization that brought home more than just their pay check.

Still further on, the economic recession at the beginning of the 1980 s necessitated a renewed focus on organizational productivity and profitability in a manner consistent with the new understandings about employee relations that had developed in the 1970s. At that time, the third stage of management thought set in, emphasizing the importance of people for organizational performance. The organizational environment was growing increasingly competitive, complex and dynamic. The Japanese industrial challenge raised Western curiosity about the importance and possibilities of organizational culture as a competitive factor. Studies of Japanese management techniques seemed to point to the importance of group motivation and organizational culture (Pascale and Athos, 1981; Ouchi, 1981).

At the same time organizational culture was 'discovered' as an important aspect of successful 'Western' organizations. Peters and Waterman's excellent companies were all U.S.-based organizations (Peters and Waterman, 1982) and, although using concepts borrowed from Japanese examples, Ouchi and Jaeger (1978) described the emergence of their 'theory Z-organizations' as logically based in the development of Western society rather than as a reaction to the competitive pressures from 'the East.' Sorge (1989) argued that a general reorientation of thinking occurred, from a world view built on logic, reality as the sum of the explanations of the parts, and a striving for universalistic principles, to a view accepting paradox, focusing on holistic explanations of reality, and a recognition of the idiosyncracy ('partikularität') of specific situations (Sorge, 1989). Both the interest in Japanese management techniques and the changing approach to management issues in the West have resulted in an increased attention for organizational culture. As a mechanism for coordination and control in organizations it seemed particularly attractive and promising. Organizational culture was seen as a crucial factor for sustained organizational viability of organizations of the future, as it seemed to influence the possibilities for organizational learning and creativity, and thus for sustained organizational effectiveness (e.g. Senge, 1990; Mills, 1991).

Thus, in the late 1970s and early 1980s the interest in organizational culture as an aspect of organizational functioning and an important management issue became thoroughly established. In the scientific community, organizational culture became a hot and much debated topic. In general the economic importance of culture was established by Hofstede in his book 'Culture's Consequences' (Hofstede, 1980). Hofstede (amongst other things) found that national culture was statistically related to national 
economic performance (Hofstede, 1980). Also the general idea of the impact of organizational culture quickly established itself. It may be best exemplified by Ouchi (1980) who described the organizational value system as a coordinating mechanism next to the organizational hierarchy and the price mechanism of the market. In organizations relying on the clan mechanism common traditions and shared values guided the actions of individual members of the organization, making rules and formal procedures superfluous (Ouchi, 1980). Similarly, Mintzberg described the missionary configuration (1979) and the 'quasi-missionary type' of organization (1983), where the behavior of organization members was coordinated largely through socialization and the resulting standardization of norms. Ideology could be considered the key part of this kind of organization. Now, with thedevelopment of organizational culture research as an established field of study, textbooks on organizational culture start appearing to claim their place next to volumes about strategy, structure and formal management control (Trice and Beyer, 1993; Hofstede, 1991; Schein, 1992).

\section{Roots in management theory}

The concept of organizational culture is not that new. As early as 1951 the Tavistock Institute published a longitudinal study of the development of the organizational culture of a British steel factory from 1948 to 1950 (Jaques, 1951). In this study organizational culture was defined in a manner consistent with most contemporary textbook definitions of the concept (e.g. Robbins, 1993):

'The culture of the factory is its customary and traditional way of thinking and of doing things, which is shared, to a greater or lesser degree by all its members, and which new members must learn, and at least partially accept, in order to be accepted into service in the firm.' (Jaques, 1951:251)

Lammers (1986) pointed out that the organizational form Peters and Waterman (1982) describe as excellent resembles the organic model of Burns and Stalker (1961) and the representative organization of Touraine (1965). In a similar attempt to capture the theoretical essence of excellent (culture driven) organizations Soeters showed their resemblance to social movements, emphasizing the difficulty of maintaining the intense involvement of organization members generated by 'charismatic activation' (Soeters, 1986:308), and their possibly myopic attitude to their external environment:

'In the process of mobilization, the transfer of values gets absolute priority. Thus, the employees are integrated into the movement in such a way that there are few opportunities to have an independent life outside the movement. (...) The group conscience overwhelms individual opinions. (...) In an almost monomaniac way, the central beliefs of the movement are endlessly repeated.' (Soeters, 1986:304)

In fact, attention for organizational culture or its equivalents has been around as long as most other constructs of organizational theory. Two important early contributions to our understanding of organizational culture were Barnard's discussion of the informal 
organization (Barnard, 1938) and Selznick's description of the process of institutionalization (Selznick, 1957).

Chester Barnard's 'The functions of the executive,' published in 1938, can safely be considered one of the first comprehensive management texts. Barnard described the importance of the social structure of the organization elaborately. His discussion of organizational purpose (Barnard, 1938:86) can be compared to contemporary discussions of the organization's mission. His discussion of the function of the informal organization (p.122) and its importance for decision-making (p.186) is similar to contemporary discussions of the impact of organizational culture. Barnard summarizes the role of the informal organization as follows:

'The chief functions of this informal organization are expansion of the means of communication with reduction in the necessity for formal decisions, the minimizing of undesirable influences, and the promotion of desirable influences concordant with the scheme of formal responsibilities.' (Barnard, 1938:227)

Finally, Barnard focuses on 'the moral aspect of cooperation' which he distinguishes from the organizational structure and process. Barnard defines morals as guiding and controlling the behavior of individuals (Barnard, 1938:261). His discussion of moral codes shows the responsibility of the executive in the formation of organizational cultures or 'moral codes' (p.274). Barnard argues that in this respect 'established organizations seem to outgrow their leaders.' Here Barnard points to the process of institutionalization, more elaborately discussed by Selznick (1957).

Selznick focuses on the process of institutionalization in organizations which he describes as the 'institutional embodiment of purpose.' Selznick argues that it starts where the role of organizational engineers stops:

'From the engineering perspective, the organization is made up of standardized building blocks. ... The limits of organization engineering become apparent when we must create a structure uniquely adapted to the mission and role of the enterprise. ... certain firms or agencies are stamped by distinctive ways of making decisions or by peculiar commitments to aims, methods, or clienteles. In this way the organization as a technical instrument takes on values. ... This process of becoming infused with value is part of what we mean by institutionalization.' (Selznick, 1957:138)

The above definition clearly points to the process of culture formation, the formation of a corporate value system (Peters and Waterman, 1982:279). The 'distinctive ways of making decisions' point to organizational practices that can arguably be considered to be the heart of organizational culture (Hofstede et al. 1990).

\section{Definition of organizational culture}

After gaining a general idea of the meaning of organizational culture in organizations it 
is time to turn to a formal definition of the construct in the context of this study. In this book we follow Hofstede's definition of culture as 'the collective programming of the mind which distinguishes the members of one human group from another,' thus focusing on cultures as systems of values (Hofstede, 1980:21). Focusing on mental programming Hofstede's definition of culture is clearly in line with the view adopted by Trice and Beyer (1993). Trice and Beyer follow Geerlz (1970) describing culture as the mental complement to the kind of genetic programs that pattern animal behavior:

'Because human behavior is less specifically regulated by genetic programs, it exhibits greater variability and pliability. Throughout human history, cultures have provided much of the additional guidance needed for human beings to collectively survive, adapt, and achieve. For what the genetic code does not provide, human beings have developed cultural codes. (...) Organizations, like other social collectivities, tend to produce and preserve shared responses and shared experiences of uncertainty and chaos. (...) Collectively they hold certain ideologies about how to deal with recurrent problems and uncertainties. They arrive at their shared ideologies through collective experience and repeated social interactions over time.' (Trice and Beyer, 1993:3-4)

In the study of organizational cultures the human groups of interest are work organizations and the cultures studied organizational cultures. Now, what is the place of organizational culture in the whole of organizations? We view organizational culture as an independent aspect of organizations, which, although interrelated with other aspects of the organization, has a momentum of its own. As postulated by Pennings and Gresov (1986) the organization's cultural subsystem is interrelated with the organization's techno-economic and structural sub-systems and with societal level technoeconomic, structural, and cultural subsystems.

Our definition of culture also positions culture clearly outside the mind of the crganization's member. Although the individual's perceptions of culture and the culture itself are closely related, culture is the product of social interaction and as such has an impact on the perceptions of the individual actor. Or as Geertz put it: 'Man is an animal suspended in webs of significance he himself has spun; I take culture to be those webs' (Geertz, 1973:5; quoted by Allaire and Firsirotu, 1984). Even when studying culture as the shared aspects of individual's belief systems (Eoyang,1985) culture must be considered as independently developing from the individual belief systems, because for transmitting messages between actors there is a shared system of coding and decoding that resides outside the individual and can only be changed by collective action.

The assumption that organizational culture should be conceived as an independent product of interaction between individuals means that: (1) organizational culture should be studied at the organizational level and not at the level of single individuals;

\footnotetext{
' Considering organizational culture a 'product of minds' independent of the perceptions of the individual actor does not mean that it is impossible to study organizational culture using individual's perceptions of it. When studying organizational culture, looking at average culture scores might give perceptions of aspects of culture from which the individual's bias has been filtered out. (see chapter 6)
} 
(2) individuals can differ in their amount of 'integration' and personal identification with the culture; and (3) creative and significant individuals can influence the organization's culture.

\section{The impact of organizational culture}

What is the influence of culture in organizations? Generally, we can distinguish two types of answers to this question. One type of answer focuses on the nature of organizational culture and describes what it means to 'have' a culture (e.g. Trice and Beyer, 1993). It emphasizes the influence of culture on group processes. The other answer focuses on the influence of organizational culture on the effectiveness of work organizations (e.g. Ouchi, 1980). It is this second focus that will be addressed in this book.

An example of the first type of description comes from the recent work of Trice and Beyer (1993). In their general opening discussion about organizational culture they describe the construct through its characteristics and its consequences. Cultures are collective, emotionally charged, historically based, inherently symbolic, dynamic, and inherently fuzzy. Positive consequences of cultures are the management of collective uncertainties, the creation of social order, continuity, collective identity, and commitment. Negative consequences are subsumed under the heading of the encouragement of ethnocentrism, pointing to the risks of rigidity, selective perception and extreme commitment (Trice and Beyer, 1993: 2-12). These descriptions of the effects of organizational cultures focus on their meaning for the understanding of the functioning of groups of people, but not specifically on the meaning of organizational culture for the functioning of work organizations.

In this dissertation, however, we will focus on the influence of organizational culture on the effectiveness of work organizations. An important contribution to the understanding of the influence of organizational culture on work organizations was made by Ouchi in 1980. In his article 'Markets, hierarchies and clans' (Ouchi, 1980) he distinguishes three 'mechanisms of mediation or control' for organizations: market prices, hierarchical rules, and clan traditions. Reliance on the market mechanism actually means no organization, activities of individuals being coordinated and controlled through the price mechanism in the market. In contrast, hierarchies and clans provide alternatives for the market mechanism through formal organization. Reliance on hierarchy means coordination and control of activities through a system of rules enforced by legitimate (organizational) authority. Reliance on clan traditions.means coordination and control of activities through shared values and traditions that tell organization members what to do (Ouchi, 1980). The clan mechanism thus can be seen as an operationalization of the organizational culture construct 'avant la lettre.' This description of the impact of organizational culture focuses on the effect of shared values and strongly advocates a reliance on strong cultures as mechanisms for organizational coordination and the direction of organization members to a set of common goals. A whole stream of research has followed the article of Ouchi focusing on the importance of organizational culture in organizations. It differed from the earlier work on organizational climate in that the emphasis was now on the impact of behav- 
ioral premises of employees on their work behavior, rather than on the influence of the work situation on employees' (work) attitudes.

Over time, the argument about the impact of organizational culture in organizations has become more subtle. To organize the literature Denison (1990) distinguished four 'basic hypotheses' describing the different processes by which culture can influence organizational performance: the involvement hypothesis, the consistency hypothesis, the adaptability hypothesis, and the mission hypothesis. The four hypotheses should be read as broad research questions that have guided studies of organizational culture. The four hypotheses fit a framework based on two distinctions (see also table 2.1 below): (1) organizational culture can either influence internal or external effectiveness of the organization; (2) organizational culture has been studied as either a facilitator of change, or a force aiding organizational stability.

Table 2.1 'The culture and effectiveness model' (Denison, 1990:15)

\begin{tabular}{|l|l|l|}
\hline $\begin{array}{l}\text { external point of } \\
\text { reference }\end{array}$ & Adaptability & Mission \\
\hline $\begin{array}{l}\text { internal point of } \\
\text { reference }\end{array}$ & Involvement & Consistency \\
\hline & $\begin{array}{l}\text { change and } \\
\text { flexibility }\end{array}$ & $\begin{array}{l}\text { stability and } \\
\text { direction }\end{array}$ \\
\hline
\end{tabular}

Denison describes the involvement hypothesis as guiding the research that considers organizational culture as a variable that influences intrinsic motivation of employees. It relates to Ouchi's idea of clans (1980) and to the positive impact on performance of employee participation (Miller and Monge, 1986). Looking at the impact of organizational culture through the lens of the involvement hypothesis, we see culture as influencing individual employee's values and (work-) goals, thus influencing their sense of responsibility and ownership of the organizational goals (Denison, 1990). It focuses on enhanced self and social control by the organizational participants.

The consistency hypothesis focuses on the impact of organizational culture on organizational consensus and coordination. It builds on the premise that a strong culture clarifies what needs to be done in the organization, thus reducing the need for corrimunication. The consistency hypothesis focuses on the organizational level impact of organizational culture. It is an efficiency argument focusing on the fact that a common value base facilitates interaction between organizational participants and the coordination of their activities. A related issue is the possibly negative influence of the relatively rigid organizational value base in cases of organizational change (Schwartz and Davis, 1981).

The adaptability hypothesis focuses on the impact of organizational culture on the organizational ability to change. Denison grounds this in two distinctive arguments. One is that organizational culture provides clarity and security. It provides overall structure and thus makes adaptive behavior on a lower level less uncertain and threatening. The ability to 'see the big picture' enhances the likeliness of adaptation and change within it. The other argument focuses on three specific aspects of organi- 
zational culture that influence the organizational member's ability and willingness to adapt: (1) the ability and willingness to perceive and respond to the external environment (external customers); (2) the ability and willingness to respond to internal customers (cooperation within the organization); and (3) the capacity to restructure and reinstitutionalize changes in the organizational culture (Denison, 1990:12). This means that, on the one hand, a strong culture can provide security and clarity, facilitating change within the existing grand organizational arrangements. On the other hand, it means that certain cultures promote adaptability more than others.

The fourth 'lens' for looking at culture Denison distinguished can be described as the 'mission hypothesis.' It focuses on the 'shared definition of the function and purpose of an organization and its members.' (Denison, 1990:13) The organizational mission provides a sense of direction and meaning to the work in the organization. It focuses on the organizational culture as the heart of the organizational identity and the organization's role and place in the larger society, thus enhancing its member's identity. In this way, Denison argues, organizational culture adds to the long-term commitment of members to the organization, and it provides clarity and direction (Denison, 1990). The emphasis here is on the legitimating role of the organizational identity. A related argument was proposed by Selznick (1957) who described institutionalization as the 'process of becoming infused with value.' Selznick described the critical role of leadership as (1) setting the basic mission of the organization, and (2) creating a social organism capable of fulfilling that mission (Selznick, 1957:135-136). A similar role for organizational culture was described by Weick (1985), who argued that 'both strategy and culture contain premises, axioms, and first principles that define the nature of appropriate action' (Weick, 1985:383).

A discussion of culture and its function as a management tool also asks for attention to the ethics of the 'ideological' side of organizational culture. A 'strong' corporate identity might well be all-absorbing and relentless in dealing with individual idiosyncrasies and creativity (Soeters, 1986), promote 'groupthink' (Janis, 1983), and corporate myopia (Soeters, 1986; Earl, 1984). Strong corporate ideologies also provoke opposition. Golden (1992) points out how people cope with the coercive forces of cultures and are able to 'survive' them. In the curiosity about organizational culture there may be an underlying wish to promote what has been called 'organizational citizenship behavior' in work organizations, a situation where individuals voluntarily help others on the job without the promise of rewards (Organ,1988). Lack of attention to the important moral and political issues in this regard limits our understanding of the nature of organizational citizenship behavior. In an evaluation of the development of the research on organizational culture Sorge (1989) strikes a similar chord. He argues that when discussing the impact of organizational culture it is important to keep in mind the holistic nature of the concept and its key concern with the specifically human additions to the functioning of organizations. Sorge argues that the 'Humanistische Anspruch' of organizational culture is arguably its most important contribution to management theory. It emphasizes the specific human qualities of creativity, learning to achieve goals, and the human ability to reevaluate organizational goals and set new targets for learning in the organization. He warns against the use of the concept as a narrowly defined management tool for steering and controlling the work force, be- 
cause then it looses its signiticance and meaning (Sorge, 1989:204).

\section{Organizational culture in context}

After discussing the impact of organizational culture in organizations it is important to put the impact of organizational culture in perspective. However, questions like 'In what kind of organizations is organizational culture most important?' and 'Are there substitutes for culture as far as its impact on organizational performance is concerned?' have not been addressed in the literature. Most writers only pay lip service to the idea that organizational culture is an organizational subsystem that interacts with other organizational subsystems. Arguments for a thorough analysis of the interrelationships (e.g. Pennings and Gresov, 1986) have not yet found their way into empirical analyses. The issue of the complementary nature of these subsystems and even their partial interchangability, as already addressed by Ouchi (1980) and Wilkins and Ouchi (1983), is a related subject that has been neglected. After a decade in which the importance of the organizational culture construct for explaining organizational functioning has been firmly established, the interrelationships between the several 'competing' organizational control mechanisms of which organizational culture is only one, seems to deserve careful attention.

This understanding puts into perspective the claims of management gurus in the beginning of the nineties who prophecized the emergence of a new type of flexible firms, largely relying on organizational culture (the clan mechanism) for the kind of simultaneous loose-tight properties (Peters and Waterman, 1982) needed to maintain coordinated creativity and flexibility in the midst of an ever faster changing environment (e.g. Handy, 1989; Mills, 1991). It is consistent with the recent arguments of writers pointing out the remaining importance of the hierarchical mode of control (Jaques, 1990; Romme, 1996) and the evidence for the resurgence of hierarchical modes of control and coordination in of a number of highly successful, large, mostly international, organizations (Ritzer, 1993). These organizations rely strongly on task. specialization, routinization and hierarchy. The increasing success and importance of these organizations, coined by Ritzer (1993) as the 'McDonaldization of society,' creates an awareness of the remaining importance of the formal organizational structure in organizations. Therefore, the aim of this dissertation study is to evaluate the impact of organizational culture empirically, studying the importance of organizational culture in relation to the organizational context.

\section{Organizational culture and leadership}

The growing interest in organizational culture in the past decade has been accompanied by a renewed attention for leadership in organizations (e.g. Schein, 1985, 1992; Siehl, 1985; Eoyang, 1985; Smith and Peterson, 1988; Bryman, 1992). In any discussion of organizational culture, the concept of leadership seems crucially important. In one of the first comprehensive texts on organizational culture Schein $(1985,1992)$ emphasized the interrelatedness of the two concepts: 
'When one brings culture to the level of the organization and even down to groups within the organization, one can see more clearly how it is created, embedded, developed, and ultimately manipulated, managed, and changed. These dynamic processes of culture creation and management are the essence of leadership and make one realize that leadership and culture are two sides of the same coin.' (Schein, 1992:1)

For this reason it seems important to include the concept of leadership in any study that investigates the importance of organizational culture in relation to its organizational context. Chapter 4 discusses the influence of leadership in detail. 


\section{CHAPTER 3}

\section{EMPIRICAL STUDIES OF ORGANIZATIONAL CULTURE}

In this chapter the empirical research on organizational culture will be reviewed. The chapter focuses on the quantitative empirical evidence for the existence of organizational culture and its influence in work organizations. In the first section the difference between organizational culture and organizational climate is discussed. This discussion shows the two concepts are essentially different, but closely related. Then, in section 3.2, the results of studies measuring organizational culture and organizational climate are summarized. Furthermore, the evidence for their influence on organizational performance is discussed. It is shown that some gaps remain in the comparative analysis of organizational cultures and the evaluation of the impact of culture on organizational performance. After that, section 3.3 focuses on the influence of the organizational context on culture and climate formation. Further investigation of the impact of organization structure, objective management characteristics, and employee demography on organizational culture seems useful. Finally, section 3.4 concludes by summarizing the important research questions remaining to be answered.

\subsection{Organizational culture and climate}

Before proceeding with a discussion of the empirical research on organizational culture, the 'culture-climate debate', as Denison (1990) calls it, needs to be addressed. Although organizational culture and climate are two (empirically) closely related concepts, there is a fundamental difference between them. Understanding this difference enriches our understanding of both concepts.

Climate research, on the one hand, focuses on the description of the work-atmosphere as perceived by the organizational members. Climate measures can be seen as an evaluation of the present work environment by the employees of an organization (e.g. James and Jones, 1974; Hellriegel and Slocum, 1974). Culture research, on the other hand, is trying to map behavioral preferences of organization members (e.g. Hofstede, 1980; Eoyang, 1985). At the heart of the matter, scholars of organizational culture are not interested in what people think. Students of organizational culture look at the underlying mechanisms that influence human perception, motivation and action. They focus on how members of organizations organize and relate their various ideas and understandings of the workplace, and how they approach and solve problems (Eoyang, 1985). Students of organizational climate, on the other hand, register the outcomes of this process. They focus on the perceived work atmosphere, as it is measurable in organizations. The distinction can be clarified by looking at an example. In a review of the differences between organizational culture and organizational climate research. Denison (1990) argues that power distance (as an aspect of organizational culture) and aloofness (as an aspect of organizational climate) clearly represent the overlap between culture and climate. These two concepts, however 
show clearly the difference in focus between culture and climate. 'Power distance' refers to the prior disposition (or norm) of an individual in a group towards acceptance of power inequalities. 'Aloofness' expresses the individuals judgment of a situation, using this norm: a supervisor is perceived as aloof if his behavior creates a larger power inequality than the subordinate judges as desirable, comparing it to his own norms.

However, the difference between operationalmeasures of organizational culture and climate is fuzzy and has been questioned lately, most directly by Denison (1990, 1993). When reviewing the literature both terms seem be used as substitutes, with just a slight difference. In their review of 'theories of organizational cultures' Allaire and Firsirotu (1984) position organizational climate studies at the origin of the organizational culture research:

'Indeed, it may be asserted that the body of literature and research on organizational climate was the first and, till recently, foremost attempt at giving an empirical basis to the notion of 'culture' in organizations.' (Allaire and Firsirotu, 1984:204)

In his review of the 'culture-climate debate' Denison (1990) concludes that, in essence, culture and climate researchers are investigating the same subject. He supports this with the following argument:

'First, both concepts focus on organization-level behavioral characteristics, (...) second, both concepts cover a very wide range of phenomena. Topics range from the deeply held assumptions that form the basis of a culture to the actual practices and patterns of behavior that are rooted in those assumptions. (...) More important, the relationship between these two extremes (underlying assumptions and actual behaviors) is perhaps the most interesting aspect of the phenomenon to study. Third, both concepts share a similar problem. They must explain the way in which the behavioral characteristics of a system affect the behavior of individuals, while at the same time explain the way in which the behavior of individuals, over time, creates the characteristics of an organizational system.' (Denison, 1990:24)

It is too easy, though, to collapse organizational culture and climate into one construct. Denison's first and third argument are important, because they point to the fact that empirical researchers in culture and climate research can learn from each other. Regarding the second point, however, there seems to be some merit in looking at the behavioral characteristics of organizations from different viewpoints. It certainly seems wise, as Denison argues, to integrate the ideas from culture and climate research. This, however, does not mean that the two constructs should be collapsed into one construct. Collapsing them implies not appreciating the conceptual difference in focus between culture and climate research. In fact, students of organizational culture seem to have occupied some territory that has been left almost unexplored by the climate researchers. When Hellriegel and Slocum evaluate the research on organizational climate in 1974 they argued: 
'In sum, there seems to be an overemphasis, relatively speaking, on people oriented scales. This may be partially a consequence of abstracting climate items from satisfaction scales. [...] A more subtle explanation, which admittedly is somewhat speculative, is that most instruments have been developed by professionals with a strong background in psychology who are primarily interested in the human side of the enterprise.' (Hellriegel and Slocum, 1974:261)

When looking at the difference between organizational climate and organizational culture research it seems that this is exactly the void that culture researchers have tried to fill. Where climate research focuses mostly on employee perceptions of their own work situation, organizational culture research investigates the organizational value base that influences employee behavior. Investigating this value-base means measuring the premises guiding employee behavior. Differences in these premises are reflected in the different ways in which people interpret similar work situations and the actions they propose to cope with typical organizational problems. Still, however, the differences reside mostly on the level of the analytical premises of study. Especially in the quantitative empirical research domain, the differences between the two concepts seem to disappear. This might be caused by the non-availability of welltested organizational culture questionaires. Much of the recent quantitative research on organizational culture uses measures of organizational climate as proxies for the measurement of underlying organizational culture (e.g. Denison, 1984, 1990). Recently, however, Hofstede et al. (1990) and O'Reilly et al. (1991) developed survey instruments to measure the organizational culture construct. These instruments are attempts to chart the value base of the organization members, rather than their work attitudes. Using these instruments might enhance the interpretability of results when testing hypotheses about the impact of organizational culture in work organizations.

\subsection{Organizational culture, climate and performance}

There are still relatively few studies using quantitative empirical techniques for studying the impact of organizational culture on organizational performance. Perhaps this is due to the definition of the concept, which is a broad and holistic one. Most theoretical definitions of organizational culture emphasize the richness and the complexity of the phenomenon. Especially when trying to distinguish organizational culture from organizational climate this richness and complexity are being emphasized. However, many studies lack an empirical base, are exploratory case studies, or are grounded in the Organizational Behavior research tradition greatly relying on studies investigating the impact of organizational climates in organizations (see section 3.1). A general complaint of writers focusing on the impact of organizational culture on organizational performance is the lack of empirical work on the topic (Denison, 1990; Hofstede. 1990). Furthermore, very few empirical studies have related cultural characteristics to some measure of corporate financial performance. On top of this, the results of these few studies were mixed (Gordon and DiTomaso, 1992). These mixed results might partly be due to empirical limitations of the studies. 
This section reviews the literature on what Hofstede (1991) called 'the soft factor in organizations' and the latter's influence on organizational performance. The focus will be on quantitative empirical studies of organizational culture and climate and on studies that directly link organizational culture and climate to organizational performance. It is important to recognize that we focus on the organizational level of analysis. For our evaluation of previous work on climate this means that studies focusing on what James and Jones (1974) define as 'organizational climate' will contribute most to our understanding. Table 3.1 summarizes the studies that we investigated, either reporting on the effect of organizational culture and climate on organizational performance empirically, or proposing empirically testable hypotheses. To get an idea of the importance of these studies for our understanding of the organizational culture performance nexus the following four questions are answered below.

1 How are organizational culture and climate measured?
2 How are they related to organizational performance?
$3 \quad$ What do the results of these studies tell us about the relationship between
$4 \quad$ organizational culture and organizational performance?
4 What do these findings imply for further research?

\section{The measurement of organizational culture and climate}

Many of different approaches have been selected to study the 'soft factor in organizations.' It has been studied as organizational climate (Ostroff, 1993; Hansen and Wernerfelt, 1989; de Cock et al., 1984; Gordon and Cummins, 1979; Lawler III et al., 1974; Payne and Mansfield, 1973), and as organizational culture (Sheridan, 1992; Gordon and DiTomaso, 1992; O'Reilly et al., 1991; Hofstede et al., 1990; Denison, 1990, 1984; Reynolds, 1986; Gordon, 1985). Other studies focused on specific aspects of organizational culture and climate like job satisfaction and organizational commitment (Tett and Meyer, 1993) or customer service climate (Weitzel et al., 1989; Schneider et al., 1980). A number of the studies investigating organizational culture also make use of measures of organizational climate as approximations for organizational culture in their empirical analyses (e.g. Denison, 1990, 1984) or work with instruments that were developed from scales that were intended to measure organizational climate (Gordon and DiTomaso, 1992; Gordon 1985). Instruments especially developed to measure organizational culture are still extremely scarce. Hofstede et al.'s 'Organizational culture module' (1990) and O'Reilly et al.'s 'Organizational culture profile'-instrument (1991) are two influential examples.

However, the differences between the measurements of organizational culture and climate have to be placed in perspective. As discussed in section 3.1, the climate instruments are measuring the respondent's evaluation of his work environment against his individual values, whereas the culture instruments attempt to measure individual attitudes that reflect differences in work-related values between people. However, due to the nature of quantitative empirical measurement, both climate 
Table 3.1 Evaluating the impact of organizational culture and climate in organizations

\begin{tabular}{|c|c|c|c|c|}
\hline Author(s) & $\begin{array}{l}\text { Independent } \\
\text { variables }\end{array}$ & $\begin{array}{l}\text { Intermediary / con- } \\
\text { textual }\end{array}$ & Dependerıt variables & Description \\
\hline $\begin{array}{l}\text { Sheridan (1992), } \\
\text { organizational culture } \\
\text { and employee retention, } \\
\text { AMJ }\end{array}$ & $\begin{array}{l}\text { organizational cultu- } \\
\text { re profile. } 7 \text { dimensi- } \\
\text { ons (O'Reilly et al., } \\
\text { 1991) significant: } 1 \\
\text { detail; } 2 \text { stability; } 4 \\
\text { team orientation; } 5 \\
\text { respect for people. } \\
\text { also significant: } \\
\text { culture "performance } \\
\text { interaction }\end{array}$ & $\begin{array}{l}\text { gender, marital } \\
\text { status, salary, } \\
\text { grade point avera- } \\
\text { ge, University lo- } \\
\text { cation, performan- } \\
\text { ce, voluntary termi- } \\
\text { nation }\end{array}$ & $\begin{array}{l}\text { + employee reten- } \\
\text { tion }\end{array}$ & $\begin{array}{l}\text { compared } 6 \text { identical organizations (accounting firms, } \\
\text { period } 6 \text { years). also makes argument for comparing } \\
\text { identical organizations (1039). conclusions show culture } \\
\text { effect to be stronger than person-job-fit effect ( } 1051 \text { ) and } \\
\text { significant effect of interaction job performance }{ }^{*} \text { culture. }\end{array}$ \\
\hline $\begin{array}{l}\text { O'Reilly, Chatman and } \\
\text { Caldwell (1991), people } \\
\text { and organizational } \\
\text { culture: a profile com- } \\
\text { parison approach to as- } \\
\text { sessing person- } \\
\text { organization fit, AMJ }\end{array}$ & $\begin{array}{l}\text { organizational } \\
\text { culture profile } \\
\text { instrument. } 7 \\
\text { dimensions. }\end{array}$ & $\begin{array}{l}\text { person-job fit on } \\
\text { cultural dimensions }\end{array}$ & $\begin{array}{l}\text { job satisfaction and } \\
\text { organizational } \\
\text { commitment after } 1 \\
\text { year. job turnover } \\
\text { after } 2 \text { years }\end{array}$ & $\begin{array}{l}\text { organizational culture profile - instrument. norms } \\
\text { regarding the completion of the work tasks (three): } 1 \\
\text { detail, } 2 \text { stability and } 3 \text { innovation. norms regarding } \\
\text { interpersonal relationships (two): } 4 \text { team orientation and } 5 \\
\text { respect for people. norms regarding individual actions } \\
\text { (two): } 6 \text { outcome and } 7 \text { agressiveness. }\end{array}$ \\
\hline $\begin{array}{l}\text { Hansen and Wernerfelt } \\
\text { (1989), determinants of } \\
\text { firm performance: the } \\
\text { relative importance of } \\
\text { economic and orga- } \\
\text { nizational factors, } 5 \mathrm{MJ}\end{array}$ & $\begin{array}{l}\text { economic variables } \\
\text { and organizational } \\
\text { variables. } \\
\text { 'survey of organiza- } \\
\text { tions' (Taylor and } \\
\text { Bowers, 1972) two } \\
\text { variables selected: } \\
\text { a. emphasis on } \\
\text { human resources; b. } \\
\text { emphasis on goal } \\
\text { accomplishment }\end{array}$ & & $\begin{array}{l}\text { 5-year average } \\
\text { return on assets } \\
\text { (compustat) } \\
\text { organizational } \\
\text { (climate) model ex- } \\
\text { plains twice as much } \\
\text { variance as eco- } \\
\text { nomic model. }\end{array}$ & $\begin{array}{l}\text { level of analysis: organization (402). selected two } \\
\text { dimensions of organizational climate because 'we found } \\
\text { the climate variables to have a noticeable amount of } \\
\text { collinearity' ( } 404 \text { ). reasons for selection ( } 405) \text { : } 1 \text { well-- } \\
\text { grounded in major streams of research, } 2 \text { represent } \\
\text { logical tension between attention to employee's needs } \\
\text { and task accomplishment, } 3 \text { the least correlated among } \\
\text { the climate dimensions. specific economic and } \\
\text { organizational factors independent predictors of } \\
\text { performance. organizational factors explain twice as } \\
\text { much variance in firm profit rates as economic factors } \\
\text { (industry profitability, relative market share, and firm size). }\end{array}$ \\
\hline
\end{tabular}




\begin{tabular}{|c|c|c|c|c|}
\hline Author(s) & $\begin{array}{l}\text { Independent } \\
\text { variables }\end{array}$ & $\begin{array}{l}\text { Intermediary / con- } \\
\text { textual }\end{array}$ & Dependent variables & Description \\
\hline $\begin{array}{l}\text { Barney (1986), } \\
\text { organizational culture: } \\
\text { can it be a source of } \\
\text { sustained competitive } \\
\text { advantage? AMR }\end{array}$ & $\begin{array}{l}\text { Culture (holistic, } \\
\text { theoretical) }\end{array}$ & & $\begin{array}{l}\text { competitive } \\
\text { advantage (theore- } \\
\text { tical) }\end{array}$ & $\begin{array}{l}\text { 'a firm's culture can be a source of sustainable } \\
\text { competitive advantage if that culture is valuable, rare, and } \\
\text { imperfectly imitable.' (663) }\end{array}$ \\
\hline $\begin{array}{l}\text { Zamrnutto and O'Connor } \\
\text { (1992), gaining } \\
\text { advanced manufacturing } \\
\text { technologies' benefits: } \\
\text { the roles of organization } \\
\text { design and culture. AMR }\end{array}$ & $\begin{array}{l}\text { organization design, } \\
\text { organizational } \\
\text { culture (competing } \\
\text { values model) }\end{array}$ & & $\begin{array}{l}\text { succesfull } \\
\text { introduction of } \\
\text { advanced } \\
\text { manufacturing } \\
\text { technologies }\end{array}$ & $\begin{array}{l}8 \text { hypotheses. competing values model (Quinn, 1988; } \\
\text { Quinn and Rohrbaugh, 1981, 1983) two dimensions: } \\
\text { flexibility-control and internal-external. these identify four } \\
\text { value systems: group, developmental, hierarchical, and } \\
\text { the rational value system. }\end{array}$ \\
\hline $\begin{array}{l}\text { Denison (1984), bringing } \\
\text { corporate culture to the } \\
\text { bottom ine, Org Dyn }\end{array}$ & $\begin{array}{l}\text { 'the survey of } \\
\text { organizations' } \\
\text { (University of Michi- } \\
\text { gan's Institute for } \\
\text { Social Research). } \\
\text { dimensions (p.11): a. } \\
\text { organization-of-work } \\
\text { index; b. decision- } \\
\text { making practices } \\
\text { index. } \\
\text { cultural strength }\end{array}$ & & $\begin{array}{l}\text { financial perfor- } \\
\text { mance: inco- } \\
\text { me/investment ratio } \\
\text { (effective utitization } \\
\text { of resources over } \\
\text { time); income/sales } \\
\text { ratio (indicator of } \\
\text { operating efficien- } \\
\text { cy). And both varia- } \\
\text { bles standardized } \\
\text { year } 0 \text { to year }+5\end{array}$ & $\begin{array}{l}\text { study in } 34 \text { companies. financial performances } \\
\text { standardized by industry. good work organization: } \\
\text { 'companies with a culture that encourages the } \\
\text { development of adaptable work methods linking } \\
\text { individuals to the goals of an organization have a clear } \\
\text { competitive advantage' (13): immediate and longterm } \\
\text { performance of group with high scores on 'good work } \\
\text { organization'-dimension better. decision-making } \\
\text { practices: 'when periormance relative to competitors is } \\
\text { examined, there appears to be a small initial advantage } \\
\text { associated with a participative culture that steadily widens } \\
\text { over the five-year period.' (13) Strong culture: 'high } \\
\text { consistency is associated with high current performance } \\
\text { and short-term perlormance, but is associated with low } \\
\text { long-term performance.' (18) }\end{array}$ \\
\hline
\end{tabular}




\begin{tabular}{|c|c|c|c|c|}
\hline Author(s) & $\begin{array}{l}\text { Independent } \\
\text { variables }\end{array}$ & $\begin{array}{l}\text { Intermediary / con- } \\
\text { textual }\end{array}$ & Dependent variables & Description \\
\hline $\begin{array}{l}\text { Denison ( } 1990 \text { ), } \\
\text { corporate culture and } \\
\text { organizational effec- } \\
\text { tiveness }\end{array}$ & $\begin{array}{l}\text { 'survey of organiza- } \\
\text { tions' indexes } 1 \text {. } \\
\text { organization of work, } \\
2 \text { emphasis on } \\
\text { human resources, } 3 \text {. } \\
\text { decision-making } \\
\text { practices, } 4 \text { interunit } \\
\text { coordination. } \\
\text { cultural strength for } \\
\text { the four above } \\
\text { dimensions. }\end{array}$ & & $\begin{array}{l}\text { financial } \\
\text { performance: inco- } \\
\text { me/sales, income/in- } \\
\text { vestment, and both } \\
\text { variables standardi- } \\
\text { zed. year } 0 \text { to year } \\
+5\end{array}$ & $\begin{array}{l}\text { correlation results for } 1984 \text { study lour dimensions of } \\
\text { 'culture'(65): organization of work and emphasis on } \\
\text { human resources (consistent correlations over } 5 \text {-year } \\
\text { period (range: } 0.26-0.63 \text { and } 0.15-1.54 \text { ). decision-making } \\
\text { practices and interunit coordination almost no relationship } \\
\text { with immediate performance, but strong correlations to } \\
\text { performance years }+3 \text { to }+5 \text {. explanation Denison (68): } 1 \\
\text { and } 2 \text { : 'thermometers' of the existing state, evaluation of } \\
\text { nature of link between individuals and organization. } 3 \text { and } \\
4: \text { the 'barometers,' comprise judgments of processes } \\
\text { that, over time, serve to knit together an organization. } \\
\text { cultural strength (variance within organization) positively } \\
\text { related to immediate performance, and negatively related } \\
\text { to performance after year three (78) } \\
\text { Denison argues that his operationalization of culture is far } \\
\text { from adequate, 'clearly concerned with the more manifest } \\
\text { elements of culture, rather than the underlying } \\
\text { assumptions and values that lie at an organization's core.' } \\
\text { (69) } \\
\text { extension of the model: 'adaptabilify and involvement are } \\
\text { likely to occur at the same time, but are in some ways. } \\
\text { incompatible with mission and consistency. At the same } \\
\text { time, however, the fundamental assumption of this model } \\
\text { is that the most succesful organizations display all four } \\
\text { cultural characteristics at once. ...research agenda...' } \\
\text { (188) }\end{array}$ \\
\hline
\end{tabular}




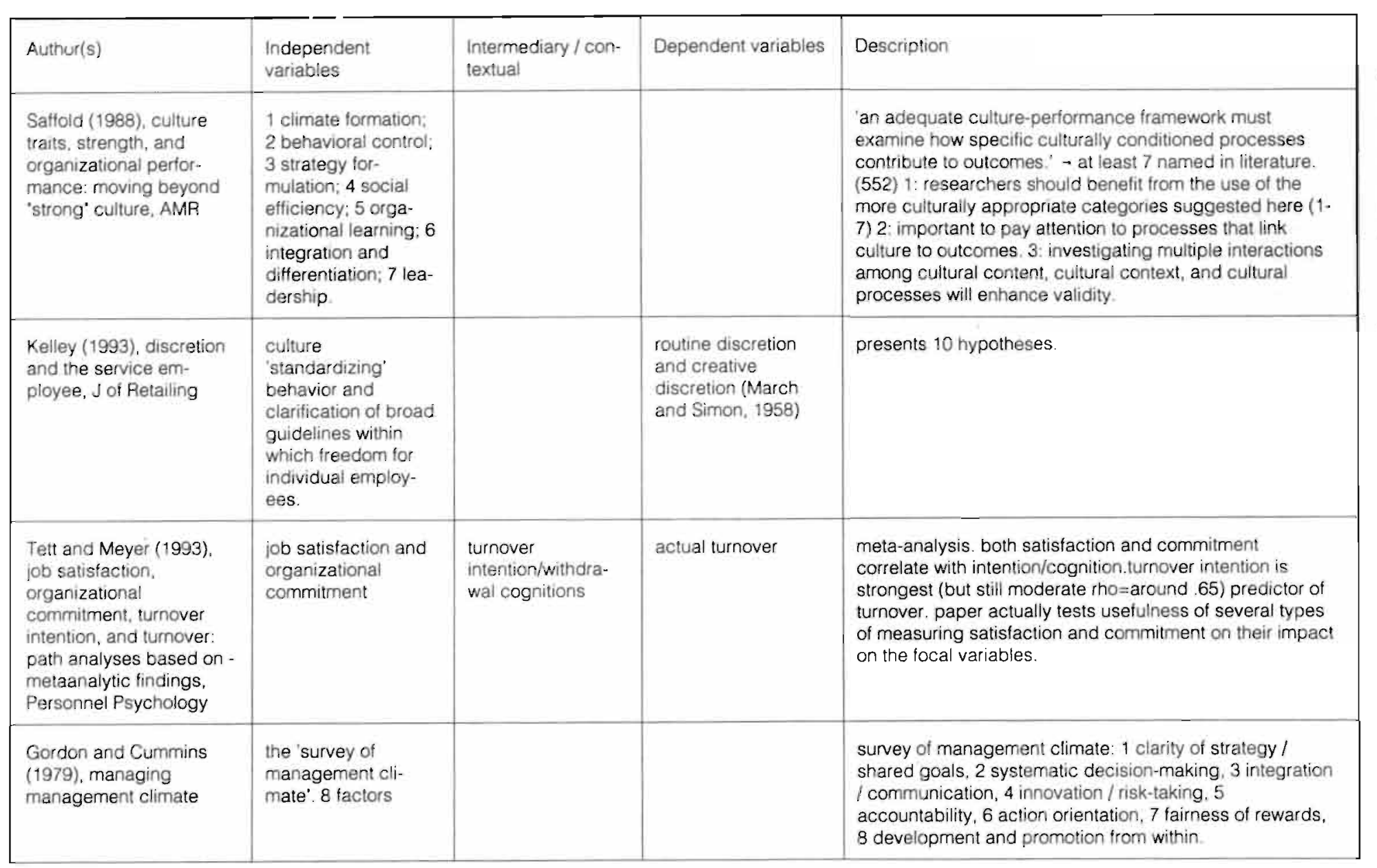




\begin{tabular}{|c|c|c|c|c|}
\hline Author(s) & $\begin{array}{l}\text { Independent } \\
\text { variables }\end{array}$ & $\begin{array}{l}\text { Intermediary / con- } \\
\text { textual }\end{array}$ & Dependent variables & Description \\
\hline $\begin{array}{l}\text { Gordon (1985), the } \\
\text { relationship of corporate } \\
\text { culture to industry sector } \\
\text { and corporate perfor- } \\
\text { mance, in: Kilmann et al. }\end{array}$ & $\begin{array}{l}\text { adaptation from the } \\
\text { survey of mgmt } \\
\text { climate: adaptability } \\
\text { (factors } 6+4) \text { and } \\
\text { stability (factors } \\
(3+8+7) \text {. }\end{array}$ & & $\begin{array}{l}\text { corporate perfor- } \\
\text { mance: growth and } \\
\text { profitability }\end{array}$ & $\begin{array}{l}\text { organizations in dynamic industries show highest } \\
\text { performance when high score on adaptability dimension. } \\
\text { organizations in static utilities industry show highest } \\
\text { performance when high score on stability dimension. }\end{array}$ \\
\hline $\begin{array}{l}\text { Gordon and DiTomaso } \\
\text { (1992), predicting } \\
\text { corporale performance } \\
\text { from organizational } \\
\text { culture, J of M Studies }\end{array}$ & $\begin{array}{l}\text { 'survey of } \\
\text { management } \\
\text { climate' (Gordon } \\
\text { and Cummins, 1979; } \\
\text { Gordon, 1985). } \\
\text { dimensions: adapta- } \\
\text { bility and stability. } \\
\text { cultural 'strength': } \\
\text { average std dev. } \\
\text { adaptability and } \\
\text { stability }\end{array}$ & & $\begin{array}{l}\text { calculated assets } \\
\text { and premium growth } \\
\text { for } 1982 \text { to } 1987 \text {. }\end{array}$ & $\begin{array}{l}\text { study in the life-insurance industry. deregulation changed } \\
\text { environment into dynamic. three aspects of culture } \\
\text { measured: adaptability (combination of action orientation } \\
\text { and innovation/risk taking scales of Gordon and } \\
\text { Cummins) and stability (combination of integration /com- } \\
\text { munication, development and promotion from within; and } \\
\text { fairness of reward scales of Gordon and Cummins); and } \\
\text { cultural strength (of both scales and averaged for both } \\
\text { scales). } \\
\text { hypothesis } 1 \text { supported: strength related to performance } \\
\text { in the near future (like Denison, } 1984,1990 \text { ) hyp } 2 \\
\text { supported: comparies in dynamic industries perform best } \\
\text { when their culture fosters adaptability rather than stability. }\end{array}$ \\
\hline $\begin{array}{l}\text { Hoistede et al (1990), } \\
\text { measuring organizational } \\
\text { cultures: a qualitative } \\
\text { and quantitative study } \\
\text { across twenty cases. } \\
\text { ASQ }\end{array}$ & $\begin{array}{l}\text { structural } \\
\text { characteristics of the } \\
\text { organization. }\end{array}$ & & $\begin{array}{l}\text { 'organizational } \\
\text { culture mocule.' } 6 \\
\text { dimensions }\end{array}$ & $\begin{array}{l}\text { development of } 6 \text { dimensions. process vs results } \\
\text { oriented, employiee vs job oriented, parochial vs } \\
\text { professional, open vs closed systems, loose vs tight } \\
\text { control, normative vs pragmatic. correlated to structural } \\
\text { characteristics (measures of size, structure, control } \\
\text { system, profile of top management and employees) }\end{array}$ \\
\hline
\end{tabular}




\begin{tabular}{|c|c|c|c|c|}
\hline $\begin{array}{l}\text { Weitzel et al. (1989), the } \\
\text { influence of employee } \\
\text { perceptions of customer } \\
\text { service on retail store } \\
\text { sales, J of Retaiting }\end{array}$ & $\begin{array}{l}\text { survey of customer } \\
\text { service attitudes } \\
\text { among sales } \\
\text { personnel. signifi- } \\
\text { cant: } 4 \text {. specific-to- } \\
\text { product customer } \\
\text { service } 6 \text {. specific } \\
\text { knowledge and } \\
\text { information available } \\
\text { to meet customers } \\
\text { needs }\end{array}$ & $\begin{array}{l}\text { Control variable: } \\
\text { store size (square } \\
\text { feet of sales } \\
\text { space) }\end{array}$ & $\begin{array}{l}\text { sales-per-payroll- } \\
\text { hour }\end{array}$ & $\begin{array}{l}\text { setting fabric retail stores. controlled for for size as } \\
\text { context variable and for number of employee (Hise et al., } \\
1983 \text { ) by using sales-per-payroll-hour as performance } \\
\text { measure. (32) 'the primary explanatory variable was store } \\
\text { size as expected with an F-square of } 0.47 \text { by itself, but } \\
\text { employees' attitudes toward customer service made a } \\
\text { significant additional contribution ( } p<0.0001) \text {.'(37) } \\
\text { actually, both dimensions that made significant } \\
\text { contributions ( } 4 \text {. and } 6 \text {.) point to the quality of their task. } \\
\text { specific ability and the support (information/knowledge) } \\
\text { the employees perceive to get from the company. }\end{array}$ \\
\hline $\begin{array}{l}\text { Ostroff ( } 1993 \text { ), the effects } \\
\text { of climate and personal } \\
\text { infliences on individual } \\
\text { behavior and attitudes in } \\
\text { organizations, Org } \\
\text { Behavior and Human } \\
\text { Decision Processes }\end{array}$ & $\begin{array}{l}\text { organizational } \\
\text { climate and personal } \\
\text { orientation variables } \\
\text { explained significant } \\
\text { amount of variance. } \\
\text { climate-person in. } \\
\text { teraction variables } \\
\text { not significant. }\end{array}$ & & $\begin{array}{l}12 \text { satisfaction } \\
\text { scales ( } 1 \text { for each } \\
\text { climate / personal } \\
\text { orientation - dimensi- } \\
\text { on), two aspects of } \\
\text { commitment, six } \\
\text { items assessing } \\
\text { involvement, indivi- } \\
\text { dual's adjustment to } \\
\text { the school, stress, } \\
\text { absenteeism, } \\
\text { intention to turnover, } \\
\text { and seif-evaluation } \\
\text { of job performance. }\end{array}$ & $\begin{array}{l}\text { sample: two groups of teachers from } 29 \text { secondary } \\
\text { schools. group } 1 \text { ( } n=607 \text { ) for measuring personal } \\
\text { orientation. group } 2(n=590 \text { ) for measuring organizational } \\
\text { climates. climate measures ( }+ \text { personal orientation } \\
\text { measures) included of: participation, cooperation, } \\
\text { warmth, social rewards, growth, innovation, autonomy, } \\
\text { intrinsic rewards, achievement, hierarchy, structure, } \\
\text { structure, extrinsic rewards. } \\
\text { canonical correlation analysis: climate scores explained } \\
9 \% \text { of variation in individual outcomes (69). personal } \\
\text { orientation variables explained } 12 \% \text { of variance in } \\
\text { outcomes ( } 71 \text { ). additional } 10 \% \text { of variance in outcomes } \\
\text { explained by personal orientations when the effects of } \\
\text { climate were accounted for. climate-person interactions } \\
\text { 'had virtually no effect on outcomes when climate and } \\
\text { personal orientation main effects were accounted for. ( } 71 \text { ) } \\
\text { Moderated regressions: climate significantly related to } \\
\text { outcomes, personal orientations produced significant } \\
\text { tncreases in R-square, climate-person interaction effects } \\
\text { had no significant effects. (73) }\end{array}$ \\
\hline
\end{tabular}




\begin{tabular}{|c|c|c|c|c|}
\hline Author(s) & $\begin{array}{l}\text { Independent } \\
\text { variables }\end{array}$ & $\begin{array}{l}\text { Intermediary / con- } \\
\text { textual }\end{array}$ & Dependent variables & Description \\
\hline $\begin{array}{l}\text { Lawler III et al. (1974), } \\
\text { organizational climate: } \\
\text { relationship to or- } \\
\text { ganizational struclure, } \\
\text { process and perfor- } \\
\text { mance, Organizational } \\
\text { Behavior and Human } \\
\text { Performance }\end{array}$ & $\begin{array}{l}\text { org structure } \\
\text { (significant: span of } \\
\text { control and tall/flat } \\
\text { structure) and org } \\
\text { process variables } \\
\text { (significnat: per- } \\
\text { formance review } \\
\text { frequency, perf rev } \\
\text { relation to compen- } \\
\text { sation program, } \\
\text { professional } \\
\text { autonomy, as- } \\
\text { signment generality, } \\
\text { informal budget } \\
\text { account. }\end{array}$ & $\begin{array}{l}\text { org climate } \\
\text { evaluated on bi- } \\
\text { polar adjective } \\
\text { scale. five factors: } \\
1 \text { competent / po- } \\
\text { tent, } 2 \text { responsible, } \\
3 \text { practical, } 4 \text { risk- } \\
\text { oriented, } 5 \\
\text { impulsive }\end{array}$ & $\begin{array}{l}\text { org performance } \\
\text { (evaluation by own } \\
\text { director and } \\
\text { objective composite } \\
\text { measure (146)) and } \\
\text { job satisfaction (in } \\
\text { six areas) }\end{array}$ & $\begin{array}{l}117 \text { R\&D organizations. structural variables only related to } \\
\text { factor } 2 \text { 'responsible.' process variables related to all the } \\
\text { climate variables. climate related to the director's } \\
\text { perception of the quality of his administrative staff. Not to } \\
\text { his perception of the quality of the research work. The } \\
\text { satisfaction measures are strongly related to the climate } \\
\text { measures (except for factor } 2 \text { 'responsible.' structure and } \\
\text { process variables were not significantly related to } \\
\text { performance and job satisfaction. (may be due to nature } \\
\text { of research setting: research labs) }\end{array}$ \\
\hline $\begin{array}{l}\text { Payne and Mansfield } \\
\text { (1973), relationships of } \\
\text { perceptions of organiza- } \\
\text { tional climate to or- } \\
\text { gan zational structure, } \\
\text { context, and hierarchical } \\
\text { position, ASQ }\end{array}$ & $\begin{array}{l}\text { contextual and } \\
\text { structurai variables: } \\
1 \text { functional specia- } \\
\text { lization, } 2 \text { formali- } \\
\text { zation of role } \\
\text { definition, } 3 \text { lack of } \\
\text { autonomy, } 4 \text { chief } \\
\text { executive's span of } \\
\text { control, } 5 \text { organizati- } \\
\text { onal size, } 6 \text { size of } \\
\text { parent organization, } \\
7 \text { age, } 8 \text { work-flow } \\
\text { integration, } 9 \\
\text { dependence }\end{array}$ & & $\begin{array}{l}\text { modified business } \\
\text { organization climate } \\
\text { index (BOCI ... } \\
\text { Payne and Preysey, } \\
1971) .19 \text { dimen- } \\
\text { sions. }\end{array}$ & $\begin{array}{l}20 \text { organization climate scales: } 1 \text { leaders' psychological } \\
\text { distance. } 2 \text { questioning authority, } 3 \text { egalitarianism, } 4 \\
\text { management concern for employee involvernent, } 5 \text { ope:- } \\
\text { mindedness, } 6 \text { emotional control, } 7 \text { future orientation, } 8 \\
\text { scientific and technical orientation, } 9 \text { intellectual } \\
\text { orientation, } 10 \text { job chailenge, } 11 \text { task orientation, } 12 \\
\text { industriousness, } 13 \text { altruism, } 14 \text { sociability, } 15 \\
\text { interpersonal agression, } 16 \text { rules orientation, } 17 \\
\text { administrative efficiency, } 18 \text { conventionality, } 19 \text { readiness } \\
\text { to innovate, } 20 \text { orientation to wider commuri: } / \text {. (517 / } \\
522 \text { ). significant correlations appear, especially between } \\
\text { the measures ol size and organizational dependence of } \\
\text { other (parent) orgarizations. }\end{array}$ \\
\hline
\end{tabular}




\begin{tabular}{|l|l|l|l|l|}
\hline Author(s) & $\begin{array}{l}\text { Independent } \\
\text { variables }\end{array}$ & $\begin{array}{l}\text { Intermediary / con- } \\
\text { textual }\end{array}$ & Dependent variables & Description \\
\hline $\begin{array}{l}\text { de Cock et al. (1984), } \\
\text { Organisatie klimaat index } \\
\text { voor profit organisaties } \\
\text { (OKIPO) en de verkorte } \\
\text { vorm (VOKIPO) }\end{array}$ & & $\begin{array}{l}\text { dutch translation of } \\
\text { modified business } \\
\text { organization climate } \\
\text { index (Payne and } \\
\text { Mansfieid, 1973) } \\
\text { OKIPO }\end{array}$ & $\begin{array}{l}\text { 14 general } \\
\text { dimensions of orga- } \\
\text { nizational culture }\end{array}$ & $\begin{array}{l}\text { 1 external vs internal emphasis, 2 task vs social focus, 3 } \\
\text { safety vs risk, confirmity vs individuality, 5 individual vs } \\
\text { group rewards, 6 individual vs collective decision-making, } \\
7 \text { centrailized vs decentralized decision-making, 8 ad } \\
\text { hockery vs planning, 9 stability vs innovation, 10 } \\
\text { cooperation vs competition, (xx) basis for commitment, 11 } \\
\text { simple vs complex organization, 12 informal vs formalized } \\
\text { procedures, high vs low loyalty, 14 ignorance vs } \\
\text { knowledge of organizational expectations. }\end{array}$ \\
\hline $\begin{array}{l}\text { Reynolds (1986), } \\
\text { Organizational culture as } \\
\text { related to industry } \\
\text { position and perfor- } \\
\text { mance: a preliminary re- } \\
\text { port, J of Mgmt Studies }\end{array}$ & $\begin{array}{l}\text { organizations from } \\
\text { three industries; } \\
\text { organizational posi- } \\
\text { tons (three 'types of } \\
\text { work) }\end{array}$ & & $\begin{array}{l}\text { no difference in culture between excellent companies } \\
\text { (Peters and Waterman) and non-excellent companies. }\end{array}$ \\
\hline
\end{tabular}


and culture instruments register attitudinal information of people, leaving only a small difference in the data resulting from culture and climate surveys. Therefore, some dimensions of culture and climate might actually be interpreted in both ways (i.e. as culture or climate variables). In this pioneering period of the quantitative empirical evaluation of the impact of organizational culture on organizational performance the proximity of the areas of organizational climate and organizational culture research is very important. The results of studies looking at the impact of aspects of climate on organizational outcomes (e.g. Ostroff, 1993; Hansen and Wernerfelt, 1989) or using organizational climate measures as proxies for dimensions of cultures (Denison, 1984, 1990) are very illuminating. To advance the research, however, the use of empirical measurement instruments specifically designed to measure differences in organizational cultures is important.

What aspects of organizational culture and climate have been measured in previous research? In this context we discuss the aspects of culture and climate that have consistently reappeared in empirical studies published in the most important Englishlanguage journals over the past three decades. Table 3.1 summarized the studies included in our review. These studies show a diversity of measurement instruments, each focusing on different aspects of organizational culture and climate. Six important aspects of culture and climate consistently reappear in the analyses: administrative efficiency, communication / cooperation, organizational innovativeness, employee orientation, openness, and results orientation. These are summarized in table 3.2.

Seven studies measured administrative efficiency. The measures emphasize quality, effectiveness and efficiency of the organization of work. An important aspect of this variable is the quality of the short-term task communication in the organization. Seven studies measured communication or room for cooperation. A major theme here is the holistic approach toward working in the organization. Communication and coordination are the basis for integration of the specialized activities of organization members toward organizational activity. Organizational innovativeness is measured in eight studies. It points to the room for change and development in the organization, the attention that is paid to new ideas, and the fervor with which new ideas are put to the test in the organization. Eight studies measure employee orientation. The variables point to the recognition of people as valuable assets to the organization that need (and are worth) consideration and attention. Four studies measure openness as an aspect of organizational culture or climate. Openness is closely related to communication and cooperation. The difference, however, is significant. Openness points to the possibility to speak freely, communication and cooperation refer to the quality of relationships between specialist parts of the organization. Seven studies included a measure describing results orientation. Results orientation points to a focus on the quality of the outcomes of work, rather than the specific form of the work process that leads to the outcomes. It seems useful to at least include these dimensions in future analyses of the impact of organizational culture and climate in organizations. 
Table 3.2 Aspects of organizational culture and climate

Administrative efficiency

- organization of work (Denison, 1990)

- clarity of goals and systematic decision-making (Gordon and Cummins, 1979)

- quality of job support (task knowledge and information) (Weitzel et al., 1989)

- competent / potent organization (Lawler III et al., 1974)

- administrative efficiency (Payne and Mansfield, 1973; de Cock et al., 1984)

- ignorance vs knowledge of organizational expectations (Reynolds, 1986)

Communication / cooperation

- team orientation (O'Reilly et al. 1991)

- interunit coordination (Denison, 1990:44)

- integration / communication (Gordon and Cummins, 1979)

- stability (Gordon, 1985; Gordon and DiTomaso, 1992)

- cooperation (Ostroff, 1993)

cooperation vs competition (Reynolds, 1986)

Organizational innovativeness

- innovation (O'Reilly et al., 1991)

- innovation / risk taking (Gordon and Cummins, 1979)

- adaptability (Gordon, 1985; Gordon and DiTomaso, 1992)

- innovation (Ostroff, 1993)

- organizational innovativeness (Payne and Mansfield, 1973; de Cock et al., 1984)

- stability vs innovation (Reynolds, 1986)

Employee orientation

- respect for people (O'Reilly et al., 1991)

- emphasis on human resources (Hansen and Wernerfelt, 1989; Denison, 1990)

- employee orientation (Hofstede et al., 1990)

- warmth and social rewards (Ostroff, 1993)

- management concern for employee involvement (Payne and Mansfield, 1973; de Cock et al, 1984)

- task vs social focus (Reynolds, 1986)

Openness

- openness (Hofstede et al. 1990)

- open mindedness (Payne and Mansfield, 1973; de Cock et al., 1984)

decision-making practices (Denison, 1990:43)

Results orientation

- outcome orientation (O'Reilly et al., 1991)

- emphasis on goal accomplishment (Hansen and Wernerfelt, 1989)

- action orientation (Gordon and Cummins, 1979)

- results orientation (Hofstede et al., 1990)

- external vs internal emphasis (Reynolds, 1986)

- informal vs formalized procedures (Feynolds, 1986)

- service enthusiasts vs service bureaucrats (Schneider et al., 1980)

When reviewing the impact of culture and climate in organizations, two further concepts consistently reappear: cultural strength and work satisfaction. In empirical studies cultural strength is often measured as an aspect of organizational culture being related to organizational performance (e.g. Denison, 1984, 1990; Gordon and DiTomaso, 1992). Cultural strength is most often defined as the consistency of em- 
ployee answers, using some measure of response deviation from the mean as the indicator. It thus does not point to a qualitative characteristic of organizational culture, but to consistency or level of agreement about the culture in the organization. The work satisfaction concept leads a double life. Some studies operationalize work satisfaction as a dependent variable and look upon work satisfaction scores as an outcome measure. The focus then is on how organizational culture and climate influence employee satisfaction (e.g. Ostroff, 1993; Lawler IIl et al., 1974; Vogelaar, 1990). In other studies work satisfaction is considered as an independent or intermediate variable influencing, for example, turnover intention, withdrawal cognitions, and actual job turnover (Tett and Meyer, 1993). Because of its role as intermediary variable, work satisfaction will show up both as dependent and independent variable in a number of tables further on in this review.

\section{Organizational culture, climate and performance}

Measures of performance differ greatly between studies. Six studies investigated the impact of organizational climate or culture on various aspects of financial performance. Most of them used aggregate measures of performance. Hansen and Wernerfelt (1989) employed a five-year average return on assets. Denison (1984, 1990) calculated corporate income/investment ratios and income/sales ratios for five years following his culture measurement. Gordon and DiTomaso (1992) introduced calculated assets and premium growth as the dependent performance variable in their study of organizations in the insurance industry. Other studies used specific performance measures like job turnover (Tett and Meyer, 1993; Sheridan, 1992; O'Reilly et al., 1991). intended job turnover and individual work attitudes (Ostroff, 1993), and subjective assessments of performance made by the directors of the R\&D laboratories under study (Lawler III et al., 1974). Table 3.3 summarizes the dependent variables that were related to aspects of organizational culture and climate in the studies discussed in this section.

The table reveals that the performance indicators used can be roughly divided in six categories. First, the aggregated, corporate level, financial performance indicators are performance measures that point to general financial ratios like return on assets (Hansen and Wernerfelt, 1989) and income/sales ratio (Denison, 1990). Second, the indicators of unit level (non-)financial performance point to financial and non-financial indicators that reflect directly the performance of the unit under study. Examples are Schneider et al.'s measure of customer treatment in their study of the impact of climate on the performance of branches of a bank (Schneider et al., 1980) and Weitzel et al.'s measure of sales per pay-roll hour in their study of store effectiveness in a fabric retail organization (Weitzel et al., 1989). Unit-level performance measures can be directly linked to unit culture. Third, a number of studies have linked organizational culture and climate to objective measures of employee behavior. Examples are measures relating to employee turnover (Tett and Meyer, 1993; Sheridan, 1992; O'Reilly, 1991) and absenteeism (Ostroff,1993). Fourth, employee attitudes reflect employee evaluations of the organizational situation. Partly, these variables are 'dependents by design' in the sense that they are closely related to the measures of organizational 
climate that also reflect attitudinal information. However, the employee attitude variables are meant to reflect the employees' state of mind that is the outcome of their functioning in a specific organization with a specific organizational culture and organizational climate. The table shows two additional categories: 'organization' and 'theoretical.' In the organization category we find Reynolds' (1986) study, which did not focus on separate performance indicators but compared organizations with characteristics of excellence as defined by Peters and Waterman (1982) with organizations that were not excellent by those standards. The theoretica/ category summarizes studies that propose hypotheses about the impact of organizational culture on performance, but do not contain empirical evidence about the relationship.

Table 3.3 Dependent variables related to organizational culture and climate

Aggregated, corporate level, financial performance

- 5 year average return on assets (Hansen and Wernerfelt, 1989)

- income / investment ratio ( $\mathrm{t}=0$ to $\mathrm{t}=+5$ years) (Denison, 1984, 1990)

- income / sales ratio $(t=0$ to $t=+5$ years) (Denison, 1984, 1990)

- growth (Gordon, 1985)

- profitability (Gordon, 1985)

- calculated assets growth (Gordon and DiTomaso, 1992)

- calculated premium growth (Gordon and DiTomaso, 1992)

Unit level (non-)financial performance

- sales per payroll hour (Weitzel et al., 1989)

- self-evaluation of organizational performance (Lawler III et al., 1974)

- customer treatment (Schneider el al., 1980)

Employee turnover

- employee retention (Sheridan, 1992)

- employee turnover at $t=+2$ years (O'Reilly et al. , 1991)

- employee furnover meta-analysis (Tett and Meyer, 1993)

Employee attitudes

- job satisfaction at $\mathrm{t}=+1$ year (O'Feiliy et a!., 1991)

- organizational commitment at $t=+1$ year (O'Reilly et al., 1991)

- turnover intention / withdrawal cognitions (Tett and Meyer, 1993)

- satisfaction, commitment, involvement, adjustment to the organization, stress, absenteeism.

intention to turnover, self-evaluation of job performance (Ostroff, 1993)

- job satisfaction (Lawler III, 1974)

Organization

- organization has characteristics of excellence or not (Reynoids, 1986)

Theoretical

- competitive advantage (Bamey, 1986)

- successful introduction of advanced manufacturing technologies (Zammutto and O'Connor, 1992)

- room to exercize routine discretion and creative discretion (Kelley, 1993)

The results of these studies are encouraging, because they show that culture and climate are significantly related to organizational performance (as will be discussed in the next section). However, the performance measures used are either very specific, 
pointing to one aspect of organizational performance (e.g. employee turnover and employee attitudes), or they are aggregated to such a degree that the relationship with organizational performance becomes vague. In the latter situation only general statements can be made about the nature of the relationships between organizational culture and organizational performance. This leaves room for studies at the intermediary level where the focus is on 'bottom line performance' at the unit level. Thus, studies that relate organizational culture to the bottom line performance of the specific unit under study would be desirable, to make more specific inferences with respect to the influence of organizational culture on financial performance.

\section{What can the studies tell us?}

On average, the outcomes of these studies seem to indicate that there is a relationship between organizational culture and performance. Most studies that related organizational culture and climate to organizational performance found significant relationships. Hansen and Wernerfelt (1989) showed that in regression analysis a behavioral model, using two dimensions of organizational climate as independent variables, explained twice as much of the variance in the five-year average return of investments of companies as an economic model of the organization using industry profitability, relative market share, and firm size as independent variables. In a largescale investigation Denison $(1984,1990)$ related four proxies of organizational culture to present and future organizational performance. Two dimensions (organization of work and emphasis on human resources) were related to both present and future organizational performance. The two other dimensions (decision-making practices and inter-unit coordination) were not related to present performance, but showed a significant impact on future performance (Denison, 1990). These findings point to a causal relationship where culture variables influence present and future performance. Denison's findings also revealed the impact of a strong organizational culture. The strength of an organizational culture was positively related to present performance, but negatively related to future organizational performance (Denison, 1990). This finding was confirmed in a study by Gordon and DiTomaso (1992) who related two aspects of organizational culture (adaptability and stability) to organizational performance. They showed that in a dynamic industry organizations that scored high on adaptability tended to perform better. They also found a strong relationship between the strength of organizational culture and short-term performance. Other studies related aspects of organizational culture and climate to non-financial outcome variables, revealing an impact of organizational culture and climate on, for example, employee turnover (Sheridan, 1992; O'Reilly, 1991), turnover intention (Tett and Meyer, 1993), job satisfaction (O'Reilly et al., 1991; Lawler III et al., 1974), organizational commitment (Ostroff, 1993; O'Reilly et al., 1991), and absenteeism (Ostroff,1993). The relationships between the main dimensions of organizational culture and climate and the main performance categories suggested by the evidence of the studies presented in this chapter are summarized in table 3.4

As argued before, intermediate level analyses of the impact of organizational culture on organizational performance seem useful, as the studies to date have mostly fo- 
cused on either aggregate data (annual report style performance data), or on specific aspects of organizational performance (e.g. employee turnover and absenteeism), but seldomly used financial performance data gathered at the level of the unit of analysis (Weitzel et al. (1989) is an exception). Studies that are able to relate the organizational culture of a unit to its specific bottom line performance can thus be very valuable.

Table 3.4 Relationships between culture and performance

\begin{tabular}{|c|c|c|c|c|c|c|c|c|}
\hline \multirow[t]{2}{*}{ Performance var } & \multicolumn{8}{|c|}{ Aspects of organizational culture and climate } \\
\hline & $\begin{array}{l}\text { admi- } \\
\text { ni- } \\
\text { strative } \\
\text { effi- } \\
\text { ciency }\end{array}$ & $\begin{array}{l}\text { com- } \\
\text { mu- } \\
\text { nicati- } \\
\text { on } / \\
\text { coop- } \\
\text { eration }\end{array}$ & $\begin{array}{l}\text { organi- } \\
\text { zatio- } \\
\text { nal } \\
\text { inno- } \\
\text { vative- } \\
\text { ness }\end{array}$ & $\begin{array}{l}\text { em- } \\
\text { ployee } \\
\text { orien- } \\
\text { tation }\end{array}$ & $\begin{array}{l}\text { open- } \\
\text { ness }\end{array}$ & $\begin{array}{l}\text { results } \\
\text { orien- } \\
\text { tation }\end{array}$ & $\begin{array}{l}\text { culture } \\
\text { stre- } \\
\text { ngth }\end{array}$ & $\begin{array}{l}\text { satis- } \\
\text { facti- } \\
\text { on }\end{array}$ \\
\hline corp level perf & + & $+(\mathrm{ftr})$ & & + & $+(\mathrm{ftr})$ & + & + & \\
\hline unit-level perf & + & & & & & & & \\
\hline employee turnover & & & & - & & & & - \\
\hline empl. attitudes & + & + & + & + & & & & + \\
\hline absenteeism & & - & - & - & & & & $(-)$ \\
\hline
\end{tabular}

\section{Further research}

The evaluation of the empirical research on the impact of organizational culture and climate on organizational performance can be summarized as follows:

1. In quantitative empirical studies measurement of organizational culture and climate has overlapped. Although successful in this pioneering stage of quantitative analysis of the impact of organizational culture in organizations, the differences between the constructs should be appreciated. The amount of quantitative empirical studies using original organizational culture measures is still small.

2. Analyzing the dimensions of organizational culture and climate that are used and validated in the studies presented above, a number of dimensions reappear in one form or another in most of the studies. These dimensions are administrative efficiency, communication / cooperation, organizational innovativeness, employee orientation, openness, and goal emphasis or results orientation. It seems useful to include these dimensions in future analyses of the impact of organizational culture and climate in organizations.

3. Analyzing the empirical evidence linking these dimensions of organizational culture and climate to different aspects of performance raises the question of the relationships of these dimensions with a broader range of organizational performance indicators. Is there a difference in the kinds / aspects of performance influenced by the six aspects of culture and climate? 
4. In the studies discussed above organizational culture and climate were either related to aggregate measures of performance that can only be generally related to climate and culture, or to specific measures of performance that describe organizational performance only partially. Studies that are able to relate organizational culture and climate to the bottom line performance which is fully attributable to the organization (or unit) under study might provide a valuable addition to the existing body of literature.

\subsection{Context and culture formation}

The question of culture formation is important. It is important to know what variables influence an organization's culture and how it develops. This knowledge is useful for managers who have to cope with their organization's culture every day, but also for researchers, because it helps to understand the concept of organizational culture. A lot of previous work describes culture formation in a theoretical sense and gives advise on how it can be understood and managed (e.g. Trice and Beyer, 1993; Schein, 1985,1992; Smith and Peterson, 1988; Peters and Waterman, 1982; Deal and Kennedy, 1982). The discussion about how organizational culture can be influenced, however, is mostly very general and focuses specifically on 'cultural tools.' Trice and Beyer, for example, distinguish seven 'levers to manage cultures:' ideologies, cultural forms (symbols, language, stories, managerial practices, training activities, rewards), socialization (rites of passage, enhancement, degradation, and role models), subcultures (occupational mix of organization members, reward leaders of subcultures, use of countercultures as lever for change), leadership, and environments (influence objective and perceived environment) (Trice and Beyer, 1993:362-37).

In this section we will review the empirical evidence that has been presented about the impact of a number of independent variables on organizational culture. As before, we will not limit ourselves to the evidence presented regarding the formation of culture. We will also evaluate the evidence from organizational climate research that has a long tradition of studying related aspects of the 'human factor in organizations.' Two elaborate review studies summarized the research investigating organizational climate as the dependent variable. Hellriegel and Slocum (1974) reviewed the research on organizational climate looking at 'measures, research and contingencies.' Payne and Pugh (1976) reviewed the evidence on the relationship between organizational struciure and climate. First, the conclusions of these two studies will be summarized, then we will focus on the outcomes of seven studies that have appeared in the last ten years. Finally, we will discuss the implications of these studies for future research.

\section{Two reviews: organizational climate as a dependent variable}

This section will summarize and discuss the conclusions of reviews of the research on organizational climate as a dependent variable by Hellriegel and Slocum (1974) and Payne and Pugh (1976). 
Hellriegel and Slocum (1974) concluded that climate research, until 1974, had mainly focused on four variables influencing organizational climate: the impact of leadership style, managers' personality needs, organization structure, and training programs. In studies of the first two variables (the impact of leadership style and managers' personality needs) organizational climate was often used as an intervening variable linked to job performance or satisfaction. The studies of the influence of organization structure and training programs focused directly on their impact on organizational climate (Hellriegel and Slocum, 1974:274-276). The findings for the four variables were the following.

Leadership. Leadership clearly influences organizational climate. Three different organizational climates (authoritarian-oriented, democratic-friendly, achieving) were created by instructing the presidents of three simulated businesses how to act. Performance levels differed between the businesses. The achieving climate produced the most, and the democratic-friendly climate resulted in the highest level of worker satisfaction (Litwin and Stringer, 1968).

Managers' personality needs. The evaluated studies show that managers' personality needs, such as needs for achievement, affiliation, and autonomy, slightly influence the evaluation of organizational climate and that personality needs play a moderating role with respect to the influence of organizational climate on job attitudes of managers. Organization structure. Perceptions of climate differ with the employees' level in the organization, the perceived degree of bureaucratization of the organization, the employee's decision making discretion, and the employee's orientation toward the environment. A customer orientation, for example, produces a higher perceived individual autonomy than a stockholder orientation.

Training programs. The study of training programs was limited to the evaluation of a number of studies of the impact of sensitivity training on employees' organizational climate perceptions. Sensitivity training reduces the discrepancy between the trainee's climate preferences and his climate perceptions. The training sessions also seemed to have a lasting effect.

Payne and Pugh (1976) specifically reviewed the evidence on the relationship between organization structure and organizational climate. they distinguished subjective and objective measures of both structure and climate. Payne and Pugh indicated a lack of studies relating objective structural measures to perceptual climate measures (Payne and Pugh, 1976:1152), although the evidence available reveals 'conceptual similarity between results based on objective structure measures and perceptual climate measures' (Payne and Pugh, 1976:1169). Especially measures of organizational size show consistently strong correlations with various operationalizations of organizational climate. Besides, Payne and Pugh (1976) asked for more attention to the impact of hierarchical position on perceived organizational climate. They concluded that there was 'a disregard for the systematic differences in measures of perceived organizational climate and structure between different positions in the structural hierarchy' (Payne and Pugh, 1976:1168).

These two review studies pointed out that a number of contextual variables influence 'the human factor in organizations.' These variables seem to be important explanatory 
variables of organizational climate. Especially leadership, organizational size, and position in the structural hierarchy were shown to affect the perceived organizational climate. Still, as Payne and Pugh argue, there is a relative lack of evidence on the relationship between objective measures of structure and perceived organizational climate.

\section{Recent studies: organizational culture as a dependent variable}

This section reviews the more recent studies evaluating organizational culture as a dependent variable. Table 3.5 provides a summary of the studies included in the discussion. Two important questions can be asked in the evaluation of the evidence on organizational culture as a dependent variable. 1) What variables were studied as contextual determinants of organizational culture? and 2) What do the results of these studies tell us about the possible relationship between these 'contextual variables' and organizational culture?

\section{Determinants of organizational culture}

A number of general and specific contextual variables have been advanced in previous research. The contextual variables that showed significant relationships with culture have been summarized in table 3.6. Broadly, they can be divided into variables describing aspects of the industry, the organization, management, and employees. An important variable that has a significant influence on organizational culture, but which is not addressed in the current study, is national culture (e.g. Hofstede, 1980; Hofstede et al., 1990; Soeters and Schreuder, 1988). The present study, however, focuses on differences between organizations in one national cultural setting. Therefore, the influence of national culture is not included.

Industry differences. Industry characteristics show significant correlations with organizational culture. Reynolds (1986) compared organizational cultures of computer firms, franchise restaurants, and international advanced technology firms. He found significant differences in cooperativeness, employee orientation, use of formal procedures (results orientation), and need for social conformity (a striving for cultural strength). Hofstede et al. (1990) argued that four of the six dimensions of organizational culture they had uncovered mainly related to 'the type of work the organization does and to the type of market in which it operates' (Hofstede et al., 1990:306). In the empirical analysis two dimensions of organizational culture correlated with 'type of work.' Labor intensive (office) organizations scored more results oriented than materials intensive (manufacturing) organizations. Private companies scored higher on pragmatism, indicating a customer orientation; public companies showed a normative orientation, indicating a reliance on internal quality standards. Chatman and Jehn (1994) compared the cultures of organizations in four industries (accounting firms, consulting firms, 


\begin{tabular}{|c|c|c|c|c|}
\hline Author & $\begin{array}{l}\text { Independent varia- } \\
\text { bles }\end{array}$ & $\begin{array}{l}\text { Intermediary / con- } \\
\text { textual }\end{array}$ & Dependent variables & Description \\
\hline $\begin{array}{l}\text { Reynolds (1986), } \\
\text { organizational culture as } \\
\text { related to industry, positi- } \\
\text { on and performance: a } \\
\text { preliminary report, J of } \\
\text { mgmt studies }\end{array}$ & $\begin{array}{l}\text { organizations from } \\
\text { three industries: } \\
\text { organizational posi- } \\
\text { tions (three 'types of } \\
\text { work)' }\end{array}$ & & $\begin{array}{l}14 \text { general dimensi- } \\
\text { ons of culture (see } \\
\text { table } 3.1 \text { ) }\end{array}$ & $\begin{array}{l}\text { study shows major differences in work values between } \\
\text { industries and among positions. } \\
\text { industry differences: computer: least social conformity. } \\
\text { most cooperative; franchise restaurants: greates task } \\
\text { focus, least risk-taking, highest social conformity, and } \\
\text { decision making individualized and centralized; Int'l ad- } \\
\text { vanced technology industrial firms: moderate social con- } \\
\text { formity, most complex orgarization, greatest use of formal } \\
\text { procedures. (338) } \\
\text { positions: 1) operative or clerical roles: minimal risk ta- } \\
\text { king, individual and centralized decision making, simple } \\
\text { organization, casual / intormal work routines; } 2 \text { ) professio- } \\
\text { nal staff and technical operatives: least social conformity, } \\
\text { relatively complex organization, formalization of important } \\
\text { procedures; } 3 \text { ) managers highest degree of social } \\
\text { contormity, moderate organizational complexity, some } \\
\text { degree of formalization. (340) } \\
\text { major differences in work values among positions are } \\
\text { related to the importance of: working conditions, security } \\
\text { of employment, collegial cooperation, prestige of the or- } \\
\text { ganization, clarity of job requirements, nature of preferred } \\
\text { management styles. work beliefs vary in: trust in others, } \\
\text { workers' dislike (inherent) of work, most appropriate per- } \\
\text { sonal management style. ( } 340 \text { ) }\end{array}$ \\
\hline
\end{tabular}




\begin{tabular}{|c|c|c|c|c|}
\hline Author & $\begin{array}{l}\text { Independen! varia- } \\
\text { bles }\end{array}$ & $\begin{array}{l}\text { Intermediary / con- } \\
\text { textual }\end{array}$ & Dependent variables & Description \\
\hline $\begin{array}{l}\text { Hofstede et al. (1990), } \\
\text { measuring organizational } \\
\text { cultures: a qualitative } \\
\text { and quantitative study } \\
\text { across twenty cases, } \\
\text { ASQ }\end{array}$ & $\begin{array}{l}\text { unit-level } \\
\text { characteristics: size, } \\
\text { private vs public } \\
\text { firms, manufacturing } \\
\text { vs office units, } \\
\text { structure, control sy- } \\
\text { stem, time budget } \\
\text { top-manager, profile } \\
\text { of top } 5 \text { managers, } \\
\text { and profile of em- } \\
\text { ployees }\end{array}$ & & $\begin{array}{l}\text { six organizational } \\
\text { culture module di- } \\
\text { mensions. }\end{array}$ & $\begin{array}{l}\text { the presented unit-level characteristics (size, private vs } \\
\text { public firms, manufacturing vs office units, structure, con- } \\
\text { trol system, time budget top-manager, piofile of top } 5 \\
\text { managers, and profile of employees) are the characteris- } \\
\text { tics that showed significant and meaningful correlations; } \\
\text { with organizational culture. dimensions P1, P3, P5 and P6 } \\
\text { showed to be related to unit characteristics that were rela- } \\
\text { ted to industry differences. dimerisions P2 (employee vs. } \\
\text { job orientation) and P4 (open vs closed) seemed to be } \\
\text { related to the philosophy of the founder of the unit or com- } \\
\text { pany. dimensions P2 and P4 correlated with measures of } \\
\text { size, structure, control system, top management profile } \\
\text { and employee profile. }\end{array}$ \\
\hline $\begin{array}{l}\text { Pratt and Beaulieu } \\
\text { (1992), organizational } \\
\text { culture in public accoun- } \\
\text { ting; size, technology. } \\
\text { rank, and functional area, } \\
\text { AOS }\end{array}$ & $\begin{array}{l}\text { firm size, firm audit } \\
\text { technology, employ- } \\
\text { ee rank, functional } \\
\text { area }\end{array}$ & & $\begin{array}{l}\text { power distance (PD) } \\
\text { and uncertainty } \\
\text { avoidance (UA) } \\
\text { (Hofstede, 1980, } \\
\text { 1982) }\end{array}$ & $\begin{array}{l}338 \text { respondents from accounting firms across the U.S. } \\
\text { firm size (small/large), firm technology (structured/un- } \\
\text { structured), employee rank (staff / senior / manager). } \\
\text { functional area (Management Advisory Services / non- } \\
\text { MAS) } \\
\text { findings comparing the values of respondents grouped by } \\
\text { organizational variable. for employees of: large firms PD is } \\
\text { higher and UA is lower; structured firms PD is lower, UA, } \\
\text { not significant (NS). staff highest PD, manager lowest, UA } \\
\text { NS; Management consultants lower PD adn lower UA. }\end{array}$ \\
\hline
\end{tabular}




\begin{tabular}{|c|c|c|c|c|}
\hline Author & $\begin{array}{l}\text { Independent varia- } \\
\text { bles }\end{array}$ & $\begin{array}{l}\text { Intermediary / con- } \\
\text { textual }\end{array}$ & Dependent variables & Description \\
\hline $\begin{array}{l}\text { Gordon (1991), industry } \\
\text { determinants of organiza- } \\
\text { tional culture, AMR }\end{array}$ & $\begin{array}{l}\text { competitive } \\
\text { environment, cus- } \\
\text { tomer requirements, } \\
\text { societal expectati- } \\
\text { ons }\end{array}$ & & & $\begin{array}{l}\text { 'if an organization is to survive, it will be built on certain } \\
\text { assumptions required by the industry, and its from these } \\
\text { assumptions that certain values emerge, which, in turn, } \\
\text { help define useful forms.' ( } 401 \text { ) } \\
\text { competitive environmen! (complexity, stability / dyna- } \\
\text { mism, munificence), customer requirements (demands } \\
\text { for reliability or novelty), societal expectations (e.g. shift } \\
\text { from preemininence of property rights (just provide servi- } \\
\text { ces/products and jobs) to human rights (health, safety) } \\
\text { market (de-)regulation) }\end{array}$ \\
\hline $\begin{array}{l}\text { Chatman and Jehn } \\
\text { (1994), assessing the } \\
\text { relationship between } \\
\text { industry characteristics } \\
\text { and organizational cultu- } \\
\text { re: how different can you } \\
\text { be?, AMJ }\end{array}$ & $\begin{array}{l}\text { industry technology } \\
\text { and industry growth }\end{array}$ & & $\begin{array}{l}\text { organizational cultu- } \\
\text { re profile (O'Reilly } \\
\text { et., 1991) see table } \\
3.1\end{array}$ & $\begin{array}{l}\text { sample: } 8 \text { accounting firms, } 3 \text { consulting firms, } 3 \text { freight } \\
\text { transport firms, and } 1 \text { U.S. Postal service group. OCP. } \\
\text { factor patterns similar for the different firms. 'Although the } \\
\text { organization level is important in explaining the variance } \\
\text { in cultures, industry differences explain more variation } \\
\text { than organization differences for six of the seven culture } \\
\text { dimensions.' (537) (not for outcome orientation) }\end{array}$ \\
\hline $\begin{array}{l}\text { Ashforth (1985), climate } \\
\text { formation: issues and } \\
\text { extensions, AMR }\end{array}$ & $\begin{array}{l}\text { roles of: the work } \\
\text { group, affect, corpo- } \\
\text { rate culture, symbo- } \\
\text { lic management, } \\
\text { physical setting }\end{array}$ & & $\begin{array}{l}\text { climate formation } \\
\text { through 'the } \\
\text { memberships' efforts } \\
\text { to understand the } \\
\text { organization' }\end{array}$ & $\begin{array}{l}\text { hypotheses on factors that influence climate formation } \\
\text { from an interactionist perspective. roles of: the work } \\
\text { group, affect, corporate culture, symbolic management. } \\
\text { physical setting }\end{array}$ \\
\hline $\begin{array}{l}\text { Harrison and Carroll } \\
\text { (1991), Keeping the faith: } \\
\text { a model of culturai } \\
\text { transmission in formal } \\
\text { organizations, ASQ }\end{array}$ & $\begin{array}{l}\text { model parameters: } \\
\text { recruitment selectivi- } \\
\text { ty, socialization in- } \\
\text { terisity, employment } \\
\text { duration / employee } \\
\text { turnover, organiza- } \\
\text { tional growth rate }\end{array}$ & & $\begin{array}{l}1 \text { equilibrium mean } \\
\text { enculturaltion level, } \\
2 \text { standard deviation } \\
\text { of enculturation at } \\
\text { equilibrium, } 3 \text { time } \\
\text { required to reach } \\
\text { equilibrium. }\end{array}$ & $\begin{array}{l}\text { computer model of cultural transmission. Different 'para- } \\
\text { meter settings' for seven organizational forms: } 1 \\
\text { japanese-style, } 2 \text { american manufacturing, } 3 \\
\text { governmental-bureaucratic, } 4 \text { professional, } 5 \text { entrepre- } \\
\text { neurial, } 6 \text { Z-type, } 7 \text { collectivist-democratic. }\end{array}$ \\
\hline
\end{tabular}


freight transport, U.S. postal service) using O'Reilly et al.'s (1991) organizational culture profile measure. They found the between-industry cultural differences to be significantly larger than the within-industry differences. Pennings and Gresov (1986) and Gordon (1991) evaluated the existence of industry differences in cultures theoretically. Pennings and Gresov (1986) discussed the interrelationships between the techno-economic, structural and cultural subsystems operating at the societal and organizational level. According to them, the relative importance of congruence of the subsystems within the organizations as opposed to the cross-level congruence of each subsystem (societal - organization level) is an important research question (Pennings and Gresov, 1986: 325). Gordon (1985) identified a number of industryspecific competitive, customer and societal requirements which should be incorporated in the organizational culture of successful firms. He argued that 'if a particular company's industry-driven assumptions and resultant values were not widely shared, many of its actions would conflict with the most basic requirements of the markets it serves, a situation that would seriously affect its ability to survive (Gordon, 1991:402).

Table 3.6 determinants of culture

\begin{tabular}{|c|c|}
\hline determinants of cuiture and climate & evidence \\
\hline $\begin{array}{l}\text { Industry differences } \\
\text { - technology } \\
\text { - private / public firms } \\
\text { - industry values (competitive envi- } \\
\text { ronment, customer-, and societal } \\
\text { expectations) }\end{array}$ & $\begin{array}{l}\text { Reynolds (1986) } 3 \text { industries; Hofstede (1990) manufacturing } \\
\text { / office; Pratt and Beaulieu (1992) functional area; Chatman } \\
\text { and Jehn (1994) } 4 \text { industries } \\
\text { Hofstede (1990) } \\
\text { Gordon (1991) }\end{array}$ \\
\hline $\begin{array}{l}\text { Organization } \\
\text { - size } \\
\text { - organizational position } \\
\text { - control system } \\
\text { - physical setting } \\
\text { - organizational growth rate }\end{array}$ & $\begin{array}{l}\text { Hofstede (1990); Pratt and Beaulieu (1992) } \\
\text { Reynolds (1986); Pratt and Beaulieu (1992) employee position } \\
\text { and rank } \\
\text { Hofstede (1990); Pratl and Beaulieu (1992) firm audit technol- } \\
\text { ogy structured / unstructured } \\
\text { Ashiorth (1985) } \\
\text { Harrison and Carroll (1991) }\end{array}$ \\
\hline $\begin{array}{l}\text { Management } \\
\text { - time budget top-manager } \\
\text { - top } 5 \text { managers profile } \\
\text { - Human resource mgmt } \\
\text { - symbolic management }\end{array}$ & $\begin{array}{l}\text { Hofstede (1990) } \\
\text { Hofstede (1990) } \\
\text { Harrison and Carroll (1991) socialization intensity, recruitment } \\
\text { selectivity } \\
\text { Ashforth (1985) }\end{array}$ \\
\hline $\begin{array}{l}\text { Employee demography } \\
\text { - profile of employees } \\
\text { - employee turnover }\end{array}$ & $\begin{array}{l}\text { Hofstede (1990); Ashforth (1985) work group; } \\
\text { Harrison and Carroll (1991) }\end{array}$ \\
\hline
\end{tabular}

Studies of Gordon (1991). Harrison and Carrol (1991). and Ashforth (1985) were theoretical studies Harrison and Carroll (1991) built a computer simulation model of cultural transmission. 
The organization. The impact of organization variables has been studied less widely, with less focus, and in a more exploratory fashion than the impact of industry differences. The studies have addressed the impact of organizational size, organizational position of respondents, organizational control system, organizational growth and physical layout of the organization. In two articles the impact of organizational size was studied. Hofstede et al. (1990) showed that measures of size correlated with two out of six dimensions of organizational culture. Size was positively correlated with employee orientation and professionalism. Pratt and Beaulieu (1992) found that in large accounting organizations power distance was higher and uncertainty avoidance was lower. Both Reynolds (1986) and Pratt and Beaulieu (1992) showed that organizational position and employee rank were related to the evaluation of organizational culture by the members of the organization. Reynolds (1986) revealed significant differences between operative and clerical worker, professionals / technical staff, and managers on dimensions reflecting innovativeness, employee orientation, results orientation, and the need for social conformity (cultural strength). Pratt and Beaulieu (1992) compared staff, accountants, and management consultants in U.S. accounting firms on measures of power distance and uncertainty avoidance. They also found significant differences in value-orientations between these groups. Hofstede et al. (1990) and Pratt and Beaulieu (1992) studied the impact of the organizational control system. Hofstede et al. (1990) established a relationship between three control system variables and two dimensions of organizational culture. A focus on profits correlated positively with job orientation, a focus on budget control negatively. Furthermore, less strict control of the internal communication process was reflected in an employee orientation and openness in the organization. Pratt and Beaulieu (1992) investigated the effect of a firm's audit technology (structured or unstructured) and found it was related to the cultural values held by the firm's employees. The degree of structuration showed a weak negative relationship with power distance.

These studies established empirical evidence of the relationship between organizational characteristics and organizational culture. Two other studies are interesting for their focus on the enculturation process from a theoretical perspective. Harrison and Carroll (1991) illustrated the influence of organizational turnover rates, varying degrees of recruitment selectivity, varying intensities of management socialization, and varying organizational growth rates on the outcomes of the enculturation process in a computer simulation of the process of culture formation. All four variables had a different impact on the mean enculturation level, the standard deviation of enculturation at equilibrium, and the time required to reach an equilibrium state. The organizational growth rate (as an aspect of organization) was positively related to the speed of enculturation (Harrison and Carroll, 1991). A second theoretical argument was put forward by Ashforth (1985). In a theoretical analysis of the process of culture formation from an interactionist perspective Ashforth argued for the importance of the physical setting in which the actual work was performed. Although somewhat outside the scope of an economic and organizational analysis it is important to notice that factors such as the arrangement of furniture and equipment, and noise levels all influence the locus, quantity, and nature of interactions (Ashforth, 1985:844).

The review of the impact of organizational variables shows that they can be expected 
to influence organizational culture and climate. However, the presented studies have a number of limitations. Reynolds (1986) study was exploratory in nature and design; Hofstede et al. (1990) studied the impact of organizational differences in a heterogenous sample of organizations coming from different industries; Pratt and Beaulieu (1992) focused on aspects of 'national culture' (the value-level), rather than more appropriate measures of organizational culture (the practices-level). Therefore, their outcomes would point to differences in selection and self-selection, rather than to aspects of organizational culture formed by socialization into the organization (Soeters and Schreuder, 1988). Concluding, we can say that studies focusing on the organization level of analysis that are able to control for industry differences might provide a valuable addition to the studies reviewed here. The empirical evidence for the influence of organization characteristics on organizational culture is still meager.

Management. Hofstede et al. (1990) related four objective aspects of the profile of the top-five managers to organizational culture (at least one woman, average education level, average age, and promoted from ranks.) The four variables were significantly related to several dimensions of culture. 'At least one woman in the top five management team' was positively correlated with openness, the average education level of the top five was positively correlated with a process orientation, an employee orientation, professionalism, and loose control. Average age was positively related to professionalism and the number of managers that were promoted to their top position internally was positively correlated with a process orientation. In their computer simulation of the enculturation process Harrison and Carroll (1991) showed the impact of several Human Resource Management (HRM) variables under the control of management. They showed a positive effect of recruitment selectivity on the mean enculturation level and the time to equilibrium (i.e. time to stable level of enculturation), and a positive impact of the degree of management socialization on cultural strength (Harrison and Carroll, 1991). A theoretical argument for the influence of symbolic management (Eoyang, 1985) made by Ashforth (1985) points to the impact of leadership on organizational culture. The impact of leadership on organizational culture and climate is an important area of research. The literature on the impact of leadership on organizational culture will not be addressed here. It will be discussed in the next chapter.

Employee demography. Only one empirical study (Hofstede et al., 1990) evaluated the impact of the employee demography on organizational culture and climate.

Hofstede et al. found positive correlations of the percentage of female employees and female managers with openness. Average employee seniority correlated negatively with employee orientation and positively with openness. Average age correlated negatively with employee orientation. Average education level and recent growth in number of employees correlated positively with loose control. In their computer simulation Harrison and Carroll (1991) show employee turnover to be positively related to time to equilibrium and, in case of a professional organization, to cultural strength. The findings of Hofstede et al. (1990) and Harrison and Carroll (1991), complemented by the theoretical arguments made for the importance of employee demography as an independent variable by Ashforth (1985) and Pfeffer (1982, 1985), ask for a further empirical examination of the influence of employee demography on organizational culture. Again, as was the case with the organization variables, a valuable analysis 
would control for other contextual variables. Studies that are able to control for differences in organizational technology (industry differences) would be useful for isolating the effect of demographic variables on organizational culture.

\section{Work satisfaction}

The studies presented above focused on the impact of contextual variables on aspects of organizational culture. None of the above studies showed the impact of the context on another important human factor in the organization: work satisfaction. Work satisfaction is not the central focus of discussion in this study, but it should be noted that research on the antecedents of work satisfaction includes a number of the dimensions discussed above. In a short review of the antecedents of work satisfaction Vogelaar (1990) points out that evidence indicates correlations of work satisfaction with employee demography and employee position. Research seems to evidence that organization characteristics influence work satisfaction mostly through the intervening influence of individual-level variables such as employee position and task characteristics, possibly because these directly affect the individual (Vogelaar, 1990:47). This, however, leaves open the possibility of a direct effect of organizational climate and culture on work satisfaction, because these organization-level variables do affect the individual organization member directly.

\section{Summary}

The review of the literature shows that several contextual variables are significantly related to organizational culture and climate. Table 3.7 summarizes the relationships that have been established by previous research between the contextual variables and the culture and climate variables distinguished in section 3.1 (administrative efficiency, communication / cooperation, organizational innovativeness, employee orientation, openness, results orientation, and cultural strength.) The table shows that the kind of work done in an organization seems to be a strong determinant of an organization's culture. In the more recent empirical studies cultural differences were shown to be related to industry variables and to the organizational position of the group of employees studied. Preliminary evidence shows several other organizational variables to be also related to organizational culture, such as organizational size (also a prominent explanatory variable in previous climate research), type of control system, objective characteristics of management, and employee demography. Still, the empirical evidence on these relationships is scarce. 
Table 3.7 Relationships between context and culture

\begin{tabular}{|c|c|c|c|c|c|c|c|c|}
\hline & $\begin{array}{l}\text { adinin. } \\
\text { effi- } \\
\text { ciency }\end{array}$ & $\begin{array}{l}\text { commu- } \\
\text { nication / } \\
\text { coop- } \\
\text { eration }\end{array}$ & $\begin{array}{l}\text { org. } \\
\text { innova- } \\
\text { tiveness }\end{array}$ & $\begin{array}{l}\text { emplo- } \\
\text { yee } \\
\text { orienta- } \\
\text { tion }\end{array}$ & $\begin{array}{l}\text { open- } \\
\text { ness }\end{array}$ & $\begin{array}{l}\text { results } \\
\text { orienta- } \\
\text { tion }\end{array}$ & $\begin{array}{l}\text { culture } \\
\text { strength }\end{array}$ & $\begin{array}{l}\text { satis:- } \\
\text { faction. }\end{array}$ \\
\hline $\begin{array}{l}\text { industry diffe- } \\
\text { rences }\end{array}$ & & $x$ & & $x$ & & $x$ & $x$ & \\
\hline size & $x$ & & & $x$ & & & & \\
\hline $\begin{array}{l}\text { employee } \\
\text { position }\end{array}$ & & & $x$ & $x$ & & $x$ & $x$ & $x$ \\
\hline $\begin{array}{l}\text { control sys- } \\
\text { tem }\end{array}$ & $x$ & & & $x$ & $x$ & & & \\
\hline management & & & & $x$ & $x$ & $x$ & $x$ & \\
\hline $\begin{array}{l}\text { employee } \\
\text { demography }\end{array}$ & & & & $x$ & $x$ & & $x$ & $x$ \\
\hline
\end{tabular}

\section{Further research}

Considering research to date, the organizational context seems to have an important influence on organizational culture and climate. Although with respect to organizational culture most studies are still exploratory in nature, a number of conclusions can be drawn from a review of the literature.

1. By now, an impact of industry variables on organizational culture has been established. The findings have been fairly general and exploratory. Theoretically grounded studies, for example elaborating and testing the theoretical relation-ships proposed by Gordon (1991), would be useful.

2. For structured evidence on organization level contextual influences on 'the human factor in organizations, ' however, we have to rely on the results of climate research and infer possibly similar relationships between organization level variables and organizational culture. Furthermore, Payne and Pugh (1976), in a review of the work on the relationship between organizational structure and climate, already concluded that there was a lack of evidence on the relationship between objective measures of the organizational context and perceived organizational climate. Only a few studies have related organization variables such as size and type of control system to organizational culture empirically (Hofstede et al., 1990; Pratt and Beaulieu, 1992). Most studies compare organizations in different industries, which makes it difficult to investigate the impact of purely organization-level characteristics on organizational culture. The same holds for the empirical evidence on the impact of employee demography on organizational culture. In a preliminary investigation Hofstede et al. (1990) found some general correlations between the two constructs, but further research seems useful.

3. A third field of inquiry that has not yet developed to its full potential involves the 
relationship between various more or less objective management characteristics and organizational culture. Although leadership research has clearly pointed out the important symbolic role of management in the process of culture formation research relating more objective factors of management to organizational culture is scarce.

Concluding, our evaluation of the research evidence seems to point to two fruitful directions for the study of organizational culture as a dependent variable. One is the further investigation of the impact of industry characteristics on organizational culture. The other is the analysis of the impact of organization level variables such as organization structure, objective management characteristics and employee demography. Important structure variables were identified in previous research, including organizational size and organizational position or rank. The study of the impact of objective management characteristics and employee demography on organizational culture is still almost non-existent.

\subsection{Conclusion}

The research discussed in this chapter presented evidence on the form and impact of organizational culture and climate in organizations. To benefit from the outcomes of research in related areas our review was not confined to an analysis of the outcomes of studies on organizational culture, but more broadly oriented at the evidence on the form and impact of what Hofstede (1991) called 'the soft factor in organizations,' thus also including the outcomes of organizational climate research. On the basis of the previous research discussed in this chapter a number of conclusions for further research can be drawn. First, in the pioneering stage of quantitative empirical organizational culture research, climate instruments have been used as measures of organizational culture. Although this was fruitful, the difference between the concepts should be appreciated. Empirical studies using original organizational culture measures are still scarce. Second, six aspects of the 'human factor in organizations' appear consistently in the empirical research. These dimensions are administrative efficiency, communication / cooperation, organizational innovativeness, employee orientation, openness, and goal emphasis or results orientation. It seems useful to include these dimensions in future analyses of the impact of 'the human factor' in organizations. Third, studies have shown that different aspects of culture influence different performance measures (e.g. Denison showed that two dimensions of culture had a positive impact on present performance and two other dimensions had an impact on future performance). It seems interesting to compare the influence of the six dimensions described above on a number of performance variables. Fourth, there seems to be a lack of studies relating organizational culture to the bottom line performance which is fully attributable to the organization (or unit) under study. Fifth, the kind of work done in an organization is a strong determinant of organizational culture. Industry characteristics and the organizational position of employees are strongly correlated to the perceived organizational culture. An important question is what aspects of organizational culture describe differences between organizations which are not determined by industry effects, because these are the aspects that are, at least partly, under managerial discretion. Sixth, there is a lack of evidence on the influence of 
organization-level context variables on the form and impact of organizational culture when controlling for industry effects. A number of organizational factors have shown to be related to organizational culture and climate: organizational size, type of control system, objective characteristics of management, and aspects of employee demography. However, the evidence in this area is still rudimentary. An investigation of the influence of aspects of the organizational context on organizational culture seems useful.

As for this study our aim is to study the importance of organizational culture for the effective performance of organizations in relation to the organizational context, our review of the organizational culture and climate literature leaves us with the following focus for this investigation. First, six dimensions of organizational culture and climate appear consistently in empirical research and can thus be considered important starting points for future research on aspects of organizational culture and climate. In general, these dimensions seem to have a significant impact on organizational performance, but measurements of organizational performance are often flawed. Our first objective thus is to substantiate the positive influence of these six dimensions of organizational culture and climate on organizational performance. Second, organizational culture research has mostly studied industry differences. On the basis of the existing evidence, however, we expect a substantial influence of organization-level contextual variables, both on organizational culture and on organizational climate. Therefore, our second objective is to evaluate the influence of contextual variables at the organizational level on organizational culture and organizational climate. This will help us to put the role of organizational culture for organizational performance into perspective. 



\section{CHAPTER 4}

\section{LEADERSHIP}

The question whether leadership makes a difference to the performance of organizations still evokes a lot of debate (e.g. Pfeffer, 1983, 1992). However, empirical studies seem to point to a general impact of leadership in organizations. Thomas (1988), for example, showed that, although non-leadership variables explained most of the performance variation, leadership effects explained around 50 to 60 percent of the remaining unexplained performance variation, and Boone et al. (1996) report an influence of CEO personality on small firm performance in the Belgian furniture industry. The idea of the significance of leadership in organizations has recently gained support, not only because of findings such as those of Thomas and Boone et al., but mainly because of the increased attention for the impact of organizational culture on business performance, and the alleged impact of leadership on culture formation. Some scholars even argue that the management of culture is one of the most basic leadership tasks (see chapter 2). In any discussion of organizational culture, the concept of leadership therefore seems crucially important. in its purest definition leadership is defined as a process of reinterpretation, reorganization and restructuration of a group's understanding of their situation:

'.. an interaction between two or more members of a group that often involves a structuring or restructuring of the situation and the perceptions and expectations of the members.' (Bass, 1990)

This definition clearly points out the conceptual importance of leadership for organizational culture. Structuring and restructuring the situation, if successful, involves a certain influence on group members' perception and evaluation of the (organizational) situation. Actually, organizational culture can be seen as the residue of the leadership actions of all organization members throughout the organization, comparable to the set of formal rules and regulations that are the residue of formal decision-making in organizations. Thus, organizational culture might be defined as leadership (the reordering of organizational value preferences) frozen into organizational common sense (the organizational value structure).

In most research and public discourse, however, leadership is personalized, in the sense that 'somebody leads the others.' The leader sets goals and makes decisions, thus clarifying (interpreting) what is important and structuring the situation. Leadership is personalized, because then it is more tangible and easier to notice, but mostly because we are interested in how and why certain individuals have a larger impact on the 'structuring and restructuring of the situation' than others.

In this chapter leadership is also operationalized as an attribute of 'a leader.' First, section 4.1 describes leadership research as one of three views on the role of management in the organization. Then section 4.2 reviews the development of leadership research and two present foci for leadership research. These foci for leadership 
research are discussed in section 4.3 and 4.4 . Section 4.3 discusses the results of research along the lines of the two traditional dimensions initiating structure and consideration. Section 4.4 discusses the more recent research on charismatic leadership. Finally, section 4.5 concludes that an empirical integration of the traditional leadership model and the charisma-model might enhance our understanding of the relationships between the two.

\subsection{Management and leadership}

Studies of management in organizations have recently been putting increasing emphasis on the leadership aspect of the managerial job. Historically, managerial work has been studied from several viewpoints. To put our discussion of the impact of leadership into perspective we will shortly discuss three different views or three perspectives on management: the management function in the organization, managerial work as what managers do, and management as leadership.

The management function in the organization. Thinking about the functions of management in organizations has started at the beginning of this century with the writings of the French mining engineer Henri Fayol (1914). Fayol argued that the management function in organizations had to be fulfilled, just as five other crucial functions of organizations:

'All activities to which organizational undertakings give rise can be divided into the following six functions: 1) technical (engineering, production, manufacture, adaptation); 2) commercial (buying, selling, exchange); 3) financial (search for an optimum use of capital); 4) security (protection of assets and personnel); 5) accounting (stocktaking, balance sheets, costs, statistics); 6) managerial (planning, organizing, commanding, coordinating, controlling). Whether the undertaking is simple or complex, large or small, these six essential functions are always present.' (Fayol, 1984:9)

Focusing on the management function, Fayol then goes on to explain the qualitative difference between the management functions and the other functions of organization:

'Management (...) is neither an exclusive privilege nor a particular responsibility of the head of an organization or its senior members; it is an activity spread across all members of the 'body corporate't - the total personnel structure of the organization. The managerial function is quite distinct from the other five essential functions; it supersedes them and, in effect, directs them toward the achievement of the objectives of the undertaking. The managerial function seeks to derive optimum advantage from all available resources and to assure the smooth working of the six essential functions including the managerial function itself.' (Fayol, 1984: 13)

\footnotetext{
1 'Body corporate' is the translation of Fayol's 'corps social,' pointing to the group of employees involved in the activities of the organization (Fayol, 1984:5)
} 
Having thus described the management function Fayol then enumerates what has to be done in the organization to fulfill the management function:

'To manage is (...): 1) to plan: examine the future and lay out of the actions to be taken; 2) to organize: lay out the lines of authority and responsibility; build up the dual structure, material and human, of the undertaking; 3) to coordinate: lay out the timing and sequencing of activities; bind together, unify, and harmonize all activities and efforts; 4) to command: put the plan into action; set the work in operation; 5) to control: monitor and correct; see that everything occurs in conformity with established rules and expressed command.' (Fayol, 1984:13)

In his description of the function of management Fayol emphasizes the theoretical function of management in the organization. His approach is relatively technical, identifying the various functions that have to be performed to operate an organization. In a comparable way Barnard (1938) discusses the social functions of the management in the organization. In his book 'The functions of the executive' he focuses on the role of managers in the process of formal organization, which he defines as 'the concrete social process by which social action is largely accomplished.' (Barnard, 1938:3).

Managerial work as what managers do. The theoretical discussion of the function of management in organizations somehow created the impression that the management task was one of deliberate rational planning, giving orders, and of a detached steering of the organization. In practice, however, this was not the case. From a study of the work behavior of five chief executives Mintzberg concluded that managerial work could be characterized by brevity, variety, and fragmentation (Mintzberg, 1973). To make sense of the multitude of activities in which his CEOs engaged Mintzberg organized 'what managers do' in ten managerial roles. These ten roles are part of each managerial position:

'The concept of role (...) has made its way from the theater to management via the behavioral sciences. A role is defined as an organized set of behaviors belonging to an identifiable office or position (...). Individual personality may affect how a role is performed, but not that it is performed. Thus, actors, managers, and others play roles that are predetermined, although individuals may interpret them in a different way.' (Mintzberg, 1973:54)

The ten roles can be organized in three groups that are related: the interpersonal roles, the informational roles, and the decisional roles (Mintzberg, 1973). Mintzberg argues that the need and ability to perform the managerial roles is grounded in a manager's formal authority and status. The manager operates as the formal link between 'his organization' and its environment. Three interpersonal roles arise directly from his formal authority (the figurehead role, the leader role and the liaison role). His interpersonal contacts enable the manager to fulfill three informational roles (monitor. disseminator, and spokesman). Finally, because only he has 'full and current information, ' the manager performs four decisional roles that, according to Mintzberg 'justify his great authority and his powerful access to information' (Mintzberg (1973:77). 
Together the ten roles give an idea of what managerial work is like:

'The roles are described individually, but they cannot be isolated. (...) these ten roles form a gestalt - an integrated whole. In essence the manager is an inputoutput system in which authority and status give rise to interpersonal relationships that lead to inputs (information), and these in turn, lead to outputs (information and decisions). One cannot arbitrarily remove one role and expect the rest to remain intact.' (Mintzberg, 1973:58)

Although the 'leadership role' is one of the ten roles described, Mintzberg argues that it 'clearly is among the most significant of all roles' (1973:61):

'In analyzing the activities that make up the leader role, we must note first that leadership permeates all activities; its importance would be underestimated if it were judged in terms of the proportion of a manager's activities that are strictly related to leadership. (...) in virtually everything he does, the manager's actions are screened by subordinates searching for leadership clues.' (Mintzberg, 1973:61)

Thus almost all roles distinguished by Mintzberg have aspects of leadership in them. In the interpersonal roles the manager functions as the leader and symbolic personification of his organization. In the informational roles, what the manager communicates, how he makes sense out of his environment, how he organizes information and emphasizes some things over others, clarifies his leadership vision. Finally, the manager's activities in the decisional roles show most directly how the manager seeks to implement his leadership vision. The manager's actions in the decisional role are continuously interpreted by his subordinates as the practical outcomes of the leadership vision. The manager's subordinates continually seek reconfirmation of the leadership vision asking themselves 'he talks the talk, but does he walk the walk?' Thus, the leadership role permeates all other roles to a certain extent. The key role of leadership as Mintzberg sees it, is 'to effect an integration between individual needs and organizational goals' and to unite the elements of the organization into a cooperative enterprise by providing a clear vision. He argues that

'it is in the leader role that managerial power most clearly manifests itself. Formal authority vests the manager with great potential power; leadership activity determines how much of it will be realized.' (Mintzberg, 1973:62)

Leadership. Although Mintzberg argues that leadership is important, he studies it as an aspect of managerial work. In contemporary management thinking leadership has become a central concept for the understanding of managerial effectiveness in organizations. With the increasing attention for organizational culture as a critical success factor for contemporary organizations (as discussed previously in chapter 2 and 3 ) the concept of leadership is considered more and more important. Leadership can arguably be seen as the prime tool for steering and managing organizational culture: 
'When one brings culture to the level of the organization and even down to groups within the organization, one can see (...) clearly how it is created, embedded, developed, and ultimately manipulated, managed, and changed. These dynamic processes of culture creation and management are the essence of leadership and make one realize that leadership and culture are two sides of the same coin.' (Schein, 1992:1)

The importance of leadership for understanding the dynamics of organizational culture makes a separate analysis of the concept of leadership and its effects useful in this study.

\subsection{Trends in leadership theory and research}

In leadership research the main research questions have always been how a leader influences his subordinates and to what extent his leadership activities have had an impact. In a review of leadership theory and research up to the 1980s Bryman (1992) distinguishes the four periods summarized in table 4.1.

Table 4.1 Trends in leadership theory and research

\begin{tabular}{|c|c|c|}
\hline Period & Approach & Core theme \\
\hline Up to late $1940 \mathrm{~s}$ & Trait approach & Leadership ability is innate \\
\hline $\begin{array}{l}\text { Late } 1940 \text { s to late } \\
1960 \text { s }\end{array}$ & Style approach & $\begin{array}{l}\text { Leadership effectiveness has to do } \\
\text { with how the leader behaves }\end{array}$ \\
\hline $\begin{array}{l}\text { Late } 1960 \text { s to early } \\
1980 \text { s }\end{array}$ & Contingency approach & $\begin{array}{l}\text { It all de pends; effective! leadership is } \\
\text { affected by the situation }\end{array}$ \\
\hline Since early $1980 \mathrm{~s}$ & $\begin{array}{l}\text { New leadership approach } \\
\text { (includes charismatic leadership) }\end{array}$ & Leaders need vision \\
\hline
\end{tabular}

Source: Bryman (1992:1)

The trait approach. During the first period, up to the late 1940s, the trait approach was fashionable. In this first period students of leadership were mostly concerned with identifying personality traits of good leaders. Their assumption was that leadership ability is innate. Although in the late 1940 s the trait-approach was abandoned as unfruitful, more recent reviews of trait-research take a less extreme position and accept the influence of specific personality aspects of leaders:

'The leader is characterized by a strong drive for responsibility and completion of tasks, vigor and persistence in the pursuit of goals, venturesomeness and originality in problem solving, drive to exercise initiative in social situations, selfconfidence and a sense of personal identity, willingness to accept the consequences of his or her decisions and actions, readiness to absorb interpersonal stress, willingness to tolerate frustration and delay, ability to influence other people's behavior, and the capacity to structure social interaction systems to the purpose at hand.' (Bass 1990:87) 
However, Bass hastens to add that

'the conclusion that personality is a factor in differentiating leadership does not represent a return to the pure trait approach. It does represent a sensible modification of the extreme situationalist point of view (...) [which] denied the influences of individual differences, attributing all variance among persons to the fortuitous demands of the environment.' (Bass, 1990:87)

Bass comments that a practical application of the renewed interest in the trait approach can be found in the use of assessment centers for determining leadership potential. Another issue in the trait tradition is the influence of gender on leadership performance. In a recent book Helgesen (1990) describes the results of a diary study of successful female managers using the approach of Mintzberg (1973). She showed clear differences between the work styles of Mintzberg's five male top managers in the early 1970 s and her four female top managers in the early 1990 s. For example, Mintzberg's managers worked at an unrelenting pace, with no breaks in activity during the day; Helgesen's women worked at a steady pace, but with small breaks scheduled throughout the day. The female managers did not view unscheduled tasks and encounters as interruptions, as Mintzberg's men did; they emphasized caring, being involved, helping, and being responsive. The female managers focused on 'the ecology of leadership,' clearly making time for more long-term oriented activities, where Mintzberg's male managers became overly absorbed in the day-to-day tasks of management. In all the women seemed to focus on the process of management rather than the completion of more narrowly defined tasks. Helgesen concludes that women might be better equipped to fulfill leadership roles in contemporary organizations, emphasizing their different approach to communication and their ability to combine the efficient with the humane (Helgesen, 1990). In the last edition of the 'Handbook of Leadership' (Bass, 1990) the chapter dedicated to the issue of women and leadership was considerably expanded. The research on the issue seems to show mixed results. Bass argues that new research remains important, because the role of women in the workplace is changing rapidly.

The style approach. The second period, starting in the late 1940s, abandoned the trait approach, which, at that time, was seen as relatively unfruitful. Instead, research

focused on leadership as a more interactional construct occurring between the leader and the led. Leadership style was studied as perceived by the leader's subordinates. This research has proven fruitful. Two dimensions of leadership appeared consistently here: 1) a concern for group maintenance and consideration for employees (consideration): and 2) a concern with the structuration of the work task of the group (initiating structure). Studies have focused on the impact of the two dimensions on employee attitudes, task performance, and group performance. A highly influential popularization of the research in this tradition is Blake and Mouton's 'Managerial grid' (Blake and Mouton, 1964, 1985). They labeled the two dimensions 'concern for production' and 'concern for people.' Their basic underlying assumption was: the more leadership the better. Their theoretical optimum was 'team management' characterized by a high score on both dimensions. 
The contingency approach. The third period described by Bryman celebrates the contingency approach to leadership. The emphasis is on the situational relativity of the effectiveness of leadership styles. Leadership style effectiveness is determined by, for example, situational favorableness to the leader (Fiedler, 1967), employee task maturity (Hersey and Blanchard, 1969), and task clarity (House and Mitchell, 1987). The empirical research in this period clearly builds on the outcomes of the leadership style investigations. Thus the contingency approach can be seen as an extension of the leadership style approach.

The new leadership approach. The fourth period started at the end of the 1970 s. Bryman labels this period as the era of the 'new leadership approach.' Under this heading studies of charismatic leadership (e.g. House, 1977; Conger and Kanungo, 1987, 1988), transformational leadership (e.g. Burns, 1978; Bass, 1985a), leadership as opposed to management (e.g. Zaleznik, 1977), visionary leadership (Sashkin, 1988; Westley and Mintzberg, 1989), and magic leadership (Nadler and Tushman, 1989) are summarized. The central interest of the new leadership approach is something related to the concept of charisma. Bryman argues that although researchers have labeled the issue differently, they focus on only slightly different aspects of the issue. Something like charismatic leadership is at the core of each of the competing theories (Bryman, 1992:113). The interest in organizational culture and charismatic leadership revived the attention for personal aspects of leadership.

\section{Present foci for leadership research}

Considering the present leadership research, four foci for leadership can be distinguished along two dimensions. The first dimension is the operationalization of the concept of leadership style. The second dimension focuses on the dependent variables influenced by the leader.

First, leadership style is operationalized in two general ways. First, in the tradition of the early studies of leadership style, leadership is operationalized in a technical and relational manner. Two dimensions of leadership describe the role of the leader as one of maintaining group relationships (consideration) and one of structuring the work task of the group (initiating structure). Second, from the late 1970s onward the concept of charisma has become important, reflecting attention for the motivational influence of a leader on his subordinates on a more emotional level. Studies in this tradition have measured charisma as the key dimension of transformational leadership, studying its impact on subordinates and the organization (e.g. Bass, 1985).

The second dimension focuses on the dependent variables influenced by leadership. Students of leadership have looked at its impact in two different ways. On the one hand, studies focused on the impact of leadership on employee attitudes like work satisfaction, employee commitment, organizational climate and organizational culture. On the other hand, studies directly related leadership style to employee task performance or group / organizational performance. The different foci of leadership re- 
search are summarized in table 4.2 .

Table 4.2. Different foci for leadership research

\begin{tabular}{|c|c|c|}
\hline \multirow[t]{2}{*}{ Impact of leadership } & \multicolumn{2}{|c|}{ Operationalizarion of leadership } \\
\hline & $\begin{array}{l}\text { Consideration and initiating } \\
\text { structure }\end{array}$ & Charismatic leadership \\
\hline $\begin{array}{l}\text { impact of leadership on em- } \\
\text { ployee attitudes like work satis- } \\
\text { faction, employee commitment, } \\
\text { organizational climate and } \\
\text { organizational culture }\end{array}$ & $\begin{array}{l}\text { e.g. job satisfaction, satisfac.. } \\
\text { tion with supervisiori, employee } \\
\text { commitment; job involvement: } \\
\text { task motivation }\end{array}$ & $\begin{array}{l}\text { e.g. employee commitment., } \\
\text { job involvement, task motiva- } \\
\text { tion, task satisfaction, percei- } \\
\text { sed role conflict and role ambi- } \\
\text { guity }\end{array}$ \\
\hline $\begin{array}{l}\text { impact of leadership on emi- } \\
\text { ployee tasik performance or } \\
\text { group / organizational perfor- } \\
\text { mance }\end{array}$ & $\begin{array}{l}\text { e.g. job performance, individual } \\
\text { task performance, perceived } \\
\text { store efficiency, business vol- } \\
\text { ume, costs, growth }\end{array}$ & $\begin{array}{l}\text { e.g. individual task perform- } \\
\text { ance, consolidated unit per- } \\
\text { formance }\end{array}$ \\
\hline
\end{tabular}

The discussion of the evidence on the impact of leadership in the subsequent sections is organized by operationalization of the leadership concept. The main objective of the discussion is to present an overview of the key results in this field, not to review the literature extensively. First, the outcomes of the traditional leadership style studies are discussed, focusing on the impact of initiating structure and consideration. Then, the literature on the impact of charismatic leadership is discussed. For a broad review of the literature the interested reader is referred to Bass (1990), who provides a more extensive review of the leadership literature than could ever be achieved in the context of this dissertation study. In the past five years empirically oriented leadership researchers have focused on the impact of transformational leadership in organizations, thus focusing on the impact of charismatic leadership in organizations. The results of these studies will be discussed in section 4.4 .

\subsection{Leadership as a relational concept: structuring and consideration}

From the beginning of the 1950 s onward a relatively consistent body of knowledge has developed about the impact and measurement of leadership style. The outcomes of this, mostly empirically based, research have been consistent, but have a relatively narrow focus. The research 'tradition' started with the Ohio State Leadership studies in the 1950s, investigating differences in leadership styles as they were perceived by the leader's subordinates. The hypotheses / assumptions in this research tradition are that (i) leaders fulfill distinct functions in the group process, (ii) their performance on these functions can be measured independently, and (iii) that individual leaders may emphasize different aspects of leadership. Bass (1990) has extensively reviewed the outcomes of the studies in this tradition. The evidence has shown two independent styles to reappear consistently: autocratic / work-related leadership and democratic / person-related leadership (Bass, 1990:416). Although many studies suggested specific additions or alterations of the basic two-dimensional model, subsequent empirical research only confirmed the two independent dimensions. From exploratory factor analyses on data sets from earlier studies Miller (1973) concluded that consideration 
and initiating structure could be considered two 'meta-dimensions' of leadership. Bass explains the consistent reappearance of the two dimensions as follows:

Why do we emerge with just two overarching clusters of leadership styles? Possibly because there are only two ways of changing a follower's behavior (apart from using drugs or physical force). The leader alters either the follower's information, understanding, and ability to cope with the task at hand or the follower's motivation to deal with the task.' (Bass, 1990:419)

These two ways of changing a follower's behavior can occur together, and are to some extent complementary. They describe two empirically independent aspects of leadership that, taken together, describe a person's leadership style.

\section{A theoretical basis: performance and maintenance}

The two dimensions of leadership style were derived empirically. Several researchers proposed more elaborate and more refined models of leadership, but empirically these were not consistently supported. Philipsen (1965), for example, proposed four styles (social, instrumental, stable, and dynamic leadership) based on Parsons' (1959) 'model of organizational action orientation', but finally concluded that only the social and the instrumental dimension were stable. Miller (1973 cited in: Bass, 1990:519520) argued that there might be a hierarchical pattern in leadership styles. In his multilevel factor analyses he showed that on a two-factor level 'consideration' and 'structuring' could be considered the basis for a hierarchical refinement of the empirically distinguished behavioral leadership dimensions.

Misumi (1985) offers a theoretical grounding for this distinction from a Japanese perspective. In Japan leadership research has progressed along the lines of the Performance-Maintenance (PM) theory of leadership. The PM-theory can provide a way of understanding the empirical Ohio State dichotomy:

'The P[erformance]-function is that which is directly oriented toward accomplishing work, while the M[aintenance]-function is oriented toward maintaining social stability. (...) The theory postulates that the M-function facilitates the work-promoting aspect of $P$ leadership, especially encouraging subordinates not to rebel against $P$, and by reducing the stress that can be produced through an exclusive P-function emphasis. The PM-theory is held together by this basic conceptual formulation rather than by any single empirical research approach.' (Misumi and Peterson, 1987:221)

The theoretical, rather than empirical, grounding of the PM theory is further exemplified by the assumption that the empirical measurement of $P$ and $M$ leadership may differ between cultures:

'Results show significant differences between countries in how specific leader behaviors are interpreted. For example, talking with your boss about work 
problems is more highly correlated with a consideration / $\mathrm{M}$ attribution in the United Kingdom than it is in the United States.' (Misumi and Peterson, 1987:224)

This line of reasoning relates to Hofstede's argument about the cultural relativity of organizational theory (Hofstede, 1980a). It would go beyond the scope of this study to discuss this issue here in detail.

\section{Initiating structure and consideration in the Netherlands}

In the Netherlands Philipsen (1965; 1970) and Syroit (1979) have done leadership research in the 'Ohio State tradition.' Both developed a Dutch language questionnaire measuring leadership style. Philipsen translated and extended Fleishman's (1957) Supervisory Behavior Description Questionnaire (SBDQ) and initially found four factors describing leadership style: social (sociaal), instrumental (instrumenteel), stable (evenwichtig), and dynamic (dynamisch) leadership (Philipsen, 1965). In replications, the stable and dynamic leadership factors were not consistently reproduced and disappeared into the social leadership factor (Philipsen, 1970). Syroit (1979) reproduced Fleishman's two-factor solution with a questionnaire exactly resembling the original SBDQ (Flesihman, 1953). He named the two dimensions 'mensgericht leiderschap' (consideration) and 'taakgericht leiderschap' (initiating structure). These dimensions resembled Philipsen's dimensions of social and instrumental leadership.

\section{The impact of consideration and initiating structure}

In his review of the evidence on the impact of consideration and initiating structure Bass (1990) summarized a number of outcome variables that showed a relationship with initiating structure and consideration. Although the evidence was mixed, a number of studies reported a positive influence on, for example, rated leader effectiveness, group relations, group cohesiveness, unit effectiveness, satisfaction with the company, absenteeism and turnover, and group performance (Bass, 1990:527). In a meta-analysis of studies published after 1968, Fisher and Edwards (1988) revealed a clear positive influence of consideration and initiating structure on job performance. overall job satisfaction, and satisfaction with supervision. The correlations were strongest for consideration leadership (Edwards and Fisher, 1988 in: Bass 1990:534). These studies show empirical evidence for the correlations of leadership with employee attitudes, job satisfaction, and job performance. However, the evidence for the impact of leadership styles on organization-level performance is still scarce. Of specific relevance in this context is a study of Bowers and Seashore (1966). Bowers and Seashore studied the impact of a four-factor leadership model on organizational effectiveness. They concluded that (i) leadership had a varying but significant impact on employee satisfaction, business volume, business costs, and business growth, (ii) that this relationship was not always direct, e.g. managerial interaction facilitation was related to perceived rivalfy among agents, which, in turn was related to business growth, and (iii) that the impact of leadership was dependent on personal and motiva- 
tional aspects of the employees (Bowers and Seashore, 1966). These results show clearly that both a direct and an indirect effect of leadership on organizational outcomes can be expected. Furthermore, they point to the moderating impact of contextual variables, such as the manager's influence acceptance and rivalry among subordinates, on the influence of leadership on performance.

\section{The situational dependence of leadership effectiveness}

Bowers and Seashore (1966) already showed a moderating influence of the organizational context on leadership effectiveness. In his review Bass (1990) also points to a number of contextual variables that moderate leader effectiveness. Examples are the group's function and task, the impact of the leader 'upstairs', the size of the group led, the structure of the work group, the amount of group cohesion, group conflicts, and interaction effects between initiating structure and consideration (Bass. 1990:535). The issue of a moderating effect of contextual variables on leadership effectiveness has also been taken up by scholars providing a theoretical grounding for their expectations of this moderation.

Employee task maturity. Hersey and Blanchard (1969a; 1982) discussed the impact of employee task maturity on leadership effectiveness. In their 'situational leadership model' Hersey and Blanchard (1969a; 1982a) argued that the mix between concern for people and production should be decided on taking into account the subordinates: level of task maturity. The model was built on the assumptions (amongst others) that

'the most effective behavioral style of leaders is one that varies with the situation (Fiedler, 1967; Korman, 1966); the best attitudinal style is a high task- and a high relations orientation (Blake and Mouton, 1964); and the job and the psychological maturity of the followers is most crucial in determining which behavioral style of leaders will result in the most effectiveness (Argyris, 1962)' (Hersey and Blanchard, 1969a cited in Bass, 1990:488)

Hersey and Blanchard's model has had to endure a lot of theoretical and methodological critique (Bass, 1990), but its intuitive appeal has kept it alive.

Task clarity. House and Mitchell's path-goal theory (House and Mitchell, 1983) discussed the mediating impact of task clarity on the type of leadership that is needed. It indicates that the influence of consideration and initiating structure is contingent upon the structure of the job. When job structure is high, consideration often serves as a mitigating factor in aligning -- and even motivating -- employees. Initiation, on the other hand, only has an effect when job structure is low and the supervisor alleviates the ambiguity and stress that might be associated with a job that is ill-specified, whose objectives are poorly articulated, and where the technology is fuzzy (Koene el al., 1992). Garcia, 1987) studied the leadership requirements necessary in different situations. 
The key constructs in Fiedler's 'dynamic theory of leadership' (1967) are the leader's motivational basis and situational favorableness. Situational favorableness is operationalized as the leader's situational control. It is determined by task structure and the subordinates' acceptance of the leader (Fiedler and Garcia, 1987). The leader's motivational basis is measured by having the leader describe his personal attitude towards his 'least preferred co-worker' (|pc). A positive attitude toward the lpc is indicative of relationship motivation. A negative attitude toward the lpc indicates taskmotivation. This distinguishes task-motivated from relationship-motivated leaders. According to Fiedler a leader needs different motivational (personality) characteristics to survive in a situationally favorable or unfavorable environment. A task-motivated leader will function best in either an extremely favorable or an extremely unfavorable situation. A relationship-motivated leader is most effective in a situation that is moderately favorable (Fiedler, 1967). Fiedler's 'dynamic theory of leadership' (Fiedler, 1967) was criticized for several reasons. First, the lpc-instrument was not considered a good measure of the leader's motivational structure. Second, the theory did not clarify how the leader's situational effectiveness was influenced by his task or relationship motivation. Still, Fiedler's theories explicitly recognize the importance of a leader's environment for his personal functioning and highlights the fact that leaders will react differently to environmental stimuli, as also Kalma (1990) has argued when he looked at different predispositions of leaders regarding social and aggressive dominance.

The moderating influence of the organizational context. Studies describing the moderating influence of the organizational context on leadership effectiveness emphasized the influence of organization design, technology, task structure, employee training, and organizational climate (Howell et al., 1990; Williams et al., 1988; Kerr and Jermier. 1978). In recent empirical investigations the hypothesized moderating impact of the contextual variables could not be shown, although the supposed moderators did have a main effect on organizational effectiveness (Podsakoff et al., 1993a, 1993b). An investigation of the influence of organizational culture on leadership effectiveness showed a moderating influence of culture on the impact of people-oriented and taskoriented leadership behaviors, but not on the impact of charismatic leadership (kioene, Pennings, and Schreuder, 1992). Considerate leaders seemed to be more effective in people-oriented cultures. Leaders perceived as structuring seemed more effective in task-oriented cultures. A measure of charismatic leadership in the same study seem-ed to be less influenced by cultural differences. It was argued that this difference might be explained by differences in how charismatic, structuring and considerate leadership impact subordinate behavior.

\section{Summary}

In all, research to date has provided evidence showing that consideration and initiating structure leadership can be expected to impact organizational performance (both directly and indirectly through employee attitudes). Studies also show that effects of consideration and initiation of structure are dependent on the organizational context. However, there is (i) a lack of evidence on the impact of consideration and initiating structure on organizational culture and objective measures of performance, and (ii) a 
lack of evidence on the impact of organizational culture on leadership effectiveness.

\subsection{Extension of the leadership style research: charismatic leadership}

Although research on the basic two-dimensional model resulted in a reasonably coherent body of knowledge, uneasiness about its completeness has kept researchers looking in different directions. The model seemed empirically robust, but researchers kept looking for extensions of the model with the 'gut'-feeling that leadership was more than the rather technical aspects of leadership that could be measured using the consideration and initiating structure scales. A fruitful extension of the model surfaced at the end of the 1970s. Researchers started to emphasize the charisma of a leader. The concept of charisma was introduced by Weber, who defined it as follows:

'The term 'charisma' will be applied to a certain quality of an individual personality by virtue of which he is considered extraordinary and treated as endowed with supernatural, superhuman, or at least specifically exceptional powers or qualities. These are such as not to be accessible to the ordinary person, but are regarded as of divine origin or as exemplary, and on the basis of them the individual concerned is treated as a 'leader'.' (Weber, 1968: vol I p.241, as quoted by Bryman, 1992:24)

The interest in organizational culture (Pettigrew, 1979) and charismatic leadership (Handy, 1976; House, 1977; Burns, 1978) revived attention for personal aspects of leadership. It re-introduced attention for the personality of the leader and his influence on his subordinates. In contrast to the two-dimensional model of leadership, which focuses mainly on the technical and relational aspects of leadership as initiating structure and consideration, the charismatic leadership model focused on the emotional impact of a leader on his followers:
'At the crux of the phenomenon of charisma is the emotional response of the follower to the charismatic leader. (...) The charismatic leader reduces the followers' resistance to changing their attitudes and frees their responses by arousing emotional responses toward him or her and a sense of excitement and adventure.' (Bass, 1990:194)

Etzioni (1961) suggested that charismatic leadership is necessary wherever decisions about organizational purpose are taken. It is necessary to induce subordinates to accept guidance in expressive matters, value judgments and decisions (referenced by Bass;1990:200). Defined like this, charismatic leadership easily fits an untaken position in the spectrum of leadership styles. While consideration and initiating structure are mainly concerned with facilitating the ongoing operations in a work group, charismatic leadership adds a structuration of meaning to the tasks of the leader. Thus, unlike the Ohio State leadership style dimensions, the importance of a leader's charisma was grounded in theory. At the end of the 1970 s House published his '1976 theory of charismatic leadership' (House, 1977), Zaleznik produced an article focusing on the personal differences between managers and [charismatic] leaders 
(Zaleznik, 1977), and Burns published 'Leadership' (Burns, 1978). Especially Burns' theorizing about the difference between transactional and transformational leaders has provided an important basis for the later empirical operationalizations of charisma as a component of transformational leadership (e.g. Bass, 1985). Burns described transformational leadership as a situation in which 'one or more persons engage with others in such a way that leaders and followers raise one another to higher levels of motivation and morality' (Burns, 1978:20). In his '1976 theory of charismatic leadership' House (1977) described the 'charismatic leader's effect on followers' as arousing

'trust in the correctness of the leader's beliefs, unquestioning acceptance of the leader, identification with the leader, and emotional involvement of followers in the mission.' (House, 1977:191).

House stated seven propositions about 1) the antecedents of charismatic leadership (the personality characteristics of the leader, and the situational favorability allowing for charismatic leadership (perceptive followers and the possibility to define the followers' roles in ideological terms)) and 2) the behavioral characteristics of charismatic leaders ((self-)image-building, communicating ideological goals, simultaneously communicating high expectations of, and confidence in followers, and arousing motives congruent with the organization's mission). Similarly, Conger and Kanungo describe the process through which a charismatic leader exerts influence (Conger and Kanungo, 1987,1988a): first, a charismatic leader assesses the status quo and finds; that it needs to change; then he needs to formulate 'an inspirational vision that is highly discrepant from the status quo, yet within the latitude of acceptance for his subordinates'; finally, he will have to achieve this vision by personal example, taking risk, using countercultural forces in the organization, empowering his followers, impression management, leading the way, building follower trust, and motivation.

According to Conger and Kanungo, charismatic leadership will then lead to high internal cohesion, low internal conflict, high value congruence, and high consensus in the organization. Besides, it will lead to high emotional attachment to the leader, high psychological commitment to the organizational goals, and high task performance of the individual followers (Conger and Kanungo, 1988a:81). in a similar vein Soeters (1986:306) described the influence of a charismatic leader in terms of the mobilization process in social movements and emphasizes the followers' emotional orientation toward the leader, where the leader in turn takes his followers seriously and considers them as equal partners in the movement.

Summarizing, charismatic leadership can be defined as the highly personal impact of a leader on his followers, directly focused at their motivational value-base. Charismatic leadership is achieved by setting a personal example of motivated good behavior and providing subordinates with meaningful goals in the workplace on both task and personal levels.

\section{Personality differences between leaders and managers}

Although some of the effects of charismatic leaders can be influenced by the situation 
(like the availability of a worthwhile goal, different from the status quo), much of the charismatic impact seems to be based in how the charismatic operates in day-to-day situations. The leader's personality is considered a key aspect of the charismatic impact on others. In his review of the evidence Bass (1990) argues that research has confirmed eight characteristics of charismatic leaders: requisite abilities, personality characteristics (such as self-esteem, generosity, and honesty), expressive behavior, self-confidence, self-determination, freedom from internal conflict, eloquence, and activity (high energy level) (Bass, 1990:188-192). Zaleznik (1977) focused on these personal differences and distinguished charismatics, whom he labeled 'leaders,' from other managers. Leaders adopl a personal, active attitude toward goals (steering organizations into new directions.) Managers work within the boundaries of an organizational structure. Leaders try to open up the organization and question the status quo, so as to be able to reach new solutions for long standing problems. Managers prefer to work with people, but on a low emotional involvement basis. Leaders are driven by personal goals and are more emotionally involved.

'Managers may lack empathy, or the capacity to sense intuitively the thoughts and feelings of others. (...) The distinction is simply between a manager's attention to how things get done, and a leader's to what the events and decisions mean to participants.' (Zaleznik, 1977:73)

According to Zaleznik the constant attention to the meaning of events and decisions is related to a personality characteristic of the charismatic leader. While for a manager belonging to the organization and acting in its best interests are intrinsically rewarding, Zaleznik points to the perception of separateness of the leader to explain his ability to change the organizational status quo:

'Leaders (...) may work in organizations, but they never belong to them. Their sense of who they are does not depend upon memberships, work roles, or other social indicators of identity. (...) In considering the development of leadership, we have to examine two different courses of life history: (1) development through socialization, which prepares the individual to guide institutions and to maintain the existing balance of social relations; and (2) development through personal mastery, which impels an individual to struggle for psychological and social change. Society produces its managerial talent through the first line of development, while through the second leaders emerge.' (Zaleznik, 1977:7475)

A similar argument has been made by Kuhnert and Lewis (1987). They focused on the personal differences between transactional and transformational leaders and argued that transformational leaders functioned on a higher level of awareness than other people. Like Zaleznik they describe (transformational) leaders as personalities that define their selves in terms of their internal values and standards, learning and developing over the course of their lives (Kuhnert and Lewis, 1987).

In their descriptions of charismatic leadership, both Zaleznik (1977) and House (1977) point to an emotional aspect of leadership that is not recognized in the initiating 
structure and consideration dimensions of the two-dimensional leadership model.

The focus here on the impact of charismatic leaders in organizations does not mean that the use of the concept is limited to the organizational sphere of human activities. Political and religious leaders can have a profound impact on people's behavior and attitudes. Film stars, musicians and pop artists can equally be evaluated on their charismatic effect on groups of people, infusing meaning into their daily life and into the commercial circus profiting from their performance.

\section{The impact of charismatic leadership}

The descriptions of charismatic leadership point to an impact of charismatic leadership that differs from the impact of consideration and structuring leadership. The latter two have a direct impact on both employee motivation and the work activities of the subordinates. Charismatic leadership has its strongest effect on subordinate's motivation. It feeds on an emotional bond between the leader and the led:

'The value, popularity, and celebrity status that others attribute to a [charismatic] leader engenders in followers strong emotional responses $(. .$.$) beyond$ the ordinary exchange of compliance for promises of reward or threats of punishment. (...) Admiration of the charismatic leader and the desire to identify and to emulate him or her are powerful influences on followers.' (Bass,

1990:193)

An important aspect of the charismatic's impact on his subordinates' behavior seems to be that on their personal 'belief systems'. This impact of charismatic leadership clearly links it to the concept of organizational culture. While initiating structure and consideration focus on coping with the task and the social structure within the existing organizational belief system (or organizational culture), charismatic leadership focuses on the ability of a leader to actively manage the organizational culture. Regardless of the organizational culture, a leader perceived as charismatic will infuse meaning into the day-to-day activities of his subordinates and thus shape the organizational culture. This can happen both in a work-oriented and a relationship-oriented manner.

Eoyang (1985) gives a clear description of how a charismatic leader influences his subordinates' belief system. He defines an individual's belief system as the way in which the individual has mentally organized 'chunks' of experience and understanding into a meaningful and coherent personal understanding of the world. In his view a charismatic leader will challenge the quality of his followers' belief systems and provide them with alternatives that better fit new or formerly contradictory experiences and cognitions:

'transformational leadership may serve to reconcile psychological contradictions between various cognitions and experiences by providing a coherent symbolic context which incorporates the disparate elements into a coherent context.' (Eoyang, 1985:115) 
When leaders are able to provide their employees with answers to the paradoxical demands of work life, they will increase their motivation and vision in their own work, thus increasing work performance and increasing their flexibility within their individual job. Besides, the personal involvement of charismatic leaders in their work can make them more effective as role models, showing their employees involvement, active engagement in work, and a meaningful approach to work:

'The extent to which people inhabit the full emotional spectrum [in their work] is shaped partly by how fully present their leaders are. Authority figures offer models of experience and behavior that are followed, consciously or not, by subordinates (Bowlby, 1980; Schein,1985). If organization members feel authorized to become psychologically present by cultural norms and the examples of their leaders, they are more likely to do so.' (Kahn, 1992:336)

This means that a charismatic leader can be expected to have a very personal impact on his subordinates' attitudes towards their work. When a leader is perceived as charismatic in the work situation, this means that, regardless of the organizational situation (or culture), he has reached his subordinates and motivated them to do their work.

The above description pointed out the mechanism through which charismatic leaders influence the organizational culture (their employees value system). In this respect it is important to notice two things. First, a charismatic leader can emphasize very different values (Schein, 1983) and, second, the way a charismatic leader strives to influence his organization's culture can be different too (Trice and Beyer, 1991). First, Schein (1983), showed the difference between the impact of a founder and a professional manager on the culture of an organization. Schein studied the impact of leadership on five basic assumptions underlying organizational culture: the organization's relationship to its environment, the nature of reality and truth, the nature of human nature, the nature of human activity, and the nature of human relationships. Schein argued that the impact of the founder of an organization differs from the impact of subsequent professional managers because of two reasons: 1) there are structural and positional differences as managers maintain an existing culture in somebody else's organization, whereas founders are building a new culture in their own organization; and 2) there are clear differences in orientation between founders and professional managers with respect to motivation and emotional orientation, analytical orientation, and interpersonal orientation. These differences influence both the quality and the quantity of their respective influence on organizational culture. Second, Trice and Beyer (1991) focus on different ways in which a leader can influence organizational culture. On the one hand, a leader can try to innovate by building (adding) a new (aspect of) culture or by changing part of the existing culture. On the other hand, a leader can strive to maintain a culture, either by keeping the existing culture vital, or by trying to reconcile and integrate diverse interests of existing subcultures.

Concluding, a theoretical argument can be made for the influence of charismatic leaders on organizational culture. A charismatic leader is able to establish an emotional bond with his subordinates. It is important to be aware that although a charis- 
matic leader always has an impact on the organizational culture, the content and aim of this impact differs.

\section{Empirical research on charisma}

Charismatic leadership has become a popular topic for investigation in the 1980s, although there is still a lack of empirical research. The paucity of empirical research on charismatic leadership before 1980 is noted in several studies (Bass, 1990:201). The theoretical recognition of something 'more' than the two dimensions that resulted from the Ohio State leadership studies provoked empirical research trying to extend the basic two-dimensional model. Howell and Frost (1985), Peterson, Phillips, and Duran (1989), and Koene, Pennings and Schreuder (1992) empirically studied extensions of the two-dimensional model, comparing the effectiveness of consideration and structuring leadership to the effectiveness of charismatic leadership. Peterson, Phillips, and Duran (1989) included both traditional measures of consideration and initiating structure, and a measure of charismatic leadership in a comparison of the Japanese PM-scales with a number of U.S. leadership scales. Both consideration and initiating structure correlated significantly with the charisma dimension. Of all measures included in their study, the consideration scale correlated most strongly with the charisma scale. Studying the correlations of the leadership scales with job involvement, organizational commitment and store effectiveness, consideration and charisma showed the highest correlations with job involvement and store effectiveness. Charisma showed the highest correlation with organizational commitment (Peterson, Phillips, and Duran, 1989:67). Howell and Frost (1989) presented the results of a laboratory experiment, investigating the impact of a charismatic, a considerate, and a structuring leader on subordinate task performance, task adjustment (higher experienced task satisfaction and lower role conflict and ambiguity), and the quality of the participants's relation with the leader. They found higher task performance and better task adjustment under the charismatic leader, and a stronger impact of the (externally determined) level of group productivity norms on individual task motivation under the considerate and structuring leaders (Howell and Frost, 1989). Finally, Koene, Pennings, and Schreuder (1992) compared the impact of consideration, initiating structure, and charismatic leadership in different organizational cultures. They also found intercorrelations between the measures of consideration, initiating structure, and charisma. Besides, they showed that organizational culture moderated the effect of initiating structure and consideration, while no such interaction was detected for charismatic leadership.

These studies show that charisma has a distinct impact on employee task performance and organizational performance. Two studies also show the impact of charisma to be less situationally dependent. Charisma has an impact on performance, regardless of the (cultural) context in which the leader operates. This in contrast to the impact of consideration and initiating structure that varies with the (cultural) context. Finally, two studies show correlations between the empirical operationalizations of charisma and the two traditional dimensions of leadership. 


\section{Transactional and transformational leadership}

The three studies discussed above basically used charisma as an extension of the well-established 'Ohio State Dichotomy.' However, other charisma-research uses a different empirical framework. Bass was the first to develop a completely new set of leadership dimensions, based on the theoretical transactional / transformational dichotomy presented by Burns (1978). With his Multifactor Leadership Questionnaire (MLQ) he found five factors. Three factors reflected transformational leadership: charisma, individualized consideration, and intellectual stimulation; two factors reflected transactional leadership: contingent reward and management by exception. Table 4.3 below shows examples of the items used to measure the five leadership dimensions.

\section{Table 4.3 Dimensions of transformational and transactional leadership}

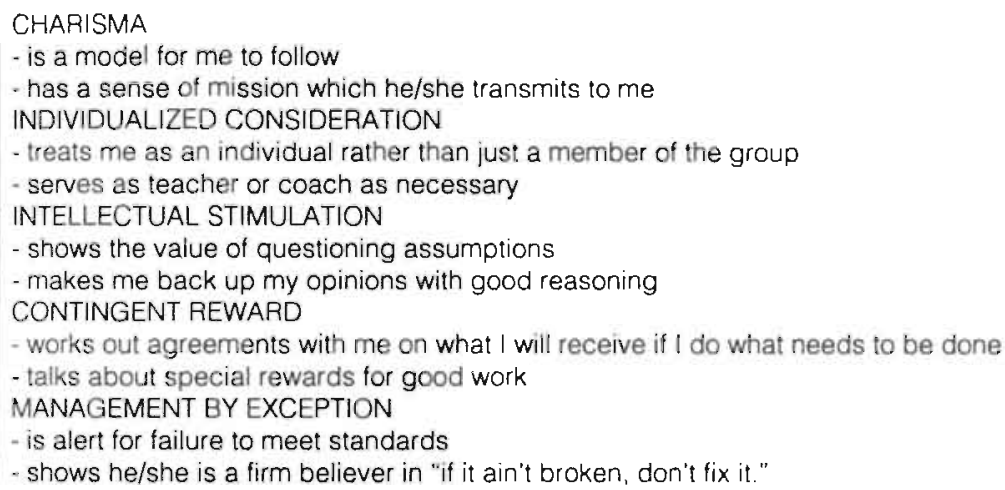

Of the five factors the charismatic leadership factor explained $66 \%$ of the covariance of all the items (Bass, 1985). The charismatic leadership factor also correlated strongly with the other two transformational factors individualized consideration and intellectual stimulation. Bass's operationalization of Burns' (1978) theory of transformational leadership (Bass, 1985) has started a fruitful stream of empirical studies (Howell and Avolio, 1993; Avolio, Bass and Yammarino, 1988; Avolio, Waldman and Einstein. 1988; Seltzer and Bass, 1987; Bass, 1985). This new empirical operationalization of leadership added a new perspective for studying leadership styles - that of transformational leadership. It also showed the relatively large influence of the charisma-factor on the transformational leadership concept. It therefore seems warranted to look at charisma as the most influential aspect of the new way of looking at leadership.

The focus on a new conceptualization of leadership has diminished the attention for the results of the older leadership research focusing on initiating structure and consideration. Still, the two operationalizations can be seen as complementary. Avolio and Bass (1988) argue:

'Bass's model cuts across these two dimensions. Initiation can be transactional or transformational. So can consideration. The transformational leader may provide a new strategy or vision to structure the way to tackle a problem. The 
transactional leader may clarify the "right" way of doing things. Likewise, consideration for a subordinate's current needs and self-interests is likely to be transactional, whereas consideration for a subordinate's long-term personal development in alignment with organizational needs is transformational leadership.' (Avolio and Bass, 1988:36)

The implicit model advanced by Avolio and Bass in this quotation is shown in table 4.4. Initiating structure leadership guides subordinates in what should be done. Consideration leadership focuses on how people should work together to accomplish whatever needs to be done. Charismatic leadership, finally, focuses on why the work should be done, thus giving meaning to the work and explaining the importance of activities and of specific ways of working together.

Table 4.4 implicit model Avolio and Bass (1988)

\begin{tabular}{|c|c|c|}
\hline & $\begin{array}{c}\text { Transactional } \\
\text { (non-charismatic) }\end{array}$ & $\begin{array}{c}\text { Transformational } \\
\text { (charismatic) }\end{array}$ \\
\hline Initiating structure & $\begin{array}{l}\text { clarifying 'right' way of doing } \\
\text { things }\end{array}$ & motivating the right thing to do \\
\hline Consideration & $\begin{array}{l}\text { coping with current needs and } \\
\text { self-interests vis-à-vis company } \\
\text { needs and constraints }\end{array}$ & $\begin{array}{l}\text { showing opportunities for per- } \\
\text { sonal development in context } \\
\text { of corporate vision }\end{array}$ \\
\hline
\end{tabular}

The charismatic's impact can be described as an impact through what Eoyang (1985) calls 'symbolic leadership,' focusing on the meaning of what is to be done, by providing guidance as to how the work activity should get a place in the subordinate's value system.

\section{Transformational leadership and performance}

In several empirical studies transformational leadership, and especially the charismatic leadership dimension, has shown to explain variance in organizational effectiveness over and above the transactional dimension and the older leadership dimensions (consideration and initiating structure). However, as can be seen from Bass (1990) and Avolio and Bass (1988) who reviewed studies that related transformational leadership to organizational performance, the performance measures used were mostly qualitative evaluations or indirect measures of organizational performance. Most studies linked charismatic leadership to performance criteria like satisfaction ratings and leader-performance judgments by subordinates and superiors. For example, Avolio, Bass and Yammarino (1988) showed that there was a relationship between charismatic leadership and organizational effectiveness as perceived by the employees, even if they controlled for common methods bias (see: Avolio and Bass, 1988). Only some studies have linked charismatic leadership to direct, financial, and quantitative measures of performance, but often only in experimental situations. Avolio. Waldman, and Einstein (1988), for example, showed that the charismatic leadership scores were related to company profits in a business game played by MBA students. A recent study by Howell and Avolio (1993), however, is of interest for two reasons. 
First, Howell and Avolio studied the impact of transformational leadership on a more or less objective measure of unit performance: consolidated unit-performance measured as the difference between realization and planned performance. Transformational leadership showed an impact on this financial measure of performance. Second, they studied the moderating influence of the culture variable 'support for innovation' on the effectiveness of transtormational leadership and found that culture mediated the impact of individualized consideration and intellectual stimulation, but did not influence the impact of charisma. Thus, as also shown by Koene et al. (1992), the impact of charismatic leadership seems to be relatively unaffected by the organizational cultural context in which the leader operates.

\subsection{Conclusion}

The research discussed in this chapter covers a period from the end of the $1950 \mathrm{~s}$ onward. Leadership style research started with the distinction of two technical aspects of leadership: initiation of structure and consideration. Although effective as a research vehicle and also intuitively acceptable, there seemed to be something missing. At the end of the 1970 s charismatic leadership became popular, it coped with what the other factors did not really take into account: emotion, passion, and motivation in the workplace.

The factors from the two-style model answered the question 'how well does the leader perform his management task?' Is he able to structure and organize the work and sustain a reasonable level of organizational performance (initiation of structure)? Is he able to maintain a working group in which people like to work and in which people cian concentrate on performance (consideration)? The charisma factor, on the other hand, measured how well the leader could communicate a sense of meaning of the work to his employees.

On the basis of the previous research discussed in this chapter a number of conclusions for further research can be drawn. First, the evidence shows that consideration and initiating structure seem to influence organizational performance, both directly, and indirectly through employee attitudes. Second, the effects of consideration and initiating structure depend on the organizational context in which a leader operates. Third, there is a lack of studies regarding the impact of consideration and initiating structure on organization-level, objective measures of performance. Fourth, charismatic leadership shows an impact on organizational performance, not influenced by the cultural context. The impact of other dimensions of leadership does seem to be affected by cultural differences. The evidence about these effects, however, is still scarce. Fifth and finally, the impact of charisma on organizational effectiveness is operationalized by relating it to mostly qualitative performance measures, measures of individual's task performance, and objective performance measures in experimental laboratory studies. There is a lack of empirical evidence relating charisma to objective measures of organizational performance.

To address these issues the empirical analyses in the following chapters will evaluate 
the influence of consideration, initiating structure and charismatic leadership on organizational culture, climate and objective measures of financial performance. 


\section{CHAPTER 5}

\section{RESEARCH QUESTIONS AND RESEARCH DESIGN}

This chapter concludes the theoretical discussion of organizational culture and leadership. Section 5.1 discusses the research questions for this study, bridging the gap between the theoretical review of the literature and the empirical investigation by translating the possibilities for further research identified in the previous chapters into the practical research questions that guide this study. Section 5.2 describes the empirical setting of our study, focusing on its advantages and disadvantages for answering our research questions. Then, the research design will be explained. Finally, section 5.4 presents the outline of the empirical analyses presented in the next four chapters.

\subsection{Research questions}

What do we want to find out with our empirical investigation? In this section this question will be answered in detail, drawing on our evaluation of the literature in the previous chapters. First, in chapter 2 the aim of this study was stated as: 'to evaluate the impact of organizational culture empirically, studying the importance of organizational culture in relation to the organizational context.' In addition, chapter 4 explained the importance of the concept of leadership for organizational culture. The analysis of the literature on organizational culture and leadership in chapters 3 and 4 raised our curiosity about three broad issues. The operationalizations of organizational culture and leadership; the influence of the organizational context on organizational culture, climate, leadership, and organizational performance; and the impact of culture, climate and leadership on organizational performance.

\section{The operationalization of organizational culture and leadership}

For different reasons the operationalizations of organizational culture and leadership are interesting. Both are often measured using aggregated perceptions of individual respondents as proxies. Organizational culture is then measured by asking individuals to describe the organizational culture in their workplace. Organizational culture is measured with questions like 'Where I work the organization is only interested in the work people do,' 'Where I work new employees need more than a year to feel at home' (Hofstede et al., 1990), and 'There are many new ideas here' (de Cock et al., 1984). Leadership is similarly measured by asking individuals to evaluate their leader on several criteria. It is measured with questions like 'He lets group members know what is expected of them,' 'He is friendly and approachable' (Syroit, 1979) and 'He is a model for me to follow' (Bass, 1989).

Regarding the operationalization of organizational culture two issues are important. First, there has been a lot of debate about the empirical operationalization of organiz- 
ational culture in quantitative research. The question whether it is different from organizational climate points to unclarity about how organizational culture should be measured. Many of the early quantitative empirical studies of organizational culture have used measurement instruments based on climate instruments for practical reasons (e.g. Gordon and DiTomaso, 1992; Denison, 1990). Only recently measurement instruments are being developed that specifically measure organizational culture (O'Reilly et al., 1991; Hofstede et al, 1990). However, the recent organizational culture instruments have mostly been developed to measure cross-industry differences. Chatman and Jehn (1994) showed that O'Reilly et al.'s (1991) instrument clearly measured variation between industries and scored much more homogeneous between organizations within industries. Also Hofstede et al. (1990) pointed out that they interpreted four of their dimensions as reflecting industry culture differences and two as reflecting values of the founder or current management (thus also varying within one industry). It thus seems interesting to analyze what dimensions of organizational culture and climate describe differences between organizations within one industry when using the presently existing organizational culture instruments that have not been specifically developed for measuring within-industry differences. This analysis reveals the dimensions that reflect a possible competitive advantage of an organization compared to its direct competitors.

1. Which dimensions of organizational culture and climate explain differences between organizations within one industry?

Regarding the operationalization of leadership the relationship between the traditional operationalization of leadership as initiating structure and consideration and the recent operationalizations emphasizing charismatic leadership is important. Empirically the two have been developed independently and although we argued the concepts could be differentiated theoretically (see section 4.4), empirical research has shown that the dimensions are correlated significantly (e.g. Peterson, Phillips, and Duran, 1989). Using the existing measurement instruments, it seems interesting to analyze the relationships between initiating structure, consideration, and charisma, because these relationships can illuminate the overlap in the empirical operationalization of these dimensions.

2. What is the relationship between the traditional leadership dimensions of initiating structure and consideration and the recent operationalizations of leadership as exemplified in the charisma-dimension?

\section{The influence of the organizational context}

It is important to recognize that organizational culture, climate, and leadership are not the only factors influencing organizational performance. To put the impact of organizational culture and leadership in perspective it seems important to analyze the impact of the organizational context on organizational performance. Examples of contextual variables are organizational size, employee demography, and geographic location. In chapter 6 we identify the contextual variables that have to be taken into 
account as alternative explanations for performance differences, when studying the impact of organizational culture and leadership on organizational performance.

Furthermore our review of the literature (see chapter 3.3) showed a relative lack of studies investigating the impact of the objective organizational context on organizational culture and climate. Therefore it also seems interesting to analyze the impact of the organizational context on the social variables measuring organizational culture, climate, and leadership. These considerations resulted in the following two research questions (figure 5.1).

3. What is the impact of the organizational context on

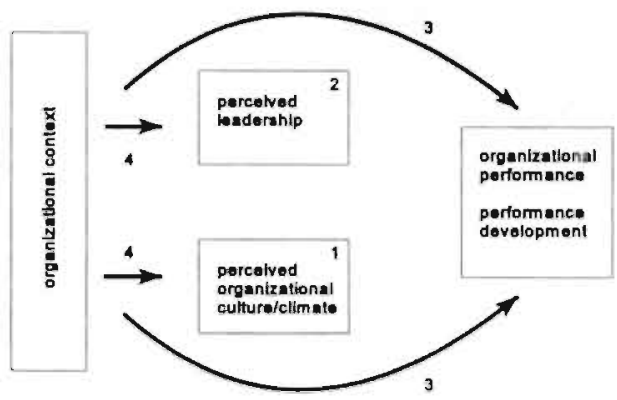
organizational performance?

4. What is the impact of the organizational context on the social variables measuring organizational culture, climate and leadership?

\section{The impact of culture, climate and leadership on organizational performance}

Past studies have confirmed a relationship between aspects of organizational culture and climate, and organizational performance (see chapter 3.2). Furthermore, some of these studies found correlations between organizational culture and future pertormance, suggesting a causal relationship of organizational culture influencing organizational performance. Most studies, however, have only related a few aspects of culture and climate to an often even more limited number of performance variables (see chapter 3.2). It would therefore be interesting to compare the impact of different aspects of organizational culture and climate on a variety of organizational performance measures. More specifically, evaluating the type of performance measures related

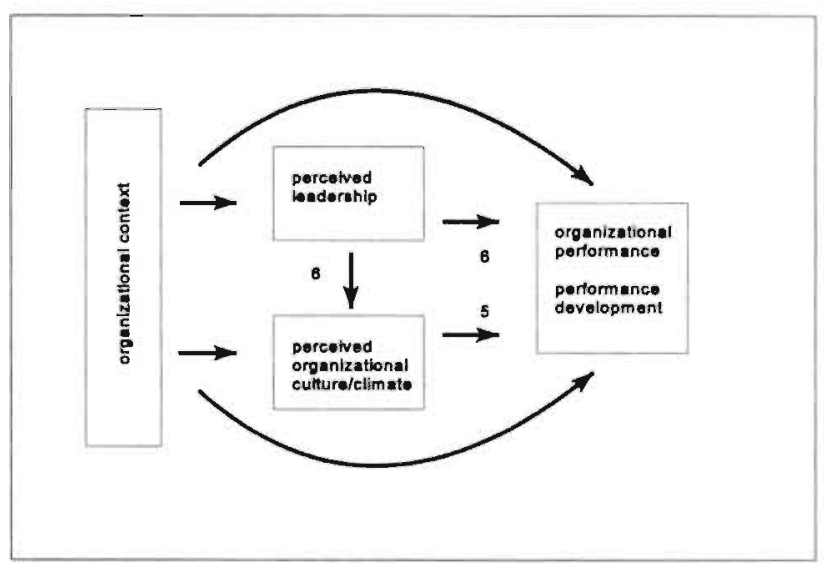

Figure 5.2 Impact on performance 
to organizational culture in previous research, it seems interesting to investigate the relationship of organizational culture and climate with the bottom line performance which is fully attributable to the unit under study(see chapter 3). Similarly, studies of leadership have found correlations between leadership dimensions and organizational performance, but studies of leadership have seldomly related leadership dimensions directly to financial, bottom line organizational performance (see chapter 4). Although our primary interest here is in the influence of leadership on organizational culture and through culture on organizational performance, an evaluation of the direct impact of leadership on organizational performance and its indirect impact (via organizational culture and climate) is interesting. These considerations resulted in the following research questions (figure 5.2).

5. How do the social variables influence the various indicators of bottom line organizational performance which is fully attributable to the organizational units under study?

6. Is there an effect of the leadership dimensions on bottom line organizational performance?

In chapter 6.2 the quantitative performance of the supermarket stores in our sample is discussed and five variables are selected as operationalizations of different aspects of store performance.

\subsection{The empirical setting}

The empirical investigation was conducted in fifty supermarket stores of a major European food retailer. In this section we describe our field setting at the moment of our empirical investigation in 1990. Some aspects of the organizational setting have evolved since then. The fifty stores were located throughout the Netherlands. The supermarket chain is one of the largest chains in the Dutch market, differentiating itself with a high-quality, high-service strategy. Both this quality strategy and the fast growth of the supermarket chain made human resource management an important issue for the company, creating an emphasis on employee training and development.

The supermarket organization. The supermarkets were all large self-service stores with a broad range of food and small household-non-food products. The company maintained approximately 500 stores, including franchise branches. It used the same store formula in all of its stores. There were differences in the range of products sold, depending on the size of the stores, but these did not affect store image. For the company-owned stores there were strict guidelines and standard operating procedures for the daily work, supported by a rich supply of internal training possibilities. For all positions in the store some kind of formal company-training was required. The stores included in our study were all owned by the parent company.

Each store was headed by a store manager who was responsible for the performance 
of 'his store'. The store manager was clearly the 'figurehead' (Mintzberg, 1973) of his organizational unit. He had a significant amount of discretion in running his store, proposing short-term goals for it and deciding on, for example, commercial activities and the hiring of new employees. Store managers also had to be able to communicate their 'vision' for the store to its employees. On the other hand, the store managers worked within the boundaries of corporate policy. Prices were determined centrally. the product assortment left little room for discretion, and specialized head office departments offered support and guidance in matters like store design, management and employee training, and advertising. Store management also had to operate within the company's management philosophy which, at the time of our study, emphasized a shift from 'salesman to manager' for the members of the stores' management teams, indicating a shift from a purely operational focus to a more managerial approach to store management.

In his store, a store manager was supported by a management team of two to six department managers, depending on the size of the store, and an administrative assistant. The stores employed between 20 and 150 employees, mostly on a part-time basis. On average, the stores employed 57 full-time equivalents. These differences in size were accompanied by noticeable differences in job specialization, the use of formal planning and control, and the amount of delegation of authority to the department managers. An emphasis on formal planning was often accompanied by a more analytic approach of their work by the members of the management team. The stores also differed significantly in the degree of modernization of the store. Some, mostly larger stores had recently been remodeled and were state-of-the-art supermarkets. with fully computerized inventory-systems, supported by scanning check-out registers. In other, mostly small stores the store design was still some design-generations behind and the new technologies had only been introduced partly (e.g. manual barcode readers for checking the inventories). These stores were operating with a less sophisticated technical system, reflected in lower productivity standards for the older stores.

The superior of the store manager, the group manager, had a span of control of 16 to 20 stores (his group). He functioned as a supervisor and internal management consultant to the store managers of his group. Besides this support, a store manager could also draw on the expertise of the group personnel manager and company-wide commercial and technical support departments for specialized help.

Studying organizational culture, leadership, and performance in this setting has some distinctive advantages and disadvantages. These will be discussed below.

Leadership. The store manager is close to the workfloor. Especially in the smaller stores he works intensively with his subordinates. Depending on the size of the store, the store manager will delegate more of the operational leadership tasks to his department managers. This means that in smaller stores most employees see the store

\footnotetext{
1 Only stores with male store managers were studied, because not enough female store managers were available to make gender a useful variable in the study design.
} 
manager as the boss, whereas in the larger stores the store manager is a more distant and symbolic leader. These differences, however, seem to be gradual. Everybody who spends a substantial amount of time working in the store knows the store manager. This means that differences in the leadership behaviors of store managers may have an impact on the organizational culture, even in larger stores. Furthermore, the store manager, with his responsibility for the store as a whole, operates as the figurehead of a distinct organizational unit. He is expected to develop (short-term) goals for his store and has to be able to communicate his vision for the store to his subordinates. This role in 'fine-tuning' and communicating the store's mission seems to make an investigation of the charismatic qualities of the store manager worthwhile. When studying leadership in this context, however, one has to be aware of the fact that the store manager is not the organization's CEO. Thus his direct superior and the organizational corporate policy can have a significant impact on his performance as a store manager. In our sample, corporate policy was more or less the same for all the stores, but the direct superior was different for most stores.

Organizational culture. Comparing the organizational culture of the stores within one company has advantages and disadvantages as well. Disadvantageous is that most previous comparative organizational research has compared culture between organizations in different industries. Therefore, most instruments developed to measure organizational culture contain variables that specifically relate to 'industry culture' (see chapter 3). These might not produce much variance in a 'within-industry' comparison. Studying organizational culture in one organization, however, does have a related distinctive advantage. It means studying organizational culture in fifty organizations which are technically almost identical, selling the same products and using the same formal goals and procedures. This seems to be the purest setting to study 'man-made' cultural differences and their impact on organizational performance. Thus, our study resembles a 'Most Similar Systems Design' as opposed to a 'Most Different Systems Design' (Przeworski and Teune, 1970). In the sample we have fifty organizations with very similar primary processes, organization structures, formal procedures, and general market orientations. The cultural differences found between stores can thus almost fully be attributed to the differences in how people working in different stores cope with their organizational environment. Comparing relatively identical stores also automatically standardizes most contingent industry factors mediating the impact of a certain organizational culture. Our setting therefore lends itself to a normative discussion of 'the best' culture for a supermarket store of this chain. This specific outcome also points to a possible weakness of this study as it raises the question of the generalizability of the outcomes to organizations operating in other industries. Any generalization thus has to be based on an evaluation of the significance of our findings in the retail industry for organizations in other contexts.

Organizational performance. A further advantage of the research setting is that the company records could be used as a source of well-comparable performance data. As explained above, the within-company measurement reduces a lot of the 'environmental noise'. The remaining organizational differences between the stores like organizational size and store age can be adequately measured using data from company records. 


\subsection{The research design}

The empirical study discussed in the next chapters was conceived at the request of the company. For an understanding of the overall research design and its limitations it is important to understand this background of the empirical investigation. At the moment this research project was conceived, the supermarket chain was reanalyzing the position and role of its store management. They asked us to investigate the influence of store culture on store performance, because they saw variations in store performance that they expected to be related to organizational culture. Besides, they noted that store managers seemed to 'take their own culture along' as they moved from store to store. To further analyze their question we interviewed several department managers who had frequently moved between stores in a pilot study. These department managers knew many different store managers and their personal styles. The exploratory interviews from this pilot study substantiated the expectation of significant differences in store culture and between store managers. We formulated our understanding of the issue in two general research questions: (i) is there a relationship between organizational culture, leadership and performance for the stores of this supermarket chain? and (ii) If there is such a relationship, is it the leader who influences the culture, and how does he do this?

To answer these questions we decided to investigate the relationships between the store manager's leadership style, store culture, and store performance in a survey study in fifty company-owned stores of the supermarket organization. Furthermore, we studied the impact of the store managers' leadership in four case studies of store manager succession.

In the cross-sectional survey study we distributed questionnaires in 50 stores of the supermarket chain and measured employee perceptions of a number of social variables regarding leadership style, organizational culture, climate, and work satisfaction. We then related the results of this survey to the bottom line business results of the fifty stores. The major disadvantage of the cross-sectional study, however, is the weakness of causal inferences on the basis of the empirical results. Also, detailed information looses some of its explanatory content while it is quantified. Although it is important to recognize these limitations of the cross-sectional survey approach, one should not undervalue the usefulness of quantitative comparative research. This is clearly argued by Cohen and Cohen (1983):

We find the old saw that "correlation does not mean causation," although wellintentioned, to be grossly misleading. Causation manifests itself in correlation, and its analysis can only proceed through the systematic analysis of correlation and regression.' (Cohen and Cohen, 1983:15)

Still, to partly offset the limitations of the survey study we conducted longitudinal case study investigations in four stores. In the longitudinal investigation we traded in some of the generalizability for richness of description. It focused on the effects of supermarket manager succession in four stores. In three in-depth interviews with the store managers and management team members of these four stores in the course of a 
year, we tried to gain as much information as possible about the transition and change processes the stores were going through. The case studies provided us with more indepth information about the culture formation process, which enabled us to gain a deeper understanding of the organizational culture in the stores through a relatively 'thick' description (Geertz, 1973) of the functioning of organizational culture in the supermarket stores. The main purpose of the case studies was to support the causal explanations for the results found in the survey study. With this effort at triangulation we hope to reduce the critique on pure cross-sectional studies (what do these relationships actually mean?) and pure case studies (but are these findings generalizable?). The results of the case studies as such are not presented in this dissertation.

\section{Sample}

The study was conducted in fifty stores of a large Dutch supermarket chain. In sampling 50 stores from a total of approximately 450 company-owned stores in the Netherlands we were led by three considerations. 1) The emphasis in the crosssectional study was on establishing relationships that were generalizable to all 450 stores in the country. 2) Company executives expected an influence of store size and market differences on store culture and store performance. 3) The study had to be done within the restrictions of the available resources. To be able to reconcile these considerations a representative sample of fifty stores was selected, geographically located throughout the whole country and ranging in size from very small to very large. Initially we selected 60 stores. Store executives considered 10 stores inappropriate for study because of special circumstances in the stores, either influencing performance or making a study on organizational culture inconvenient at the time. Geographically, 24 stores were located in the urbanized west of the Netherlands (Noord-Holland, Zuid-Holland and Utrecht), 20 stores in the south (Noord-Brabant, Zeeland and Limburg), and 6 stores in the north of the country (Friesland and Overijsel). The selected stores were all headed by a male supermarket manager because not enough female managers were available to include store manager gender in the research. At the time only five company-owned stores were headed by female managers. The size distribution of the stores resembled the actual distribution of supermarket stores for the company that existed in the Netherlands: more medium sized stores and less small stores. The actual distribution is shown in table 5.1. Considering the decrease of small stores and the increase of medium and large stores, the emphasis on bigger stores is useful. 
Table 5.1 sample and store size

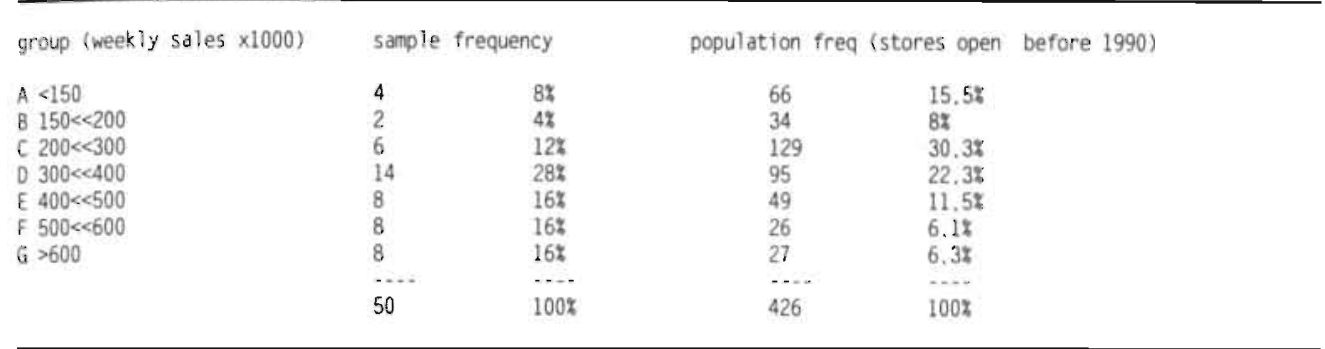

\section{Data collection}

In the survey study two sources provided us with information about the stores.

1 Financial performance information for the fifty stores was provided by the head office and described store performance over a 2,5 year-period. The head office also provided us with contextual information about store organization and market circumstances for the fifty stores in the sample.

2 A questionnaire administered among all store employees who worked more than 12 hours a week provided information about the social variables measuring perceived organizational culture and climate, satisfaction and leadership style of the store manager.

The data collection was supported by the company. In all interactions with members of the company the study was presented as a scientific research project that was initiated for two purposes. The researcher's objective was to do a PhD-project on the impact of organizational culture in organizations and the company's purpose was to support an informed study of its organizational culture. Mostly the study was welcomed because, at the time of the field study, organizational culture was a much debated but only vaguely understood concept in the company.

Company data banks. For obtaining the relevant contextual and performance data about the fifty stores in the sample we visited the head-office of the company several times to get access to most store information data bases.

Questionnaire survey. The questionnaire survey was developed using, grosso modo, validated Dutch-language instruments measuring aspects of organizational culture, climate and leadership, employee satisfaction, employee demography, and some other variables. The questionnaire was tested in small pilot surveys in two stores. In the final survey 2172 employees spread over the fifty stores were selected for participation in the survey study. These were the employees who worked more than 12 hours per week in the stores, and could thus be expected to be aware of and affected by the store's culture. The questionnaires were mailed to the home address of the employees, with a letter of support indicating the importance of the study for the company. Respondents were asked to fill out the questionnaire completely and to 
return it in the enclosed preaddressed envelope to the researcher. In the explanation of the purpose of the survey the researcher also emphasized the complete confidentiality of the individual's responses and explained that in the final report to the company individual respondents or stores would not be identifiable. The questionnaire contained 128 questions. It took respondents approximately twenty minutes to complete the questionnaire.

\section{Survey response}

As indicated before, 2172 employees were selected to participate in the final survey, 1228 questionnaires were sent back, giving us an overall response rate of $57 \%$. There are large absolute response differences between the stores. These, however, can largely be explained by the absolute differences in size between the stores in the study. Sample totals differed accross stores. In store 3 the questionnaire was sent to only eight people, compared to a total of 96 in store 50 . Table 5.2 below shows the average, minimum and maximum response scores for the fifty stores.

Table 5.2 Sample and response per store

\begin{tabular}{|l|l|l|l|l|}
\hline & mean & std dev & minimum & maximum \\
\hline response percentage & $58 \%$ & $17 \%$ & $32 \%$ & $100 \%$ \\
\hline total number of questionnaires sent & 43 & 20 & 8 & 96 \\
\hline total number of questionnaires received & 24 & 11 & 5 & 56 \\
\hline
\end{tabular}

For all stores the response percentage was above $30 \%$. In 43 stores it was over $40 \%$. In store 3 five questionnaires were returned, in store 1 and 6 seven, and in store 10 nine questionnaires were returned. For all other stores the response was eleven or more questionnaires.

The demography of the respondents resembles the store demography. The mean age, mean time with the company, and percentage of male employees in the response set resemble the sample characteristics. As the present study is comparative, our main interest is the stability of between-store variation in these characteristics. Table 5.3 shows the correlations of the response set demographical variables with the corresponding sample variables. The correlations are relatively high and significant, indicating the covariation of the response set and the sample variables (table 5.3).

Table 5.3 Correlations store demography with response-set demography

\begin{tabular}{|l|l|l|l|}
\hline & $\begin{array}{l}\text { Mean age } \\
\text { (response) }\end{array}$ & $\begin{array}{l}\text { Percentage males } \\
\text { (response) }\end{array}$ & $\begin{array}{l}\text { Time with company } \\
\text { (response) }\end{array}$ \\
\hline Mean age (store) & $0.75^{* * *}$ & ns & $0.24^{*}$ \\
\hline Percentage males (store) & ns & $0.59^{* * *}$ & ns \\
\hline Time with the company (store) & ns & ns & $0.71^{* * *}$ \\
\hline
\end{tabular}

$N=50 * *: p<0.001^{*}: p<0.1$ 


\subsection{Procedure for data analysis}

The chapter outline for the following and plan for analysis broadly follow the three issues addressed in section 5.1: the operationalizations of organizational culture and leadership; the direct influence of the organizational context; and the impact of culture, climate and leadership on organizational performance.

First, the empirical data will be evaluated in chapter 6 . The scales measuring the social variables will be validated and the operationalizations of organizational culture and leadership will be discussed. Furthermore, chapter 6 introduces the performance variables and variables measuring the organizational context. Chapter 7 discusses the influence of the organizational context on organizational performance and the social variables. Furthermore, the relationships between the social variables are investigated. The analyses in this chapter form the basis for the analyses in chapter 8 . Chapter 8 reports the influence of the social variables on organizational performance, first investigating the additional explanatory power of the social variables after the variation explainable with the contextual variables has been accounted for, and second, studying the influence of the social variables on organizational performance, taking into account the relationships between the social variables established in chapter 7. Finally, Chapter 9 summarizes the findings presented in chapters 6,7 , and 8 , and evaluates their importance for our understanding of the impact of organizational culture and leadership in organizations. 


$$
\text { - }
$$




\section{CHAPTER 6}

\section{VARIABLE DESCRIPTION}

This chapter describes the variables used in the empirical analyses. It presents the operationalizations of the concepts introduced in chapter 5 . The discussion of the variables is organized as follows.

Section 6.1 discusses the variables measured in the questionnaire survey: the focal constructs in this study (organizational culture, climate and leadership) and a variable measuring perceived work satisfaction. The questionnaire variables are discussed most elaborately in this chapter. These are measured using a number of questions (a scale) for each variable. For each variable the use of the scale has to be validated for this specific study. Then, the validity of aggregation to the organizational level has to be confirmed for the scales that were defined at the individual level of analysis (i.e. the scales that were originally developed to measure perceptions of individuals). Finally, the resulting variables are analyzed looking at the descriptive statistics for each variable and the simple bivariate correlations between the variables.

Section 6.2 discusses the performance variables used as indicators of store performance. First, store performance is analyzed in general. Then, the performance variables included in our study are presented. Finally, the descriptive statistics for the variables show what kind of performance differences are to be explained in this study and how the performance variables correlate.

Section 6.3, finally, discusses the variables used to describe the organizational context and employee characteristics. First, the organizational context of supermarket stores is sketched, pointing out the important contextual variables that can be expected to differ significantly between stores. Then, the selected contextual variables are described, considering the descriptive statistics for these variables.

Thus, the key purpose of this chapter is to operationalize the theoretical concepts of organizational culture, climate, leadership, organizational performance, and organizational context. It provides basic descriptive information about the kind and quality of the data employed in the empirical analyses presented in the subsequent chapters. In the process, the description of the statistical properties of organizational culture, climate and leadership provides the information for answering the first two research questions.

Research question 1: 'Which dimensions of organizational culture and climate explain differences between organizations within one industry?

Research question 2: 'What is the relationship between the traditional leadership dimensions of initiating structure and consideration and the recent operationalizations of leadership as exemplified in the charisma-dimension?'

These research questions are discussed in the concluding paragraph of section 6.1 . 


\subsection{The questionnaire variables}

Four groups of variables in this study were measured in the questionnaire survey in fifty supermarket stores: organizational culture, organizational climate, supermarket manager leadership, and employee work satisfaction. In this section the formation and validation of the variables is described.

\section{The questionnaire data}

The questionnaire used in this study measured aspects of employee perceptions of their work and their workplace. The questions selected for inclusion in the questionnaire were partly chosen because they seemed particularly relevant in the supermarket situation, and partly because they represented established scales measuring social aspects of the organizational work environment in the stores. Table 6.1 below shows the topics that were measured using previously established scales. Only the items measuring these topics were included in the analyses presented here. An overview of the items used to measure these constructs is shown in appendix 1. Appendix 1 thus shows our ex ante expectations about the questions that could be used to measure the different aspects of organizational culture, climate, leadership and satisfaction.

\section{Table 6. 1 Previously established scaies}

Satisfaction (Vogelaar, 1990):

SATISFACTION

Organizational culture (OCM. Hofstede et al., 1990):

PROCES VS RESULTS ORIENTATION

EMPLOYEE VS WORK ORIENTATION

PROFESSIONAL VS PAROCHIAL ORIENTATION

OPEN VS CLOSED CULTURE

TIGHT VS L.OOSE CULTURE (CONTROL)

NORMATIVE VS PRAGMATIC (CUSTOMER ORIENTATION)

Organizational climate (OKIPO, de Cock et al., 1984):

ORGANIZATION EFFICIENCY

ATTENTION FOR NEW IDEAS

Organizational climate (Pennings, 1989): COMMUNICATION

Leadership (Syroit, 1979: House, 199?):

INITIATING STPUCTURE LEADERSHIP

CONSIDERATION LEADERSHIP

Leadership (Bass, 1989)

CHARISMATIC LEADERSHIP 


\section{Scale evaluation and variable construction: factor analyses}

Most scales used in this study are calculated using factor analysis. Factor analysis is a method for data reduction that aims to construct one or more new variables (factors) that best capture the variation in the original (larger) set of variables (items) (Kleinbaum et al., 1988). Several clusters of items were analyzed separately, because there was a theoretical rationale for expecting a specific grouping of the items within those clusters and significant interrelationships between the various clusters. Separate factor analyses were done for the organizational culture items, the items measuring organizational climate, the leadership items, and the items making up the satisfaction scale. The outcomes of the factor analyses are discussed below.

For organizational climate, leadership and satisfaction, the analyses were done at the level of the individual respondents. This means that the factor analysis summarizes the relationships between the item-scores of the individuals regardless of the source of the variation (within- or between store differences)'. For organizational culture the analysis was performed on the organizational level i.e., using group mean scores for the factor analysis, because the scales / variables measuring organizational culture were defined at this level (Hofstede et al., 1990, 1993). The variables were developed using the following line of reasoning.

1. The variables under study are theoretical constructs aimed at describing aspects of organizational culture, climate, leadership and satisfaction. Each of these constructs is measured with a number of questions (a scale) of which the answers are supposed to measure the underlying construct. The questions used to measure the constructs have been developed in previous research.
2. Factor analyses and reliability testing (section 6.1.3) were used to confirm validity and internal consistency of the proposed scales. Questions that did not behave according to expectations were assumed to be ineffective in this specific research setting, and were therefore dropped from the scale.

3. If these tests confirmed the proposed scales, it was assumed that most of the variation in the total set of items was caused by the theoretical constructs on which the scales were based. It was also assumed that no item perfectly measured one construct and that, although the constructs are theoretically independent, this might not be the case for their practical measurement. Therefore the values for the assumed underlying (latent) variables were calculated using the outcomes of the factor analyses. First, the scoring coefficients were calculated in the factor analyses. Then, the scoring coefficients were multiplied with the raw variables and the products summed up to produce the value of the theoretical variables.

4. For the variables developed at the individual level of analysis (organizational cli-

Controlling for store influences (by standardization of the scores per store i.e., giving the responses within each store a mean of 0 and a standard deviation of 1), to filter out the organizationlevel variation, did not influence the outcomes of the factor analyses significantly 
mate, leadership, and satisfaction), the next step was to evaluate the appropriateness of aggregating the individual level scores to the organizational level (section 6.1.4). If the amount of within-organization agreement was sufficient for a meaningful aggregation of the variables, the variables were aggregated to the organizational level and ready for use in the subsequent organizational level analysis.

To test the stability of the factor structures presented above three additional factor analyses were done on subsamples of the data. An analysis was done discarding the 10 largest stores, one discarding the 10 smallest stores, and one analysis was done with only the work-floor employees of the stores. These three analysis showed factor structures identical to the ones presented above. From this it can be concluded that the factor structures are stable.

In the next four sections the outcomes of the factor analyses for organizational culture, climate, leadership, and satisfaction are discussed in detail.

Organizational culture. For measuring organizational culture we used an instrument developed by Hofstede et al. (1990), the Organizational Culture Module (OCM). The instrument measures six dimensions of organizational culture using the mean questionnaire scores as organization-level raw data (Hofstede et al., 1990, 1993). In the analysis, however, the data did not provide a clear factor structure for the six-factor model. The analyses showed that only a two-factor solution based on the items measuring employee vs job orientation and the items measuring open vs closed culture was clearly interpretable (see table 6.2 below). There are two explanations for this finding. The first is technical in nature. Because in this study we did not use the complete OCM-questionnaire, but only an 18-item summary of $\mathrm{it}^{2}$, the fact that the original factor structure cannot be reproduced is not surprising. A factor analysis summarizes the covariation in a group of items in the best possible manner. If items are left out, a new factor analysis will show a different factor structure. This explanation, however, does not support the content validity of the measured scales. The second explanation is more theoretically based and is consistent with the distinction between aspects of organizational and industry culture discussed in chapter 3 . In their description of the six dimensions of organizational culture Hofstede et al. argue that four of the six dimensions actually describe differences in industry culture, relating to 'the type of work the organization does and the type of market in which it operates.' (Hofstede et al., 1990:306). These four dimensions are results vs process orientation, parochial vs professional, loose vs tight, and normative vs. pragmatic. The two remaining dimensions, employee vs job orientation and open vs closed culture, are determined by 'the philosophy of founders and top leaders' of the organization (Hofstede et al., 1990:306). As our research setting is a comparison of stores within one industry (even within one company) it is plausible that the dimensions of industry culture could not be established. The dimensions reflecting 'the philosophy of founders and top leaders', on the other hand, should show consistent differences between

${ }^{2}$ The 18 items were identified as key items in the scales. These iterns were used to calculate the scores on the six dimensions of organizational culture using the formulas developed by Hofstede's research team. 
stores (as our data show they do), because they point to the human interpretation of the organizational situation. This interpretation maydiffer for each storemanager and management team and thus for each store organization (storemanagers might for example emphasize salesmanship, financial prudence, or people management.)

Table 6.2 Factor structure two-factor solution for organizational culture

Factor pattern organizational culture after varimax rotation

ECUL OCUL

\begin{tabular}{|c|c|c|c|}
\hline ITEM202 & 0.63669 & 0.50376 & much concern for personal problems of employees \\
\hline ITEM210 & .0 .78729 & -0.30233 & organization oniy interested in work people do \\
\hline ITEM223 & 0.89152 & -0.01815 & mgmt generous with little things \\
\hline$E M$ & -0.48136 & -0.68821 & organization and people closed and secretive \\
\hline FNo2 & 0.06793 & -0.88718 & only very special people fit in organization \\
\hline ITEM21. & -0.36705 & -0.67217 & new employees need more than a year to feel at home \\
\hline
\end{tabular}

The two-factor solution for the items measuring employee vs job orientation and open vs closed culture is clearly interpretable. The first factor reflects the dimension employee orientation and the second openness. Two items show relatively strong secondary loadings, which do not disappear in an oblique rotation of the factor structure. This seems to indicate that the questions used to measure the underlying constructs (employee orientation and openness) are not perfect empirical measures of the theoretical constructs in this setting. The factor scores (based on the raw variables and the factor scoring coefficients) for the two factors can be used as the values for the latent variables that best summarize the variation in the questions measuring employee orientation and openness. The resulting variables are labeled employeeorientation (ECUL) and openness (OCLIL).

Organizational climate. In the questionnaire we included three scales to measure aspects of organizational climate: readiness to innovate, organization efficiency, and communication (see appendix 1). The organizational climate scale-structure was broadly reproduced in the factor analysis. The readiness to innovate scale reproduced as an independent factor. However, the factor analysis pointed to an overlap between the organization efficiency scale and the communication scale and four items showed relatively strong secondary loadings. The scales were rearranged by discarding the four items that showed strong cross-loadings and reassigning one item to another scale.

A new factor analysis with varimax rotation produced three clear factors that could be labeled readiness to innovate (INNO), task communication (TCOM), and general communication (GCOM). The general communication factor was based on Pennings communication scale, the task communication factor on the OKIPO-scale organization efficiency, and the readiness to innovate factor reproduced the OKIPO-scale. Table 6.3 below shows the factor pattern after varimax rotation in SAS. The factor scores for these three factors were used as variable scores for the climate variables INNO, TCOM and GCOM. 
Table 6.3 Factor structure three-factor solution for organizational climate

Factor pattern organizational climate after varimax rotation

\begin{tabular}{|c|c|c|c|c|}
\hline & INNO & GCOM & TCOM & \\
\hline ITEM401 & 0.37464 & 0.25917 & 0.50414 & the work is well-organized here \\
\hline ITEM4I6 & 0.17160 & 0.05607 & 0.79826 & everybody here always knows what to do \\
\hline ITEM424 & 0.15895 & 0.17934 & 0.78261 & everybody here has a clear task \\
\hline ITEM429 & 0.06282 & 0.27097 & 0.66055 & I know exactly what is expected of me in this store \\
\hline ITEM403 & 0.81960 & 0.17204 & 0.16382 & many new ideas are tried out here \\
\hline ITEM405 & 0.75764 & 0.25527 & 0.20998 & finding a new approach is encouraged here \\
\hline ITEM406 & 0.85786 & 0.13712 & 0.13180 & There are many new ideas here \\
\hline ITEM408 & 0.27638 & 0.71951 & 0.20735 & $\begin{array}{l}\text { my boss makes an effort to inform me about changes that } \\
\text { could be important for me }\end{array}$ \\
\hline ITEM41] & 0.18209 & 0.82358 & 0.16813 & my boss informs me about. what is happening in the company \\
\hline ITEM426 & 0.13867 & 0.84281 & 0.20671 & my boss. informs me about what is happening in our store \\
\hline
\end{tabular}

Leadership. The questions about leadership included in the questionnaire were expected to measure three aspects of leadership: charismatic leadership, consideration and initiating structure. The leadership scale-structure was reproduced in the factor analysis. For all but three items the primary factor-loading was consistent with the scale expectations. For two other items there was no clear primary loading. All five items were removed from the scales. The remaining items produced a factor structure consistent with the ex ante scales. However, the cross-loadings of several items indicated that measurement of the three leadership constructs was still imperfect. In an oblique rotation the items clearly loaded on one of the factors. The interpretation of the factors was identical to the varimax solution. However, the charisma and consideration factors correlated strongly, indicating that the operationalization of the two constructs is not independent. The oblique factor structure is shown in table 6.4.

Table 6.4 Oblique factor structure for leadership questions

Factor pattern leadership after oblique rotation

\section{COLOS CHLDS ISLDS}

$\begin{array}{lrrr}\text { ITEM621 } & 0.16947 & 0.76105 & -0.01405 \\ \text { ITEM623 } & 0.13407 & 0.80168 & -0.02143 \\ \text { ITEM624 } & 0.16609 & 0.70302 & 0.00755 \\ \text { ITEM625 } & 0.01509 & 0.92472 & -0.02839 \\ \text { ITEM626 } & -0.04561 & 0.84627 & 0.10598 \\ \text { ITEM629 } & 0.15085 & 0.68692 & 0.04394\end{array}$

ITEM602

ITEM604

ITEM606

ITEM608

ITEM610

ITEM612

ITEM614

$\begin{array}{llll}0.74235 & -0.09960 & 0.19449\end{array}$ he is a model for me to follow

he makes me proud to be associated with him

he encourages understanding of points of view of other members he is a source of inspiration for me

he has a sense of mission which he transimits to me

he has a special gift of seeing what it is that is really important for me to consider
he backs. up what people in his work group do
he is friendly and approachable he gives: advance notice of changes
he looks out for the personal welfare of group menbers
he is easy to understand
he puts suggestions of the people under him into operation
0.15143
$\begin{array}{lll}0.59102 & 0.21818 & 0.0259\end{array}$
$\begin{array}{lll}0.76699 & 0.13518 & -0.08640\end{array}$ he makes those under him feel at ease when talking with them


Table 6.4 Oblique factor structure for leadership questions (continued)

$\begin{array}{lrrrl}\text { ITEM611 } & 0.22368 & -0.07182 & 0.65353 & \text { he nokes. sure that his role in the store is understood } \\ \text { ITEM613 } & -0.14856 & -0.01677 & 0.83801 & \text { he decides what shall be done and how it shall be done } \\ \text { ITEM615 } & -0.01388 & 0.11294 & 0.61194 & \text { he schedules the work to be done } \\ \text { ITEM616 } & 0.04837 & 0.06258 & 0.74277 & \text { he naintains definite standards of performance }\end{array}$

correlations between the (oblique) factors-scores ( $n=1229$ )

$\begin{array}{llll} & \text { CHLDS } & \text { COLDS } & \text { ISLDS } \\ \text { CHLOS } & 1 & & \\ \text { COLDS } & 0.66 & 1 & \\ & 0.0001 & & \\ \text { ISLDS } & 0.17 & 0.248 & 1 \\ & 0.0001 & 0.0001 & \end{array}$

The relationship between the charisma and consideration factors asks for further analysis. Both concepts are important aspects of our current understanding of leadership in organizations. Rather then just chosing one of the two dimensions for further analyses, it is therefore interesting to compare the effects of charisma and consideration and evaluate similarities and differences. In this context an independent analysis of the consideration and initiating structure items on the one hand, and the charismaitems on the other hand seems warranted. The items measuring charisma originated from an operationalization of the leadership construct that is conceptually different from the operationalization of leadership in the tradition of the Ohio State leadership dimensions consideration and initiating structure (e.g. Avolio and Bass, 1988).

In the separate factor analyses consideration and initiating structure fit the expected two-factor model. A varimax-rotation shows two clearly interpretable, independent factors. The two factors cover $59 \%$ of the variance of the items. For this study the factor scores for these two factors are taken as the values for the consideration (COLDS) and initiating structure (ISLDS) leadership variables. The factor scores are shown in table 6.5 below.

Table 6.5 Two-factor structure consideration and initiating structure leadership

Factor pattern consideration and initiating structure items after varimax rotation

COLDS ISLDS

$\begin{array}{lrrl}\text { ITEM602 } & 0.78248 & 0.13952 & \text { he backs up what people in his work group do } \\ \text { ITEM604 } & 0.84654 & -0.06137 & \text { he is friendly and approachable } \\ \text { ITEM606 } & 0.75534 & 0.13671 & \text { he puts suggestions of the people under him into operation } \\ \text { ITEM608 } & 0.85458 & 0.01847 & \text { he makes those under hin feel at ease when taiking with them } \\ \text { ITEM610 } & 0.64643 & 0.24248 & \text { he gives advance notice or changes } \\ \text { ITEM612 } & 0.74961 & 0.16472 & \text { he looks out for the personal welfare of group menters } \\ \text { ITEM614 } & 0.78816 & 0.09146 & \text { he is easy to understand } \\ \text { ITEM611. } & 0.19793 & 0.65411 & \text { he makes sure that his role in the store is understood } \\ \text { ITEM613 } & -0.10779 & 0.81990 & \text { he decides what shall be done and how it shall be done } \\ \text { ITEM615; } & 0.11962 & 0.63511 & \text { he schedules the work to be done } \\ \text { ITEM616 } & 0.14656 & 0.76184 & \text { he maintains definite standards of performance }\end{array}$

A one-factor model for the charisma-items covers $74 \%$ of the variance in the original 
items. The factor-score for this factor is used as the value of the charismatic leadership-variable (CHLDS) in this study. The factor loadings for the charisma factor are shown in table 6.6.

Table 6.6 One-factor solution charismatic leadership

Factor pattern 1-factor model for the charisma items

\section{CHLDS}

[TEM621 0.88187 he is a model for me to follow

ITEM623 0.88849 he makes me proud to be associated with him

ITEM624 0.82741 he encourages understanding of points of view of other members

ITEM625 0.92171 he is a source of inspiration for me

ITEM626 0.83472 he has a sense of mission which he transmits to me

ITEM629 0.81148 he has a special gift of seeing what it is that is really important for me to consider

Satisfaction. Work satisfaction was measured using a validated scale from the University of Leiden (Vogelaar, 1990). The questions were expected to measure the variation in one latent underlying construct: work satisfaction. In previous research the Cronbach's alpha for the seven-item scale was 0.86 . The Cronbach's alpha for the twelve-item version was 0.89 (Vogelaar, 1990:139). Here all items of the seven-item version of the scale were included (see appendix 1). Testing a one-factor model for the satisfaction scale showed that one factor could explain $58 \%$ of the variance in the variables. The Cronbach's alpha for the satisfaction scale in this study was .87 . For this study the variable SATIS was calculated as the factor score of the one-factor model for the satisfaction items. The factor loadings for the items are shown in table 6.7 below.

Tüble 6.7 One-factor solution work satisfaction

Factor Pattern satisfaction scale

SATIS

$\begin{array}{lrl}\text { ITEM102 } & -0.77881 & \text { I Iind my work often boring } \\ \text { ITEM104 } & 0.71757 & \text { my work is interesting } \\ \text { ITEM106 } & 0.82546 & \text { in general I perform my work with pleasure } \\ \text { ITEM107 } & 0.76360 & \text { my work is like a hobby to me } \\ \text { ITEM110 } & 0.80616 & \text { I am very satisfied with my present work } \\ \text { ITEM112 } & -0.62723 & \text { I often feel the day will never end } \\ \text { ITEMI13 } & 0.80769 & \text { I am mostly enthusiastic about my work }\end{array}$

\section{Evaluating scale reliability}

Scale reliability is often evaluated by looking at the internal consistency of a scale. In an internally consistent scale the items of the scale covary. The internal consistency of scales can be evaluated using Cronbach's alpha $(\alpha)$. A large $\alpha$ indicates 'that there is very little variance specific to individual items' (Cortina, 1993:100). In general, scales with alphas over .70 are considered internally consistent. However, scale length influences the level of $\alpha$, and the $\alpha>70$ criterion is in fact arbitrary (Cortina, 
1993:101). Cortina therefore argues that it should not be used as sole measure of empirical scale reliability. Here, Cronbach's alpha is used to supply additional information about the properties of the scales developed in the factor analysis. Table 6.8 presents the Cronbach's $\alpha$ for these scales. Following the $\alpha>.70$ rule-of-thumb the internal consistency of the leadership and climate scales formed on the basis of the above presented factor analyses proves to be satisfactory. Only the initiating structure scale shows an $\alpha=69$. Adding a variable from the five dropped earlier in the factor analysis would bring $\alpha$ up above .70, but this addition is not supported in the factor analysis and would provide a mere cosmetic improvement of the alpha-coefficient. For the satisfaction scale the alpha is clearly in the safe range $(\alpha=.87)$. The organizational culture scales are analyzed at the organizational level. Hofstede et al. $(1990,1993)$ argue that the organizational level relationships between items differ from the individual level relationships, reflecting the different underlying mechanisms determining the individual level and organizational level components of the variation in item scores. Thus, the assessment of scale reliability, basically evaluating the relationships between the items in a scale, has to be done at the appropriate level. As the organizational culture scales were developed at the organizational level, their reliability also has to be evaluated at the organizational level. Following the $\alpha>70$ rule-of-thumb both organizational culture scales also show satisfactory alpha-scores.

Table 6.8 Cronbach's alphas

ALPHA ITEMS

Organizational culture

EMPLOYEE OFIENTATION (ECUL)

OPEN CULTURE (OCUL)

$\begin{array}{ll}76 & 3 \\ 73 & 3\end{array}$

Organizational climate:

TASK COMMUNICATION (TCOM)

READINESS TO INNOVATE (INNO)

$73 \quad 4$

GENERAL COMMUNICATION (GCOM)

Leadership:

CHARISMATIC LEADERSHIP (CHLDS)

$93 \quad 6$

CONSIDERATION LEADERSHIP (COLDS)

INITIATING STRUCTURE LEADERSHIP (ISLDS)

3

3

Work satisfaction:

SATISFACTION (SATIS)
7
4

\section{Validating aggregation: within-store agreement}

Employing variables defined at the level of individual members of the organization for use in an organization-level analysis presents us with the question of the validity of aggregating the individual level results to the organizational level. In this study the climate, leadership and satisfaction variables are defined at the individual level of analysis. These have to be aggregated to the organizational level of analysis. The organizational culture variables are already organization-level variables and point to 
dimensions that do not exist, or at least are not defined, at the individual level. For the climate, leadership and satisfaction variables it is necessary to validate their aggregation to the organizational level. Two basic assumptions regarding the locus of the variance in the data underly the meaningful aggregation of individual level data to the group level. In aggregating we assume within-group homogeneity and between-group heterogeneity of the data (Klein et al., 1994).

Traditionally, an ANOVA-test or a similar test like the WABA-analysis (Dansereau et al., 1984 ) is used to compare within- and between-group variance. Conclusions about the significance of both kinds of variance are drawn on the basis of this relative comparison. Columns 3 and 4 of table 6.9 below show the ANOVA results for the climate and leadership variables.

Table 6.9 ANOVA and within-group agreement scores for culture, climate and leadership

\begin{tabular}{|c|c|c|c|c|c|c|c|c|}
\hline scale & $\begin{array}{l}\text { number of } \\
\text { items (i) }\end{array}$ & F-value & $\mathrm{Pr}>\mathrm{F}$ & $\begin{array}{l}\text { mean Aw - } \\
g(i)\end{array}$ & $\begin{array}{l}\text { std diev } \\
\text { Riwg(i) }\end{array}$ & $\begin{array}{l}\text { Riwg(i) } \\
>0.70\end{array}$ & $\begin{array}{l}\text { Riwg(i) } \\
\geq 0.80\end{array}$ & $\begin{array}{l}\text { Riwg(i) } \\
>0.90\end{array}$ \\
\hline SATIS & 7 & 1.28 & .0993 & 86 & 10 & 48 & 43 & 18 \\
\hline CHLDS & 6 & 697 & .0001 & .79 & .12 & 40 & 31 & 6 \\
\hline COLDS & 7 & 4. 13 & .0001 & 88 & 08 & 49 & 46 & 24 \\
\hline ISLOS & 4 & 406 & 0001 & 80 & .07 & 45 & 30 & 1 \\
\hline TCOM & 4 & 1,17 & 1985 & 81 & 06 & 46 & 35 & 4 \\
\hline INNO & 3 & 2.30 & 0001 & 88 & .08 & 47 & 47 & 26 \\
\hline GCOMI & 3 & 2.18 & .0001 & 62 & .19 & 24 & 1 & 0 \\
\hline
\end{tabular}

The table shows that the differences between stores are significant, for all variables but the task communication variable (TCOM). This, however, does not mean that TCOM is not an organization-level concept. Although some argue that the withingroup variation should be smaller than the between-group variation to be able to speak of an organization-level phenomenon (e.g. Yammarino and Markham, 1992; Dansereau et al., 1984), there are two convincing arguments against this position. First, there is the technical issue of the underestimation of within-group agreement by the ANOVA-procedure in cases where the total amount of variance is limited (George, 1990; George and James, 1993). This is clearly the case in our sample of fifty supermarkets from the same retail chain. Second, George and James (1993) summarize the theoretical arguments against this approach as follows:

'This [conclusion] is problematic because it essentially implies that unless a group stamps out all individual differences, it is essentially not having any meaningful effects. Individuals do not lose their individuality by being members of a group. Group effects can be powerful, and yet one might still observe variation and covariation within groups.' (George and James, 1993:800)

Large within-store variation can be attributed to several sources, e.g. differences in demographic factors and hierarchical position between respondents within the stores (Koene et al., 1996), independently of between-group variance. Therefore, analyses that compare the within-group variation to the between-group variation miss the point 
of the separate assumptions asking for a) within-group homogeneity and b) betweengroup variation formulated by Klein et al. (1994). Two independent measures for considering the assumptions separately are the Rwg-measure of within-group agreement and the ANOVA F-test determining the statistical significance of between-group variation.

The basic assumption for meaningful aggregation of individual level data to the group level is the existence of homogeneity of within-group responses. For example, organizational climate can be defined as 'perceptual agreement' between organization members which implies 'a shared assignment of psychological meaning' in the organization (James, 1982:221). In this study it is therefore necessary to point out that there is 'perceptual agreement' within stores on the variables that are defined at the level of individual respondents i.e., climate, leadership and satisfaction. Also we assume that perceptual agreement is not an either/or issue, but can vary across organizations.

Therefore, a measure of agreement is needed that is independent of between-group variation and that is able to capture different levels of agreement in groups. James et al.'s measure of within-group interrater agreement Rwg (James et al., 1984; 1993) fulfills these two requirements. Basically, the Rwg compares the actual distribution of responses (showing the actual agreement in the response-group) to an expected distribution of responses in case of a complete lack of within-group agreement. Rwg compares the actual within-group variance, $S_{x}{ }^{2}$, with the expected variance in case of completely random response, $\sigma_{E}^{2}$ (the theoretical benchmark). Within-group agreement is then assessed as 'the degree to which the observed ratings reflect a reduction in error variance relative to the theoretical benchmark' (James et al., 1993:307). The values for Rwg range from 0 (no agreement) to 1 (perfect agreement). The formula for calculating the Rwg is:

$$
R w g=\left(\sigma_{E}^{2}-S_{x}^{2}\right) / \sigma_{E}^{2}=1-\left(S_{x}^{2} / \sigma_{E}^{2}\right)
$$

In this study the agreement-scores were calculated using the Rwg(j), the multiple-item version of James et al.'s agreement index (James et al., 1984). It is important to notice that the Rwg is not without flaws. Its interpretation, although 'logical, legitimate and meaningful,' is a matter of judgment (James et al., 1993). There still is a lack of empirical evidence on the behavior of the Rwg index. Furthermore, it 'suffers from the same problems inherent in all such agreement indexes: the ambiguity of establishing the distribution of expected variance' (Kozlowski and Hattrup, 1992:166). For the interpretation of Rwg-index scores we follow James et al. (1993). Rwg=1.0 is the outcome in case of perfect agreement of all raters. $R w g=0.0$ is the outcome in case of a perfectly random response of all raters (less then zero scores are set to zero ${ }^{3}$ ). $\mathrm{R} w g=.86 \mathrm{sug}$ gests a 'high, but not perfect level' of interrater agreement. Rwg $=.47$ suggests a 'reasonably low level' of interrater agreement (James et al., 1993:308). To suggest acceptable levels of agreement, Rwg-scores should be higher than 'the Rwg $=0.70$

${ }^{3}$ Negative scores are possible because the sample variance $\left(S_{x}{ }^{2}\right)$ can be larger than the assumed population variance $\left(\sigma_{x}{ }^{2}\right)$ based on random variation technically (see James et al., 1993:308). but also, for example, in case of the existence of strongly divergent subcultures (Koene et al., 1995) 
ballpark figure for a "good" amount of agreement' for most of the units under study (George, 1990:110).

Of the variables measuring climate, leadership and satisfaction all but one pass the rule-of-thumb test of Rwg $>0.70$. Only general communication (GCOM) falls below this criterion. Still, the score of Rwg $=0.62$ shows that the individuals in the stores show reasonable agreement on the evaluation of this dimension.

Thus, the ANOVA and the Rwg-test together validate the organizational level analysis of climate, leadership and satisfaction, showing high within-group agreement and significant between-store variation. Within-group agreement determined using the Rwg-test; significant between-group variation determined using the ANOVA F-test. Only for the task communication variable (TCOM) the variation between stores should be considered random ( $F$-value $=1.17 ; \mathrm{Pr}>\mathrm{F}=.1985$ ) according to the ANOVA. The high Rwg-score for TCOM, however, changes this interpretation. It means that, although TCOM shows clear within-group agreement and can thus be aggregated, the small between-store variation makes it doubtful if the variable is of significance in describing differences between stores. In this vein it can be argued that TCOM, measuring the clarity of individual tasks, is strongly related to corporate job design and task definitions. This might strongly limit the amount of variance of this variable between stores, meaning that relatively small variations might point to relatively large underlying differences in work attitudes and values in the various stores. It could thus be argued that the significance of variation between stores should be determined by the explanatory power of a variable at the store level, rather than in a statistical ANOVA-test. The significance of the between-store differences for TCOM will thus show in the further analyses at store level. Therefore, the TCOM variable will be taken along in the analysis. Of course, possible organization-level relationships for this variable will have to be carefully interpreted, avoiding the interpretation of random variation.

\section{Descriptive statistics and correlations}

After determining the validity of aggregation of the organizational climate, leadership and satisfaction variables to the organization level, we have an organization level data base with nine variables measuring organizational culture, organizational climate, supermarket manager leadership and work satisfaction for the fifty store sample. Before these variables are used in further analyses, it is important to look at the descriptive statistics of the nine variables, and to evaluate the correlations between them. Table 6.10 shows the descriptive statistics for the nine variables. When reading the table it is important to keep in mind the following points: (1) the table shows the descriptive statistics for the store means of the nine variables, it is therefore unlikely to find extreme scores in this table; (2) only the relative measures are of real importance. 
because the questionnaire data can be regarded as interval data ${ }^{4}$; and (3) all scores are factor scores i.e., calculated estimates of the scores of the latent variables expected to cause the variation of the questionnaire item scores. The factor scores are standardized scores with a mean of 0 and a standard deviation of 1 . The organizational culture factor scores have been calculated at the organizational level, ECUL and OCUL thus show a mean of 0 and a standard deviation of 1 at the organizational level. The other factor scores were determined at the individual level of analysis. At the (aggregated) organizational level the means and standard deviations thus are not equal to 0 and 1 respectively.

Table 6.10 Descriptive statistics questionnaire variables

\begin{tabular}{|c|c|c|c|c|c|c|}
\hline variable & label & $N$ & Mean & Std Dev & Minimum & Maximum \\
\hline ECUL & employee orientation & 50 & 0 & 1.00 & -3.23 & 2.28 \\
\hline OCUL & open culture & 50 & 0 & 1.00 & -2.18 & 2.12 \\
\hline TCOM & task communication & 50 & -0.04 & 0.27 & -0.93 & 0.51 \\
\hline INRO & readiness to innovate & 50 & -0.07 & 0.35 & -1.03 & 0.66 \\
\hline GCOM & general comunication & 50 & .0 .02 & 0.33 & -0.81 & 0.71 \\
\hline COLOS & consideration & 50 & -0.04 & 0.55 & -1.74 & 0.89 \\
\hline ISLDS & initiating structure & 50 & -0.12 & 0.48 & -1.98 & 0.60 \\
\hline CHLDS & charisma & 50 & -0.07 & 0.47 & -1.24 & 0.68 \\
\hline SATIS & work satisfaction & 50 & 0 & 0.26 & -0.79 & 0.62 \\
\hline
\end{tabular}

Furthermore, it is important to check for and understand the relations between the organizational culture, climate, leadership and satisfaction variables. The bivariate correlations for the variables are presented in table 6.11 below.

Table 6.11 Correlations for the social variables

Pearson Correlation Coefficients / Prob > $|\mathrm{R}|$ under Ho: Rho=0 / N $=50$

ECUL OCUL INNO GCOM TCOM COLDS ISTLOS CHLDS SATIS

\begin{tabular}{|c|c|c|c|c|c|c|c|c|}
\hline ECUL & 1.00 & & & & & & & \\
\hline OCUL & 0.00 & 1.00 & & & & & & \\
\hline INNO & $0.40 * *$ & $0.24^{\star}$ & 1.00 & & & & & \\
\hline GCOM & $0.63^{\star \star \star}$ & 0.22 & $0.28 *$ & 1.00 & & & & \\
\hline TCOM & $0.46^{\star \star \star}$ & $0.33^{*}$ & $0.32 *$ & $0.37^{* \pi}$ & 1.00 & & & \\
\hline COLDS & $0.64 * \star \star x$ & $0.27^{*}$ & $0.48^{\star \star \star}$ & $0.65^{\star \star \star}$ & $0.45^{\star *}$ & 1.00 & & \\
\hline ISLDS & 0.19 & -0.13 & $0.39 \star \star \star$ & 0.20 & 0.18 & -0.04 & 1.00 & \\
\hline CHLDS & $0.58^{\star \star \star}$ & 0.17 & $0.52^{* \star * *}$ & $0.68^{* \star \star *}$ & $0.35 *$ & $0.82^{\star \star * *}$ & $0.36 *$ & 1.00 \\
\hline SATIS & $0.29 *$ & $0.41 * *$ & $0.39 \star \star \star$ & $0.31 *$ & $0.40^{* \star}$ & $0.44 * \star$ & 0.07 & $0.54 * * *$ \\
\hline
\end{tabular}

Significance levels $\cdots: p<0.001 \cdots: 0<0.01^{*}: p<0.1$

ECUL and OCUL are uncorrelated because their variable scores were calculated from a factor analysis at the organizationat level.

4 Although not everybody would agree with this choice (e.g. Hildebrand, 1986:49), it is a practical prerequisite to use a number of important insightful statistical analyses (such as factor analysis and regression analysis) 
The correlations have two explanations. First, the correlations might point to legitimate, theoretically explainable relationships. For example, correlations between leadership and organizational climate might point to an actual causal relationship between the variables. Second, correlations might point to a conceptual overlap between two variables. For example, an overlap between two leadership variables might mean that the hypothesized constructs do not actually exist, but refer to one and the same concept in different ways.

Theoretically explainable relationships. Correlations that can be explained in a causal way are the correlations between leadership and the other variables. Charisma (CHLDS) and consideration (COLDS) are both positively correlated with an employee oriented culture (ECUL), and with the climate variables (innovativeness (INNO), task communication (TCOM), and general communication (GCOM)). In this manner initiating structure (ISLDS) is related to one climate variable: innovativeness. Likewise, the correlations between satisfaction (SATIS) and the other variables can be explained in a causal manner, assuming that the social environment in which one operates influences the perceived satisfaction with the work situation.

Relationships that point to a conceptual overlap. Correlations that might be explained as caused by conceptual overlap between the constructs are the correlations among the leadership variables and the correlations between the organizational culture and climate variables. This is most clear for the correlation between charisma and consideration. CHLDS and COLDS correlate .82, giving the two variables $67 \%$ shared variance: this might point to an overlap in the empirical operationalization of the concepts. The following argumentation supports the overlap explanation for the correlations between the leadership variables. The empirical research on transformational leadership, on the one hand, tries to capture the essence of the variation in employee perceptions of leadership with five leadership dimensions. Our charisma dimension (CHLDS) is one of those five. The empirical studies of leadership in the Ohio State tradition, on the other hand, try to capture the essence of the variation in employee perceptions of leadership with the two other dimensions incorporated in this study: initiating structure (ISLDS) and consideration (COLDS). Because the dimensions in both traditions aim at describing the whole spectrum of leadership perceptions, it can be expected that the dimensions overlap to a certain extent. Although researchers who focus on the study of charismatic leadership emphasize the novelty and distinctiveness of the concept (e.g. Avolio and Bass, 1988), empirical evidence thus seems to show that the older 'consideration' operationalization, at least to some extent, resembles the new charisma operationalizations. Other researchers also found significant correlations between charisma and consideration and initiating structure (Peterson, Phillips, and Duran; 1989).

Likewise, conceptual overlap could be considered an explanation for the correlations between the organizational culture variable 'employee oriented culture' and the three climate variables. However, their conceptual difference (see chapter 3.1) and the relatively small amount of shared variation (at most $40 \%$ ) point out that these variables measure different aspects of organization's internal social environment. 
Implications for further analyses. The correlations between the questionnaire variables show that the social variables are closely related. In the analyses with these variables it is therefore very important to take into account these interrelationships and to show clearly how the specific model deals with the relationships between the variables. The findings here have implications for the research model. Expected causal relationships have to be built into the model, and conceptual overlap warrants the assumption of overarching latent variables, explicit variable selection, or separate analyses.

\section{Dimensions of organizational culture, climate and leadership}

After this analysis and evaluation of the questionnaire data we can conclude that the questionnaire has provided us with nine variables that describe aspects of organizational culture, climate, leadership and employee work satisfaction. The culture and climate variables measure aspects of organizational culture and climate that have consistently appeared in quantitative empirical research on these topics (see chapter 3). The leadership variables reflect three important aspects of leadership (see chapter 4). Finally, work satisfaction is often studied in relationship with organizational culture, climate and leadership (see chapter 3 ). The variables are to some extent related, which complicates the anajysis in the subsequent chapters. For each analysis using the questionnaire data it is important to clarify how the relationships between the questionnaire variables will be interpreted: as possibly causal relations or as artifacts of overlapping operationalizations of, in principle, independent theoretical constructs. Furthermore, reviewing the findings presented in this chapter provides tentative answers to research questions 1 ('Which dimensions of organizational culture and climate explain differences between organizations within one industry?') and 2 ('What is the relationship between the traditional leadership dimensions of initiating structure and consideration and the recent operationalizations of leadership as exemplified in the charisma-dimension?').

Organizational culture and climate. In their analyses Hofstede et al. (1990:306) identified two dimensions of organizational culture as reflecting 'the philosophy of founders and top leaders,' thus focusing on the impact of people on the organizational culture: the employee orientation dimension and the openness dimension. The other four reflected industry differences of organizational culture. Employee orientation (ECUL) and openness (OCUL) could be validated as variables describing differences between the supermarket stores. The scales measuring the two dimensions were confirmed through factor analysis and showed sufficient internal consistency. Thus, ECUL and OCUL can indeed be considered organizational level dimensions of organizational culture. As can be seen from the review in chapter 3 , the two dimensions also reflect social aspects of the organization that have been studied in other organization research. Employee orientation was measured as respect for people (O'Reilly et al., 1991), emphasis on human resources (Hansen and Wernerfelt, 1989), warmth and social rewards (Ostroff, 1993), management concern for employee involvement (Payne and Mansfield, 1973), and task vs. social focus (Reynolds, 1986). Openness was measured as openmindedness (Payne and Mansfield, 1973) and decision-making practices (Denison, 1990). The four industry dimensions of culture could not be 
reproduced as consistent dimensions in our (within-company / within-industry) analysis.

The three organizational climate scales were broadly reproduced in the analyses. All three measured aspects of organizational climate that consistently reappear in studies of the social aspect of organizations. Task communication (TCOM) resembled the measures of administrative efficiency, general communication (GCOM) the measures of communication / cooperation, and readiness to innovate (INNO) the measures reflecting organizational innovativeness (see chapter 3 ). Furthermore, they described differences between stores in our within-industry sample. The organizational climate measures used thus all focus on how people understand their work situation and work together, emphasizing the kind of differences that can arise between organizations within one industry.

Leadership. Both the recent operationalizations of leadership, revolving around the concept of charisma, and the older operationalizations with consideration and initiating structure as focal concepts attempted to describe the essence of variation in employees' leadership perceptions. The strong relationship between the leadership variables consideration and charisma reported in section 6.1 .5 is thus not unexpected, and could be explained as overlap in the empirical operationalizations of the concepts. This finding substantiates the outcomes of previous research indicating the empirical relationship between charisma and consideration (Peterson, Philips, and Duran, 1989). For leadership research this means that a sole focus on the new operationalizations of leadership, emphasizing charismatic and transformational leadership (e.g. Bass, 1985; Avolio and Bass, 1988; Howell and Avolio; 1993), overlooks a rich body of useful evidence: first, because the older leadership operationalization might not be as limited and confining as the proponents of the newer operationalizations want us to believe (see chapter 4); second, because the present leadership operationalizations do not purely measure the focal concepts (such as consideration and leader charisma). Further refinement of the measures, along the lines of the theoretical concepts (contrasting charisma with consideration), might aid the development of more precise and useful measurement instruments.

For this study this interpretation of the empirically determined leadership dimensions means that the variables measuring initiating structure and consideration can be used in the analysis as reflecting two validated independent constructs, but that the measure of charismatic leadership, although emphasizing a different and important aspect of leadership, should be interpreted as partly measuring the same aspect of leadership as the consideration dimension.

\subsection{Performance variables}

The performance variables are another important group of variables in this study. In the reviews of the literature in chapters 3 and 4 we concluded that with respect to the impact of organizational culture and climate on organizational performance two kinds of empirical studies would be useful (see chapter 3). First, studies that relate organi- 
zational culture and climate to a broader range of organizational performance indicators. Studies until now have focused on narrowly defined performance indicators. It is interesting to investigate whether different aspects of culture and climate also influence different aspects of organizational performance. Second, there seems to be a lack of studies relating organizational culture to the bottom line financial performance which is fully attributable to the organization (or unit) under study. Therefore, studies that are able to address this relationship might provide a valuable addition to the existing body of literature describing the impact of organizational culture and climate on organizational performance. With respect to leadership we concluded that there is a lack of information about the relationship of leadership with objective, organizationlevel measures of performance. All this means that for this study we had to identify a number of objective measures of organizational performance at the level of the supermarket stores that would cover a range of different aspects of store performance, focusing on those aspects of performance that can be influenced by the store culture.

A variety of financial performance measures was available to describe store performance. For the selection of the performance variables it is important to assess the relative importance of the various components of financial performance for the operating profit of a single supermarket store. This section first describes the general cost structure of the supermarket stores in our sample. Then, three types of performance indicators are identified, pointing at specific aspects of performance relevant in the context of this study: (i) (bottom line) store performance, (ii) cost performance, and (iii) personnel performance. Finally, five performance variables are selected for further use in the empirical investigations in chapters 7 and 8.

Table 6.12 reveals the cost structure of the average supermarket in our sample. The table reveals the different cost categories as a percentage of the total sales for the fifty stores in the sample and the variation of these percentages between stores. If figures were not available n.a. was put in the table. For the selection of performance indicators in this study it is important to distinguish between aspects of performance (or costs) that are outside the supermarket's control and those over which the supermarket, or rather the supermarket manager and his team of employees, have some discretionary power. Only these performance indicators are of interest in the context of the present study because they can be affected by a store's organizational culture, as store culture has its influence through the people working in the specific store. Store sales should be regarded as an independent, store-related, variable. Although the supermarket manager and his employees can have some influence on the level of sales exploiting the store's possibilities, differences in sales volume between the stores are mostly determined by the (imposed) differences in market focus of the stores. Total gross gain is the margin on sales, selling price minus cost price of the products. Again, a supermarket manager has almost no influence on total gross gain. The selling price is determined by the company head office and cost price is determined by the bargaining results of the buyers at the central purchasing departments of the chain. The supermarket manager may have some impact on the tota gross gain by ordering the right amount of products at the right time and influencing the store's product assortment. In general, however, the product assortment of a certain type of store is fixed. Further variables that are largely outside the discretionary power of the 
supermarket manager are production and distribution costs, fixed costs, and company overhead and advertising. The level of these variables is determined by the head office of the company. Production and distribution costs is a fixed amount of the country-wide distribution costs allocated to a specific store. The fixed costs category represents the store's own fixed costs of, for example, rent and depreciation. Company overhead and advertising is also allocated to the store by the head office.

Table 6.12 Cost structure average supermarket store in sample $\mathrm{e}^{5}$

\begin{tabular}{|c|c|c|c|c|}
\hline & Mean & Std dev & Minimum & Maximum \\
\hline Total sales & $100 \%$ & & & \\
\hline$\%$ cost price of products & n.a. & & & \\
\hline \multicolumn{5}{|l|}{ 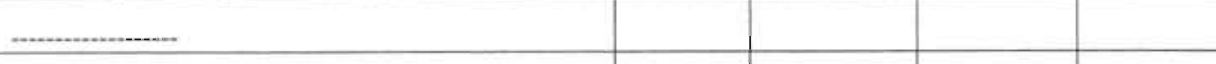 } \\
\hline Total gross gain & n.a. & & & \\
\hline$-1+$ inventory depreciation and revaluation & -.99 & .17 & -.59 & -1.42 \\
\hline$\%$ production and distribution costs & n.a. & & & \\
\hline \multicolumn{5}{|l|}{ - } \\
\hline Gross gain after prod and distr costs & 19.62 & 1.07 & 17.08 & 21.44 \\
\hline \% wages & -8.55 & .78 & -7.16 & -11.05 \\
\hline \% other controllable costs & -2.46 & 45 & -1.81 & -3.72 \\
\hline \multicolumn{5}{|l|}{ 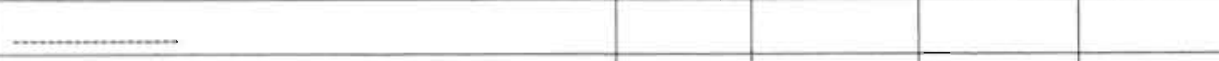 } \\
\hline Gross results (store contribution income) & 8.61 & 1.66 & 4.41 & 11.08 \\
\hline$\%$ fixed costs (store overhead) & -2.87 & 81 & -1.45 & -4.96 \\
\hline \multicolumn{5}{|l|}{ 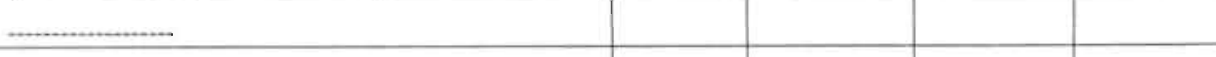 } \\
\hline Net results (company contribution income) & 5.74 & 1.96 & .98 & 8.72 \\
\hline \% company overhead and advertising & n.a. & & & \\
\hline $1+$ other costs and income & n.a. & & & \\
\hline \multicolumn{5}{|l|}{$+\ldots$} \\
\hline Operating profit & 3.16 & 1.97 & -1.74 & 6.15 \\
\hline
\end{tabular}

Variables over which the supermarket manager has some discretion (i.e., variables which can be influenced in the store) are inventory depreciation and revaluation, wages, and other controllable costs. Inventory depreciation and revaluation is built up of the total losses that can be accounted for, caused by breakage, theft and losses on products with a quality expiration date on the one hand, and the total of gains on products through price increases of inventory on the other. Wages is the amount of wages payed to the employees of the store. Other controllable costs is the summation of the other cost categories over which the supermarket manager has some sort of 
discretion. The other controllable costs category summarizes unexplainable stock losses, personnel costs, packaging costs, housing and environmental costs, and other expenses. Table 6.13 below shows wages, other controllable costs and fixed costs, as a percentage of the gross gain after production and distribution costs. It emphasizes the impact of the main store-specific cost categories on the actual store performance. The table shows the importance of wages and other controllable costs for the store's net results.

Table 6.13 Store-specific costs as percentage of gross gain after production and distribution costs

\begin{tabular}{|l|l|l|l|l|}
\hline & Mean & Std dev & Minimium & Maximum \\
\hline Gross gain after prod and distr costs & $100 \%$ & & & \\
\hline$\%$ wages & 43.74 & 5.23 & 36.51 & 58.90 \\
\hline \% other controllable costs & 12.63 & 2.58 & 8.79 & 20.33 \\
\hline$\%$ fixed costs (calculated) & 14.66 & 4.16 & 7.57 & 25.05 \\
\hline & & & & \\
\hline Net results & 28.97 & 9.37 & 5.67 & 43.05 \\
\hline
\end{tabular}

For determining the final operating profit two other cost variables have to be taken into account: 'company overhead and advertising' and 'other costs and income.' However, these are not important for determining the performance of the individual supermarket stores in this study. As explained above, company overhead and advertising is determined by the head office and is not under the discretion of the supermarket manager. Other costs and income is normally an insignificant remainder of costs and revenues generated through unusual activities in a store.

The analysis of the stores' cost structure shows the importance of the other controllable costs categories as management variable for store management, as fixed costs cannot be influenced in daily management practice and wage costs should also be considered partly fixed. Table 6.14 below, presents a break-down of the costs summarized in the other controllable costs category: unexplainable stock losses, personnel costs, packaging costs, housing and environmental costs, and other expenses.

Table 6.14 Components of other controllable costs

\begin{tabular}{|l|l|l|l|l|}
\hline & Mean & Std dev & Minimum & Maximum \\
\hline Other controllable costs & $100 \%$ & & & \\
\hline Stock losses (planning) & 22.31 & 6.70 & 8.76 & 38.47 \\
\hline Stock losses (correction to planning) & 0.37 & 9.41 & -19.86 & 24.25 \\
\hline Personnel costs & 17.28 & 3.03 & 10.11 & 22.77 \\
\hline Packaging costs & 9.82 & 3.90 & 2.61 & 18.08 \\
\hline Housing and environmental costs & 32.15 & 6.61 & 13.18 & 48.40 \\
\hline Other expenses & 18.07 & 4.71 & 2.67 & 32.31 \\
\hline
\end{tabular}


Unexplainable stock losses is the amount of goods intended for sale that disappears between delivery at the store and sales to the customer. Stock losses are divided up into a planned component and a correction for the planning. The correction is done twice a year after a store-wide inventory check. Personne/ costs is the amount of money spent by employees during work (travel expenses, gifts to employees, company clothing, and other costs). Packaging costs are the costs for packing fresh products sold to the customers. Housing and environmental costs are costs like energycosts, cleaning costs, technical maintenance, etc. Other expenses are, for example, telephone and administration costs, 'small materials,' accidents and damages, membership costs, and store advertising.

\section{Performance indicators for supermarket stores}

Studying the aspects of store performance that can be influenced by organizational culture, climate and leadership, three groups of quantitative performance variables can be distinguished: first, variables related to a store's final performance (store performance); second, variables specifically related to costs (cost performance); and third, variables specifically related to personnel performance. Variables from the different categories are related to each other, but only within their category they point to a similar subject. The three groups are summarized below (table 6.15). The financial variables discussed in the previous paragraph are only a subset of the variables considered here. Measures like productivity, sick leave and sales per square meter are not variables that describe final store performance; they do, however, help to gain insight in the process of getting to the final financial outcomes.

Table 6.15 Quantitative performance variables

\begin{tabular}{|l|l|l|}
\hline Store performance & Cost performance & Personnel performance \\
\hline $\begin{array}{l}\text { Gross results (GRRES) } \\
\text { Opet results (NTRES) }\end{array}$ & $\begin{array}{l}\text { Other controllable costs (CSTS) } \\
\text { Fixed costs store (FXCST) } \\
\text { Company overhead (CMOHD) }\end{array}$ & Total wages (WAGE) \\
\hline Sales per square meter (SQM) & & $\begin{array}{l}\text { Productivity (ACTPROD) } \\
\text { Prod difference (PRODDIF) } \\
\text { Sick leave (SICKLV) }\end{array}$ \\
\hline
\end{tabular}

Store performance. The measures of store performance presented above point to the bottom line performance of the stores. Gross results (GRRES) is the purest indicator of direct store performance. Net results (NTRES) takes into account the store's own fixed costs. Operating profit (OPROF) shows the store's results after correction for company-wide overhead. These measures are calculated as a percentage of gross sales. The sales per square meter (SQM) is an indicator of the efficient use of store space.

Cost performance. The cost performance category contains variables that show the most important cost factors influencing store performance. 'Other controllable costs' (CSTS) is a summation of the controllable costs of store operations, from telephone bills to pricing materials and canteen-costs to company clothing. Fixed costs (FXCST) are the store's own fixed costs of, for example, rent and depreciation. Company 
overhead $(\mathrm{CMOHD})$ is independent of store performance. All the variables are calculated as a percentage of the gross sales of the store.

Personnel performance. The personnel performance category contains several indicators of personnel performance. It shows the important category of personnel costs (WAGE). WAGE indicates the total labor cost of a store as a percentage of its gross sales. The other indicators of personnel performance are productivity and sick leave as a percentage of budgeted hours for the store (SICKLV). Productivity was measured as the 'productivity difference' of a specific store. It compared actual store productivity (ACTPROD) to the productivity level expected for the specific store by central management (OPWU), taking into account its handicaps in layout, logistics, customer types, etc. This productivity difference score (PRODDIF) is the most exact measure of productivity performance, because the productivity standard reflects each store's specific circumstances as perceived by the head office of the company (independent of the store's sick leave record.)

\section{Calculation of the performance variables}

The variable scores were calculated taking the mean scores of each performance variable for the first seven four-week periods following the return of the questionnaires that measured the social variables. As already indicated, most scores were measured relative to a constant base i.e., costs and results were shown as percentages of sales, and sick leave hours as a percentage of total amount of budgeted hours.

\section{Selection of the performance variables}

For the selection of performance variables we have to study the relationships between the measures of performance. The correlation matrix in appendix 2 presents the correlations for the above described performance variables.

Store performance. For store performance net results (MNTRES) will be used because of its close relationship to MGRRES and MOPROF. MNTRES, by taking into account store fixed costs, also captures the entrepreneurial ingenuity of a store manager and his employees in making the store profitable. MNTRES is the purest indicator of a store's contribution to overall company profits. The sales per square meter variable (SQM) actually measures the degree to which the assets are put into productive use. It therefore shows a strong negative correlation with the fixed costs as a percentage of total sales (MFXCST). This effect, however, is also incorporated in the MNTRES-variable. For more specific analyses, MNTRES could be split into a variable measuring variable cost performance, gross results (MGRRES), and a variable roughly measuring the utilization of assets, the fixed costs percentage (MFXCST).

Cost performance. For cost performance we will use controllable costs (MCSTS). MCSTS is a direct measure of a store's cost performance. The other cost indicators are less relevant for evaluating the performance of store personnel as they are largely 
outside their influence.

Personnel performance. For personnel performance we will use three indicators. First, the amount of wages as a percentage of the total sales of the store (MWAGE ). This variable indicates the impact of the wage costs on final store performance. The wage level can be slightly influenced by a store manager through his hiring policy. Second, the productivity difference (MPRODDIF ) measures the departure of a store's productivity from the standard for that specific store. This seems to be the most direct measure of personnel performance available. Third, we included the sick leave percentage (MSICKLV) as an indicator of managerial performance regarding the humane aspect of operating a store, management's performance in steering and guiding its personnel.

The table below presents the descriptive statistics for the five performance variables that were selected to describe the store performance for the fifty supermarket stores in our sample.

Table 6.16 Descriptive statistics selected performance variables

\begin{tabular}{|c|c|c|c|c|c|}
\hline Variable & Label & Mean & Std Dev & Minimum & Maximum \\
\hline MNTRES & net results & 5.74 & 1.96 & 0.98 & 8.72 \\
\hline MCSTS & controllable costs & 2.46 & 0.45 & 1.81 & 3.72 \\
\hline MAGE & wage costs & 8.55 & 0.78 & 7.16 & 11.06 \\
\hline MPRODDIF & productivity difference & 3.61 & 5.32 & -10.01 & 19.48 \\
\hline MSICKLV & sick leave & 11.77 & 3.12 & 5.78 & 19.65 \\
\hline
\end{tabular}

\section{Performance development since 1989}

The performance measures discussed above were calculated roughly as the mean performance for the first half year after the administration of the questionnaire (see above). Besides this we also calculated performance development of the stores in our sample over a two-year period by comparing the mean variable scores for the first seven periods of 1991 with the mean variable scores for the first seven periods in 1989. Consequently, these performance development scores indicate the performance development in the two years before the administration of the questionnaire moasuring the social variables (the questionnaire was sent out in december 1990). Table 6.17 presents the descriptive statistics for the performance development variables for the fifty stores.

Tuble 6.17 Performance development since 1989

\begin{tabular}{|c|c|c|c|c|c|}
\hline Variable & Labei & Hean & Std Dev & Minimum & Maximum \\
\hline ONTRES & dvip net resuits & 0.08 & 1.50 & -4.73 & 3.37 \\
\hline DCSTS & dvip controllable costs. & 10.18 & 0.51 & -0.89 & 1.55 \\
\hline DWAGE. & dulp. wage costs & 0.74 & 0.62 & -0.90 & 2.20 \\
\hline DPROODIF & dvip productivity difference & -0.62 & 6.95 & -21.34 & 14.01 \\
\hline DSICKLV & dvip sick leave. & 1.39 & 4.31. & -6.06 & 11.93 \\
\hline
\end{tabular}




\section{Correlations between the performance variables}

Table 6.18 below summarizes the bivariate correlations between the selected performance variables. It shows significant correlations between the cost, profit, and productivity-difference variables (MCSTS, MNTRES, and MPRODDIF). Furthermore, it indicates that the better performing stores have shown the largest increase in performance over the two-year period. The stores scoring high on productivity in 1991 (MPRODDIF) also show the largest increase in productivity over the last two years (DPRODDIF). Further, changes in costs and results over the past two years (DCSTS and DNTRES) are strongly related.

Table 6.18 Correlations between selected performance variables

Fearsoa Curalation Cefficients / Prob > |R| under Ho: Rhom / N $=50$

\begin{tabular}{|c|c|c|c|c|c|}
\hline & MNTRES & MCSTS & MNAGE & MPROOOIf & MSICKLV \\
\hline $\begin{array}{l}\text { WNTRES } \\
\text { net resuits }\end{array}$ & 1.00 & & & & \\
\hline $\begin{array}{l}\text { MCSis } \\
\text { controllable costs }\end{array}$ & $-0.61 * *$ & 1.00 & & & \\
\hline MUAGE & $-0.70^{x-4 \pi}$ & $0.40^{\star}$ & 1.00 & & \\
\hline $\begin{array}{l}\text { wage costs } \\
\text { MPRo00If } \\
\text { Product ivity difference }\end{array}$ & $0.33^{*}$ & .0 .45 & -0.21 & 1.00 & \\
\hline $\begin{array}{l}\text { MSICKLV } \\
\text { sick leave }\end{array}$ & $-0.25 *$ & $0.25 *$ & 0.22 & -0.17 & 1.00 \\
\hline $\begin{array}{l}\text { DNTRES } \\
\text { dvlp net results }\end{array}$ & $0.41^{k *}$ & $.0 .42 \pi i$ & $-0.31 *$ & $0.33^{*}:$ & .0 .23 \\
\hline $\begin{array}{l}\text { DCSTS } \\
\text { dvip controllable costs }\end{array}$ & $\cdot 0.30^{*}$ & $0.34 *$ & 0.22 & $-0.24 \pi$ & 0.16 \\
\hline $\begin{array}{l}\text { DWAGE } \\
\text { dvip nage costs }\end{array}$ & $-0.25 *$ & $0.39 * *$ & $0.28 *$ & $-0,3 \cdot 4^{*}$ & 0.16 \\
\hline $\begin{array}{l}\text { oppo00If } \\
\text { dvip productivity difference }\end{array}$ & 0.17 & $-0.46 \sin x$ & -0.08 & $0.67^{\text {k*k }}$ & -0.16 \\
\hline \multirow{2}{*}{$\begin{array}{l}\text { osickiv } \\
\text { dvip sick leave }\end{array}$} & -0.08 & -0.10 & 0.12 & 0.14 & $0.58 * m$ \\
\hline & DNTRES & DCSTS & DWAGE & DPROOOIF & DSICXLV \\
\hline $\begin{array}{l}\text { DWTRES } \\
\text { orlp net results }\end{array}$ & 1.00 & & & & \\
\hline $\begin{array}{l}\text { DCSTS } \\
\text { dvip controllable çosts }\end{array}$ & $-0,72 * * *$ & 1,00 & & & \\
\hline $\begin{array}{l}\text { DWAGE } \\
\text { dvip wage costs }\end{array}$ & $-0.81 \times * 4$ & $0.53^{n k \pi}$ & 1.00 & & \\
\hline $\begin{array}{l}\text { DPRODOIf } \\
\text { dvlp productivity difference }\end{array}$ & $0.43^{k *}$ & $-0.29 *$ & $.0 .54 \mathrm{kr}$ & 1.00 & \\
\hline $\begin{array}{l}\text { DSICKLV } \\
\text { dulp sick leave }\end{array}$ & 0.02 & 0.08 & .0 .18 & 0.18 & 1.00 \\
\hline
\end{tabular}

Significance levels "*: $p<0.001^{\prime \prime}: p<0.001^{*}, p<0.1$

\subsection{The context variables}

The contextual variables are the last important group of variables in this study. They represent alternative causes of performance variation, and are considered as possible determinants of culture too. The impact of the organizational context on organizational culture and climate was discussed in chapter 3 . We concluded that most of the studies relating context to culture and climate focused on the impact of subjective measures of organization or industry characteristics. Research addressing the impact of organizational level contextual variables, controlling for the industry effect, would fill a gap in the present body of knowledge on the etiology of organizational culture and 
climate. Organizational variables of specific interest are organizational size. type of control system, objective characteristics of the organization's management, and aspects of employee demography (see chapter 3). The discussion in this section focuses on the differences between the fifty supermarket stores in the sample that might be significant in the context of our study of organizational culture, climate and leadership in these organizations.

As mentioned previously, the sample in this study consists of fifty stores all belonging to one supermarket chain. This ensured that the stores were similar in many respects. The stores had a standard general image, store layout and store design; the internal organization, the rules and regulations were similar; floor personnel was trained using standardized training modules; and management was trained following an elaborate company management model. However, the stores in our sample differ on four important variables: store size, physical constraints (store logistics and store age), store demography, and market. These variables are expected to influence store performance and perceived organizational culture, climate and leadership.

Store size. The supermarket stores in our sample differ greatly in size. The largest supermarket in the sample sells more then eight times as much as the smallest store. Organizational size can be measured in a variety of ways. Physical store size can be used (square meters sales space VOB), although this is not always a good indicator of store size. Actual sales volume (gross sales) can differ between stores of the same size. The gross sales volume (MSALES) is another variable that points to store size. The sales volume is a measure of economic size, rather than physical size of a store. It partly determines the amount of employees in a store, as the amount of budgeted hours for each store depends on the expected sales volume and productivity standard for that specific store. The amount of employees is determined by the actual amount of full time equivalents used in a store (STSIZE), and the amount of parttimers and fulltimers in the store (the mean amount of hours worked by the store's employees).

In the company the sales volume of the stores was used as the basis for planning and budgeting. Therefore, gross sales (MSALES) seems to be a good indicator of the economic size of the supermarket stores in our sample. Both the number of employces and the amount of sales space are closely related to the gross sales volume. In our sample of fifty stores the number of people working in the stores, measured as the amount of fulltime equivalents (STSIZE) correlates strongly with the gross sales level $(r=0.99, p<0.0001)$. The sales level also correlates strongly with the amount of sales space $(r=0.82, p<0.0001)$. The strong correlation with STSIZE, however, opens the possibility to use number of fulltime equivalents as a measure of organizational size, which is more in line with the traditional measures of size used in studies in, for example, the Aston-tradition (Miller and Dröge, 1986:543) and might provide a more intuitive sense of size of a store as it directly relates to the number of people working 'under' the supermarket manager. Consequently, we will use the amount of fulltime equivalents (STSIZE) as indicator of store size, emphasizing the size of the social organization of the supermarket stores. 
Physical constraints. Second, we consider the aspect of physical constraints on the performance of individual stores. The stores differ in their physical layout, differences in floor space, customer routing, store image, and store logistics. The influence of these factors on store operations is reflected in the differences in the estimated standard productivity measures for the stores in the sample. Physical constraints can be operationalized by looking at the norm productivity for employees in the different stores of the supermarket chain in this study. The norm productivity (NRMPROD) for each store is determined by a central department at the head office of the supermarket chain, based on the 'handicaps' of each specific store. The norm productivity is clearly determined by more than just the size of the store. Its correlation with sales space (VOB) is insignificant $(r=0.13, p=0.37)$. Its correlation with sales volume (MSALES), however, is significant $(r=0.46, p=0.0009)$ and points to economies of scale.

Store demography. Store demography is another important organizational context variable. Demography refers to 'the composition in terms of basic attributes such as age, sex, educational level, length of service or residence, race, and so forth of the social entity under study' (Pfeffer, 1983:303). The above definition already shows that organizational demography can be operationalized emphasizing very different aspects of employees. The variables age, tenure, education, race, and sex have been most generally used as indicators of organizational demography (Pfeffer, 1983, 1985; O'Reilly et al., 1989; Tsui and Egan, 1992). Pfeffer argues that the tenure distribution, the length of service distribution in an organization, is a major descriptive: statistic of organizational demography. Most operationalizations are based on the years of service in the organization. Years of service also reflects employee's time of entry in the organization (Pfeffer, 1983, 1985). The impact of organizational demography is relatively underdeveloped area of research. The empirical evidence on the impact. of organizational demography on organizational performance is still weak.

Ideally, context variables, being demographical atributes, should be measured for each store, and not just for a store's respondents. Focusing on the demographic. variables deemed most important in previous research, the available store variabies were 'mean age of the employees' (AAGE), their 'mean number of years with the company' (COMTNR), and the 'percentage of male employees' (PMALE). For three variables, we will use the response set demographics as proxies for the store variables because these variables seem to highlight interesting aspects of the organizational demography in the context of this study: the mean level of employee education (EDUC), the average employee position in the organization (PRJOB), and the mean amount of contract hours of the employees in the store per week (WTIME). We will take a pragmatic approach and select only those demographic variables for use in the further analyses that show significant differences between stores. Table 6.19 shows the mean value for the demographic variables, the between-stores standard deviation and the F-value for the test of significant differences between stores. 
Table 6.19 Differences in demography between sample stores

\begin{tabular}{|l|l|}
\hline variable description & F-value \\
\hline AAGE average employee age & $1.92 \cdots$ \\
\hline PMALE percentage male employees & 1.15 \\
\hline COMTNR years in company & $2.77 \cdots *$ \\
\hline EDUC level of formal education (scale 1-8)† & 1.04 \\
\hline STOTNR years in store (scale 1-6) + & $2.03 \cdots$ \\
\hline PRJOB present job (scale 2-6) + & .87 \\
\hline WTIME official working time & $1.94 \cdots \cdots$ \\
\hline
\end{tabular}

Significance of the findings: "**: $p \leq 0.001^{* *}: p<0.01^{*}: \rho<0.05$

All basedi on actual store demography, except $\dagger$ : based on response set demography

The table shows that the response groups of the different stores differed significantly by age (AAGE), mean time with the company (COMTNR), mean time with store (STOTNR), and official working time (WTIME). These four demographic variables will therefore be retained in the further analyses.

Market. Finally, market differences can also be expected to be important contextual variables. The type of customer can be expected to influence store performance through differences in buying behavior. It may also influence the organizational culture, because through the frequent interaction between store employees and customers, customer expectations will be communicated directly to employees and can thus be expected to influence their work values. The impact of market differences is not the focus of this study. However, market differences will be accounted for in two ways. First, market differences are partly reflected in the organizational size variables, as the larger stores tend to attract different customers because they have a regional function, compared to a neighborhood function for the smaller stores. Second, the type of customers can be operationalized by determining the percentage ' $A$ ' to ' $D$ ' social class customers in the stores market area. The social class grouping is a standard classification used in marketing research. For example, Class A pointing at the wealthy, directors of large enterprises, most of the self-employed, staff employees of large companies, high civil servants, etc.; Class D pointing at the least wealthy, uneducated workers, the unemployed, and people on a state pension (Leeflang and Beukenkamp, 1981:365). The social class was operationalized by one variable (CSTMRS) indicating the 'average social class' of the customers in the store's market area. It was calculated as the mean of customer class ${ }^{6}$ weighted by the percentage of customers in that class in a range of two kilometers around the store. We did not measure primary and secondary competition, however, the larger stores probably have less primary competitors (offering the same product range and service) than the smaller stores.

${ }^{6}$ Social class $A=5$; class $B+=4$; class $B-=3$; class $C=2$; class $D=1$. 


\section{Descriptive statistics and correlations}

This section summarizes the descriptive statistics and the bivariate correlations for the contextual variables. Table 6.20 shows the descriptive statistics for the contextual variables.

Table 6.20 Descriptive statistics context variables

$\begin{array}{lrrrrrl}\text { Variable } & \text { N } & \text { Mean } & \text { Std Dev } & \text { Minimum } & \text { Maximum } & \text { Label } \\ & & & & & & \\ \text { STSIZE } & 50 & 56.64 & 24.26 & 15.16 & 119.68 & \text { store size (fte) } \\ \text { NRMPROD } & 50 & 248.73 & 18.03 & 207.67 & 299.75 & \text { norm productivity } \\ \text { AAGE: } & 50 & 28.14 & 2.04 & 24.12 & 34.48 & \text { average employee age } \\ \text { COMTNR } & 50 & 5.24 & 1.45 & 2.60 & 8.08 & \text { years in company } \\ \text { STOTNR } & 50 & 3.54 & 0.46 & 2.44 & 4.29 & \text { years in store } \\ \text { CSTMRS } & 49 & 2.95 & 0.35 & 2.14 & 4.15 & \text { social class customers }\end{array}$

Table 6.21 with bivariate correlations between the context variables below shows relatively weak relationships between the context variables. As already mentioned, norm productivity (NRMPROD) is related to store size (STSIZE): this relationship points to the existence of economies of scale for the supermarket stores, and to the fact that economies of scale are taken into account in determining the stores' norm productivity. Furthermore, the three demographic variables average employee age (AAGE). average tenure in the company (COMTNR), and show interesting correlations with customer-type variable (CSTMRS). In stores located in an area with more customers from a lower social class the average tenure of employees with the company is higher.

Table 6.21 Correlations for the context variables

Pearson Correlation Coefficients / Prob > $|\mathrm{R}|$ under Ho: Rho=0 / N=50

STSIZE

store size (fte)

NRTPROD

norm productivity

AAGE.

Average age employees

COMTNR

years in company

STOTNR

years in store

CSTMRS

social class customers

\section{STSIZE APMPRDO AAGE COMTNR STOTNR CSTMRS}

1.00

$0.34 * \quad 1.00$

$0.25 * \quad 0.17 \quad 1.00$

$0.05 \quad-0.31 * \quad 0.22 \quad 1.00$

$0.41 * \quad 0.15 \quad 0.31 * \quad 0.52 * * \quad 1.00$

$\begin{array}{llllll}0.04 & 0.25 * & -0.10 & -0.51 * * & -0.36 * & 1.00\end{array}$ 



\section{CHAPTER 7}

\section{THE ORGANIZATIONAL CONTEXT}

This chapter describes the findings of our empirical exploration of the impact of the organizational context on organizational performance and on organizational culture, climate, leadership and employee work satisfaction. It focuses on research questions 3 and 4 .

\section{Research question 3: 'What is the impact of the organizational context on organizational performance?' \\ Research question 4: What is the impact of the organizational context on the social variables measuring organizational culture, climate and leadership?'}

Research questions 3 and 4 are graphically presented in figure 7.1. The discussion of the research questions in this chapter will proceed as follows. First, in section 7.1, the impact of the organizational context on organizational performance is discussed. This discussion serves a practical purpose. The goal is to identify those aspects of the organizational context that have to be controlled for in chapter 8 when we investi-

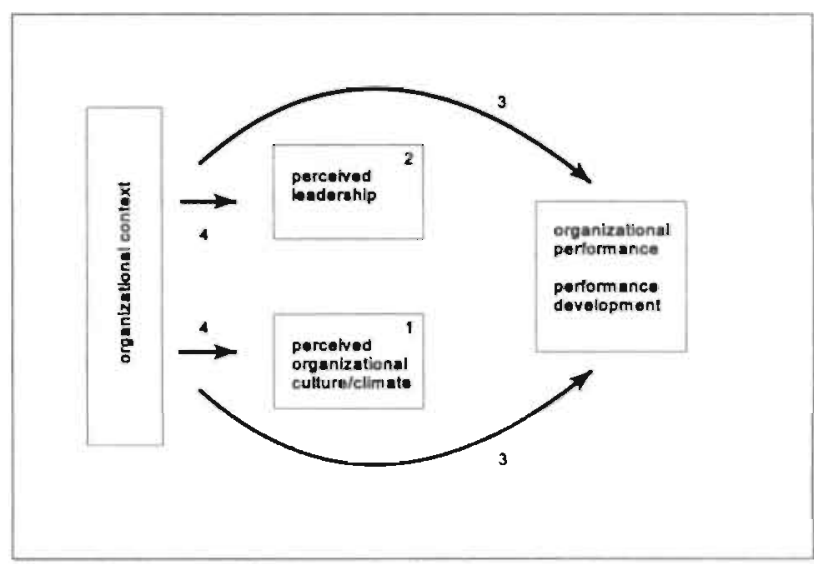

Figure 7.1 Impact of the organizational context gate the impact of organizational culture, climate and leadership on organizational performance. Then, section 7.2 reports results from the analysis of the influence of the organizational context on the social variables. The investigation of the impact of the organizational context on organizational culture and climate is the central focus of this section. Finally, section 7.3 summarizes our findings regarding the influence of the organizational context on organizational performance and the social variables.

\subsection{Organizational context and organizational performance}

The organizational context of the supermarket stores in our sample can be expected to influence the performance of the individual stores. Although the fifty stores are all of one supermarket chain, so that many aspects of the organizational context have been standardized, some aspects differ significantly between stores. In chapter 6 we identified four aspects of the context that differed between the stores and that might have a significant impact on store performance: store size, store constraints, market, and 
store demography.

The operationalizations for the organizational context were discussed earlier in chapter 6 . Store size was measured with the amount of employees working in a store, measured in fulltime equivalents (STSIZE). The store's norm productivity (NRMPROD) was the indicator for store logistics. The market context was measured by the mean customer type (CSTMRS) for the market in which the store operated. Finally, store demography was measured with the mean age of employees (AAGE), mean employee tenure with the company (COMTNR), mean employee tenure with the store (STOTNR), and the mean official working time, mean contract hours (WIIME). Store performance was measured with percentage net profit (MNTRES), variable costs percentage (MCSTS), percentage wage costs (MWAGE), productivity difference (MPRODDIF), percentage sick leave (MSICKLV), and the development of these variables since 1989 (DNTRES, DCSTS, DWAGE, DPRODDIF, DSICKLV). The correlations of the operationalizations of the four aspects of the organizational context with store performance, presented in the two tables below, show some influence of the contextual variables on store performance.

Table 7.1 Organizational context and performance

Pearson Correlation Coefficients / Prob > |R| under Ho: Rho $=0$ / N=50

\begin{tabular}{|c|c|c|c|c|c|}
\hline & MNTRES & MCSTS & MWAGE & MPRODDIF & MSICKL.: \\
\hline $\begin{array}{l}\text { STSIZE } \\
\text { store size (fte) }\end{array}$ & $0.59 * \pi \star$ & -0.17 & $-0.45^{* *}$ & 0.17 & -0.21 \\
\hline $\begin{array}{l}\text { NRMPROD } \\
\text { norm productivity }\end{array}$ & $0.65 *$ & -0.14 & $-0.82^{* * *}$ & .0 .10 & -0.17 \\
\hline $\begin{array}{l}\text { CSTMRS } \\
\text { social class customers }\end{array}$ & 0.22 & -0.02 & .0 .19 & .0 .13 & 0.03 \\
\hline $\begin{array}{l}\text { AMGE } \\
\text { average enployee age }\end{array}$ & 0.04 & $0.40^{\star \star}$ & 0.16 & -0.15 & -0.04 \\
\hline $\begin{array}{l}\text { COMTNR } \\
\text { years in company }\end{array}$ & -0.07 & -0.09 & $0.34 \pi$ & 0.20 & 0.07 \\
\hline $\begin{array}{l}\text { STOTNR } \\
\text { years in store }\end{array}$ & 0.23 & -0.10 & .0 .10 & 0.17 & $-0.36 * *$ \\
\hline $\begin{array}{l}\text { WTIME } \\
\text { average work time }\end{array}$ & -0.01 & $-0.34^{\star}$ & 0.12 & 0.11 & 0.23 \\
\hline
\end{tabular}

All correlations with a significance leveis: ${ }^{* \cdots}: p<0.001 .{ }^{*} p<0.01$ and $" p<0.10$

Table 7.1 above shows that organizational size and the productivity standard are positively correlated with final store performance (net results) and negatively with the wage percentage. The demographic characteristics of the employees are related to cost performance, the wage and sick leave percentages, but not to overall performance. In stores with older employees the controllable costs are higher. In stores with a higher average tenure with the company the wage costs are higher. Furthermore, a higher average tenure with the store is related to a lower sick leave percentage. The second table, table 7.2 below, shows the impact of the contextual variables on the performance development for our stores in the recent past. The correlations show that in the recent past the performance of the larger stores has improved significantly more than the performance of the smaller stores. The larger the store, the larger the performance increase from 1989 to 1991 . The demographical variables are correlated 
to the development of wage costs and sick leave percentages in the stores. In stores with a higher average tenure with the store there has been a relative decrease of the wage costs, indicating the influence of shared experience in a store on the effective performance of its employees. In stores with few parttimers there has been a relative increase of the sick leave percentage, possibly indicating growing performance expectations in the job, leading to higher work pressure, especially for fulltime employees.

Table 7.2 Organizational context and performance development since 1989

pearson Correlation Coefficients / Prob > |R| under Ho: Rho=0 / Number of Observations=50

\begin{tabular}{|c|c|c|c|c|c|}
\hline & DNTRES & DCSTS & DWAGE. & DPRODDIF & DSICKLV \\
\hline $\begin{array}{l}\text { STSIZE } \\
\text { store size (fte) }\end{array}$ & $0.44^{\star \star}$ & $-0.37 \star \star \star$ & $-0,43^{\star \star}$ & 0.06 & -0.11 \\
\hline $\begin{array}{l}\text { NRMPROD } \\
\text { norm productivity }\end{array}$ & 0.03 & -0.02 & 0.03 & -0.21 & -0.23 \\
\hline $\begin{array}{l}\text { CSTMRS } \\
\text { social class customers }\end{array}$ & 0.07 & -0.16 & 0.15 & -0.19 & -0.01 \\
\hline $\begin{array}{l}\text { AAGE } \\
\text { average employee age }\end{array}$ & 0.06 & -0.04 & 0.05 & -0.21 & -0.16 \\
\hline $\begin{array}{l}\text { COMTNR } \\
\text { years in company }\end{array}$ & 0.07 & 0.04 & -0.19 & 0.20 & 0.17 \\
\hline $\begin{array}{l}\text { STOTNR } \\
\text { years in store }\end{array}$ & 0.22 & -0.22 & $-0.30^{*}$ & 0.09 & -0.20 \\
\hline $\begin{array}{l}\text { WTIME } \\
\text { average work time }\end{array}$ & -0.02 & 0.05 & $0.0 ?$ & 0.17 & $0.27^{\star}$ \\
\hline
\end{tabular}

All correlations with a significance levels: $\cdots p<0.001, \cdots p<0.01$ and $" p<0.10$

From these findings we can conclude that various aspects of the organizational context are related to organizational performance. Furthermore, in the recent past larger stores have become more profitable while the demographical variables show slight correlations with wage costs and sick leave percentage.

\section{Multivariate analyses using LISREL}

The simple correlational analysis is interesting, but should mainly raise our curiosity. In chapter 6 we already showed that both the context variables and the performance variables correlated amongst themselves. Thus, it can be expected that the bivariate correlations presented in the previous section are the result of a complex set of structural relationships. To carefully measure the relationships between two focal variables it is important to control for the impact of other variables that might directly or indirectly influence the covariation of the focal variables. Multivariate approaches such as multiple regression and structural equations modelling try to evaluate the relationship between two focal variables, controlling for the influence of other variables (i.e. Cohen and Cohen, 1983; Saris and Stronkhorst, 1984). In multiple regression analysis the emphasis is on identifying the impact of a single independent variable on one dependent variable, controlling for the influences of a predefined set of other independent variables. Multiple regression analysis is a commonly used method of multivariate analysis. Structural equations analysis, especially LISREL-modelling 
(Jöreskog and Sörbom, 1989), has gained in popularity over the past decade. In structural equations analysis the hypothesized causal interrelationships of multiple dependent variables are also taken into account. A model of relationships between independent and dependent variables is specified. The outcomes of a structural equations analysis show how well the structural model fits the correlational structure of the data. Besides, the structural parameters are calculated that best reproduce the bivariate relationships between the variables in the model (as constrained by the theoretically defined model). If in the structural equations model the interrelations between the dependent variables are set to zero, the analysis resembles a multiple regression analysis (Jöreskog and Sörbom, 1989:134).

\section{Organizational context and performance}

In this section the impact of the organizational context on organizational performance is evaluated. We are mainly interested in the influence of organizational context on performance and have not formulated specific expectations for the relationships among the performance variables. Consequently, a structural equations model was specified relating the context variables to the financial and the non-financial performance indicators. As we expect that the dependent performance variables are mutually related, we let the errors for these variables correlate. The error correlations in the final model thus indicate the amount of common variation among the dependent variables that is not be explained by the independent variables in this model. The model was developed in steps. First, the store size, store constraints and market context variable customer type (CSTMRS) were related to store performance. Then, the demographic variables average age, tenure with the company, tenure with the store and average amount of contract hours were related to store performance. Finally, the significant relationships from these two analyses were included in one model that summarizes the impact of the organizational context on organizational performance. The models resulting from the first two steps in the analysis are reported in appendix 3 . Below, in table 7.3, the summary model describing the influence of the organizational context on organizational performance is shown. In calculating the final model MPRODDIF and COMTNR were left out, because if included they were not significantly related to any of the other variables in the model. The fact that the productivity difference is not determined by the objective context of the stores indicates that the norm productivity is a good indicator of the store's "handicap". As was explained in chapter 6, the productivity norm is a standard for each store indicating the expected employee productivity, considering the store's resources and market situation. Our data show that it could not be improved by taking into account any of the contextual variables evaluated in this study. In other words, our data do not show any systematic error in the calculation of the performance norm calculated for the stores by the corporate headquarters. 
Table 7.3 Impact of context and demography on organizational performance

\begin{tabular}{|c|c|c|c|c|c|}
\hline $\begin{array}{l}\text { param est } \\
\text { (t-value) }\end{array}$ & mntres & mcsts & mwage & mproddif & msicklv \\
\hline stsize & $\begin{array}{l}32 \\
(4.67)\end{array}$ & & $\begin{array}{l}-.23 \\
(3.59)\end{array}$ & & \\
\hline nrmprod & $\begin{array}{l}45 \\
(6.62)\end{array}$ & & $\begin{array}{l}-.77 \\
(12.13)\end{array}$ & & \\
\hline aage & & $\begin{array}{l}.28 \\
(3.19)\end{array}$ & $\begin{array}{l}31 \\
(5.13)\end{array}$ & & \\
\hline \multicolumn{6}{|l|}{ comtnr } \\
\hline stotnr & & & & & $\begin{array}{l}-32 \\
(2.34)\end{array}$ \\
\hline R-square & .48 & .09 & 81 & & 10 \\
\hline \multicolumn{6}{|c|}{$\begin{array}{l}\text { errors between dependent variables correlate } \\
\text { chi-square } 9 \mathrm{df}=10.67(p=.30) \\
\text { RMSEA }=.0690 \% \text { confidence interval for RMSEA }=(.0 ; .19) \text { P-test rmsea }<.05 p=.39 \\
\text { ECVI }=1.44 \text { ECVI for saturated model }=1.60\end{array}$} \\
\hline
\end{tabular}

For the fifty stores in our sample organizational size (STSIZE) has a significant impact on store performance and labor costs. Size positively influences net results as a percentage of gross sales, and is negatively related to the wage costs as a percentage of store sales. The stores' logistical situation also strongly influences store performance and labor costs. The stores' productivity standard (NRMPROD), indicating the attainable productivity level, is positively related to net results and negatively to the wage costs. Of the demographic variables, only average age (AAGE) and tenure with the store (STOTNR) have a significant impact on store performance. Average age is positively related to the level of controllable costs and the wage percentage; tenure with the store is negatively related to the sick leave percentage. Net results are not significantly affected by mean age and tenure. Lower employee turnover, indicated by longer average tenure of the employees with the store, seems to result in less sick leave in a store. The market situation as it is operationalized here (type of customers, CSTMRS) does not significantly add to the explanation of store performance.

The data show an important influence of organizational size on store performance. In essence, the supermarket stores are not very large organizations, with a work force of, on average, 57 full time equivalents. For these stores the size effect points to the existence of economies of scale and scope for the supermarket stores. Scherer and Ross: (1990) analyze scale economies in terms of three categories. Product-specific economies, associated with the volume of any single product made and sold, come from specialization and the division of labor. Plant-specific economies, associated with the total output of, in this case, a store come from expanding the size of individual processing units, such as the different food departments in a supermarket store. Finally, multiplant economies, associated with the operation of multiple stores by the supermarket company, can lead to economies with respect to, for example, physical dis- 
tribution of products to the customer, and economies of large-scale promotion and marketing. In this case the larger stores clearly benefit from product and plant-specific economies of scale. Employee tasks in the larger stores are more specialized, and larger stores can make more efficient use of the store's management assistant, computer facilities, canteen, and employee training facilities. Furthermore, one could argue that promotion and marketing activities of the supermarket organization, as well as innovations in the production process developed centrally (multiplant economies), support the larger stores better than the smaller ones. Economies of scope point to the synergy that can be attained by combining the production of more products in one operation (Scherer and Ross, 1990).

Economies of scope exist mainly in the attractiveness of the stores for the customers. Small stores carry only the basic assortment of goods. Larger stores present a wider variety of products, often with higher profit margins. Besides the higher margins on sales, larger stores attract customers more easily because of the greater choice they offer (economies of scope). In a study of retail organizations Hise et al. (1983) found a similar relationship between store size and store performance.

For the demographical variables the results seem to emphasize the importance of experience on the job and the importance of social stability for employees' well-being. The experience argument is based on the influence of average age on store performance. It runs as follows. Average age is positively related to the level of controllable costs and the wage percentage. Still, net results are not significantly affected by mean age. This might indicate that the higher (labor) costs are a direct effect of the higher cost of a more experienced and more mature labor force which compensates those higher costs with better or more efficient performance.

A simple explanation for the influence of average store tenure with the store's sick leave percentage is that both are influenced by an underlying variable, employee well-being. An alternative explanation for this relationship, however, is the social stability argument. In stores with a longer average tenure of the employees with the store the sick leave percentage is lower than in stores with a short average tenure of employees with the store. A longer average tenure with the store can be interpreted as reflecting a more stable social environment in the store. The influence of social stability is an important issue in the supermarket branche in general, where average turnover is relatively high. Social stability at the store level means clarity of role relationships and a relatively clear 'store identity.' This provides individuals, regardless of their individual tenure with the store, with a stable and relatively predictable and understandable social environment in a work situation that is rapidly developing under the pressure of technological and organizational innovations. It is important to understand that the stable social environment is defined at the organizational level. It means that the group as such has to have a relatively stable social structure.

\section{Performance development}

Likewise, the influence of the organizational context on the performance development 
of the stores over the two-year period before the measurement of the social variables was studied. First, the development of the store scores on the five performance indicators was related to organizational size, constraints and customer type; then, it was related to the demography variables; and, finally, the results of these two analyses were combined into one analysis. The combined model showed the same relationships as the separate models. Store size (STSIZE), average employee tenure with the company (COMTNR) and average employee tenure with the specific store (STOTNR) seem to influence a store's performance between 1989 and 1991. The combined model is reported in table 7.4. In the calculation of the scores for the combined model the variables measuring norm productivity and average age were left out of the analysis as these did not show any significant relationship with the performance development variables.

The larger stores show a larger improvement in their financial performance than the smaller stores. In stores with a higher average tenure with the company (COMTNR) the sick leave percentage has gone up (relative to the other stores.) In stores with a higher average tenure with the store (STOTNR) the sick leave percentage has gone down (relative to the other stores.)

Table 7.4 Impact of context and demography on performance development

\begin{tabular}{|c|c|c|c|c|c|}
\hline $\begin{array}{l}\text { param est } \\
\text { (t-value) }\end{array}$ & dntres & dcsts & dwage & dproddif & dsicklv \\
\hline stsize & $\begin{array}{l}41 \\
(3.50)\end{array}$ & $\begin{array}{l}-.36 \\
(2.71)\end{array}$ & $\begin{array}{l}-.39 \\
(3.71)\end{array}$ & & \\
\hline \multicolumn{6}{|l|}{ nrmprod } \\
\hline \multicolumn{6}{|l|}{ aage } \\
\hline comtnr & & & & & $\begin{array}{l}.32 \\
(3.71)\end{array}$ \\
\hline stotnr & & & & & $\begin{array}{l}-.43 \\
(2.82)\end{array}$ \\
\hline R-square & 18 & 13 & 16 & & 14 \\
\hline \multicolumn{6}{|c|}{$\begin{array}{l}\text { errors between dependent variables correlate } \\
\text { chi-square } 10 \mathrm{df}=6.63(p=.76) \\
\text { RMSEA }=.090 \% \text { confidence interval for RMSEA }=(.0 ; .11) \text { P-test rmsea<.05 } p=.82 \\
\text { ECVI }=1.27 \mathrm{ECVI} \text { for saturated model }=1.57\end{array}$} \\
\hline
\end{tabular}

The larger financial performance improvement in the larger stores might be due to the choice of the supermarket chain to emphasize the development of the larger stores. New techniques that increase store competitiveness are mostly designed for and implemented in the larger stores first. Most of the new technology also needs the critical mass of the larger stores to be put into productive use. These findings and their explanations are consistent with recent discussions about the benefits of larger organizations, which might be better able to reap the benefits from technological and 
social innovations in the workplace (e.g. Ritzer, 1993).

Furthermore, both average tenure with the company and average tenure with the store were related to the performance development over the last two years. As average age was not related to the performance development, this cannot be an underlying explanation for the relationships. The findings may be explained as follows. First, the positive relationship between tenure with the company and sick leave might point to a difficulty for 'old hands' to remain motivated and adapt to the relatively large changes in the supermarket work in the last decade. The recent fast developments in the supermarket work, with regard to both social and technological innovations, might be the cause of the relative increase of sick leave percentages in stores with a higher average tenure with the company. Second, the negative relationship between tenure with the store and sick leave might point to the importance of social stability and integration of employees in the organization, as discussed in the previous paragraph. It might reflect the importance of social stability of the workgroup in the midst of all these changes. However, the relationships of tenure with company and tenure with store with the sick leave variable have to be interpreted with caution. Only the relation between STOTNR and SICKLV is supported by a significant zero-order correlation.

\section{Summary: the impact of context on performance}

What now can we conclude from the data with regard to research question 3 about the impact of the organizational context on organizational performance and the organizations' performance development? First, the data indicate the existence of economies of scale and scope for the supermarket stores. The larger stores perform better. Furthermore, the performance gap between the small and the large stores seems to be growing, possibly as a consequence of the greater suitability of the large stores for an economical introduction of technological and social innovations in the workplace. Finally, the store demography variables are not strong determinants of store performance. Still, the relationships with performance seem to reflect the benefits of experience on the job and the importance of socially stable work groups for employee wellbeing on the job.

\subsection{Organizational context and the social variables}

The organizational context does not only influence organizational performance. It can also be expected to have an impact on organizational culture. In section 3.3 we concluded that previous studies have indicated an influence of industry and organization variables on organizational culture and climate. Organization-level variables that showed relationships with organizational culture and climate are, for example, organizational size, size and type of control systems, characteristics of the management team, and employee demography. In chapter 3 we also noted that there is a lack of studies relating aspects of the objective organizational context to aspects of the perceived organizational climate. Furthermore, empirical comparative studies often worked with multi-industry samples, making it difficult to isolate the influence of 
organizational variables on aspects of organizational culture and climate. As in this study the industry context is similar for all organizations, it is possible to evaluate the impact of the organizational context on the social variables. Thus section 7.2 addresses research question 4: 'What is the impact of the organizational context on organizational culture, climate, work satisfaction and leadership?' We will try to answer this question in this section for the organizational context variables that differ significantly between the stores in our sample of supermarkets: store size, store constraints, market context, and the four variables measuring store demography. As we study the impact of the organizational context on the social variables, we will also pay attention to the interrelationships between the various groups of social variables.

In table 6.11, we already showed that the social variables were interrelated. The correlation matrix shown below in table 7.5 reports the bivariate correlations of organizational context with the social variables. The table reveals that organizational size (STSIZE) and the demographic variables tenure with company (COMTNR) and tenure with store (STOTNR) are clearly related to some of the social variables.

Table 7.5 Correlations between context, culture, climate and leadership

Pearson Correlation Coefficients / Prob $>|R|$ under Ho: Rho=0 / Number of Observations

\begin{tabular}{|c|c|c|c|c|c|c|c|c|c|}
\hline & COLDS & ISLOS & CHLDS & ECUL & OCUL & TCOM & INNO & $\mathrm{GCOM}$ & SATIS \\
\hline $\begin{array}{l}\text { SISIZE } \\
\text { store size (fte) }\end{array}$ & 0.11 & $0.44^{* *}$ & $0.29 *$ & 0.09 & -0.05 & $0.26{ }^{\star}$ & $0.42^{\star \star}$ & 0.02 & 0.02 \\
\hline $\begin{array}{l}\text { NRMPROOD } \\
\text { norm productivity }\end{array}$ & 0.12 & 0.21 & 0.22 & 0.23 & $0.24^{\star}$ & 0.22 & $0.25 *$ & -0.04 & 0.09 \\
\hline $\begin{array}{l}\text { CSTMRS } \\
\text { social class customers }\end{array}$ & 0.08 & -0.03 & 0.12 & -0.13 & $0.24 *$ & -0.07 & 0.21 & -0.05 & 0.15 \\
\hline $\begin{array}{l}\text { ASE: } \\
\text { average employee age }\end{array}$ & 0.04 & 0.05 & 0.01 & 0.13 & -0.03 & 0.03 & 0.06 & -0.21 & -0.03 \\
\hline $\begin{array}{l}\text { COMTNR } \\
\text { years in company }\end{array}$ & -0.06 & 0.09 & .0 .07 & 0.14 & $-0,38^{* *}$ & -0.00 & -0.12 & 0.12 & $-0.32 *$ \\
\hline $\begin{array}{l}\text { STOTAR } \\
\text { years in store }\end{array}$ & 0.08 & 0.20 & 0.11 & $0.35^{*}$ & -0.16 & $0.28 *$ & 0.12 & 0.12 & -0.08 \\
\hline $\begin{array}{l}\text { WTIME } \\
\text { average work time }\end{array}$ & 0.04 & -0.23 & -0.01 & 0.07 & -0.00 & .0 .01 & -0.14 & $0.31 *$ & -0.14 \\
\hline
\end{tabular}

All correlations with a significance levels: $\cdots$ p p<0.001, " $p<0.01$ and $" p<010$

\section{Multivariate analyses using LISREL}

As with the previous analysis of the relationship between organizational context and store performance, the bivariate correlations are only the starting point of the analysis. Again, it can be expected that the bivariate correlations are the result of a complex set of structural relationships. Only, in studying the impact of organizational context on the social variables, the analysis will be more complicated. Here we have reason to believe there are also causal relationships among the social variables. Based on our discussion of the concepts in chapter 3 and 4, we expect that (i) leadership variables will influence organizational culture, climate, and work satisfaction, (ii) organizational culture may influence organizational climate and work satisfaction and, (iii) organiza- 
tional climate may influence work satisfaction. In this section we will therefore build a model that best reflects the general influence of the organizational context on the social variables, also considering the expected relationships between the social variables. Figure 7.2 represents our general expectations of the relationships between the concepts that guide our analysis in this chapter.

Two separate analyses were done: the first uses consideration and initiating structure as leadership indicators (model

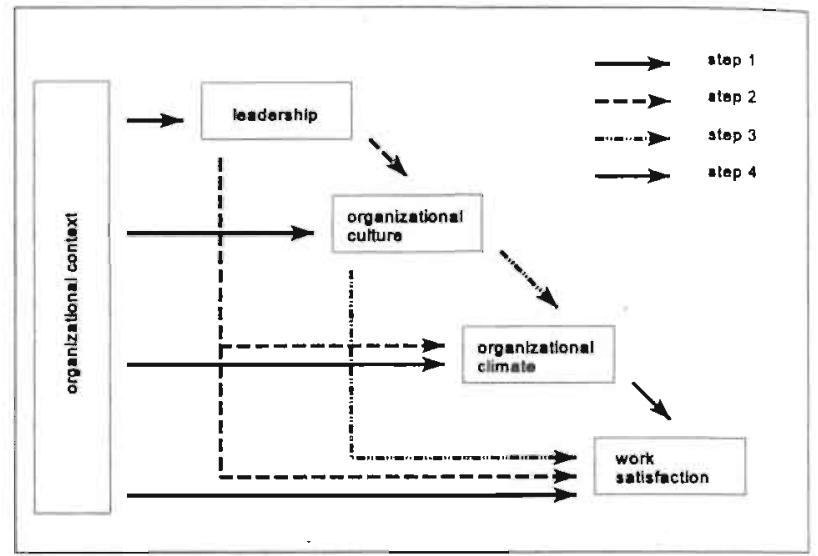

Figure 7.2 Relationships between the social variables 1); the second introduces charismatic leadership as the sole leadership variable (model II). The two analyses were done separately, because charismatic leadership correlates strongly with both other leadership dimensions. These relationships influenced the analyses. Models including the three leadership variables fail to fit the data. Thus, two models were developed to describe the relationships between organizational context, leadership, culture, climate and work satisfaction. The models differ with regard to the operationalization of the leadership construct.

Our analysis is exploratory. As in section 7.1, the structural equations-models were developed step-wise. The steps were based on our expectations for the relationships between the social variables (see figure 7.2). First, in step 1, the influence of the organizational context on the four groups of social variables was estimated. Subsequently, in step 2, the context, leadership and culture variables were combined in one analysis. Then, in step 3 , the climate variables were added. Finally, in step 4, the satisfaction variable was introduced. After each step the relationships that proved insignificant were removed from the model. In each new step, after adding a new group of variables, the relationships found in the previous steps were evaluated again. The detailed outcomes of the four steps are presented in appendix 4 . The final models describing the influence of the organizational context on the social variables are discussed below.

\section{Two models relating context and social variables}

The outcomes of model I and II show many similar results. As could be expected on the basis of the strong correlation between consideration and charismatic leadership, the effect of these two variables in the models is very much alike. The effect of inititating structure, however, is very different from that of the other two leadership variables. Therefore only model I is presented in the text. Figure 7.3 summarizes the 
structural relationships between the organizational context variables and the social variables using the consideration / initiating structure operationalization of leadership. A similar figure summarizing the outcomes of the analyses using the charisma-variable as operationalization of leadership (model II) is presented at the end of appendix 4. In the text the outcomes for both models are discussed.

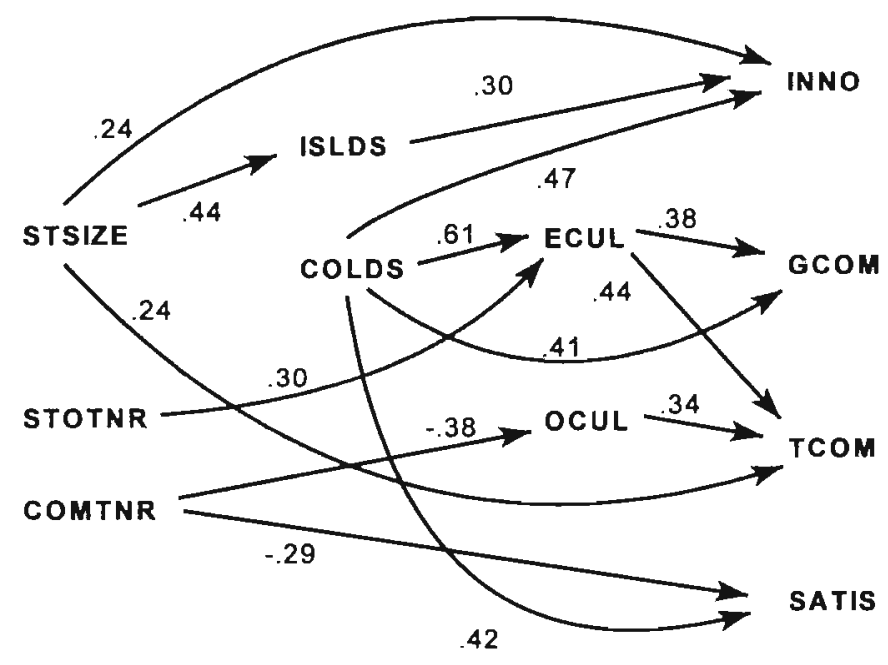

Figure 7.3 Organizational context and the social variables, model 1

The analyses show that store size is clearly related to the social variables, although its effect differs slightly between the models. It shows a notable impact on structuring leadership and the climate variables innovation and task communication. The demographic variables tenure with the company and tenure with the store influence the social variables consistently, showing an influence on both cultur variables and employee work satisfaction. Both models also show significant relationships among the social variables. The leadership variables influence organizational culture, climate and work satisfaction, and the organizational culture variables influence organizational climate and work satisfaction. These findings contribute to our knowledge about the social variables in organizations in a number of ways.

Organizational size. First, the influence of organizational size on the social variables is consistent with the findings of earlier research on the influence of organizational size on perceived organizational climate (Payne and Pugh, 1976) and organizational culture (Hofstede et al., 1990). Furthermore, because in this study the industry factor 
was fixed, organizational size can be seen as a relatively uncontaminated indicator of organizational structure, tentatively answering to Payne and Pugh's call for more attention to the relationship between objective aspects of the organizational structure and measures of perceived organizational climate.

In line with previous research on the influence of organizational size on organizational structure (e.g. Mintzberg, 1979:230) the larger stores show (i) more specialized and more formalized work systems, (ii) job descriptions are more precise and more specialized, (iii) there are more formal rules and procedures and (iv) the formal organization structure is more complicated and more important. In a typical small store, the work might be divided between no more than two departments, each headed by a department manager, whereas larger stores are managed by a team of five to six department managers, headed by the store manager. Hierarchically, the store manager becomes more distanced from the daily work in the larger stores as the operational management is delegated to the department managers. Also, the departments in the larger stores operate more independently. Where small stores rely on informal communication, the larger stores often have formal, scheduled, meetings at store level and departmental level. Considering store size (as an indicator of formal organizational structure), three relationships of organizational size with the social variables are interesting in this respect.

First, our findings indicate that store managers in the larger stores are perceived as more structuring than their counterparts in the smaller stores. Supermarket manager charisma and consideration seem to be unrelated to store size. As initiating structure does show a significant relationship with store size, this can be attributed to two underlying processes. First, there may be more demand for explicit (obvious) structuring behavior on the part of the store manager in the larger stores as there is a greater need for coordination in larger organizations. Second, the employees' perception of their supermarket managers initiating structure leadership may be influenced by the quality and pervasiveness of the formal organizational structure. In the larger stores the store manager is responsible for (and can be perceived as the initiator of) much structure, rules and regulations that come with the specialization and formal structuration of the work in the larger supermarket stores. As these formal systems are mostly task oriented, the store manager benefits most from them in his structuring role.

Second, our findings indicate that the larger stores provide more room for innovation. This finding can be explained in three ways. It might be due to the clear organization and structuration of the work in the larger stores. This clarifies overall goals and objectives of the work and thus communicates more clearly which aspects of organization are and which are not open for discussion. Furthermore, the larger stores have more elaborate formal communication structures that are intended to stimulate the creative flow of ideas related to performance improvement in the store. A third explanation points to the relative suitability of the larger stores for introducing the recent innovations. The larger stores were the first to benefit from technological innovations such as barcode scanning (Adema et al., 1984) and computerized point-of-sale information systems to enhance store decision making. The larger stores most clearly benefited 
from these relatively large capital investments and possessed a formal organizational infrastructure supporting the efficient installation of the new systems.

Finally, our findings indicate that the increased specialization and the resulting clear delineation of work tasks in the larger stores enhances the perceived quality and clarity of the task communication.

Organizational demography. As data regarding the influence of organizational demography on organizational culture and climate are scarce (see chapter 3 ), our findings can be seen as first empirical indications of the existence of this influence. Our data show that average tenure with the company (COMTNR) is negatively related to the store scores on perceived openness and work satisfaction. Average tenure with the store (STOTNR) is positively related to the perceived attention for people in the work place (employee orientation) and through this variable to the perceived general communication and task communication in the store.

The influence of average store tenure points out the importance of a stable social structure in the store for the employee orientation of the organizational culture and indirectly for the employees perception of the quality of the general communication and task communication in their store. The argument is congruent with the one made before, explaining the influence of average store-tenure on sick leave percentages: a longer average tenure with the store can be interpreted as reflecting a more stable social environment in the store, resulting in a more employee oriented culture, better communication and less sick leave.

The negative influence of average company tenure on openness and work satisfaction might indicate the growth of subcultures in the organization and a difficulty for the older employees to cope with the increasingly competitive and complex work environment in the supermarket stores and the relatively fast technological development of supermarket work in the recent years.

Leadership and organizational culture as context variables. Both leadership and organizational culture can be seen as independent / contextual variables influencing the other social variables. Of the leadership variables both consideration leadership and charismatic leadership show a clear influence on organizational culture, climate and work satisfaction. Structuring leadership only influences the innovation climate. These findings are consistent with the theoretical descriptions of the roles of consideration and charismatic leadership described in chapter 4 as influencers of the organization's social environment and the employees' understanding of it.

In our analysis the organizational culture also showed an influence on organizational climate and work satisfaction. As we described in chapter 3, previous research mostly ignored the differences between the concepts of organizational culture and organizational climate, let alone investigated the relationships between the two. In this study the relationships were relatively stable. In open cultures task communication was perceived as better. In employee oriented cultures the general communication and task communication variables were evaluated more favorably. One could argue that both 
aspects of organizational culture (reflecting the premises of behavior of the organization members) positively influence communication in the organization, influencing the behavior of both senders and receivers of information.

Concluding we can say that these findings add to our understanding of the influence of organizational size and demography on the social variables. Notable are the impact of organizational size on initiating structure leadership and the different effects of store-tenure and company-tenure on the social variables. Furthermore the evidence showed an influence of leadership and organizational culture on the other social variables. The outcomes of the analyses from this section should be interpreted in two ways. First, the existence of relationships between the organizational context, leadership, culture, climate and work satisfaction strengthens our - mostly theoretically based - belief in substantial relationships between these concepts. Second, the specific relationships between the variables measuring organizational context, leadership, culture, climate and work satisfaction point to possible specific relationships that should be studied in more detail in future research.

\subsection{Concluding remarks}

What can we now conclude about the impact of organizational context and its importance in this study?

In section 7.1 it was shown that four aspects of the organizational context significantly influence organizational performance (store size, constraints, average employee age, and mean tenure with the store). The data indicate the existence of economies of scale and scope for the supermarket stores. Furthermore, the performance gap between the small and the large stores seems to be growing, possibly as a consequence of the greater suitability of the large stores for an efficient introduction of technological and social innovations in the work place. The influence of employee age and mean tenure with the store seems to point to the benefits of experience on the job and the importance of socially stable work groups for employee well-being in the job.

Section 7.2 related the organizational context variables to the social variables. Organizational size, as an indicator of the strength of the formal organizational structure, showed significant relationships with the leader's structuring behavior and the innovation climate in the stores. This could be explained by the guiding, facilitating and communication-stimulating role the formal organizational structure can fulfill in larger organizations. This finding is consistent with previous research (Payne and Pugh, 1976) and recent theorizing on rationalization and modernization (Ritzer, 1993).

The influence of employee demography on the social variables indicates the importance of a stable social structure in the store for an employee oriented culture and the perceived quality of the general and task communication. These exploratory findings contribute to the underdeveloped empirical evaluation of the influence of organizational demography on the social variables, and indicate the importance of more research on these relationships. 
Finally, leadership and organizational culture can also be seen as independent / contextual variables influencing the other social variables. Our findings provide empirical evidence for the influence of leadership and organizational culture on the perceived social work environment in organizations, expected on the basis of our literature discussion in chapter 3 and 4 .

These findings have two implications for the analysis of the impact of the social variables on organizational performance. First, studying the impact of the social variables on organizational performance without controlling for the organizational context variables is not sufficient. Any relationship found might be interpreted as spurious, induced by the direct influence of a context variable on both the social variable and organizational performance. Second, studying the impact of the social variables on organizational performance without controlling for the relationships among the social variables i.e., the influence of leadership and organizational culture on the other social variables, presents a similar problem of interpretability of the results. 



\section{CHAPTER 8}

\section{THE SOCIAL VARIABLES AND ORGANIZATIONAL PERFORMANCE}

This chapter focuses on the impact of organizational culture, climate and leadership on organizational performance. Where the previous chapter focused on antecedents of organizational culture, climate, leadership and employee work satisfaction, the present chapter concentrates on the effects of the social variables on organizational performance. Like in chapter 7 our expectations are general. We expect an impact on performance, but at the level of the specific indicators our analysis is exploratory. The focus is on the research questions 5 and 6 (see also figure 8.1).

\section{Research question 5: 'How do the social variables influence the various indicators of bottom line organizational performance which is fully attributable to the organizational units under study?'}

Research question 6: 'Is there an effect of the leadership dimensions on bottom line organizational performance?'

As explained in chapter 3 and 4 there is a lack of quantitative empirical studies relating leadership and organizational culture to bottom line organizational performance. Most theories of leadership and organizational culture argue that both have an important impact on the performance of organizations. These assertions, although well argued, are seldomly backed up with empirical evidence. Furthermore, the studies that did investigate this relationship empirically mostly focused on one or two indicators of performance, missing the chance to investigate the differential impact of the various aspects of leadership,

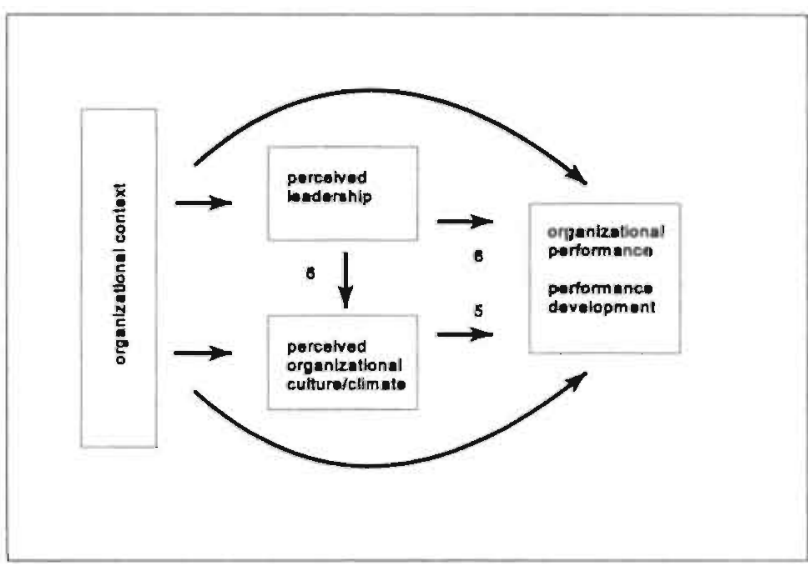

Figure 8.1 Impact of the social variables culture and climate on different aspects of performance. The aim of this study was to contribute in filling the void of empirical substantiation of these general theories about the impact of leadership and organizational culture by exploring the empirical relationships between organizational context, organizational demography, social variables, and organizational performance. This chapter describes the different ways in which the social variables influence organizational performance.

Section 8.1 focuses on substantiating the existence of a general influence of the social variables on organizational performance, on top of the influence of the organiz- 
ational context on store performance as evidenced in section 7.1. The social variables are related to performance variables measuring both average store performance and the stores' performance development over the two years before the measurement of the social variables. As we expect the social variables to be relatively stable in time, changing only slowly, the social variables can be assumed to have influenced the stores' performance development in the recent past. Section 8.2 describes the outcomes of a more detailed analyses of the relationships between the social variables and organizational performance, also taking into account the relationships among the social variables as modeled in section 7.2. In this section the model developed in section 7.2 is extended by adding the performance variables. In section 8.3 the results are discussed in detail. First, the impact of leadership on organizational performance is discussed. Second, we turn to the impact of organizational culture, climate, and work satisfaction on organizational performance. Finally, the influence of the social variables on the performance development in the stores in the recent past is evaluated. In section 8.4 our findings regarding the influence of the social variables on organizational performance are summarized and related to the research questions.

\subsection{The social variables and organizational performance}

In this section we focus on substantiating the existence of a general influence of organizational culture, climate and leadership on organizational performance. Table 8.1 shows the bivariate correlations of the social variables with organizational performance and performance development.

Table 8.1 The social variables and performance

\begin{tabular}{|c|c|c|c|c|c|c|c|c|c|c|}
\hline & MNTRES & MCSTS & MWAGE & MPROODIF & MSICKLV & DHTRES & OCSTS & DWAGE & DPRODOIF & DSICKLVV \\
\hline CHLDS & $0.56^{* \star * \star *}$ & $-0,47^{\star k \star \star}$ & $-0.32^{\star}$ & 0.21 & -0.22 & $0.41 \approx$ & $-0.43^{* k}$ & .0 .15 & 0.13 & -0.13 \\
\hline COLDS & $0.39 k *$ & $-0.36^{\star}$ & -0.17 & $0.25 *$ & -0.18 & $0.31 *$ & $-0.45^{k * k}$ & .0 .11 & 0.11 & -0.05 \\
\hline ISLOS & $0.32^{\star}$ & -0.21 & $-0.27 \star$ & 0.06 & -0.11 & $0.34^{*}$ & $=0.20$ & $-0.31 *$ & 0.21 & -0.13 \\
\hline ECUL & $0.30^{*}$ & $-0.32^{*}$ & -0.16 & 0.14 & $-0.27^{\star}$ & $0.27 *$ & $-0.26 *$ & -0.21 & 0.20 & -0.07 \\
\hline OCUL & 0.20 & .0 .10 & $\cdot 0.21$ & 0.03 & $-0.32 *$ & 0.00 & -0.05 & 0.15 & -0.13 & $-0.31 *$ \\
\hline TCOM! & $0.44^{\star \star}$ & $-0.35^{\star}$ & $-0.31 *$ & $0.37 * x$ & $-0.30 *$ & 0.21 & $-0.24^{\star}$ & -0.14 & 0.21 & -0.05 \\
\hline INNO & $0.47 * * \star$ & $-0.28 *$ & $.0 .30 *$ & 0.04 & -0.23 & $0.44^{x-\pi}$ & 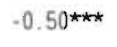 & $-0.29 \star$ & 0.03 & -0.16 \\
\hline GCOMI & $0.33^{*}$ & $-0.58^{* \star *}$ & -0.13 & $0.30 *$ & -0.27 * & $0.35^{*}$ & $-0.28 *$ & $-0.24^{\star}$ & $0.36 *$ & -0.04 \\
\hline SATIS & $0.25 *$ & -0.15 & -0.22 & 0.16 & $-0.29 \star$ & 0.16 & $-0.26^{*}$ & -0.00 & 0.05 & -0.14 \\
\hline
\end{tabular}

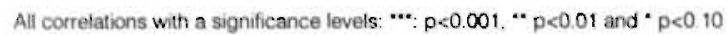

These correlations seem to indicate a possible relationship between the social variables and organizational performance. However, in chapter 7 we studied the influence of the store context and demography on store performance. The investigation showed 
a clearly significant influence of store size, constraints and employee demography on organizational performance. These contextual variables were also shown to influence the social variables, raising the possibility of spurious direct relationships between the social variables and organizational performance. For our analysis here, this means that these contextual and demographic variables need to be statistically controlled for in a study of the influence of the social variables on store performance. Practically, this means that all differences in store performance that are attributable to other factors than leadership, organizational culture, organizational climate and employee work satisfaction will be 'removed' from the analysis before we start investigating the influence of the social variables on performance. This analysis then evaluates whether adding the social variables to the model increases the percentage of explained store performance variation. Most generally we can state that any relationship between the social variables and performance indicates that the social variables are important for organizational performance, as we control for the impact of organizational context and demography, and the stores resemble each other in most different respects. This general analysis is performed in this section.

The models analyzing the impact of the organizational context on organizational performance and organizational performance development described in chapter 7 (table 7.3 and 7.4 respectively) were used as null-models. As an example, table 8.2 shows the results of adding charismatic leadership as an explanatory variable to the null-model explaining average store performance. The outcomes reveal an increase in the explained variance for both net results and controllable costs of .18. These increases are reported in table 8.3.

Table 8.2 Additional explanatory effect of charismatic leadership

\begin{tabular}{|c|c|c|c|c|c|}
\hline \multicolumn{2}{|c|}{ parameter estim ( $t$-value): } & \multicolumn{4}{|c|}{$\begin{array}{l}\text { outcomes null-model } \\
\text { outcomes null-model + charisma as explanatory variable }\end{array}$} \\
\hline & mntres & mosts & mwage & mproddif & msickiv \\
\hline stsize & $\begin{array}{l}32(4.67) \\
28(4.31)\end{array}$ & & $\begin{array}{l}-23(3.59) \\
-21(3.50)\end{array}$ & & \\
\hline nrmprod & $\begin{array}{l}45(6.62) \\
47(7.45) \\
\end{array}$ & & $\begin{array}{l}-.77(12.13) \\
-.82(13.94)\end{array}$ & & \\
\hline aage & & $\begin{array}{l}.28(3.19) \\
.30(3.40)\end{array}$ & $\begin{array}{l}31(5.13) \\
30(5.27)\end{array}$ & & \\
\hline comtnr & & & & & \\
\hline stotnr & & & & & $\begin{array}{l}-.32(2.34) \\
-.32(2.33)\end{array}$ \\
\hline chlas & $31(4.14)$ & $-.39(3.60)$ & - & - & - \\
\hline $\mathrm{R}^{2}$ & $\begin{array}{l}.48 \\
66\end{array}$ & $\begin{array}{l}.09 \\
.27\end{array}$ & $\begin{array}{l}81 \\
.82\end{array}$ & & $\begin{array}{l}.10 \\
.11\end{array}$ \\
\hline Delta- $A^{2}$ & .18 & 18 & .01 & & .01 \\
\hline
\end{tabular}


Table 8.2 Additional explanatory effect of charismatic leadership (continued)

\begin{tabular}{rll|}
\hline & null-model & null-model + charisma \\
Chi-square $=$ & $10.67 \mathrm{df}=9(\mathrm{p}=30)$ & $17.08 \mathrm{df}=16(p=38)$ \\
RMSEA $=$ & .06 & .04 \\
$90 \%$ confidence interval for RMSEA $=$ & $(.0 ; .19)$ & $(.0 ; .15)$ \\
P-test rmsea $\angle .05 p=$ & .39 & .50 \\
ECVl $=$ & 1.44 & 2.16 \\
ECVI for saturated model $=$ & 1.60 & 2.50 \\
\hline
\end{tabular}

The analyses were exploratory, in the sense that we had no previously set assumptions regarding the specific relationships of the social variables with performance in the model. We investigated the relationships of the social variables with all performance indicators. Insignificant relationships were removed from the models. Table 8.3 shows, for each dependent variable, the amount of extra variance explained by the addition of each single social variable to the models.

Table 8.3 Increase in explained performance variance

\begin{tabular}{|c|c|c|c|c|c|c|c|c|c|c|}
\hline \multicolumn{11}{|c|}{ Increase in $R^{2}$} \\
\hline & MNTRES & MCSTS & MWAGE & MPROOOIF & MSICKLV & DNTRES & DCSTS & DWAGE & DPROOOIF & DSICKLY \\
\hline CHLOS & .18 & .18 & & & & .08 & .11 & & & .01 \\
\hline COLDS & .11 & .08 & & & & .06 & .16 & .02 & & .01 \\
\hline \multicolumn{11}{|l|}{ ISLDS } \\
\hline ECUL & & .05 & & & & & & & & \\
\hline OCUL & & & & & .15 & & & & & .01 \\
\hline TCOM & .11 & .09 & & .08 & & & & & & \\
\hline INNO & 10 & .07 & & & & & .07 & & & \\
\hline GCOM & .14 & .24 & & & & .02 & & & & \\
\hline SATIS & & & & & .11 & & & & & \\
\hline
\end{tabular}

The table shows that there is a clear relationship between the social variables and store performance. After accounting for the variance that could be explained using the contextual and demographic variables, the social variables still add, in varying degrees, to the explanation of the variance in the performance indicators. Furthermore, the table presents a general overview of the different ways in which the social variables influence store performance. The leadership variables and the organizational climate variables have the strongest impact on the overall financial measures of store performance. Task communication is the only variable related to the productivity difference. Openness and work satisfaction are the only variables that are significantly related to the store's average sick leave percentage. The leadership variables only help to explain the variation in sick leave development scores for the stores in our sample. 


\subsection{Two models explaining the influence of the social variables on organiz- ational performance}

Section 8.2 describes the outcomes of a more detailed analysis of the relationships between the social variables and organizational performance. Chapter 7 showed that leadership and organizational culture can also be seen as independent variables influencing the other social variables. Thus, different social variables may influence different aspects of performance directly, or indirectly through other social variables. To investigate these direct and indirect relationships of the social variables with store performance, the two models describing the retationships among the social variables (developed in section 7.2) were used as base-line models. As was explained in chapter 7, the models differ with regard to the operationalization of leadership. In model I leadership is measured as consideration and initiating structure. In model II the charisma-variable is used as leadership operationalization. For each model the influence of the social variables on performance was analyzed for each performance variable separately. This resulted in twenty separate analyses investigating the influence of the social variables on each performance or performance development variable.

Four figures report the outcomes of the analyses and describe the influence of the social variables on organizational performance. Two figures summarize the impact of the social variables on store performance and performance development using model I (the consideration / initiating structure leadership model) as base-line model. The other two figures summarize the impact on store performance and performance development using model II (the charisma model). As in chapter 7, the outcomes of model I and model II show many similar results. Again, this could be expected on the basis of the strong correlation between consideration and charismatic leadership. Therefore, like in chapter 7 , only the figures summarizing the outcomes of the analyses using model I are presented in the text (figure 8.2 and 8.3). The other two are presented in appendix 5 . In the text the outcomes of both models are discussed. For ease of reference, table 8.4 clarifies the contents of the four figures and where to find them.

Table 8.4 Figures summarizing the outcomes of the analyses

\begin{tabular}{|c|c|c|}
\hline $\begin{array}{l}\text { Impact of social variables on (controlling for } \\
\text { organizational context): }\end{array}$ & $\begin{array}{c}\text { model I } \\
\text { Consideration / initiating structure }\end{array}$ & $\begin{array}{l}\text { motjel II } \\
\text { charisma }\end{array}$ \\
\hline Mean performance scores & $\begin{array}{l}\text { figure } 8.2 \text { : } \\
\text { net results } \\
\text { controllable costs } \\
\text { (wage percentage) } \\
\text { productivity difference } \\
\text { sick leave percentage }\end{array}$ & $\begin{array}{l}\text { figure A5.1 (appendix 5): } \\
\text { net results } \\
\text { controllable costs } \\
\text { (wage percentage) } \\
\text { productivity difference } \\
\text { sick leave percentage }\end{array}$ \\
\hline Performance development recent past & $\begin{array}{l}\text { figure } 8.3 \text { : } \\
\text { change in net results } \\
\text { change in controllable costs } \\
\text { (change in wage percentage) } \\
\text { change in productivity difference } \\
\text { change in sick leave percentage }\end{array}$ & $\begin{array}{l}\text { figure A5.2 (appendix 5): } \\
\text { charige in net results } \\
\text { change in controllable costs } \\
\text { (change in wage percentage) } \\
\text { change in productivity difference } \\
\text { change in sick leave percentage }\end{array}$ \\
\hline
\end{tabular}

The detailed results of the analyses are presented in the following paragraphs. In gen- 
eral adding the performance variables to the structural models developed in section 7.2 did not change the structural relationships between the social variables. Two parameters became insignificant. In the consideration / initiating structure model (model I) the influence of store size on the climate variable readiness to innovate disappeared. The influence of size on innovativeness became completely indirect with initiating structure leadership as the intermediate variable. In the charisma model (model II) the influence of tenure on work satisfaction proved insignificant. The relationships of the social variables with performance showed that all performance variables were influenced by the social variables, except for the wage costs variable. The wage costs, and also their development in the recent past, were strongly influenced by the contextual variables store size, store constraints, and the average age in the store $(R$-square $=0.83$ ). The social variables did not significantly contribute to the explanation of the wage costs variable, therefore it is not included in the four summary figures. In the remainder of this section the influence of the social variables on the mean store performance variables and the stores' performance development variables will be discussed separately.

\section{Store performance and the social variables}

This paragraph presents the results of the analyses relating the social variables to store performance, taking into account the influences of the relevant contextual variables. Figure 8.2 shows the results of the analyses using model I (the consideration / initiating structure model). The model statistics for model I are presented in appendix 5 .

Net resuits of the stores were influenced by the store context, but the social variables also contributed to the explanation of the variation in performance scores between the stores. In both models the level of general communication positively influenced the stores' net results. For model I general communication was the only variable that was directly influencing the stores' net results. In model II employee orientation and charismatic leadership show both direct and indirect influences (through general communication) on the net results. In both models the variation in the level of controllable costs was influenced by the context and the social variables in a similar fashion. The context variable average employee age was positively related to the level of controllable costs. The level of general communication negatively influenced the level of controllable costs, indicating that in stores where the general communication was rated to be better, the controllable costs were lower. In both models the productivity difference was also positively influenced by the quality of perceived task communication. The sick leave percentage in the stores was influenced by the organizational context and the organizational culture. A higher average tenure with the store, reflecting the relative stability of the organization's social structure, was related to lower sick leave percentages in the stores. Of the social variables the culture variable openness was influencing the sick leave percentage. In stores with an open culture the sick leave percentage was significantly lower than in stores with a closed culture. 


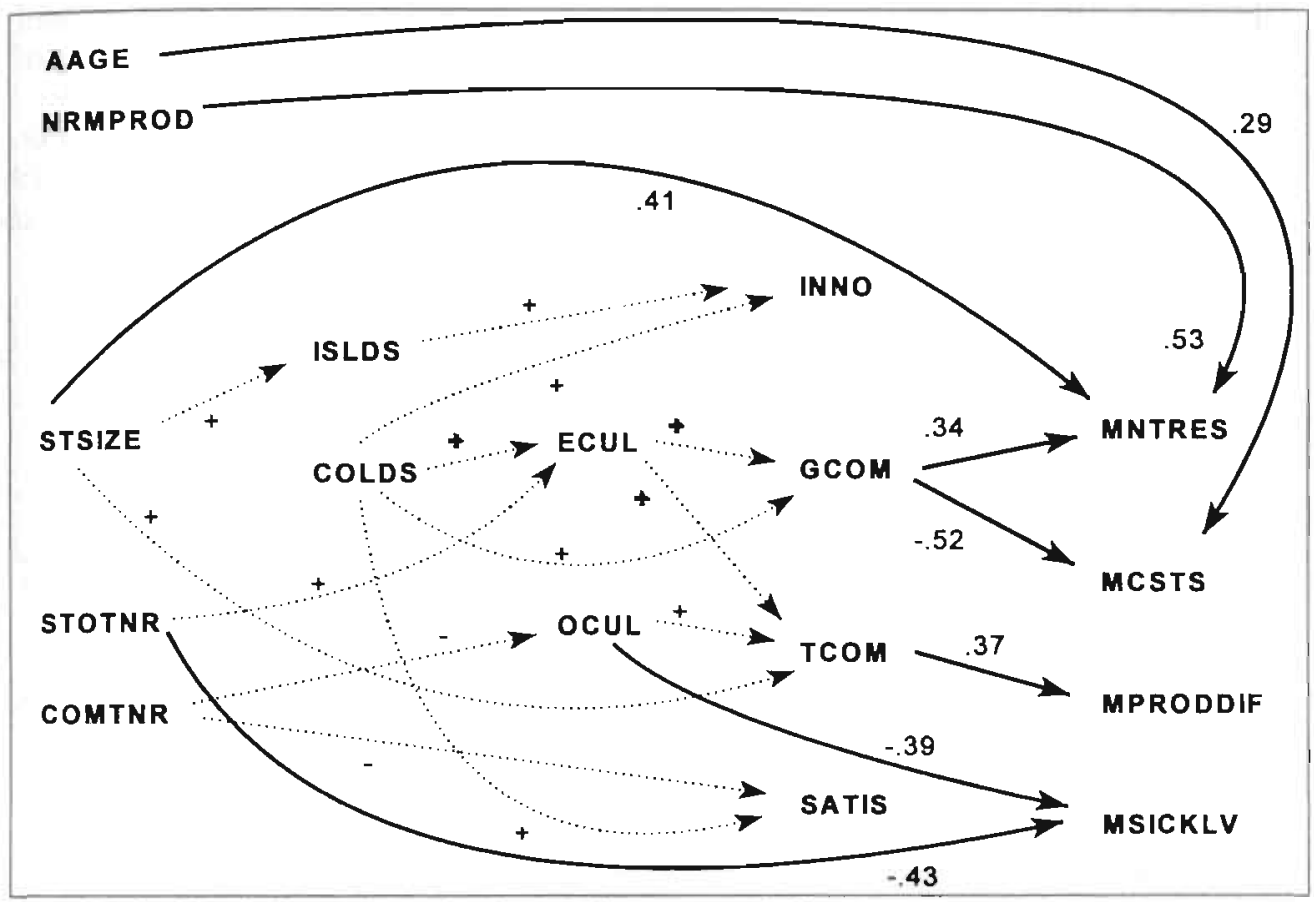

Figure 8.2 Social variables and organizational performance: model I

\section{Store performance development and the social variables}

After describing the influence on present performance, this paragraph focuses on the results of the analyses relating the social variables to the stores' performance development over the two years before the measurement of the social variables, taking into account the relevant contextual variables. As explained before, figure 8.3 shows the results of the analyses using model I. The outcomes for the charisma model (model II) are again presented in appendix 5 .

Our data show a large influence of the contextual variables on the financial performance development. Store size was the strongest single predictor of the stores' financial performance development. The larger stores showed relative increases in net results, reductions of controllable costs and reductions of the wage costs. This indicates a relative increase in cost effectiveness of the larger stores.

The development of the controllable costs, the productivity difference, and sick leave percentage were influenced by the social variables. Perceived leadership qualities are related to the controllable costs development. In stores where leadership is rated higher, the reduction in controllable costs is also larger. In model I consideration leadership shows a direct influence on controllable cost development, in model II charismatic leadership shows an indirect influence on the development of the control- 
lable costs, with readiness to innovate as an intermediate variable. The development of the productivity difference is influenced favorably by the level of general communication in the store. In stores where the general communication is rated higher, the productivity difference has become more favorable relative to the stores with a lower general communication score. Finally, in stores with a relatively open culture, the sick leave percentage has decreased more than in stores with a closed organizational culture.

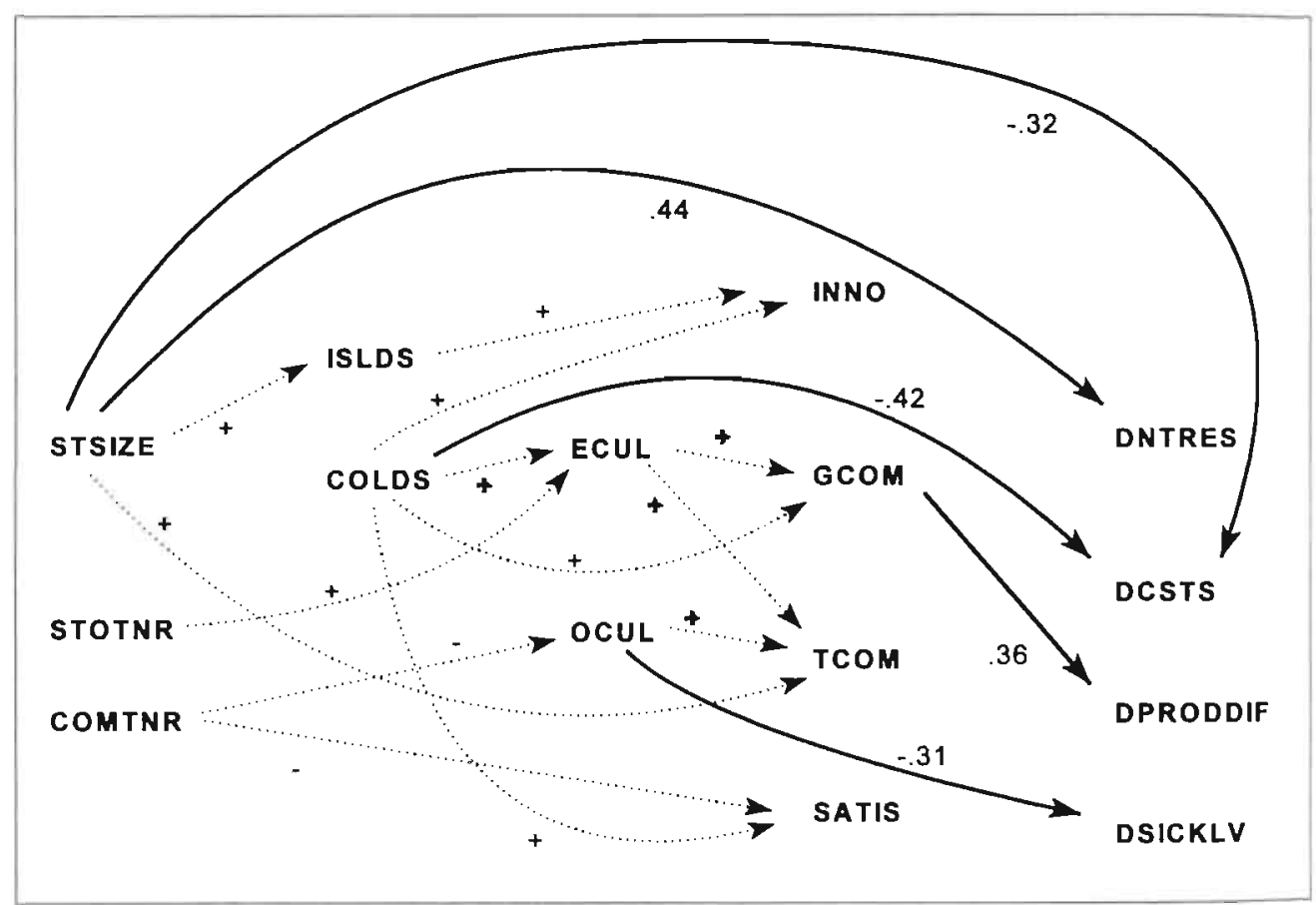

Figure 8.3 Social variables and performance development: model I

\section{Summary: impact of the social variables on organizational performance}

The findings presented above reflect the influence of the social variables on organizational performance, controlling for variations in the organizational context and taking into account the relations among the social variables. The findings from our analyses in this section are summarized in table 8.5. The tables shows the direct and indirect (between brackets) relationships of the social variables with organizational performance established in this section. Section 8.3 discusses these findings in detail. 
Table 8.5 impact of the social variables on store performance.

\begin{tabular}{|l|c|c|c|c|c|c|c|c|c|c|}
\hline & MNTRES & MCSTS & MAGE & MPROOOIF & MSICKLV & DNTRES & DCSTS & DWAGE & DPROODIF & DSICKLV \\
\hline CHLDS* & $+* /(+)^{*}$ & $(-)^{*}$ & & $(+)^{*}$ & & & $(-)^{*}$ & & $(+)^{*}$ & \\
\hline COLOS* & $(+)^{*}$ & $(-)^{*}$ & & $(+)^{*}$ & & & $-*$ & & $(+)^{*}$ & \\
\hline ISLOS* & & & & & & & & & & \\
\hline ECUL & $+* /(+)$ & $(-)$ & & $(+)$ & & & & & $(+)$ & \\
\hline OCUL & & & & $(+)$ & - & & & & & \\
\hline TCOM & & & & + & & & & & & \\
\hline INMO & & & & & & & $-*$ & & & \\
\hline GCOM & + & - & & & & & & & & \\
\hline SATIS & & & & & & & & & & \\
\hline
\end{tabular}

Direct relationships + or - , indirect relationships $(+)$ or $(-)$. Relationships only in model \& or $\|$ marked with :

\subsection{Discussion}

In the evaluation of the direct and indirect influences of the social variables on organizational performance three issues warrant a further discussion: first, the impact of leadership on store performance; second, the impact of organizational culture and organizational climate on the stores' financial performance; and finally, the impact of the social variables on the performance development of the stores in the recent past.

\section{Leadership and organizational performance}

The results presented in section 8.2 show that both consideration and charismatic leadership influence store performance, but that the bivariate relationships of initiating structure with store performance seem spurious. In the present analyses initiating structure leadership is not significantly related to any of the five performance measures in our stores. Consideration shows an indirect impact on performance through its influence on organizational culture and climate. Charismatic leadership, finally, influences store performance both directly and indirectly through organizational culture and climate. These differences in impact can be seen to support our understanding of the three leadership concepts. As discussed in chapter 4, we expected that the three aspects of leadership had a different impact on the employees and thus on organizational performance. Initiating structure leadership was mainly focused on clarifying the "right" way of doing things, structuring the work in the organization, and defining individual tasks. Consideration focused on coping with current needs and self-interests of the employees vis-à-vis company needs and constraints, and maintaining a supportive social structure in the organization. Charismatic leadership focused on motivating the right thing to do and showing employees opportunities for personal development in the context of the corporate vision (see chapter 4).

Our results show no significant impact of initiating structure leadership on store perfor- 
mance. Initiating structure does influence the climate variable readiness to innovate, but functions as an intermediate variable, itself being influenced by store size. As discussed in chapter 4, previous studies in different empirical settings did show an influence of both consideration and initiating structure on job performance, job satisfaction, and satisfaction with supervision (Fisher and Edwards, 1988) and business volume, costs and growth (Bowers and Seashore, 1966). Previous studies of contingencies in the effects of consideration and initiating structure indicated a negative influence of the structure of the work setting on the impact of initiating structure leadership (Bass, 1990:539). Our data seem to reveal that our supermarket organization has succesfully installed a clear organizational structure that supports and possibly even substitutes for (or neutralizes) individual structuring leadership capabilities of supermarket managers. This is an interesting finding, especially because it supports theoretical notions about the substitutability of leadership (Kerr and Jermier, 1978; Howell et al., 1990).

The other two leadership variables, consideration and charismatic leadership, do show direct and indirect influences on organizational performance. Again, these relationships confirm the findings of previous research on the topic. Charisma was found to influence job involvement, task motivation, employee commitment, various aspects of perceived task security (Peterson, Phillips and Duran, 1989; Howell and Frost, 1989), and also aspects of performance like perceived store efficiency (Peterson, Philips and Duran, 1989), employee self-perceptions of exerted extra effort (Bass, 1985b) and consolidated unit performance (Howell and Avolio, 1993). The results indicate that consideration and charismatic leadership are two aspects of leadership that still have added value in well-structured formal organizations, as they add human understanding, motivation and empathy to the formal organizational structure. This is also supported by the aspects of organizational performance influenced by these variables. Both consideration and charismatic leadership are related to the more general aspects of performance (net results and controllable costs) that can be influenced by individual ingenuity and entrepreneurship, rather than the more process-oriented detailed performance variables (wage costs and productivity performance). The more general aspects of performance are precisely those that depend on a clear understanding of the organization's purpose and rely on individual initiative on the part of the organization's employees. Thus, consideration and charisma seem to fulfill an important role in psychologically engaging employees in the organization (Kahn, 1992), guarding the believability of goals and the excitement about their accomplishment (Peters and Waterman, 1982:84), and infusing the organization with value beyond the technical requirements of the task at hand (Selznick, 1957:138).

For a large part the charisma variable and the consideration variable influence the same culture and climate variables. From this perspective it seems the two share an important role in determining the organizational culture and climate. The major difference between the two is the direct impact of charismatic leadership on store performance. Consideration leadership only shows an indirect influence on organizational performance through its influence on organizational culture and climate. Charisma also reveals a direct effect on store performance, influencing the store's bottom line net results. This can be seen as reflecting the charismatic's emphasis on goal setting, 
intrinsic motivation of employees and entrepreneurship. These are important qualities in an organization where the employees in the primary process always operate highly visible to, and in direct interaction with the customer.

\section{Organizational culture, climate, satisfaction and performance}

From the evaluation of the literature on the impact of organizational culture on organizational performance in chapter 3 we concluded that although there is an abundance of theoretical arguments for the importance of organizational culture in organizations, there is only little empirical evidence to substantiate these expectations. In this study aspects of organizational culture, climate and work satisfaction were measured and related to organizational performance.

The results of studying the influence of the social variables on organizational performance were presented in section 8.2. Taking into account the structural relationships between the social variables shows that not all relationships are direct influences of the specific variables on organizational performance. Four social variables showed a direct influence on organizational performance: the previously discussed charismatic leadership variable, the open culture variable, and two aspects of organizational climate (general communication and task communication). The employee orientation variable shows an indirect impact on performance through its influence on general communication and task communication in model I, and an additional direct influence on net results in model II. On the basis of our evidence the work satisfaction variable does not show a structural relationship with the performance variables.

The relationships of the social variables with organizational performance support our understanding of the concepts in this respect. In chapter 3 six aspects of organizational culture and climate were identified that returned frequently in studies investigating the social aspect of organizations. Of these six we did not measure the results orientation aspect whilst our measure for organizational innovativeness (readiness to innovate) was not significantly related to organizational performance. The other four, however, were measured by our culture and climate variables and did show significant influences on organizational performance: general communication (GCOM) measures communication / cooperation; task communication (TCOM) measures perceived administrative efficiency; readiness to innovate (INNO) measures organizational innovativeness; employee orientation (ECUL) measures employee orientation; and openness (OCUL) measures openness.

A major underlying theme for the importance of the communication / cooperation variables (and thus our general communication variable) is the inherent reference to the holistic understanding of the work situation. As explained in chapter 3 communication and coordination are the basis for the integration of the specialized activities of the organization members into coherent organized action. In essence, the general communication variable describes the employees' evaluation of how well store management has succeeded to put the specific work activities in the store in a relevant general context, thus enhancing the employees' understanding of the organization at 
large and giving them the possibility to evaluate the wider contextual meaning of their specific assignments as far as they can. The consistent and strong influence of the general communication variable on net results and controllable costs indicates its importance for the use of personal ingenuity and entrepreneurship. These findings support the arguments for the importance of a holistic and integrated approach to work for organizational learning and organizational success (e.g. Nonaka, 1994; Senge, 1990; Argyris and Schön, 1978).

The task communication variable refers to the administrative efficiency (Payne and Mansfield, 1973; de Cock et al., 1984) of the work unit as perceived by the employee It describes the perceived quality, effectiveness and efficiency of the organization of work in the store. It refers to the quality and clarity of short term task communication. It emphasizes the employees' understanding of task specialization and clarity of job demands. It was found to be the sole significant direct determinant of the stores' productivity performance (measuring how much better the stores' productivity was as compared to the productivity standard set for that specific store.) The finding of an influence of task communication on store performance is consistent with previous findings. Denison (1990) found a similar relationship between the perceived organization of work and the present performance of the organization.

Hofstede et al. (1990) define the organizational culture variable open vs. closed cultures as describing 'the organization's communication climate (Poole, 1985), a focus for attention for both human resources and public relations experts' (Hofstede et al., 1990:304). In Poole's understanding communication in itself is an important organizational practice, but it is also implicated in other aspects of organizational culture and climate as it is the medium for accomplishing much of the organization's work (Poole, 1985:80). In essence, the open vs. closed culture variable refers to the safety of the organizational situation as perceived by the employees of the organization. It is related to concept of trust, as in closed cultures employees seem less inclined to take risks (Mayer et al., 1995). Openness points to the possibility to communicate freely and seems to provide the individual employee with the possibility to 'psycholically engage' and be fully present in the work situation (Kahn, 1992). In this way openness is considered a prerequisite for employee empowerment in the organizations as empowerment depends on the employees ability to work together and trust each other in the work situation (e.g. Bowen and Lawler III, 1992; Mills, 1991)'. Although in this study openness is not directly related to bottom line financial performance, it does influence the sick leave percentage in the stores, which can be considered an indicator of employee well-being in the job.

Finally, the employee orientation variable (Hofstede et al., 1990) can be seen as representative of a group of variables that measure the recognition of people as valuable assets to the organization and the understanding that these people need consideration and attention. Hansen and Wernerfelt (1989) and Denison (1990) both showed a relationship between 'an emphasis on human resources' and organizational

${ }^{1}$ As it is an aspect of culture, openness points to a habit of free communication comparable to the values guiding communication in Fukuyama's high-trust cultures (Fukuyama, 1995). 
performance. The results of our study indicate that the employee orientation variable takes an important intermediate position in influencing organizational performance. The influence of employee orientation is not consistently direct, but seems to be one of the prerequisites for an organizational climate with good general communication and task communication. These climate variables, in turn, are directly related to organizational performance. Thus, the employee orientation concept seems to fulfill a pivotal role in the web of social variables and their influence on organizational performance. These findings support the recognition of the importance of valueing the employees as individual human beings who can be an important resource for the organization. This idea is a central argument of advocates of the learning organizations of the future that draw on the experience and ingenuity of each of their empowered employees (e.g. Mills, 1991; Senge, 1990). It is an important understanding, especially in the context of institutionalization and value management in the organization. When overemphasizing the attention payed to organizational goals, a group of employees is created that is fanatically possessed by the central values of the firm, risking corporate myopia and employee burnout (Soeters, 1986). The importance of the employee orientation variable thus also supports Sorge's assertion that the key contribution of the organizational culture thinking to the organization science might well be the revaluation and recognition of the needs and possibilities of the human factor in organizations (Sorge, 1989).

\section{Performance development in the recent past}

Considering the influence of the context and the social variables on the performance development in the stores during the two years just before the measurement of the social variables it is clear that the organizational size is the main explanatory variable for the performance development over those two years. Relative to the smaller stores, the larger ones have become more profitable and more cost effective. The arguments for the relative success of the larger stores were presented in chapter 7 . However, our data show that the social variables also have an impact. As explained in the introduction of this chapter, we expect the social variables to be relatively stable in time, changing only slowly. The social variables can thus be assumed to have influenced the stores' performance development in the recent past. The social variables influenced the development of three performance variables: controllable costs, productivity performance, and the sick leave percentage. The social variables related to the performance improvements all point to the social aspects of a learning environment. The findings support our understanding of the importance and meaning of the social variables for organizational performance as discussed in the previous section.

The leadership variables consideration and charismatic leadership showed an influence on the development of the controllable costs and the productivity difference. Consideration showed a direct influence on cost development and an indirect influence on the development of the productivity difference with culture and climate variables as intermediaries. Charismatic leadership influenced the climate variable readiness to innovate (which was also influenced by store size) and through this variable the controllable costs development. These relationships show the importance 
of supportive and motivating leadership for development and learning in the organization. Similarly, the aspects of organizational culture and climate that are related to a performance improvement over the past two years are those social variables emphasizing security and support for the employees in their job fulfillment. Employee orientation influences general communication, and general communication, in turn, can be interpreted as a prerequisite for productivity improvements beyond those expected on the basis of the norm productivity. These two characteristics of a 'learning environment' thus show to be related to the stores' performance development over the past two years. Finally, our findings show that stores with an open culture do not only show lower sick leave percentages than the other stores, but also reveal a favorable development of the sick leave percentages compared with stores with a closed organizational culture.

Why did these social variables influence the performance development? Two hypothetical explanations for our findings can be advanced. Firstly, the variables point to an environment conducive to change and development, and many things were changing in our stores at the time of our study. The supermarket company was developing larger stores, professionalizing store management, emphasizing employee training, and introducing formal analytical working methods. Partly, these developments were a reaction to the increased technological possibilities in the supermarket industry; partly, they were fostered by the company's desire to 'organize for perfection' and deliver a 'high-quality shopping experience.' The changes in the stores were aimed at both efficiency and effectiveness, and when succesfully introduced they payed off. As the social variables facilitated organizational change, this can explain the relative success of the stores scoring high on these social variables. Secondly, the company also intended to create a store organization that would be able to cope with the customer demands of the coming decades. This is reflected in the organizational innovations that were introduced with the professionalization of store management and the formal analytical working methods, emphasizing economic efficiency. It might well be the case that these new working methods ask for a social environment that counterbalances the increased formal rationality of the organizational system. In this interpretation the organization might be understood as organizing for 'hyperrationality. involving the simultanous attention for organizational efficiency and flexibility (Ritzer and LeMoyne, 1991).

\subsection{Concluding remarks, revisiting the research questions}

Coming back to the research questions about the influence of the 'social variables in organizations' on organizational performance and performance development, and the question regarding the influence of the direct and indirect impact of leadership on organizational performance, we can conclude the following on the basis of our data

First, the data clearly show an influence of the social variables on organizational performance. Adding the social variables to an explanatory model relying on objective contextual variables to explain store performance, most social variables added significantly to the explanation of the variation in one or more performance indicators. 
Second, taking into account the relationships between the social variables, it is shown that not all social variables are directly related to organizational performance. The social variables reflecting important aspects of a learning environment, such as consideration and charismatic leadership, employee orientation and general communication, show a clear relationship with the bottom line financial performance of the fifty supermarket stores in our sample. Furthermore, the open culture variable is significantly related to the sick leave percentage of the stores.

This positive impact of the social variables on organizational performance is also reflected in the influence on the performance development over the two-year period before the measurement of the social variables. Although the relationships with performance development are less clear than the relationships with the present performance in the stores, the leadership variables consideration and charismatic leadership, both culture variables employee orientation and openness, and the climate variables readiness to innovate and general communication showed a positive (direct or indirect) relationship with the stores' performance development. Two explanations were advanced for these findings: one is that the social variables reflected a social environment supporting organizational change; the other is that the social variables reflected the social complement to the increased quality of the formal organization, stimulating the use of substantive rationality to counterbalance for the increased effectiveness of the formal rational organizational system.

Finally, the leadership variables consideration and charismatic leadership showed both direct and indirect relationships with the performance variables. Charismatic leadership showed a direct influence on the stores' net results, and consideration a direct influence on the cost development in the stores over the two-year period just before the measurement of the social variables. Furthermore, both consideration and charisma influence the culture and climate variables, thus influencing store performance indirectly. The leader's structuring behavior was not related to store performance.

In all, the findings of this study are encouraging. They show clear and interpretable relationships between the social variables and organizational performance, supporting the theoretical expectation of a positive influence of the social variables on organizational effectiveness. 



\section{CHAPTER 9}

\section{CONCLUSION}

This chapter concludes our discussion of a study investigating the influence of organizational culture on effective organizational performance. Compared to its theoretical importance, the empirical evaluation of this relationship is relatively underdeveloped. As the empirical research in related fields of organizational behavior research showed useful possibilities for cross-fertilization we studied variables measuring aspects of organizational culture, leadership perceptions, aspects of organizational climate, and work satisfaction. Together, we called these the social variables. This approach enabled us to put the functioning of organizational culture in perspective. It emphasizes that organizational culture research has not developed in a vacuum, but was strongly influenced by the existing research traditions in the study of organizations. To evaluate the importance of the social variables for organizational performance various other organizational variables describing the organizational context were also included in the analysis. Thus, this study emphasized the empirical investigation of the impact of organizational culture on organizational effectiveness in its organizational context.

This chapter first summarizes the findings of our study. Then, these findings will be discussed and their meaning for understanding organizations will be evaluated. Subsequently, the limitations of our investigation are discussed. From these limitations we turn to the implications of the outcomes of our study for further research. Finally, we will address the implications of our findings for management practice.

\subsection{Summary of the findings}

In this study we analyzed the influence of nine social variables on organizational performance in a sample of fifty company-owned supermarket stores of a large retail chain in the Netherlands. In these stores we conducted a quantitative comparative study of the influence of the social variables on organizational performance. Furthermore, we measured a number of organizational characteristics of the stores and related those to the social variables and organizational performance. The

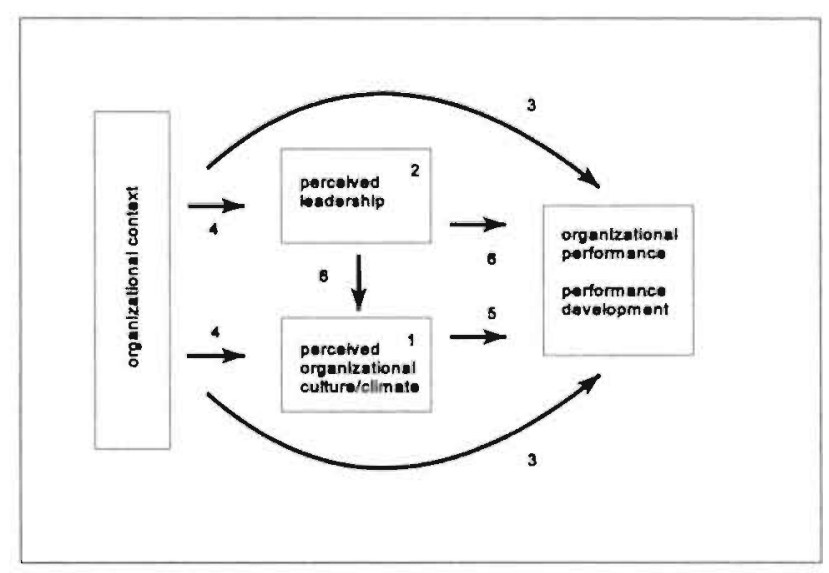

Figure 9.1 The research questions 
objective was to answer six research questions formulated in chapter 5, graphically presented in figure 9.1. Our findings with respect to these research questions are summarized below.

Research questions 1 and 2 focused on the operationalization of the concepts of organizational culture, climate and leadership, and were discussed in chapter 6 .

1. Which dimensions of organizational culture and climate explain differences between organizations within one industry?

In our analyses we used Hofstede et al.'s (1990) questionnaire to measure organizational culture in combination with three variables that measured organizational climate. Two of the six dimensions of organizational culture found by Hofstede et al. could be validated in our comparison of the stores of a large Dutch food retailer. The two dimensions (employee orientation and openness) reflect social aspects of the organization that have been frequently studied in organization research. The other four dimensions of organizational culture could not be reproduced in our within-industry setting, supporting Hofstede et al.'s supposition that these dimensions primarily reflected differences in industry culture (Hofstede et al., 1990:306). The climate measures task communication, general communication and readiness to innovate could also be validated in our within-industry setting. These three variables also reflected social aspects of the organization that have been studied in previous research.

2. What is the relationship between the traditional leadership dimensions of initiating structure and consideration and the recent operationalizations of leadership as exemplified in the charisma dimension?

In our analysis charisma and consideration correlated significantly. Initiating structure was also correlated to charisma, but was not related to consideration. This finding is consistent with findings in previous research (e.g. Peterson, Philips, and Duran, 1989). It supports our contention that, although the three leadership dimensions can be considered conceptually distinct, they are empirically related (see chapter 4 and 6).

Research questions 3 and 4 focused on the influence of the organizational context on organizational performance and on organizational culture, climate, and leadership. Our analyses of the impact of the organizational context in chapter 7 show that the organizational context influences both organizational performance and the social variables.

What is the impact of the organizational context on organizational performance?

The influence of organizational size on store performance reflects the influence of economies of scale and scope for the supermarket organizations. Our findings emphasize that for the supermarket stores in our sample size effects are positive. Furthermore, the performance development in the recent past shows an increasing gap between the profitability of the smaller and the larger stores. The larger stores have shown larger performance increases than their smaller counterparts. These findings seem to point out that the technically advanced larger stores, with their more 
elaborate explicit and formalized organizational structure, are better equiped to compete in the current market place than the smaller stores. This was also recognized by the supermarket company which strategically focused on the development of the larger stores.

What is the impact of the organizational context on the social variables measuring organizational culture, climate and leadership?

Organizational size was also found to influence the task-related aspects of leadership (initiating structure) and organizational climate (readiness to innovate and task communication). The positive impact of size on these social variables might be interpreted as the influence of the formal organizational structure. In the larger stores the formal organization structure is more complicated and more important than in the smaller stores (compare Mintzberg, 1979). One might argue that in the larger stores the company as an institution has a more pervasive (supportive) influence on the social variables through general company rules and regulations, formal requirements regarding the organizational structure of the stores, job and task descriptions, and formal company training and indoctrination programs. The more extensive formal organization might also force the store manager to pay attention to his structuring task in the organization and support his task-related leadership behaviors.

Evaluating the relationships among the social variables our findings show an influence of aspects of leadership and organizational culture on the other social variables. The leadership variables consideration and charismatic leadership influence organizational culture, climate and work satisfaction. The organizational culture variables influence organizational climate and work satisfaction. In our multivariate analyses these leadership variables and both organizational culture variables (employee orientation and openness) are independent of our operationalization of the organizational context. This means that these variables can be interpreted as a second source of variation for the other social variables.

Thus, our findings about the influence of the organizational context on organizational performance and on the social variables (research questions 3 and 4 ) are important for three reasons. First, the clear influence of store size on store performance in our sample of supermarket stores indicates that for these relatively small organizations straightforward economic efficiency considerations remain paramount for profitable performance in the market place. Second, the influence of the formal organizational context on the task-related aspects of leadership and organizational climate highlights the relationship between the formal organization and the organizational culture and climate. Third, the other social variables seem to be influenced most strongly by aspects of leadership and organizational culture which are independent of the formal organizational context.

Finally, research questions 5 and 6 focused on the influence of the social variables organizational culture, climate and leadership on organizational performance. 
The analysis of the influence of the social variables on organizational performance described in chapter 8 shows a clear relationship of the social variables with organizational performance. This finding substantiates earlier findings linking social variables to business performance (Hansen and Wernerfelt, 1989; Denison, 1990). Adding the social variables to an explanatory model relying on objective contextual variables to explain store performance, most social variables added significantly to the explanation of the variation of one or more performance indicators. Taking into account the interrelationships between the social variables, it becomes clear that not all social variables are directly related to organizational performance. The leadership variables consideration and charismatic leadership and the culture variables employee orientation and openness influence organizational performance both directly and indirectly, through their impact on the climate variables general communication and task communication, which directly influence organizational performance. Initiating structure did not show a significant influence on store performance. A possible explanation for this is that its effect is neutralized by the quality of the formal organization in the supermarkets.

Interpreting the influence of the social variables on organizational performance substantiates our theoretical expectations of the impact of organizational culture. In chapter 2 our expectations for the impact of organizational culture on organizational performance were summarized in Denison's 'culture and effectiveness model' (Derison, 1990). The model was presented in table 2.1 and is reprinted below in table 9.1 .

Table 9.1 'The culture and effectiveness model" (Denison, 1990:15)

\begin{tabular}{|l|l|l|}
\hline $\begin{array}{l}\text { External point of } \\
\text { reference }\end{array}$ & Adaptability & Mission \\
\hline $\begin{array}{l}\text { Internal point of } \\
\text { reference }\end{array}$ & Involvement & Consistency \\
\hline & $\begin{array}{l}\text { Change and } \\
\text { flexibility }\end{array}$ & $\begin{array}{l}\text { Stability and } \\
\text { direction }\end{array}$ \\
\hline
\end{tabular}

Charismatic leadership, general communication and task communication are most directly related to the organization's bottom line financial performance. Their influence on organizational effectiveness can be most readily understood as following Denison's adaptability, mission and consistency hypotheses. These variables reflect the clarity and understandability of organizational goals and the clarity of work tasks in the organization, facilitating purposeful, consistent work accomplishment by employees, and meaningful change and adaptation within the context of the general organizational goals. Openness and employee orientation show a mostly indirect influence on organizational performance, through their impact on the organizational climate variables. These variables can be understood as influencing organizational effectiveness by strengthening employee involvement in the organization. Employee orientation and openness reflect the degree to which employees consider themselves valued as human beings, feel safe and secure in the organizational context, and 
communicate freely. These aspects of organizational culture facilitate psychological engagement of employees in the work situation (Kahn, 1990) and seem crucial prerequisites for employee involvement and empowerment.

Two explanations were advanced for the influence of the social variables on the performance development of the stores in the recent past: the first arguing that these variables constituted a more favorable social environment for organizational change; the second arguing that these social variables with their emphasis on creativity and human communication complemented the increased effectiveness of the formal rational organizational system.

Concluding, we can say that the outcomes of our study show that both the organization's formal organization and the social variables are important determinants of organizational performance in the case of our supermarket stores.

\subsection{Discussion of the findings: trust and rationality in organizations}

Evaluating the contribution of organizational culture to organizational performance our conclusion about its influence has two sides: on the one hand the empirical substantiation of the relationship of the social variables with organizational performance; on the other hand, the remaining importance of the formal rational organization, as reflected in the influence of the store-size variable on organizational performance and the social variables.

First, our evidence showed that the social variables clearly contributed to the explanation of store performance. The leadership variables consideration and charismatic leadership, the culture variables employee orientation and openness, and the climate variables general communication and task communication are all significantly related to organizational performance. This finding is consistent with the claims of recent publications that consider the social nucleus of the organization a driving force behind its creativity, success and effectiveness (e.g. Mills, 1991; Senge, 1990; Pfeffer, 1994). Teamwork is considered to be the key to organizational effectiveness. Organizational effectiveness, in turn, is considered to be the primary bottle neck in contemporary organizations. The social variables consideration and charismatic leadership, employee orientation, openness and general communication all convey a sense of motivation and appreciation of the human qualities of the employees in the organization, facilitating creativity and teamwork. This sense of motivation and appreciation of employees is not conveyable in explicit organizational rules and regulations, but is a tacit understanding that has to be communicated person to person. The basic underlying variable seems to be trust. Trust with regard to motivation, task performance, and social interaction within the organization. Trust in organizations is considered a precondition for the kind of interaction between human beings that can lead to knowledge creation in the organization (Nonaka, 1994). Trust is also considered to be a key success factor for the successful empowerment of employees (e.g. Kahn, 1990; Milis, 1991). Recent developments in the organizational sciences reflect the importance of trust for organizational effectiveness. Researchers 
have recognized trust's influence on coordination and control at both institutional and interpersonal levels of organization (McAllister, 1995). Furthermore, the increasing diversity of the workforce, the increasing reliance on participative management styles, the use of work teams, and the increasing difficulty of direct supervision all suggest the importance of trust in the workplace is likely to increase during the coming years (Mayer et al., 1995; Handy, 1995). Our findings show that, in essence, the aspects of the organization's social environment related to trust have an impact on organizational performance, even in an organization with a relatively traditional production technology in a traditional industry as is the case for our supermarket stores.

Second, our findings emphasized the remaining importance of the formal rational organization, as reflected in the importance of the store-size variable. In chapter 7 this size effect was explained by the existence of economies of scale and scope for the supermarket stores and by the stores' capacity to make better use of the formal organizational structure provided by the company headquarters. The larger stores had the critical mass and the organization-structural support to invest in new technology and to introduce organizational innovations. These innovations, in turn, increased store efficiency and effectiveness, but also increased their dependency on headquarter support, thus reducing the autonomy of the individual stores. An example is the introduction of computerized point-of-sale information systems. These systems clearly increased store efficiency as the laborious pricing and inventory checking tasks were largely automated. They also increased store effectiveness, as the risk of wrong pricing was greatly reduced. The systems, however, also increased the stores dependency on the company headquarters as price information was directly fed into the cash register and automatic scales from the central headquarters computer. This size effect is an interesting finding, because it emphasizes the positive and stimulating effect that the formal organizational system can have on the performance of the operational units in large organizations. In this respect, our finding of the growing success of the larger, more formalized and rationalized supermarket stores is consistent with the observations of Ritzer (1993) regarding the growing importance and success of a number of very large and rationalized organizations.

Thus our findings emphasize the combined importance of the social variables and the formal rational organization for the performance of the supermarket stores in our study. In this perspective the popular literature seems to overemphasize the importance of the social aspect of the organization focusing mainly on the influence of creativity and teamwork on organizational effectiveness. Our findings support Romme's (1996) argument that it might be more appropriate to see the formal rational organizational hierarchy and the team organization as each other's complement, rather than as substitutes. Romme argues that neither team nor hierarchy is a viable form of organization in its pure form. Instead, he advocates circularity using team structures for learning and creativity and hierarchical structures for the communication and preservation of successful organizational practices and ideas. In essence, team and hierarchy can be understood as supporting two different kinds of rationality in the organization. The team reflects a concern for organizational learning, organizational effectiveness, fit with the organizational environment and the quality of organizational goals, in short substantial or substantive rationality (e.g. Morgan, 1986:37). The 
hierarchy on the other hand, emphasizes organizational processes, efficiency and internal consistency, in short, functional, instrumental or formal rationality. In fact, it is this combined attention for different kinds of rationality that Ritzer and LeMoyne (1991) call hyperrationality and which, they claim, is at the basis of the extraordinary organizational performance of the Japanese industry.

\subsection{Limitations of this study}

The goal of this study was to contribute to the body of knowledge on the influence of leadership and organizational culture on the functioning of organizations. Specifically. this study focused on the empirical investigation of the influence of nine social variables reflecting important aspects of leadership, organizational culture and organizational climate on organizational performance, controlling for other aspects of the organizational context. For understanding the value of this study, its limitations have to be considered. Four limitations of this study should be mentioned.

First, this study was partly exploratory, testing only general hypotheses on the relationships between the social variables and organizational performance. There is a risk of capitalizing on chance in building up the models describing the relationships between the social variables and organizational performance in steps as was done in chapters 7 and 8 . Furthermore, as the main evidence presented in this study is of a correlational nature, the relationships found can, in the strictest sense, only imply possible causal relationships. This, however, is a shortcoming of comparative research in general. The lack of previous quantitative studies jointly investigating the influence of organizational context, leadership, organizational culture and organizational climate on organizational performance made this broad analysis valuable. Future research will have to strengthen the findings presented in the above, focusing on aspects of the models discussed in chapters 7 and 8, or analyzing the proposed causal relationships between the different variables in longitudinal or experimental research.

Second, the differences between the operationalizations of consideration and charismatic leadership, and organizational culture and climate seem somewhat artificial at times. As was clarified in the text, these concepts can be clearly distinguished theoretically, but in practice their operationalizations overlap. In this study, we used existing measurement instruments and did not focus on the development of new or the adaptation of existing instruments. It is, however, important to note that the theoretical definition of the concepts underlying the social variables is often more precise than their empirical operationalization. This is an issue that needs careful attention in future research.

Third, our analysis of the influence of the social variables on the performance development in the stores could be criticized for the use of retrospective performance data. Our assumption in linking these measures to the social variables was that the social variables are relatively stable and that their measurement could also be taken as an indication of the store culture over the past two years. A useful extension of this 
study would be a prospective study, analyzing the influence of the social variables on future organizational performance.

Fourth and finally, one could be concerned about the generalizability of the findings of this study, as it was conducted in the stores of a specific supermarket chain in a specific period of time. This limitation, however, is inherent to most empirical research and can only be alleviated by replication studies in different industries and time periods.

\subsection{Further research}

Evaluating the outcomes of this study, there are a number of interesting avenues for further research.

First, replications and extensions of our analysis are likely to enhance our understanding of the specific relationships found in this study. Future research can study specific relationships in more depth, building on the framework relating the social variables to organizational performance presented in chapters 7 and 8 .

Second, the operationalization of leadership and organizational culture constructs needs more attention. The differences between the operationalizations of leadership variables should be evaluated more elaborately. Specifically the differences between the older two-factor leadership operationalization in initiating structure and consideration and the more recent operationalizations revolving around the concept of transformational leadership should be investigated. The comparison could enhance our understanding of the concepts and the precision of the operationalization of the leadership variables. The operationalization of organizational culture also needs more attention. The distinction between the quantitative operationalizations of organizational culture and climate are relatively vague. Furthermore, there is a lack of measurement instruments evaluating cultural differences at the specific organization-level. There is a growing understanding that there is a difference between dimensions of industry culture and organizational culture and that research to date has focused mainly on industry cultures (e.g. Chatman and Jehn, 1994). Research trying to isolate general organizational level dimensions of organizational culture might enhance our understanding of the concept and its usefulness in the process of organization development.

Third, our findings showed an independent influence of the social variables, describing an environment of trust in the organization, on financial organizational performance. As trust is a quality that is built over time, it can be considered a crucial and imperfectly imitable core competence for organizations that can thus lead to sustained competitive advantage in the human resources area. At present, the need to pay attention to this role of the organizational human resource base is being recognized by various authors (e.g. Boone and van Witteloostuijn, 1996; Lado and Wilson, 1994). Our findings show an influence of aspects of organizational demography (tenure with store and tenure with company) on the social variables that can be 
influenced by human resource management policies. Further research exploring the role of the organizational human resource system in guarding and developing the core human competences of the organization thus seems valuable.

\subsection{Implications for management practice}

The implications for management practice of this study are several. Three major implications are discussed below.

First, the outcomes of our study substantiate the important role of organizational culture and climate in organizations. The aspects of culture and climate measured in our study showed significant relationships with organizational financial performance. Important aspects of culture are employee orientation (a concern for people) and openness, indicating the significance of appreciating employees as valuable individuals and the opportunity to communicate freely in the organization. Important aspects of organizational climate are general communication and task communication, reflecting a communication climate characterized by clarity and understandability of the organizational goals and clarity of the work tasks in the organization. A concern for people (employee orientation) seems to be a prerequisite for a positive organizational climate. The clear influence of the general communication dimension on financial organizational performance indicates the importance of clarifying the meaning of individual employees' work tasks in the context of the general organizational goals.

Second, our findings indicate that management has two ways to influence the social variables: through the quality of its management and through the formal organizational structure. Managers and leaders in the supermarket organization seem to fulfill a pivotal role protecting the organizational culture and climate as they are the channels for communicating the specifically human demands of the organization to its employees. This is reflected in the consistent importance of people-oriented aspects of leadership for organizational performance in our sample of organizations while the task-related aspects of leadership seem to be largely substituted by a high-quality formal organization. The formal organizational structure also influences organizational climate and leadership. Our evidence shows that in the larger stores (relying more heavily on formal procedures, organization design and task descriptions) store managers scored higher on initiating structure. The larger stores also scored higher on readiness to innovate and task communication. These findings point to a supportive role of the formal organization, clarifying organizational tasks and goals, thus supporting the store manager in his structuring leadership role and providing the employees with a secure work environment within which they can be creative and flexible.

Finally, the recognition of the remaining importance of the solid economic factors of economies of scale and scope for organizational performance serves to put the influence of the social variables in perspective. It shows that performance is also clearly determined by laws of efficiency and rationality. Their importance, and thus the 
importance of a carefully designed formal organization, remains unaffected by the new demands of learning and creativity for keeping the organization effective in ever faster changing and more demanding markets.

Concluding, the outcomes of this study show the importance of combining the demands for creativity and adaptation and the demands for the preservation and communication of organizational knowledge and experience in the organization. Creativity and adaptation can be encouraged through an emphasis on the quality of the informal organization. The preservation and communication of organizational knowledge and experience can be ensured through the formal organizational hierarchy. Combining the conflicting demands of a learning environment with the requirements of formal rational operations, where new organizational knowledge is used most efficiently, seems to be the challenge for management in contemporary organizations. 


\section{APPENDICES}


152 Organizational Culture, Leadership and Performance in Context 


\section{Appendix 1}

\section{Organizational culture (OCM)}

Organizational culture was measured with six dimensions of the Organizational Culture Module (ocm) developed by Hofstede et al. (1990). In an in-depth analysis of twenty Dutch and Danish companies Hofstede et al. discovered six dimensions of organizational culture, describing differences in 'work-practices'. Four of the dimensions were labeled as describing aspects of culture varying by industry, two were dimensions relating to the 'philosophy of the founder and top leaders' of the organization (Hofstede et al., 1990:306).

Dimensions of organizational culture influenced by the industry:

p1 results vs process orientation

p3 professional vs parochial orientation

p5 tight vs loose culture

p6 normative vs pragmatic (customer orientation)

influenced by the philosophy of the founder and top leaders:

p2 employee vs work orientation

p4 open vs closed system

From the rather elaborate questionnaire Hofstede et al. selected three items per subscale to be used in the calculation of culture-'scores' on the six dimensions. For this study we selected these key-items per sub-scale for inclusion in our measurement instrument. For consistency with an on-going research project at the University of Limburg, two scales ( $p 2$ and $p 5$ ) differed slightly from the final key-item-advice presented by Hofstede et al. For one item in $p 6$ the wording was adjusted to be understandable for all respondents in our sample. In consultation with prof. Hofstede selected items were added to the three key-items per dimensions because of relevance in this specific study of supermarket stores. All items in part 2 of the questionnaire (presented in appendix 1) originate from the Organizational Culture Module (OCM) and are therefore included in the analysis.

\section{Organizational climate (OKIPO)}

To further measure organizational culture we included two scales from the 'okipo.' The Organisatie klimaatIndex voor Profit Organisaties (okipo) was developed by de Cock et al. (1984). The questionnaire was based on an english-language instrument, the Business Organization Climate Index (boci), designed by Payne and Pheysey (1971) and modified by Payne and Mansfield (1973). The okipo contains 20 scales measuring leadership (4 scales), interpersonal relations ( 3 scales), work attitudes ( 6 scales), environmental orientation (1 scale), self-control (two scales), and work routines ( 4 scales). Scales can be selected from this instrument when useful in a specific context (de Cock et al.,1984:6). 
For our study of the impact organizational culture on organizational performance we selected two scales measuring work routines: the scale measuring 'organisatorische efficientie' and the scale measuring 'bereidheid tot vernieuwing' (labeled Administrative efficiency and readiness to innovate by Payne and Mansfield (1973:517)). The scales were measured using three items per scale that de Cock et al. identified as 'the most reliable per sub-scale' (de Cock et al., 1984:42). If necessary, the wording of the items was adapted to the specific (dutch) situation. Further, selected items per scale were added when they seemed appropriate in this study of supermarket-stores.

Below, the okipo-items that were used are shown per subscale (for 'organisatie efficientie' the first three items are the ones identified by de Cock et al. as 'the most reliable per subscale').

\section{Deel 4 (altija 12.3 .45 nooit)}

(volledig mee eens 12345 volledig mee oneens)

In dit deel van de vragenlijst vragen wij u naar uw mening over het filiaal waarin u uw werk verricht.

Organisatie efficièntie

1 het weik is hier goed georganiseerd

2 het doorstromen van informatie gebeurt hier op een degelijke manier

$7 \quad$ iedereen geeft hier duidelijke en degelijke informatie door aan elkaar

4 het werk wordt hier meestal zorgvuidig gepland

16 iedereen weet hier altijd wat hij moet doen

24 iedereen heeft hier een duidelijke taak

Aandacht voor nieuwe ideeën

3 er worden hier veel nieuwe ideeēn uitgeprobeerd

5 een nieuwe aanpak zoeken wordt hier aangemoedigd

6 er zijn hier veel nieuwe ideeën

\section{Organizational climate (Pennings)}

As a third measure of organizational climate we included a scale measuring 'communication.' In a study of organizational effectiveness of branches of a large bank in the New york area Pennings (1989) found that the organizational communication climate was an important predictor of branch performance. Therefore we included a measure of organizational communication in this study, based on Penning's english-language instrument used in the bank-study. The items building the communication scale are presented below: 
Deel 4 (altijd 12345 nooit)

(volledig mee eens 12345 volledig mee oneens)

In dit deel van de vragenlijst vragen wij u naar uw mening over het filiaal waarin u uw werk verricht.

Communicatie

8 mijn baas doet moeite om mij informatie te geven over veranderingen die voor mij van belang zouden kunnen zijn

$11 \mathrm{mijn}$ baas informeert me over wat er binnen $\mathrm{AH}$ allemaal gebeurt

$15 \mathrm{ik} \mathrm{krijg} \mathrm{in} \mathrm{dit} \mathrm{filiaal} \mathrm{voldoende} \mathrm{informatie} \mathrm{om} \mathrm{mijn} \mathrm{werk} \mathrm{goed} \mathrm{te} \mathrm{doen}$

18 er is hier voldoende communicatie tussen het management-team en de medewerkers

26 mijn baas informeert me over wat er binnen ons filiaal allemaa! gebeuri

29 ik weet precies wat er in dit filiaal van me verwacht wordt

\section{Leadership (Syroit)}

Two almost 'standard' leadership scales were included in the questionnaire measuring initiating structure and consideration. The dimensions of initiating structure and consideration have been established as two dimensions describing leadership style in a stream of empirical research in the last three decades (Bass, 1990). Syroit (1979) developed a dutch translation of the Supervisor Behavior Description Questionnaire (SBDQ) of Fleishman (1953). In this study we selected the items with consistently high factor loadings from Syroit's questionnaire ( 3 for the initiating structure scale and 6 for the consideration scale). To update the questionnaire we added items that were selected from an english language questionnaire of House (1989). The items used in the scales are shown below. The items from Syroit's questionnaire are labeled with an "S".

\section{Deel 6 (altijd 12345 nooit)}

Wat is uw indruk van de manier waarop uw huidige bedrịjsleider met zijn medewerkers ongaat?

Taakgericht leiderschap (initiating structure)

is hij vraagt langzaam werkende personen meer te presteren

$3 \quad$ hij laat zijn medewerkers weten wat er van hun verwacht wordt

7 hij maakt zijn standpunten duidelijk aan zijn medewerkers

$9 \mathrm{~S}$ riij moedigt langzaam werkende mensen tot meer inspanningen aan

11 hij verzekert zich ervan dat zijn rol in het filiaal duidelijk is

$13 \mathrm{~S}$ hij beslist tot in de puntjes wat er gedaan moet worden en hoe het gedaan moet worden

15 hị maakt de indeling voor het werk dat gedaan moet worden

16 hij stelt absolute eisen aan de kwaliteit van het werk

\section{Mensgerichtheid (consideration)}

2S hij steunt wat de mensen van zijn filiaal doen

$4 \mathrm{~S} \quad h i j$ is vriendelijk en men kan gemakkelijk met hem in contact komen

hij doet kleine dingen waardoor het fijn is een medewerker van hem te: zijn

hij brengt de suggesties van zịn medewerkers in de praktijk

hij stelt zijn medewerkers op hun gemak wanneer zij met hem praten

hii geeft van tevoren informatie over dingen die gaan veranderen 


\section{Leadership (Bass)}

Besides initiating structure and consideration we included a scale measuring charismatic leadership. Charisma has recently become the focus of much leadership research. In the past decade a new questionnaire has been developed for measuring leadership styles. The Multifactor Leadership Questionnaire (MLQ) (Bass, 1985). This questionnaire is grounded in the theory of charismatic leadership and distinguishes three dimensions of transformational leadership (charisma, intellectual stimulation, individualized consideration) and two dimensions of transformational leadership (contingent reward and management by exception). Of these five dimensions, the charisma dimension was by far the most important one, explaining $66 \%$ of the variance in the items measuring transformational leadership (Bass, 1985). Therefore, we included a measure of charisma in this questionnaire based on the charisma-scale presented in Bass (1989). The items of the scale are presented below:

\section{Deel 6 (altijd 12345 nooit)}

Wat is uw indruk van de manier waarop uw huidige bedrijfsleider met zijn medewerkers omgaat?

Charismatisch leiderschap

18 ik heb volledig vertrouwen in hem

$21 \quad h i j$ is een voorbeeld voor mij

23 ik ben er trots op met hem te werken

24 hij moedigt ons aan anderen goed te begrijpen

25 hij is een bron van inspiratie voor mij

26 hij heeft een bijzondere visie die hij aan ons overdraagt

29 hij heeft een speciaal talent om problemen snel te doorzien

\section{Satisfaction}

Satisfaction was measured using a standard questionnaire from the University of Leiden (Vogelaar, 1990). In their research the cronbach's alpha for the scale was 0.86 . Here all the items were included. The items in the scale are shown below.

Deel 1 (volledig mee eens 12345 volledig mee oneens)

Satisfactie

2 ik vind mijn werk vaak vervelend

$4 \quad$ mijn werk is nogal interessant

6 over het algemeen doe ik mijn werk met veel plezier

7 mijn werk is net zoiets als een hobby voor me

10 ik ben zeer tevreden met mijn huidige werk

12 ik heb op mijn werk vaak het gevoel dat er nooit een einde aan de dag komt

13 meestal ben ik enthousiast over mijn werk 


\section{Appendix 2}

Tabie A2.1 Correlations between performance variables

\begin{tabular}{|c|c|c|c|c|c|c|}
\hline & MGRRES & MWIRES & MOPROF & $\mathrm{SOM}$ & MCSTS & MFXCST \\
\hline $\begin{array}{l}\text { MGRRES } \\
\text { gross resuits }\end{array}$ & $\begin{array}{l}1.00000 \\
0.0\end{array}$ & & & & & \\
\hline $\begin{array}{l}\text { WITRES } \\
\text { net results }\end{array}$ & $\begin{array}{r}0.91324 \\
0.0001\end{array}$ & $\begin{array}{l}1.00000 \\
0.0\end{array}$ & & & & \\
\hline $\begin{array}{l}\text { MOPROF } \\
\text { operating profit }\end{array}$ & $\begin{array}{r}0.91283 \\
0.0001\end{array}$ & $\begin{array}{r}0.99984 \\
0.0001\end{array}$ & $\begin{array}{l}1.00000 \\
0.0\end{array}$ & & & \\
\hline $\begin{array}{l}\text { soy } \\
\text { sales per square neter }\end{array}$ & $\begin{array}{r}0.08200 \\
0.5713\end{array}$ & $\begin{array}{r}0.33493 \\
0.0174\end{array}$ & $\begin{array}{r}0.33482 \\
0.0175\end{array}$ & $\begin{array}{l}1.00000 \\
0.0\end{array}$ & & \\
\hline $\begin{array}{l}\text { MCSTS } \\
\text { controllable costs }\end{array}$ & $\begin{array}{r}-0.60771 \\
0.0001\end{array}$ & $\begin{array}{r}-0.61018 \\
0.0001\end{array}$ & $\begin{array}{r}-0.60985 \\
0.0001\end{array}$ & $\begin{array}{r}-0.10468 \\
0.4694\end{array}$ & $\begin{array}{l}1.00000 \\
0.0\end{array}$ & \\
\hline $\begin{array}{l}\text { MFXCST } \\
\text { fixed costs }\end{array}$ & $\begin{array}{r}-0.16296 \\
0.2582\end{array}$ & $\begin{array}{r}-0.55080 \\
0.0001\end{array}$ & $\begin{array}{r}-0.55124 \\
0.0001\end{array}$ & $\begin{array}{r}-0.64309 \\
0.0001\end{array}$ & $\begin{array}{r}0.23271 \\
0.1039\end{array}$ & $\begin{array}{l}1.00000 \\
0.0\end{array}$ \\
\hline $\begin{array}{l}\text { MOMOHO } \\
\text { company overnead costs }\end{array}$ & $\begin{array}{r}+0.00210 \\
0.9884\end{array}$ & $\begin{array}{r}-0.01836 \\
0.8993\end{array}$ & $\begin{array}{r}-0.03616 \\
0.803 !\end{array}$ & $\begin{array}{r}-0.00259 \\
0.9858\end{array}$ & $\begin{array}{r}-0.00226 \\
0.9876\end{array}$ & $\begin{array}{r}0.04016 \\
0.7819\end{array}$ \\
\hline $\begin{array}{l}\text { MiAGe } \\
\text { wage costs }\end{array}$ & $\begin{array}{r}-0.69587 \\
0.0001\end{array}$ & $\begin{array}{r}-0.75976 \\
0.0001\end{array}$ & $\begin{array}{r}-0.75702 \\
0.0001\end{array}$ & $\begin{array}{r}-0.36868 \\
0.0084\end{array}$ & $\begin{array}{r}0.40476 \\
0.0036\end{array}$ & $\begin{array}{r}0.42433 \\
0.0028\end{array}$ \\
\hline $\begin{array}{l}\text { MACTPROO } \\
\text { actual productivity }\end{array}$ & $\begin{array}{r}0.61519 \\
0.0001\end{array}$ & $\begin{array}{r}0.74192 \\
0.0001\end{array}$ & $\begin{array}{r}0.74236 \\
0.0001\end{array}$ & $\begin{array}{r}0.43421 \\
0.0016\end{array}$ & $\begin{array}{r}-0.27216 \\
0.0559\end{array}$ & $\begin{array}{r}-0.53638 \\
0.0001\end{array}$ \\
\hline $\begin{array}{l}\text { MPRO00IF } \\
\text { productivity difference }\end{array}$ & $\begin{array}{r}0.31592 \\
0.0254\end{array}$ & $\begin{array}{r}0.32986 \\
0.0193\end{array}$ & $\begin{array}{r}0.33114 \\
0.0188\end{array}$ & $\begin{array}{r}0.05484 \\
0.7053\end{array}$ & $\begin{array}{r}-0.45106 \\
0.0010\end{array}$ & $\begin{array}{r}-0.15161 \\
0.2932\end{array}$ \\
\hline $\begin{array}{l}\text { HSIOKLY } \\
\text { sick leave }\end{array}$ & $\begin{array}{r}-0.35734 \\
0.0108\end{array}$ & $\begin{array}{r}-0.25210 \\
0.0774\end{array}$ & $\begin{array}{r}-0.25197 \\
0.0775\end{array}$ & $\begin{array}{r}.0 .05223 \\
0.7187\end{array}$ & $\begin{array}{r}0.25204 \\
0.0774\end{array}$ & $\begin{array}{r}-0.12155 \\
0.4004\end{array}$ \\
\hline
\end{tabular}

Pearson Correlation Coefficients / Prob > $|R|$ under Ho: Rho-0 / $\mathrm{N}=50$

\begin{tabular}{|c|c|c|c|c|c|}
\hline & MOMOHO & MAGE & MACTPROO & NPROOOIF & MSICKLV \\
\hline $\begin{array}{l}\text { MCHOHD } \\
\text { company overhead costs }\end{array}$ & $\begin{array}{l}1.00000 \\
0.0\end{array}$ & & & & \\
\hline $\begin{array}{l}\text { MWGE } \\
\text { wage costs. }\end{array}$ & $\begin{array}{r}.0 .13340 \\
0.3557\end{array}$ & $\begin{array}{l}1.00000 \\
0.0\end{array}$ & & & \\
\hline $\begin{array}{l}\text { MACTPROO } \\
\text { actual productivity }\end{array}$ & $\begin{array}{r}-0.04631 \\
0.7495\end{array}$ & $\begin{array}{r}-0.87340 \\
0.0001\end{array}$ & $\begin{array}{l}1.00000 \\
0.0\end{array}$ & & \\
\hline $\begin{array}{l}\text { MPROOOIF } \\
\text { productivity difference }\end{array}$ & $\begin{array}{r}-0.08042 \\
0.5788\end{array}$ & $\begin{array}{r}-0.20915 \\
0.1449\end{array}$ & $\begin{array}{r}0.19275 \\
0.1799\end{array}$ & $\begin{array}{l}1.00000 \\
0.0\end{array}$ & \\
\hline $\begin{array}{l}\text { MSICKLV } \\
\text { sick leave. }\end{array}$ & $\begin{array}{r}-0.00077 \\
0.9958\end{array}$ & $\begin{array}{r}0.21947 \\
0.1257\end{array}$ & $\begin{array}{r}-0.22099 \\
0.1230\end{array}$ & $\begin{array}{r}-0.17230 \\
0.2315\end{array}$ & $\begin{array}{l}1.00000 \\
0.0\end{array}$ \\
\hline
\end{tabular}




\section{Appendix 3}

This appendix presents the two detailed models describing the influence of two aspects of the organizational context on organizational performance. The first model reports the influence of store size, store constraints, and the market context variable customer type (cstmrs) on store performance, and the second model the influence of the demographic variables average age (AAGE), tenure with the company (COMTNR), tenure with the store (STOTNR) and average amount of contract hours (WTIME) on store performance.

Table A3.1 Impact of context on performance

\begin{tabular}{|c|c|c|c|c|c|}
\hline \multicolumn{6}{|l|}{ Model 1} \\
\hline $\begin{array}{l}\text { param est } \\
\text { (t-value) }\end{array}$ & mntres & mosts & mwage & mproddif & msicklv \\
\hline stsize & $\begin{array}{l}.34 \\
(5.26)\end{array}$ & & & & \\
\hline nrmprod & $\begin{array}{l}.50 \\
(7.96)\end{array}$ & & $\begin{array}{l}-.82 \\
(12.21)\end{array}$ & & \\
\hline \multicolumn{6}{|l|}{ cstmrs } \\
\hline R-square & .53 & & 68 & & \\
\hline \multicolumn{6}{|c|}{$\begin{array}{l}\text { errors of the dependent variables correlate } \\
\text { chi-square } 12 \mathrm{df}=14.63(p=.26) \\
\text { RMSEA }=.06990 \% \text { confidence interval for } \operatorname{RMSEA}=(.0 ; .17) \text { P-test rmsea }<.05 p=.36 \\
E C V I=1.36 \mathrm{ECV} \text { for saturated model }=1.57\end{array}$} \\
\hline
\end{tabular}

Firstly, the analysis shows that the context variables only influence the financial variables. None of the relationships with productivity performance (MPRODDIF) or sick leave (MSICKLV) is significant. Net results of the store (MNTRES) are influenced by store size (STSIZE) and store constraints (NRMPROD). Larger stores and stores with less constraints (i.e. where NRMPROD is high) perform better. Secondly, the wage costs are significantly higher in stores with more store constraints. The indicators of overall model fit show the model fits the data well.

A similar analysis can be done for the impact of store demography on store performance. Table A3.2 below shows the outcomes of the analysis for store demography and store performance. Separate analyses were done for the financial and the non-financial performance variables.

1 Thit' $\mu$-value for the chi-square test is large, the RMSEA slightly larger than .05, but the p-value for the test of close fit (RMSEA<.05) is .36. Furthermore, the expected cross-validation index (ECVI) is smaller then the ECVI for the saturated model $(1.36<1.57)$. 
Table A3.2 Impact of demographical context on performance

\begin{tabular}{|c|c|c|c|c|c|}
\hline $\begin{array}{l}\text { param est } \\
\text { (t-value) }\end{array}$ & mntres & mcsts & mwage & mproddif & msicklv \\
\hline aage & & $\begin{array}{l}.52 \\
(5.65)\end{array}$ & & & \\
\hline comtnr & & $\begin{array}{l}-.26 \\
(2.74) \\
\end{array}$ & $\begin{array}{l}.29 \\
(3.33)\end{array}$ & & \\
\hline stotnr & & & & & $\begin{array}{l}-.34 \\
(2.49)\end{array}$ \\
\hline \multicolumn{6}{|l|}{ wtime } \\
\hline R-square & & 26 & .087 & & 12 \\
\hline \multicolumn{6}{|c|}{$\begin{array}{l}\text { model fit financial dependents (MNTRES, MCSTS, MWAGE): } \\
\text { errors between dependent variables correlate } \\
\text { chi-square } 9 \mathrm{df}=14.59(p=.10) \\
\text { RMSEA }=1290 \% \text { confidence interval for RMSEA }=(.0 ; .22) \text { P-test rmsea }<.05 p=.16 \\
E C V I=1.17 \mathrm{ECVI} \text { for saturated model }=1.24 \\
\text { model fit non-financial dependents (MPRODDIF MSICKLV): } \\
\text { errors between dependent variables correlate } \\
\text { chi-Square } 7 \mathrm{df}=12.05(p \cdots .099) \\
\text { RMSEA }=.1390 \% \text { confidence interval for RMSEA }=(.0 ; .24) \text { P-test rmsea }<.05 p=.15 \\
\text { ECVI=.89 ECVI for saturated model }=.93\end{array}$} \\
\hline
\end{tabular}

The analyses show that the impact of store demography on organizational performance is not strong: the fit-indices show the models are relatively weak and the explanatory power of the independent variables is not very large. Average age and tenure influence the cost level of the store. In stores where the average age is higher, the percentage controllable costs is also higher; in stores where the average employee is longer with the company (COMTNR) the cost level is lower, but the wage percentage is higher. Furthermore, tenure with this store (STOTNR) is negatively related to the store's sick leave percentage. The average amount of contract hours is not related to any of the performance variables.

The last step in our analysis of the impact of store context variables on store performance will be the integration of the outcomes of the analyses described above in one model. The results are presented in the table in chapter 7.1 and discussed in chapter 7. 


\section{Appendix 4}

This appendix describes the results of the first three steps of the multivariate analysis of the influence of the organizational context on the social variables. The steps are discussed in section 7.2. First, in step1, the influence of the organizational context on the four groups of social variables will be estimated. Subsequently, in step 2, the context, leadership and culture variables will be combined in one analysis. Then, in step 3, the climate variables are added. The outcomes of the final step 4 , where the satisfaction variable is added to the model, are presented and discussed in section 7.2 in the text. As was explained in section 7.2, two separate analyses were done: one using charismatic leadership as the sole leadership variable, and the other using consideration and initiating structure as leadership indicators.

\section{Step 1}

First, in step 1 of the analysis, the influence of the organizational context on each of the four groups of social variables was estimated. The analyses in this first step required the estimation of regression functions as in section 7.1. Separate analyses were done for the structural context variables (store size, constraints, and market context) on the one hand and the demographic variables on the other hand. Table A4.1 below reports the outcomes of the analyses done for each group of social variables.

Table A4.1 Relationships between context and social variables: step 1

\begin{tabular}{|c|c|c|c|c|c|c|c|c|c|}
\hline $\begin{array}{l}\text { pat est } \\
\text { (t-value) }\end{array}$ & chlds & colds & isids & ecul & ocu! & tcom & inno & gcom & satis \\
\hline stsize & & & $\begin{array}{l}44 \\
(3.28)\end{array}$ & & & & $\begin{array}{l}38 \\
(2.99)\end{array}$ & & \\
\hline \multicolumn{10}{|l|}{ nimprod } \\
\hline \multicolumn{10}{|l|}{ cstmrs } \\
\hline$R^{2}$ & & & 19 & & & & .15 & & \\
\hline \multicolumn{10}{|l|}{ aage } \\
\hline comtnr & & & & & $\begin{array}{l}-.38 \\
(2.75)\end{array}$ & & & & $\begin{array}{l}-32 \\
(2.30)\end{array}$ \\
\hline stotnr & & & & $\begin{array}{l}35 \\
(2.49)\end{array}$ & & & & & \\
\hline \multicolumn{10}{|l|}{ wtime } \\
\hline$R^{2}$ & & & & .12 & .14 & & & & .11 \\
\hline
\end{tabular}

In the final analyses for each group only the relationships of store size with initiating structure leadership and innovation were significant, indicating the relatively small direct impact of the organizational context on the social variables and the importance of organizational size in this respect. Furthermore, two demographic variables showed clear relationships with the social variables. Average tenure with the company was 
negatively related to openness and work satisfaction. Tenure with the specific store was positively related to an employee oriented culture in the organization.

\section{Step 2}

In step two, the organizational context, leadership and culture variables were jointly analyzed. After adding the organizational culture variables (and in step 3 and 4 after adding the organizational climate variables and the work satisfaction variable respectively), the relationships found in the previous steps are also under scrutiny again. This helps to get an understanding of the robustness of the various relationships to different model specifications. The results are presented in the two tables below, as we perform separate analyses for the model with consideration and initiating structure as leadership variables and the model using the charisma variable as the leadership measure. Because the organizational culture variables were not directly related to the organizational context, only the relationships from context to leadership, and from leadership to organizational culture were entered into to the model.

Table A4.2 Relationships between context and social variables I: step 2

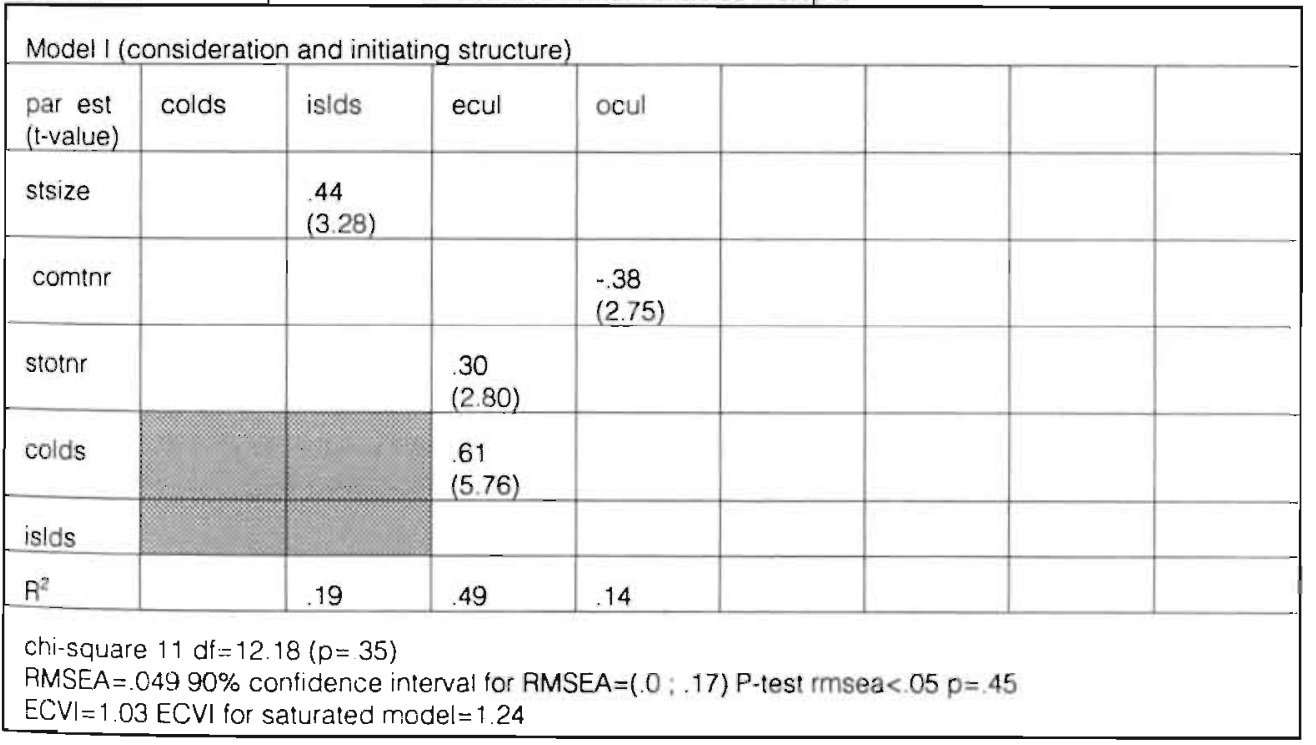

Tables A4.2 and A4.3 show the outcomes of the models estimated after the insignificant relationships had been removed from the models. The rows represent the influence of a certain variable on another variable. The columns represent the relationships of each variable as a dependent variable. The blank boxes show that relationships were insignificant. These were set to 0.00 in the final estimation of the model. The gray boxes in the model show relationships that were a priori, in the model specification, set to zero. 
Table A4.3 Relationships between context and social variables II: step 2

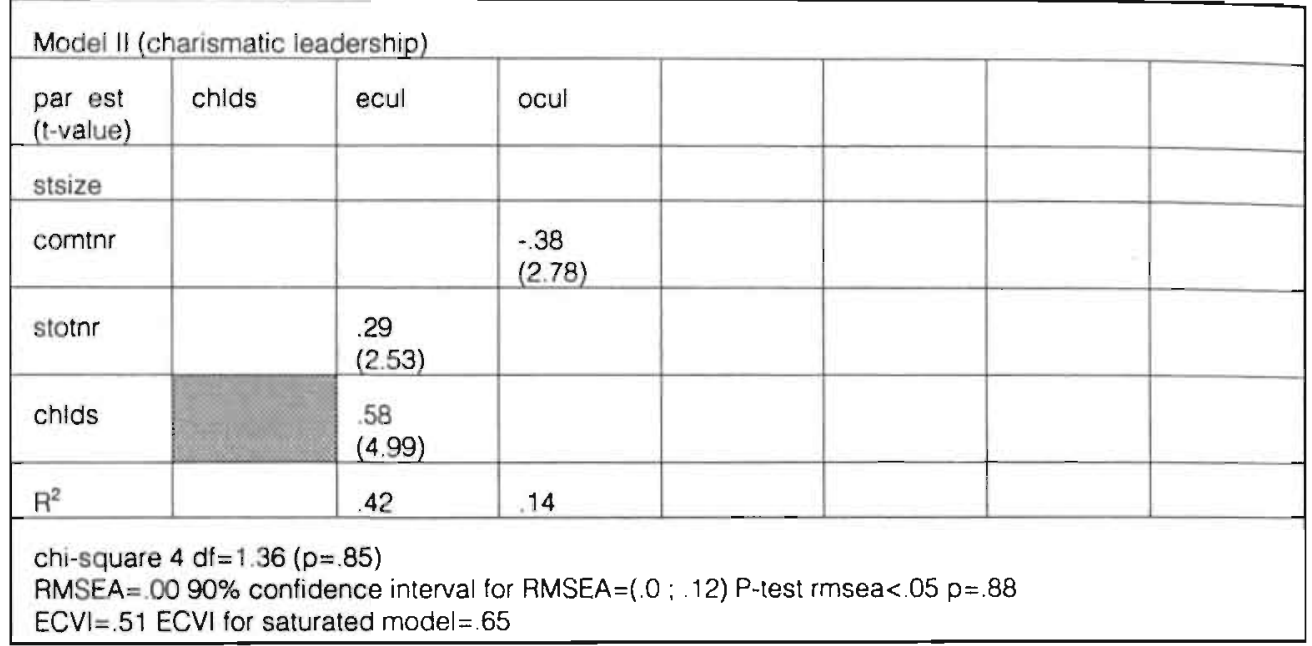

The analyses show that in both models leadership is related to employee orientation. Openness is not influenced by the aspects of leadership measured. All three leadership variables show a significant influence on employee orientation, but the influence of consideration and charisma is much stronger than the influence of structuring leadership behavior. 


\section{Step 3}

In step 3 the climate variables were entered into the model. These were expected to be influenced by the leadership and organizational culture variables. Furthermore, the readiness to innovate variable was related to the organizational context. The two tables below show the results from adding the organizational climate variables into the models.

Table A4.4 Relationships between context and social variables I: step 3

\begin{tabular}{|c|c|c|c|c|c|c|c|}
\hline $\begin{array}{l}\text { par est } \\
\text { (t-value) }\end{array}$ & colds & islds & ecul & ocul & tcom & inno & gcom \\
\hline stsize & & $\begin{array}{l}.44 \\
(3.28)\end{array}$ & & & & $\begin{array}{l}.24 \\
(1.92)\end{array}$ & \\
\hline comtnr & & & & $\begin{array}{l}-.38 \\
(2.75)\end{array}$ & & & \\
\hline stotnr & & & $\begin{array}{l}.30 \\
(2.80) \\
\end{array}$ & & & & \\
\hline colds & & & $\begin{array}{l}.61 \\
(5.76)\end{array}$ & & & $\begin{array}{l}.47 \\
(4.18)\end{array}$ & $\begin{array}{l}41 \\
(2.98)\end{array}$ \\
\hline islds & & & & & & $\begin{array}{l}.30 \\
(2.45)\end{array}$ & \\
\hline ecul & & & & & $\begin{array}{l}46 \\
(3.74)\end{array}$ & & $\begin{array}{l}38 \\
(2.75)\end{array}$ \\
\hline ocul & & & & & $\begin{array}{l}.33 \\
(2.68)\end{array}$ & & \\
\hline$R_{i}^{2^{2}}$ & & .19 & .49 & 14 & .31 & .46 & .50 \\
\hline
\end{tabular}


Table A4.5 Relationships between context and social variables 11: step 3

\begin{tabular}{|c|c|c|c|c|c|c|}
\hline \multicolumn{7}{|c|}{ Model II (charismatic leadership) } \\
\hline $\begin{array}{l}\text { par est } \\
\text { (t-value) }\end{array}$ & chlds & ecuil & ocul & tcom & inno & gcom \\
\hline stsize & & & & & $\begin{array}{l}30 \\
(2.38)\end{array}$ & \\
\hline comtnr & & & $\begin{array}{l}-38 \\
(2.75)\end{array}$ & & & \\
\hline stotnr & & $\begin{array}{l}.29 \\
(2.50)\end{array}$ & & & & \\
\hline chlds & & $\begin{array}{l}.55 \\
(4.84)\end{array}$ & & & $\begin{array}{l}.44 \\
(3.49)\end{array}$ & $\begin{array}{l}45 \\
(3.62)\end{array}$ \\
\hline ecul & & & & $\begin{array}{l}46 \\
(3.74)\end{array}$ & & $\begin{array}{l}37 \\
(2.97)\end{array}$ \\
\hline ocul & & & & $\begin{array}{l}.33 \\
(2.68)\end{array}$ & & \\
\hline$R^{2}$ & & 42 & .14 & 31 & 35 & 54 \\
\hline
\end{tabular}

\section{Step 4}

Finally, in step 4, the satisfaction variable is added to the model. It is assumed that work satisfaction is influenced by store manager leadership, organizational culture, and climate. We already saw that it was not influenced by the context variables. The thus completed model was tested, which resulted in the two models reported in the tables below.

For model I, the tabulated information is shown below (table A4.6) and the graphic representation can be found in section 7.2. For model II the outcomes are presented below in tabulated form (table A4.7) and graphically (figure A4.1).

The outcomes for both models are discussed in the main text in chapter 7 . 
Table A4.6 Relationships between context and social variables I: step 4

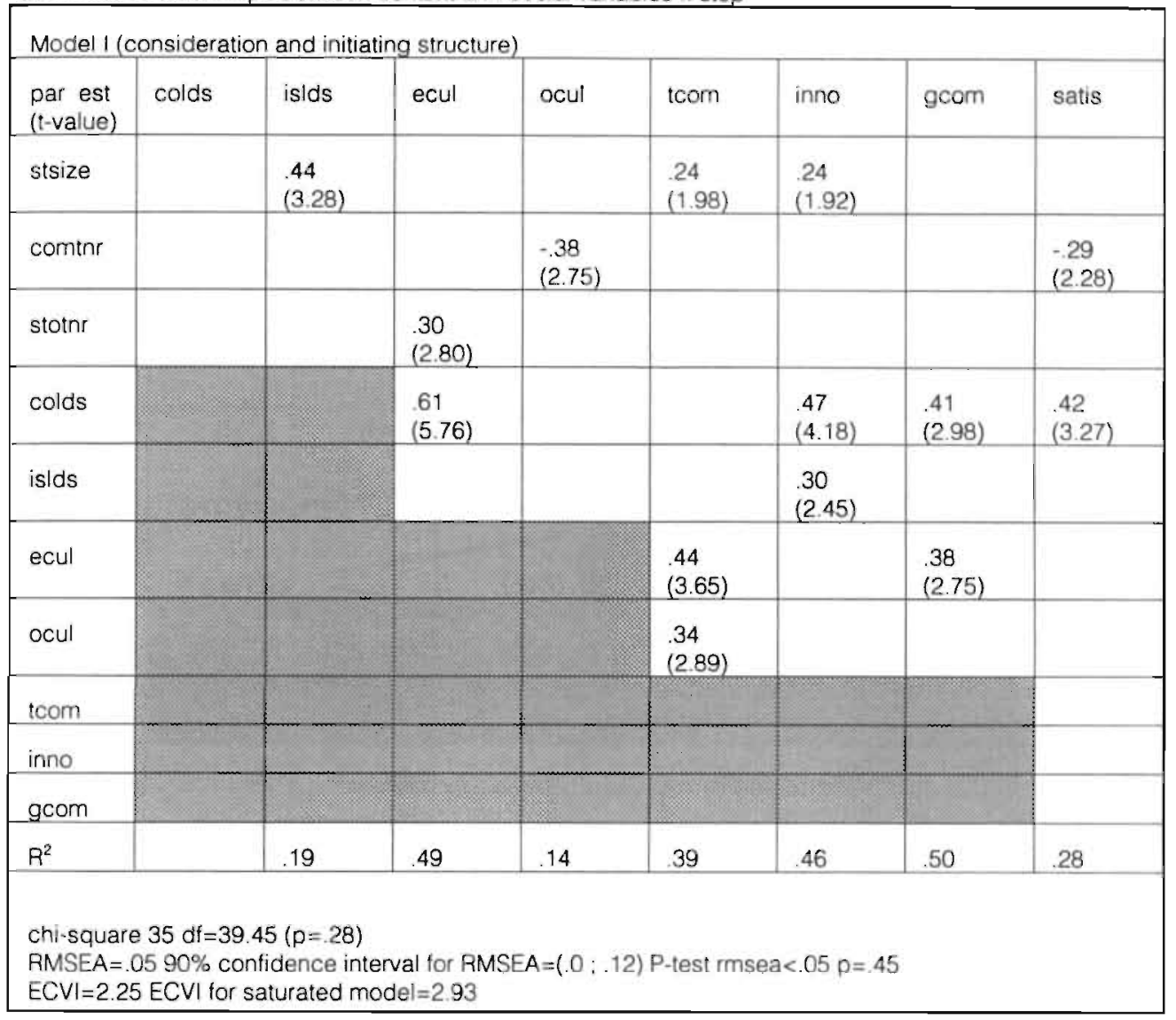


166 Organizational Culture, Leadership and Performance in Context

Table A4.7 Relationships between context and social variables II: step 4

\begin{tabular}{|c|c|c|c|c|c|c|c|}
\hline $\begin{array}{l}\text { par est } \\
\text { (t-vaiue) }\end{array}$ & chlds & ecul & ocul & tcom & inno & gcom & satis \\
\hline stsize & & & & & $\begin{array}{l}30 \\
(2.38)\end{array}$ & & \\
\hline corntnr & & & $\begin{array}{l}-.38 \\
(2.75)\end{array}$ & & & & $\begin{array}{l}-19 \\
(1.59)\end{array}$ \\
\hline stotnr & & $\begin{array}{l}.29 \\
(2.50)\end{array}$ & & & & 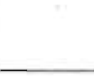 & \\
\hline chlds & & $\begin{array}{l}.55 \\
(4.84)\end{array}$ & & & $\begin{array}{l}.44 \\
(3.49)\end{array}$ & $\begin{array}{l}.45 \\
(3.62)\end{array}$ & $\begin{array}{l}48 \\
(4.25)\end{array}$ \\
\hline ecul & & & & $\begin{array}{l}.46 \\
(3.74)\end{array}$ & & $\begin{array}{l}.37 \\
(2.97)\end{array}$ & \\
\hline ocul & & & & $\begin{array}{l}.33 \\
(2.68)\end{array}$ & & & $\begin{array}{l}25 \\
(2.06)\end{array}$ \\
\hline \multicolumn{8}{|l|}{ tcom } \\
\hline \multicolumn{8}{|l|}{ inno } \\
\hline \multicolumn{8}{|l|}{ gcom } \\
\hline$A^{2}$ & & .42 & & .31 & .35 & .54 & 40 \\
\hline
\end{tabular}


The figure below presents the outcomes for model II (the charisma-model) graphically.

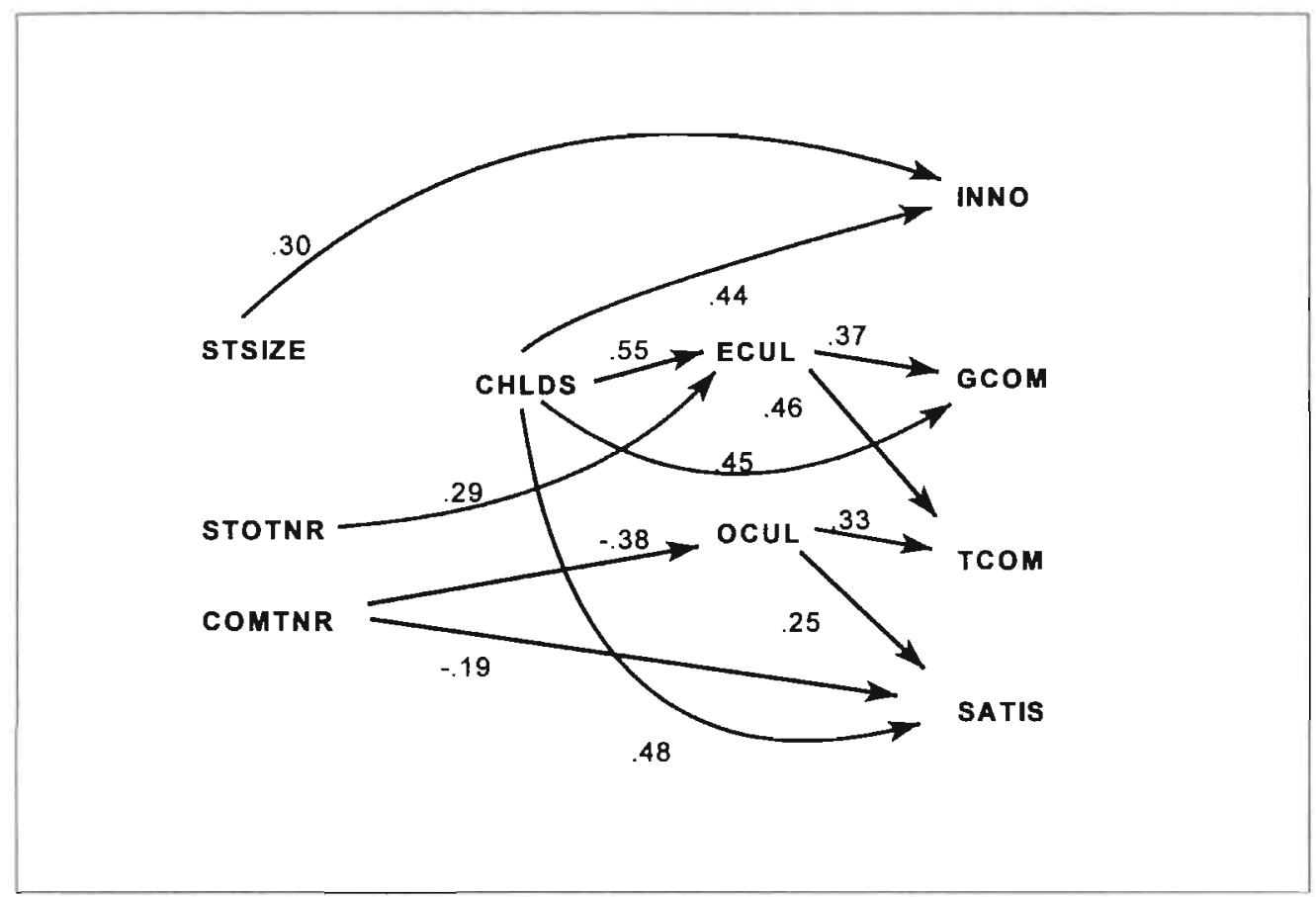

Figure A4.1 Organizational context and the social variables: model It 


\section{Appendix 5}

This appendix present additional information on the outcomes of the analyses of the influence of the social variables on organizational performance. The two figures presented in the text summarize the outcomes of ten separate analyses studying the impact of the social variables on each performance variable separately, based on model I (involving the consideration and initiating structure operationalization of leadership). The figures in the text show our outcomes for model I, whereas the two tables below summarize the relevant statistics for the analyses with each of the ten performance variables.

Table A5.1 Test statistics summary model I performance variables

\begin{tabular}{|c|c|c|c|c|c|c|c|c|c|}
\hline \multicolumn{2}{|c|}{ Model I } & \multicolumn{3}{|c|}{ Chi-square } & \multicolumn{3}{|c|}{$\begin{array}{c}\text { Root mean square error of } \\
\text { approximation }\end{array}$} & \multicolumn{2}{|c|}{$\begin{array}{l}\text { Expected cross. } \\
\text { validation index }\end{array}$} \\
\hline $\begin{array}{l}\text { performance } \\
\text { variables }\end{array}$ & R-square & chi-square & $d f$ & p-value & RUSEA & $\begin{array}{c}908 \\
\text { confidence } \\
\text { interval }\end{array}$ & $p$-value & ECVII & $\begin{array}{l}\text { ECVI for } \\
\text { saturated } \\
\text { model }\end{array}$ \\
\hline MNTRES & .73 & 70.17 & 52 & .047 & .089 & $.01: .14$ & .14 & 3.37 & 4.14 \\
\hline MCSTS & .37 & 66.79 & 53 & .097 & .077 & $.00: .13$ & .23 & 3.25 & 4.14 \\
\hline MNAGE & 83 & 84.50 & 61 & .025 & .095 & $.04: .14$ & .089 & 4.01 & 4. 88 \\
\hline MPRODOIFF & .14 & 51.83 & 46 & .26 & .053 & $.00: 12$ & .45 & 2.57 & 3.47 \\
\hline MSIOKLV & 27 & 50.30 & 45 & 27 & $.05 !$ & $.00: .12$ & .46 & 2.58 & 3.47 \\
\hline
\end{tabular}

Table A5.2 Test statistics summary model I performance development variables

\begin{tabular}{|c|c|c|c|c|c|c|c|c|c|}
\hline \multicolumn{2}{|c|}{ Model 1} & \multicolumn{3}{|c|}{ Chi-square } & \multicolumn{3}{|c|}{$\begin{array}{l}\text { Root mean square error of } \\
\text { approximation }\end{array}$} & \multicolumn{2}{|c|}{$\begin{array}{l}\text { Expected cross. } \\
\text { validation index }\end{array}$} \\
\hline $\begin{array}{l}\text { performance } \\
\text { yariables }\end{array}$ & R.square & chi-square & of & p-value & RMSEA & $\begin{array}{c}908 \\
\text { confidence } \\
\text { interval }\end{array}$ & $p$-value & ECVI & $\begin{array}{l}\text { ECVI for } \\
\text { saturated } \\
\text { model }\end{array}$ \\
\hline DNTRES & .19 & 54.58 & 46 & .18 & .064 & $.00: 12$ & .35 & 2.64 & 3.47 \\
\hline DCSTS & .31 & 49.78 & 45 & .29 & .049 & $.00 \div .11$ & .48. & 2.57 & 3.47 \\
\hline DWAGE & .19 & 51.26 & 46 & .28 & .050 & $.00: .11$ & .47 & 2.56 & 3.47 \\
\hline DPROOOIFF & .13 & 49.97 & 46 & .32 & .044 & $.00: .11$ & .52 & 2.53 & 3.47 \\
\hline OSICKLY & .096 & 53.75 & 46 & 20 & .061 & $.00: 12$ & 38 & 2.62 & 3.47 \\
\hline
\end{tabular}

As explained in chapter 8 , the figures summarizing the outcomes of the analyses based on model I are presented in chapter 8 . The outcomes of the analyses based on model II (the charisma-model) are presented in this appendix. The two figures on the next two pages show the influence on of the social variables on organizational performance, building on model II. The accompanying tables present the relevant statistics for these analyses. 


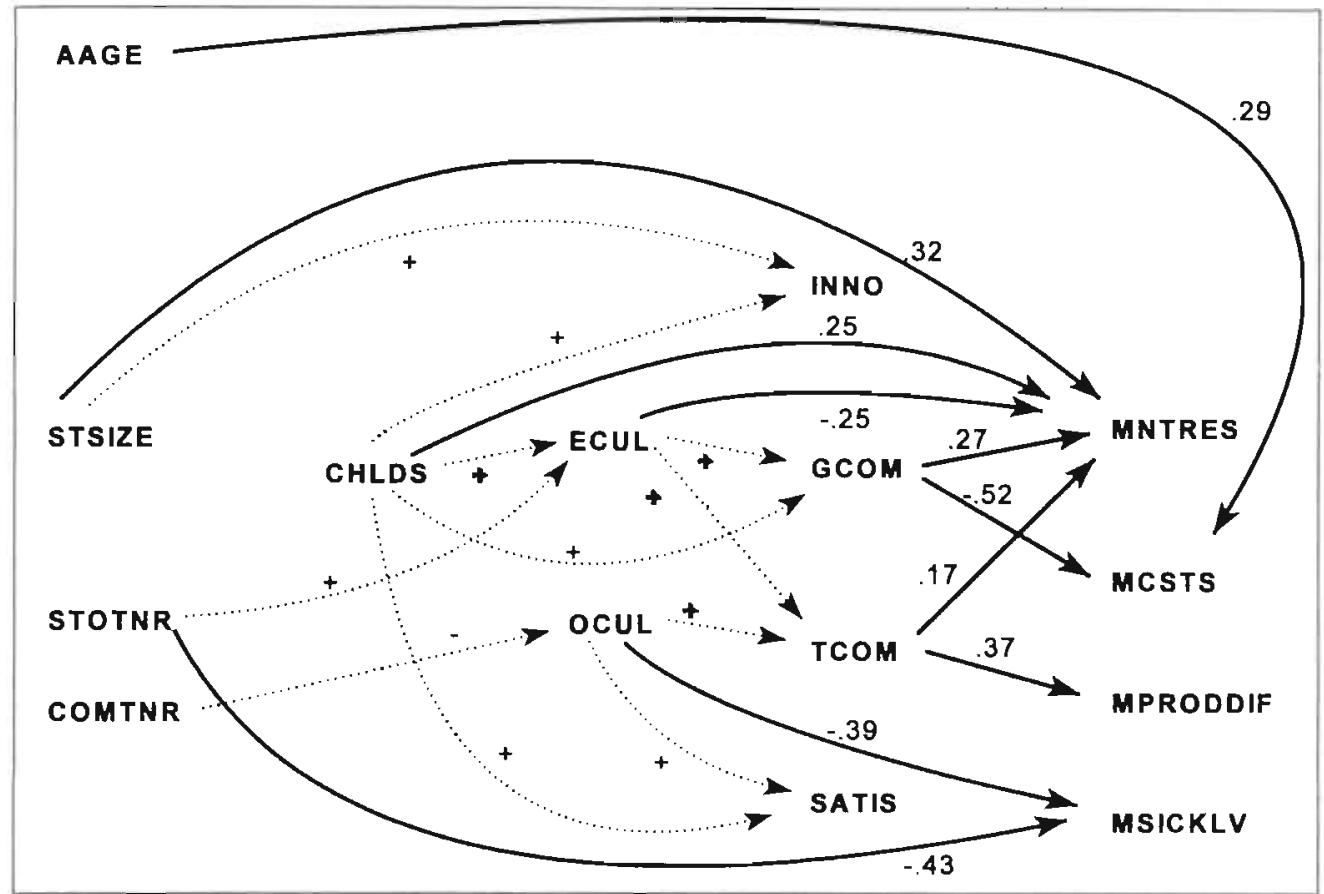

Figure A5.1 Social variables and performance: modell II

Table A5.3 Test statistics summary model II performance variables

\begin{tabular}{|c|c|c|c|c|c|c|c|c|c|}
\hline \multicolumn{2}{|c|}{ Mockel II } & \multicolumn{3}{|c|}{ Chi-square } & \multicolumn{3}{|c|}{$\begin{array}{c}\text { Root: mean square error of } \\
\text { approximation }\end{array}$} & \multicolumn{2}{|c|}{$\begin{array}{l}\text { Expected cross. } \\
\text { validation index }\end{array}$} \\
\hline $\begin{array}{l}\text { performance } \\
\text { variables }\end{array}$ & R-squire & chi-square & $d f$ & D-value & RMSEA & $\begin{array}{c}90 z \\
\text { confidence } \\
\text { interva! }\end{array}$ & p-value & ECVI & $\begin{array}{l}\text { ECVI for } \\
\text { saturated } \\
\text { model }\end{array}$ \\
\hline MNTRES & .77 & 52.89 & 39 & .068 & .090 & $.00: .15$ & .16 & 2.97 & 3.55 \\
\hline MCSTS & .37 & 61.28 & 43 & .035 & .098 & $.03: .15$ & .099 & 2.98 & 3.55 \\
\hline MUAGE & 83 & 71.70 & 49 & .019 & .10 & $.04: .15$ & .064 & 3.62 & 4.23 \\
\hline MPRCOOIFF & .13 & 44,41 & 3) & .19 & .067 & $.00: .13$ & .34 & 2.28 & 2.93 \\
\hline MSIOKLV & .27 & 43.23 & 36 & .19 & .067 & .00 .13 & .34 & 2.29 & 2.93 \\
\hline
\end{tabular}




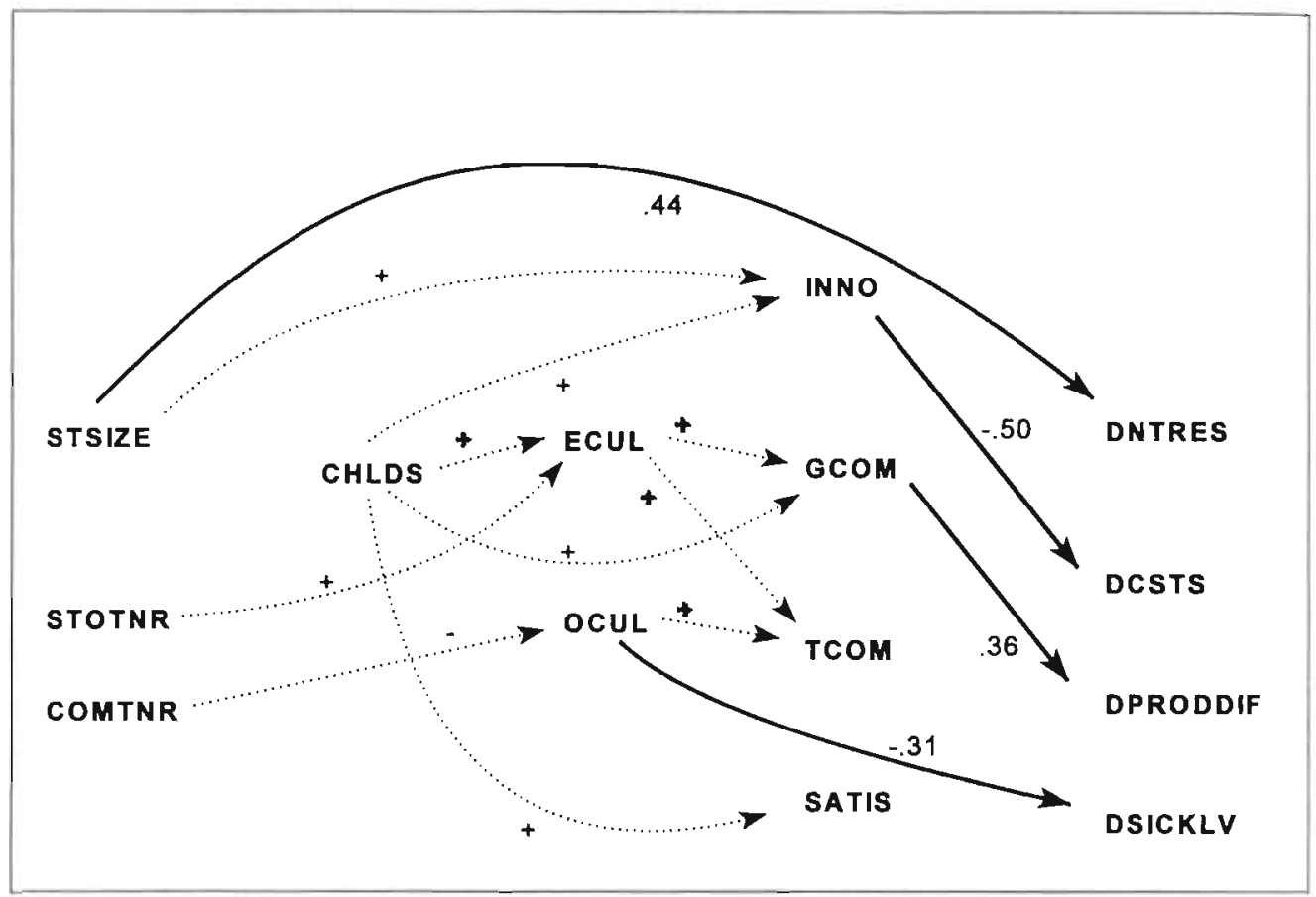

Figure A5.2 Social variables and performance development: model II

Table A5 4 Test statistics summary model II performance develooment variables

\begin{tabular}{|c|c|c|c|c|c|c|c|c|c|}
\hline \multicolumn{2}{|c|}{ Model II } & \multicolumn{3}{|c|}{ Chi-square } & \multicolumn{3}{|c|}{$\begin{array}{c}\text { Root mean square error of } \\
\text { approximation }\end{array}$} & \multicolumn{2}{|c|}{$\begin{array}{l}\text { Expected cross. } \\
\text { validation index }\end{array}$} \\
\hline $\begin{array}{l}\text { performance } \\
\text { variables }\end{array}$ & R.square & chi-square & df & p-value & RMSEA & $\begin{array}{c}\text { got } \\
\text { confidence } \\
\text { interval }\end{array}$ & p-value & ECYI & $\begin{array}{l}\text { ECVI for } \\
\text { saturated } \\
\text { mode? }\end{array}$ \\
\hline ONTRES & .19 & 47.96 & 37 & .11 & .0081 & $.00: .14$ & .23 & 2.35 & 2.93 \\
\hline DCSTS & .25 & 43.84 & 37 & .20 & .064 & $00: .13$ & .36 & 2.26 & 2.93 \\
\hline DWAGE & .19 & 47.19 & 37 & .12 & .078 & $.00: .14$ & .25 & 2.34 & 2.93 \\
\hline DPRODOIFF & .13 & 43.72 & 37 & .21 & .064 & $.00: .13$ & .37 & 2.26 & 2.93 \\
\hline OSICKLY & .096 & 46.01 & 37 & 15 & .074 & $.00: .14$ & .29 & 2.31 & 2.93 \\
\hline
\end{tabular}




\section{LITERATURE}

Allaire, Y., and Firsirotu, M., 1984, Theories of organizational culture. Organization Studies, 5 (3), $193-226$

Argyris, C., 1962, Interpersonal competence and organizational effectiveness, Homewood II: Irwin-Dorsey

Argyris, C., and Schön. D., 1978, Organizational Learning: A theory of action perspective, Reading: Addison-Wesley

Ashforth, B.E., 1985, Climate formation: issues and extensions, Academy of Management Review, 10, 4, pp 837-847

Avolio, B.J., Bass, B.M., 1988, Transformational leadership, charisma, and beyond. In: J.G. Hunt, B.R. Baliga, H.P. Dachler and C.A. Schriesheim (Eds.), Emerging leadership vista's, Lexington, MA: Lexington books

Avolio, B.J., Bass, B.M., Yammarino, F.J., 1988, An alternative strategy for reducing biases in leadership ratings, Paper, Academy of Management, Anaheim, CA.

Avolio, B.J., Waldman, D.A., and Einstein, W.O., 1988, Transformational leadership in a management game simulation, Group \& Organization Studies, 13, pp 59-80

Barnard, C.I., 1938, The functions of the executive, Cambridge, MA: Harvard University Press.

Barney, J.B., 1986, Organizational culture: can it be a source of sustained competitive advantage?, Academy of Management Review, 11, 3, pp 656-665

Bass, B.M., 1985a, Leadership and Performance beyond Expectations, New York: The Free Press

Bass, B.M., 1985b, Leadership: Good, better, best, Organizational Dynamics, 13, 3 pp 26-40

Bass, B.M., 1989, Evolving perspectives on charismatic leadership, in: J.A. Conger and R.N. Kanungo, Charismatic Leadership, the elusive factor in organizational effectiveness, San Francisco, CA: Jossey-Bass Publishers

Bass, B.M., 1990, Bass \& Stogdill's Handbook of leadership, New York: The Free Press

Blake, R.R., and Mouton, J.S., 1964. The managerial grid, Houston, TX: Gulf

Blake, R.R., and Mouton, J.S., 1985. The managerial grid III, Houston, TX: Gulf

Blunt, P., and Jones, M.L., 1992, Managing Organizations in Africa, Berlin: Walter de Gruyter

Boone, C., De Brabander B., and van Witteloostuijn, A., 1996, CEO locus of control and small firm performance: an integrative framework and empirical tests, Journal of Management Studies, 33 (forthcoming)

Boone, C., and van Witteloostuijn, A., 1996, Industry competition and firm human capital, Small Business Economics, 8, pp 1-18 
Bowen, D.E., and Lawler III, E.E, 1992, The Empowerment of Service Workers: What, Why, How and When, Sloan Management Review, Spring, pp 31-39.

Bowers, D.G., and Seashore, S.E., 1966, Predicting organizational effectiveness with a fourfactor theory of leadership, Administrative Science Quarterly, 11, 238-263

Bryman, A., 1992, Charisma and leadership in organizations, London: Sage Publications Inc.

Burns, J.M., 1978, Leadership, New York: Harper \& Row

Burns, T., and Stalker, G.M., 1961, The Management of Innovation, London: Tavistock

Chao, G.T., O'Leary-Kelly, A.M., Wolf, S., Klein, H.J., and Gardner, P.D., 1994, Organizational socialization: Its content and consequences, Journal of Applied Psychology, 79, 5, pp 730-743

Chatman, J.A., 1991, Matching people and organizations: Selection and socialization in public accounting firms, Administrative Science Quarterly, 36, pp 459-484

Chatman, J.A., and Jehn, K.A., 1994, Assessing the relationship between industry characteristics and organizational culture: How different can you be?, Academy of Management Journal, 37, 3, pp 522-553

Cock, de, G., Bouwen, R., de Witte, K., and de Visch, J., 1984, Organisatieklimaat en -cultuur: theorie en praktische toepassing van de organisatie-klimaat-index voor profit-organisaties (OKIPO) en de verkorte vorm (VOKIPO), Leuven, Belgium. Acco

Cohen, J., and Cohen, P., 1983, Applied Multiple Regression/Correlation Analysis for the Behavioral Sciences, Hillsdale, Lawrence Erlbaum Associates.

Conger, J.A., and Kanungo, R.N., 1987, Toward a behavioral theory of charismatic leadership in organizational settings, Academy of Management Review, 12, 4, pp 637-647

Conger, J.A., and Kanungo, R.N., 1988, The empowerment process: integrating theory and practice', Academy of Management Review, 13, 3, pp 471-482

Conger, J.A, and Kanungo, R.N., 1988a, Behavioral dimensions of charismatic leadership. In: J.A. Conger, R.N. Kanungo, and Associates, Charismatic Leadership, the elusive factor in organizational effectiveness, San Francisco CA: Jossey-Bass, pp 78-97

Cortina, J.M., 1993, What is Coefficient Alpha? An examination of Theory and Applications, Journal of Applied Psychology, Vol. 78, No. 1, pp 98-104.

Daft, R.L., 1992, Organization Theory and Design, NY: West Publishing Company

Dansereau, F., Alutto, J.A., and Yammarino, F.J., 1984, Theory testing in organizational behavior: The varient approach, Englewood Cliffs, NJ: Prentice Hall

Deal, T. and Kennedy, A., 1982, Corporate cultures: the rites and rituals of corporate life, Reading, Mass: : Addison-Wesley

Denison, D.R., 1984, Bringing corporate culture to the bottom line, Organizational Dynamics, 13, 2, pp 5-22 
Denison, D.R., 1990, Corporate culture and organizational effectiveness, New York NY: Wiley

Denison, D.R., 1993, What is the difference between organizational culture and organizational climate? A native's point of view on a decade of paradigm wars, Academy of Management Meeting Best Papers Proceedings

Earl, P., 1984, The corporate imagination: how big companies make mistakes, New York, NY: Sharpe

Etzioni, A., 1961, A comparative analysis of complex organizations, New York: The Free: Press

Eyoang, C., 1985, Symbolic transformation of beliel systems, In: L. Pondy, P. Frost. G. Morgan, and T. Dandridge (Eds.), Organizationa/ Symbolism, Greenwich, CT: JAI Press, pp 109-121

Fiedler, F.E., 1967, A theory of leadership effectiveness, New York: McGraw-Hill

Fiedler, F.E., and Garcia, J.E., 1987, New approaches to effective leadership: Cognitive resources and organizational performance, New York: Wiley

Fleishman, E.A., 1953, The description of supervisory behavior, Journal of Applied Psychology, 1970, 20, pp 112-120

Fisher, B.M., and Edwards, J.E., 1988, Consideration and initiating structure and their relationships with leader effectiveness: a meta-analysis, Best Papers Proceedings, Acrademy of Management, Anaheim, CA (cited in Bass, 1990a).

Fleishman, E.A., 1957, A leader behavior description for industry. In: R.M. Stogdill and A.E. Coons (Eds.). Leader behavior, its description and measurement. Columbus: Ohio State University, Bureau of Business research.

Fleishman, E.A., 1973. Twenty years of consideration and structure. In: E.A. Fleishman and J.G. Hunt (Eds.), Current developments in the study of leadership, Carbondale: Southern Illinois University Press

Freeman, F.H., Books that mean business: the management besitsellers, Academy of management review, 10, pp 345-50.

Frost, P.J., Moore, L.F., Reis Louis, M., Lundberg, C.C., Martin, J., 1985, Organizational Culture, London: Sage

Fukuyama, F., 1995, Trust. The social virtues and the creation of prosperity, New York, NY: The Free Press

Geerts, C., 1970, The impact of the concept of culture on the concept of man. pp 47-65 in Hammel, E.A., and Simmons, W.S. (Eds), Man makes sense, Boston: Little, Brown.

Geertz, C., 1973, The interpretation of cultures, New York: Basic Books

George, J.M., 1990, Personality, affect, and behavior in groups, Journal of Applied Psychology. 75, pp 107-116 
George, J.M., and James, L.R., 1993, Personality, affect, and behavior in groups revisited: comment on aggregation, levels of analysis, and a recent application of within and between analysis, Journal of Applied Psychology, 78, 5, pp 798-804

Glick, W.H., 1985, Conceptualizing and measuring organizational and psychological climate: Pitfalls in multilevel research, Academy of Management Review, 10, pp 601-616

Golden, K.A., 1992, The individual and organizational culture: strategies for action in highlyordered contexts, Journal of Management Studies, 29, January, pp 1-21

Gordon, G.G., 1985, The relationship of corporate culture to industry sector and corporate performance. In: Kilmann, R.H., Saxton, M.J., Serpa, R., and Associates (Eds.), Gaining controf of corporate culture, San Francisco: Jossey-Bass, pp 103-125

Gordon, G.G., 1991, Industry determinants of organizational culture, Academy of Management Review, 1, pp 396-415

Gordon, G.G., and Cummins, W.M., 1979, Managing Management Climate, Lexington, Mass: Lexington books

Gordon, G.G., and DiTomaso, N., 1992, Predicting corporate performance from organizational culture, Journal of management studies, 29, 6: November, pp 783-798

Handy, C.B., 1976, Understanding organizations, Baltimore: Penguin Books

Handy, C.B., 1989. The age of unreason, London: Business Books.

Handy, C.B., 1995, Trust and the virtual organization, Harvard Business Review, May-June, pp $40-50$

Hansen, G.S., and Wernerfelt, B., 1989, Determinants of firm performance: the relative importance of economic and organizational factors, Strategic Management Journal, 10, pp $399-411$

Harrison, J.R., and Carroll, G.R., 1991, Keeping the faith: a model of cultural transmission in formal organizations, Administrative Science Quarterly, 36, pp 552-582

Harrison, J.R. and Carroll, G.R., 1995, Manufacturing dissent: the emergence of organizational subcultures, paper presented at the EGOS conference, Istanbul, July,

Hartog, den, D., van Muijen, J., Koopman, P.L., 1994, Transactioneel versus transformationeel leiderschap. Een analyse van de MLQ in de Nederlandse situatie, Gedrag en Organisatie, 7. pp 155-166

Helgesen, S., 1990, The female advantage: women's ways of leadership, NY: Doubleday

Hellriegel, D. and Slocum, J.W., 1974, Organizational climate: measures, research and contingencies, Academy of Management Journal, 17, 2, pp 255-280.

Hersey, P., and Blanchard, K.H., 1969, Management of organization behavior, Englewood cliffs, NJ: Prentice-Hall 
Hersey, P., and Blanchard, K.H., 1969a, A life cycle theory of leadership, Training and Development Journal, 23, pp 26-34

Hersey, P., and Blanchard, K.H., 1982, Management of organization behavior: Utilizing human resources, Englewood cliffs, NJ: Prentice-Hall

Hildebrand, D.K., 1986, Statistical thinking for Behavioral Seientists, Boston MA: Prindle, Weber \& Schmidt

Hise, R.T, et al., 1983, Factors Affecting the Performance of Indiviual Chain Store Units: An Emperical Analysis, Journal of Retailing, Vol. 59, No. 2, pp 22-39.

Hofstede, G., 1982, Value Survey Module and Scoring Guide, Maastricht, the Netherlands: Institute for Research on Intercultural Cooperation

Hofstede, G., 1980, Cultures consequences, international differences in workrelated values, Beverly Hills CA: Sage

Hofstede, G., 1980a, Do American theories apply abroad?, Organizational Dynamics, summer, pp $42-63$

Hofstede, G., 1991, Allemaal andersdenkenden: omgaan met cultuurverschillen. Amsterdam: Contact. In English: 1991, Cultures and Organizations, Software of the mind, London: McGraw Hill

Hofstede, G., Bond, M.H., and Luk, C., 1993, individual perceptions of organizational cultures: a methodological treatise on levels of analysis, Organization Studies, 14, 4, pp 483-503

Hofstede, G., Neuyen, B., Ohayv, D.D., and Sanders, G., 1990, Measuring organizational cultures: a qualitative and quantitative study across twenty cases, Administrative Science Quarterly, 35, pp 286-316

House, R.J., 1977, A 1976 theory of charismatic leadership. In: J.G. Hunt and L.L. Larson (Eds.), Leadership: the cutting edge, Carbondale: Southern Illinois University Press

House, R.J., 1989, personal communication

House, R.J., and Mitchell, T.R., 1983. Path-goal theory of leadership. In: Pennings, J.M. (Ed.), Decision making, an organizational behavior approach, NY: Markus Wiener

Howell, J.M., and Avolio, B.J., 1993, Transformational leadership, transactional leadership; locus of control, and support for innovation: key predictors of consolidated-business-unit performance, Journal of Applied Psychology, 78, pp 891-902

Howell, J.M., and Frost, P.J., 1989, A laboratory study of charismatic leadership, Organizational Behavior and Human Decision Processes, 43, 243-269

Howell, J.P., Bowen, D.E., Dorfman, P.W., Kerr, S., and Podsakoff, P.M., 1990, Substitutes for leadership: effective alternatives for ineffective leadership, Organizational Dynamics, pp 21-38.

James, L.R., 1982, Aggreagtion bias in estimates of perceptual agreement, Journal of Applied Psychology, 67, pp 219-229 
James, L.R., Demaree, R.G., and Wolf, G., 1984, Estimating within-group interrater reliability with and without response bias, Journal of Applied Psychology, 69, pp 85-98

James, L.R., Demaree, R.G., and Wolf, G., 1993, rwg: Anassessment of within-group interrater agreement, Journal of Applied Psychology, 78, 2, pp 306-309

James, L.R., and Jones, A.P., 1974, Organizational climate: a review of theory and research, Psychological Bulletin, 81, 1096-1112

Janis, I.L., 1983, Groupthink. In: Hackman et al., Perspectives on Behavior in Organizations, McGraw-Hill, NY, pp 378-384

Jaques, E., 1951, The changing culture of a factory, London: Tavistock Publications.

Jaques, E., 1990, In praise of hierarchy, Harvard Business Review, jan-feb, pp 127-133

Johnson, G., and Scholes, K., 1993, Exploring Corporate Strategy, NY: Prentice Hall

Jöreskog, K.G., and Sörbom, 1989, LISREL 8: Structural Modeling with the SIMPLIS Command Language, Broadway, Lawrence erlbaum Associated, Inc.

Kahn, W.H., 1990, Psychological conditions of personal engagement and disengagement at work, Academy of Management Journal, 33, 4, pp 692-724

Kahn, W.H., 1992, To be fully there: Psychological presence at work. Human Relations, 45,4, pp $321-349$

Kalma, A.P., 1989, Dominantie en onzekerheidsreductie, twee uitingsvormen van het competentiemotief, unpublished doctoral dissertation, University of Utrecht, the Netherlands

Karmel, B., 1978, Leadership: a challenge to traditional research methods and assumptions, Academy of Management Review, 3, 475-482

Kelley, S.W., 1993, Discretion and the service emplyee, Journal of Retailing, 69, 1, pp 104-126

Keri, S., and Jermier, J., 1978, Substitutes for leadership: Their meaning and measurement, Organizational Behavior and Human Performance, 22, pp 374-403.

Klein, K.J., Dansereau, F., Hall, R.J., 1994, Levels issues in theory development, data collection, and analysis, Academy of Management Review, 19, pp 195-229

Kleinbaum, D.G., Kupper, L.L., and Muller, K.E., 1988, Applied Regression Analysis and Other Multivariable Methods, second edition, Boston: PWS-Kent

Koene, B.A.S., Boone, C., and Soeters, J.L., 1996, Organizational factors influencing homogeneity and heterogeneity of organizational cultures. In: Cultural complexity in Organizations: Inherent Contrasts and Contradictions, London: Sage (forthcoming)

Koene, B.A.S., Pennings, J.M., Schreuder, H., 1992, Leadership, Organizational culture, and organizational outcomes. In: K.E. Clark, M.B. Clark, D.P. Campbell (Eds.), Impact of Leadership, Greensboro NC: Center for Creative Leadership, pp 215-223 
Korman, A.K., 1966, 'Consideration,' 'Initiating structure,' and Organizational criteria -- a review. Personnel Psychology, 18, pp 349-360

Kozlowski, S.W.J., and Hattrup, K., 1992, A disagreement about within-group agreement: disentangling issues of consistency versus consensus, Journal of Applied Psychology, 77, pp 161-167

Kuhnert, K.W., and Lewis, P., 1987, Transational and transformational leadership: a constructive / developmental analysis, Academy of Management Review, 12, 4, pp 648-657

Lado, A.A., and Wilson, M.C., 1994, Human resource systems and sustained competitive advantage: a competency-based perspective, Academy of Management Review, 19, 4, pp 699-727

Lammers, C.J., 1986, De excellente onderneming als organisatiemodel, Harvard Holland Review, 8, pp 18-27.

Lammers, C.J., 1988, The interorganizational control of an occcupied country, Administrative Science Quarterly, 33, pp 438-457

Lawler III, E.E., Hall, D.T., and Oldham, G.R., 1974, Organizational climate: relationship to organizational structure, process and performance, Organizational Behavior and Human Performance, 11, pp 139-155

Leeflang. P.S.H., and Beukenkamp. P.A., 1981, Probleemgebied marketing. een managementbenadering, Leiden: stenfert kroese

Lincoln, J.R., and Zeitz, G., 1980, Organizational proporties from aggregate data: separating individual and structural effects, American Sociological Review, 45, pp 391-408

Litwin, G.H., and Stringer, R.A., 1968, Motivation and organizational climate, Boston, MA: Harvard University, Graduate School of Business Administration, Division of Research

Maijoor, S., and van Witteloostuijn, A., 1996, An empirical test of the resource-based theory: strategic regulation in the Dutch audit industry, Strategic Management Journal, (forthcoming)

Mann, F.C., 1965, Toward an understanding of the !eadership role in formal organization. In: R.Dubin (Ed.), Leadership and Productivity, San Francisco: Chandler

March, J.G., 1984, The technology of foolishness. In: Pugh, D.S., (ed.), Organization Theory: selected readings, second edition, Harmondsworth, Middlesex, England: Penguin Books

Martin, J., 1985, Can organizational culture be managed?, Introduction in: P.J. Frost, L.F. Moore, M.R. Louis, C.C. Lundberg, and J. Martirı (Eds.). Organizational culture, Beverly Hills, Ca: Sage

Mayer, R.C., Davis, J.H., and Schoorman, F.D., 1995, An integrative model of organizational trust, Academy of Management Review, 20, 3, pp 709-734 
Miller, D., and Dröge, C., 1986, Psychological and traditional determinants of structure, Administrative Science Quarterly, december, pp 539-560

Miller, J.A., 1973, A hierarchical structure of leaddership behaviors (Tech,rep.no.66),

Rochester NY: University of Rochester, Management research center

Miller, K.I., and Monge, P.R., 1986, Participation, satisfaction, and productivity: a meta-analytic review, Academy of Management Journal, 29, 727-753

Milis, D.Q., 1991, Rebirth of the Corporation, NY: Wiley \& Sons

Mintzberg, H., 1973, The nature of managerial work, New York: Haper \& Row, Pub.

Mintzberg, H., 1979, The Structuring of Organizations, Englewood Cliffs, NJ: Prentice-Hall

Mintzberg, H, 1983, Structures in Fives, Englewood Cliffs, NJ: Prentice Hall

Mintzberg, $H_{1}, 1991$, The effective organization: forces and forms, Sloan Management Review, Winter, pp 54-67

Misumi, J., 1985, The behavioral science of leadership. An interdisciplinary Japanese research program, Ann Arbor, University of Michigan Press

Misumi, J, and Peterson, M.F., 1985, The performance-maintenance (PM) theory of leadership: Review of a Japanese research program, Administrative Science Quarterly, 30, 198-223

Misumi, J, and Peterson, M.F., 1987, Supervision and leadership. In: B.M. Bass and P.J.D. Drenth (Eds.), Advances in Organizational Psychology, Beverly Hills CA: Sage Publications

Morgan, G. 1986, Images of organization, Beverly Hills CA: Sage publications

Nonaka, I., 1994, A dynamic theory of knowledge creation, Organization Science, 5, pp 14-37

O'Reilly, C.A., Caldwell, D.F., and Barnett, W.P., 1989, Work group demography, social integration, and turnover, Administrative Science Quarterly, 34, pp 21-37

O'Reilly III, C.A., Chatman, J., and Caldwell, D.F., 1991, People and organizational culture: a profile comparison approach to assessing person-organization fit, Academy of Management Journal, 34, 3, pp 487-516

Ohmae, K., 1985, Triad power: the coming of global competition, MacMillan, London

Organ, D.W., 1988, Organizational citizenship behavior: The good soldier sydrome, Lexington, MA: Lexington books

Ostroff, C., 1993. The effects of climate and personal influence on individual behavior and attitudes in organizations, Organizational Behavior and Human Decission Processes, 56, pp 56-90.

Ouchi, W.G., 1980, Markets, bureacracies, and clans, Administrative Science Quarterly, 25, pp 129-141 
Ouchi, W.G., 1981, Theory Z: how American business can meet the Japanese challenge, Mass.: Addison-Wesley.

Ouchi, W.G. and Jaeger, A.M., 1978, Type Z organization: Stability in the midst of mobility, Academy of Management Review, 3, pp 305-313.

Parsons, T., 1959, General theory in sociology, In: R.K. Merton, L. Broom, and L.S. Cottrell (Eds.), Sociology Today, New York:..., 1959, pp 3-38

Pascale, R.T. and Athos, A.G., The art of Japanese management, New York: Simon \& Schuster.

Payne, R.L., and Mansfield, R.M., 1973, Relationships of perceptions of organizational climate to organizational structure, context, and hierarchial position, Administrative Science Quarterly, 18. pp $515-526$

Payne, R.L., and Pheysey, D.C., 1971, G.G. Stern's organizational climate index: a reconceptualization and application to business organizations, Organizational Behavior and Human Performance, 6, pp 77-98

Payne, R.L., and Pugh, S.S., 1976, Organization structure and organization climate. In: M.D. Dunette (Ed.), Handbook of Industrial and Organizational Psychology, Chicago: Rand McNally, pp 1125-1173

Pennings, J.M., 1975, The relevance of the structured-contingency model for organization effectiveness, Administrative Science Quarterly, 20, 393-407

Pennings, J.M., 1989, Personal communication, confidential consumer bank study

Pennings, J.M., and Gresov, C., 1986, Techno-economic and structural correlates of organizational culture: an integrative framework, Organization Studies, 7 (4), 317-334

Peters, T.J., and Waterman, R.H., 1982, In search of excellence: lessons from America's bestrun companies, New York, NY: Harper \& Row publishers

Peterson, M.F., Phillips, R.L., and Duran, C.A., 1989, A comparison of Japanese performancemaintenance measures with U.S. leadership scales, Psychologia -- An International Journal of Psychology in the Orient, 32, 58-70

Pettigrew, A.M., 1979, On studying organizational cultures, Administrative Science Quarterly. 24, pp 570-581

Pfeffer, J., 1982, Organizations and Organization Theory, Cambridge MA: Ballinger Publishing Company

Pfeffer, J., 1983a, Organizational demography, Research in Organizational Behavior, 5, pp 299-357

Pfeffer, J., 1983b, The ambiguity of leadership. In: Hackman, J.R., ... et al.(Eds.), Perspectives on Behavior in Organization, NY: McGraw-Hill, pp 486-493 
Pfeffer, J., 1985, Organizational demography: implications for management, California Management Review, 28 (1), pp 67-81

Pfeffer, J., 1992, Managing with power, Boston MA: Harvard Business School Press

Pfeffer, J., 1994, Competitive Advantage through People: Unleashing the power of the work force, Boston, MA: Harvard Business School Press

Philipsen, H., 1965, Het meten van leiderschap, Mens en Onderneming, 19, pp 153-171

Philipsen, H., 1970, Het meten van leiderschap nader beschouwd, Mens en Onderneming. 128-135

Podsakoff, P.M., Mackenzie S.B., and Fetter, R., 1993a, Substitutes for leadership and the management of professionals, Leadership Quarterly, 4(1), pp 1-44.

Podsakoff, P.M., Niehoff, B.P., MacKenzie, S.B., and Williams, M.L., 1993b, Do substitutes for leadership really substitute for leadership? An empirical examination of Kerr and Jermier's situational leadership model, Organizational Behavior and Human Decision Processes, 54, pp $1-44$

Poole, M.S., 1985, Communication and organizational climates: review, critique, and a new perspective. in: R.D. Mc.Phee and P.K. Tompkins (eds.) Organizational Communication, pp 79 108, Beverly Hills CA: Sage

Pratt, J., and Beaulieu, P., 1992, Organizational culture in public accounting: size, technology, rank, and functional area, Accounting Organizations and Society, 17, pp 667-684

Przeworski, A., and Teune, H., 1970, The logic of comparative social inquiry, N.Y.: WileyInterscience

Reynolds, P.D., 1986, Organizational culture as related to industry, position and performance: a preliminary report', Journal of Management Studies, 23, pp 333-345

Ritzer, G., 1993. The McDonaldization of Society: An investigation into the changing character of contemporary social life, Pine Forge Press

Ritzer, G., and LeMoyne, T., 1991, Hyperrationality: An extension of Weberian and neoWeberian theory, in: Metatheorizing in Sociology, G. Ritzer, Lexington, MA: Lexington Books

Robbins, S.P., 1996, Organizational Behavior, Englewood Cliffs NJ: Prentice Hall

Romme, A.G.L., 1996, A note on the hierarchy-team debate, Strategic Management Journal, 17. $p p 411-417$

Rousseau, D.M., 1985, 'Issues of level in organizational research: multi-level and cross-level perspectives', Research in Organizational behavior, 7, pp 1-37

Saffold, G.S., 1988, Culture traits, strength, and organizational performance: moving beyond "strong" culture. Academy of Management Review, 13, pp 546-558 
Saris, W., and Stronkhorst, H., 1984, Causal Modelling in Nonexperimental Research: An Introduction to the LISREL Approach, Amsterdam.

Schein, E.H., 1983, The role of the founder in creating organizational culture, Organizational Dynamics, summer 1983, pp 13-28

Schein, E.H., 1985, Organizational culture and leadership, San Francisco: Jossey Bass

Schein, E.H., 1992, Organizational culture and leadership, second edition, San Francisco: Jossey Bass

Scherer, F.M., and Ross, D., 1990, Industrial Market Structure and Economic Performance, Boston, Houghton Mifflin Company.

Schneider, B., 1987, The people make the place, Personnel Psychology, 40, pp 437-453

Schneider (Ed.), B., 1990, Organizational Climate and Culture, San Francisco, CA: JosseyBass

Schneider, B., Parkington, J.J., and Buxton, V.M., 1980, Employee and customer perceptions of service in banks, Administrative Science Quarterly, 25, pp 252-267

Schwartz, H., and Davis, S.M., 1981, Matching corporate culture and business strategy,

Organizational dynamics, 10, pp 30-48

Seltzer,J. and Bass, B.M.,1990, Transformational leadership: Beyond initiation and consideration, Journal of Management.

Selznick, P., 1957, Leadership in Administration, NY: Harper \& Row

Senge, P.M., 1990, The fifth discipline: the art and practice of the learning organization, New York: Doubleday.

Sheridan, J.E., 1992, Organizational culture and employee retention, Academy of Management Journal, 35, 5, pp 1036-1056

Siehl, E., 1985, After the founder: an opportunity to manage culture, pp 125-140, in Frost, P.J. et al. (eds), Organizational culture, London: Sage Publications, Inc.

Simon, H.A., 1987, Making management decisions: the role of intuition and emotion, Academy of Management Executive, feb, pp 57-64

Smith, P.B., and Peterson, M.F., 1988, Leadership, Organizations and Culture, London: Sage Publications

Soeters, J.L., 1986, Excellent companies as social movernents, Journal of Management Studies, 23, 299-312

Soeters, J.L., and Schreuder, H., 1988, The interaction betweeñ national cultures and organizational cultures in accounting firms, Accounting. Organizations and Society, 13, pp 7586 
Sorge, A., 1989, Organisationskulturen: Realer Hintergrund und soziologische Bedeutung einer Modewelle. In: Kultur und Gesellschaft. Verhandlungen des 24. Deutschen Soziologentags, des 11. Osterreichischen Soziologentags und des 8 . Kongresses der Schweizerischen Gesellschaft fur Soziologie in Zurich, Frankfurt/Main: Campus Verlag

Syroit, J., 1979, Mens- en taakgerichtheid: constructie en validering van een verkorte leiderschapsschaal, Gedrag, tijdschrift voor psychologie, 3, pp 176-192

Tett, R.P., and Meyer, J.P., 1993, Job satisfaction, organizational commitment, turnover intention, and turnover: path analyses based on meta-analytic findings, Personnel Psychology, 46. $p \rho$ 259-290

Thomas, A.B., 1988, Does leadership make a difference to organizational performance? Administrative Science Quarterly, pp 388-400

Touraine, A., 1965, Sociologie de láction, Paris: Editions du Seuil.

Trice, H.M., and Beyer, J.M., 1984, Studying organizational cultures through rites and ceremonials, Academy of Management Review, 9 (4), 653-669

Trice, H.M., and Beyer, J.M., 1985, Using six organizational rites to change culture, San Francisco, Ca: Jossey-Bass

Trice, H.M., and Beyer, J.M., 1986. Charisma and its routinization in two social movement organizations, Research in Organizational Behavior, 8, pp 113-164

Trice, H.M., and Beyer, J.M., 1991. Cultural leadership in organizations, Organization Science, 2. $p p 149-169$

Trice, H.M., and Beyer, J.M., 1993, The Cultures of Work Organizations, Englewood Cliffs: Prentice Hall

Tsui, A.S., Egan, T.D., and O'Reilly III, C.A., 1992, Being Different: Relational Demography and Organizational Attachment, Administrative Science Quarterly, pp 549-579.

Vlist, R. Van der, 1989, Automatic Information Processing Activities and Operational Decision Making: A Case Study of Consequence, Information and Management, Vol. 16, pp 219-225.

Vogelaar, 1990. Arbeidssatisfactie: een consequentie van behoeftenstructuur en kenmerken van werk en werksituatie. unpublished doctoral dissertation, University of Leiden. The Netherlands

Weber, M., 1968, Economy and society (1925), 3 vols, eds G. Roth and C Wittich, New York: Bedminster

Weick, K., 1985, The significance of corporate culture. In Frost, P. et al. (Eds), Organizational culture, Beverly Hills: Sage, pp 381-389

Weitzel, W., Schwarzkopf, A.B., and Peach, E.B., 1989, The influence of employee perceptions of customer service on retail store sales, Journal of Retailing. 65, 1. 
Wilkins, A.L., 1984, The creation of company cultures: the role of stories in human resource. systems, Human Resource Management, 23, pp 41-60

Wilkins, A.L., and Ouchi W.G., 1983. Efficient cultures: exploring the relationship between culture and organizational performance, Administrative Science Quarterly, 28, pp 468-481.

Williams, M.L., et al., 1988, A preliminary analysis of the construct validity of Kerr \& Jermier's 'Substitutes for Leadership' Scales, Journal of Occupational Psychology, 61, pp 307-333.

Wofford, J.C., 1970, Factor analysis of managerial behavior variables, Journal of appliedd Psychology, 54, 169-173

Wofford, J.C., 1971, Managerial behavior, situational factors, andd productivity and morale, Administrative Science Quarterly, 1, 10-17

Yammarino, F.J., and Markham, S.E., 1992, On the application of within and between analysis: are absence and affect really group-based phenomena?, Journal of Applied Psychology, 77. pp 168-176

Yukl, G.A., 1971, Toward a behavioral theory of leadership, Organizational Behavior and Human Pertormance, 6, 414-440

Yukl, G.A., 1989, Leadership in Organizations, Englewood Cliffs, NJ: Prentice Hall

Zaleznik, A., 1977, Managers and leaders: are they different?, Harvard Business Review, 55, 5 , $67-80$

Zammuto, R.F, and O'Connor, E.J., 1992, Gaining advanced manufacturing technologies' benefits: the roles of organization design and culture, Academy of Management Review, 17, 4 , pp 701-728 



\title{
Summary in Dutch
}

\section{Organisatiecultuur, leiderschap en bedrijfsresultaten}

\begin{abstract}
Dit proefschritt gaat over de invloed van organisatiecultuur en leiderschap op de effectiviteit van organisaties. In het afgelopen decennium is er in het organisatieonderzoek en de organisatiepraktijk veel aandacht besteed aan organisatiecultuur. In de jaren tachtig was het begrip cultuur het toverwoord. Een sterke organisatiecultuur leek de oplossing voor organisaties die wilden ontsnappen aan de verstikkende invloed van formele bureaucratische structuren. Een sterke cultuur als alternatief besturingsmiddel voor de organisatie bood de ruimte aan creativiteit en gaf toch duidelijk de koers van de onderneming en de bedrijfsidentiteit aan. Inmiddels is het begrip organisatiecultuur ingeburgerd en erkend als een belangrijk aspect van organisaties. Dit neemt niet weg dat de bespreking van het begrip cultuur nog steeds weinig concreet is en de invloed van organisatiecultuur op bedrijfsresultaten nog nauwelijks empirisch is onderzocht. Gekoppeld aan de belangstelling voor cultuur is er een groeiende aandacht voor leiderschap in organisaties. Leiderschap wordt veelal gezien als een belangrijke determinant van organisatiecultuur.
\end{abstract}

Er zijn drie redenen om de invloed van organisatiecultuur en leiderschap op becirijfsresultaten te onderzoeken. Ten eerste wordt het tijd om het begrip organisatiecultuur in perspectief te plaatsen. Organisatiecultuur is slechts één aspect van organisaties, maar wordt veelal gepresenteerd als een wondermiddel voor het oplossen van de problemen van moderne organisaties. Het is daarom van belang om nu de relatieve invloed van organisatiecultuur te bestuderen ten opzichte van andere determinanten van bedrijfsresultaat. Ten tweede zijn verschillen tussen organisatieculturen tot nu toe meestal geanalyseerd op het niveau van bedrijfstakken. Het merendeel van de gevonden verschillen lijkt dan ook te worden veroorzaakt door verschillen in werkproces. Er is relatief weinig aandacht besteed aan cultuurverschillen binnen bedrijfstakken, terwijl dit nu juist de verschillen zijn waarmee een onderneming een concurrentieel voordeel kan behalen op zijn concurrenten. Bovendien gaat het hierbij om dimensies van cultuur die, anders dan bedrijfstakcultuur, in potentie beïnvloedbaar zijn door het management. Als laatste overweging is er het algemene gebrek aan kwantitatief empirisch onderzoek dat de invloed van organisatiecultuur op bedrijfsresultaten onderbouwt.

In hoofdstuk 2 wordt het begrip organisatiecultuur gedefinieerd en in een historische en theoretische context geplaatst. Cultuur wordt gedefinieerd als 'de collectieve mentale programmering waardoor de leden van een groep verschillen van die van andere groepen.' Organisatiecultuur komt tot stand door de interactie van de leden van de organisatie en weerspiegelt de manier waarop de organisatiegenoten gezamenlijk hun werk interpreteren en zin geven. De aandacht voor organisatiecultuur lijkt een nieuwe stap in het denken over organisaties waarin het functioneren van het menselijk kapitaal in de onderneming centraal wordt gesteld. Het blijkt echter dat het gedachtengoed met betrekking tot de functie van het menselijk kapitaal in de onderneming gegrondvest is in een lange traditie. 
Hoofdstuk 3 geeft een overzicht van het empirisch onderzoek naar organisatiecultuur. Kwantitatief onderzoek naar organisatiecultuur blijkt voort te bouwen op onderzoek naar organisatieklimaat. Er wordt beargumenteerd dat cultuur-en klimaatonderzoek een duidelijk verschillende invalshoek kiezen voor het bestuderen van het sociale aspect van organisaties. Een nauwkeurige evaluatie laat echter ook zien dat empirisch comparatief cultuur en klimaatonderzoek sterk op elkaar lijken. Veelal is het kwantitatieve cultuuronderzoek van de afgelopen zes jaren gefundeerd in de lange traditie van organisatieklimaatonderzoek. Veel cultuuronderzoek leunt nog sterk op klimaatonderzoek voor de empirische operationalisatie van de concepten. Onderzoek dat gebruik maakt van nieuw ontwikkelde cultuurmeetinstrumenten is schaars. Het in hoofdstuk 3 gegeven overzicht laat zien dat een zestal onderwerpen in studies van het sociale aspect van organisaties steeds terugkeert.

Hoofdstuk 4 is gewijd aan de invloed van leiderschap in organisaties. Leiders worden gezien als belangrijke determinanten van organisatiecultuur. Leiderschap wordt eerst beschreven als een specifiek onderdeel van de managementtaak in een onderneming. Een overzicht van het leiderschapsonderzoek laat vervolgens twee belangrijke onderzoekstradities zien. Ten eerste het traditionele leiderschapsonderzoek dat zich richt op taakgericht en mensgericht leiderschap. Ten tweede het recentere onderzoek naar transactioneel en transformationeel leiderschap waarin charisma als centraal element naar voren komt.

In hoofdstuk 5 wordt op basis van de conclusies uit de eerdere hoofdstukken een zestal onderzoeksvragen geformuleerd om de invloed van organisatiecultuur en leiderschap op bedrijfsresultaten in kaart te brengen. De vragen hebben betrekking op (i) de invloed van leiderschap en organisatiecultuur op bedrijfsresultaten, (ii) de invloed van de organisationele context op bedrijfsresultaten, maar ook op leiderschap en cultuur; en (iii) de kwaliteit en bruikbaarheid van de meetinstrumenten. Daarnaast beschrijft dit hoofdstuk de opzet van het empirische onderzoek. Het onderzoek werd uitgevoerd in vijftig filialen van een grote Nederlandse supermarktketen. Het leiderschap van de filiaalmanager en de filiaalcultuur werden gerelateerd aan de filiaalresultaten. Op deze manier werden vijftig organisaties vergeleken in dezelfde bedrijfstak, met een vrijwel identieke formele structuur en opererend in eenzelfde markt.

De hoofdstukken 6.7 en 8 beschrijven de uitkomsten van het empirisch onderzoek. Hoofdstuk 6 beschrijft de operationalisatie van de concepten organisatiecultuur, klimaat, leiderschap, context en bedrijfsresultaten. De kwaliteit van de meetinstrumenten en de data worden geëvalueerd. Bovendien worden de eerste twee onderzoeksvragen over de kwaliteit van de meetinstrumenten van leiderschap en cultuur besproken. De vijftig winkels blijken duidelijk te verschillen wat betreft leiderschap, organisatiecultuur en klimaat. Voor organisatiecultuur gaat het hierbij om de twee dimensies waarvan Hofstede et al. (1990) aangeven dat ze sterk worden bepaald door de oprichter en het huidige management van de organisatie: de dimensies mensgerichtheid en openheid. Bij de gemeten leiderschapsvariabelen blijken mensgericht leiderschap en charisma zo sterk met elkaar gecorreleerd dat getwijfeld mag worden aan de onafhankelijkheid van de empirische operationalisatie van de twee dimensies. 
Hoofdstuk 7 beschrijft de invloed van de organisationele context op zowel bedrijfsresultaten,als op leiderschap, cultuur en klimaat. De omvang van de winkels blijkt duidelijk van invloed te zijn op zowel de sociale variabelen leiderschap, cultuur en klimaat, als op bedrijfsresultaten. De invloed van winkelomvang op bedrijfsresultaten duidt op het bestaan van economies of scale en economies of scope voor de supermarkten. De invloed van winkelomvang op de sociale variabelen weerspiegelt de invloed van de formele organisatie: in grotere winkels is de formele organisatie uitgebreider en belangrijker dan in de kleinere winkels. Hoofdstuk 7 laat ook zien dat de sociale variabelen onderling gerelateerd zijn. Leiderschap en organisatiecultuur laten beiden een eigen invloed zien op respectievelijk organisatiecultuur en -klimaat en op organisatieklimaat. Leiderschap en formele structuur beïnvloeden het sociale aspect van de organisatie wel op een duidelijk verschillende manier. Leiderschap beïnvloedt vooral die aspecten van de sociale omgeving die te maken hebben met menselijke motivatie en vertrouwen. De formele structuur beïnvloedt vooral de helderheid, structuur en begrijpelijkheid van de organisatiedoelen en is van belang voor innovatie en de kwaliteit van taakcommunicatie in de organisatie.

Hoofdstuk 8 bespreekt de centrale onderzoeksvraag naar de invloed van leiderschap en organisatiecultuur op bedrijfsresultaten. Uit het onderzoek blijkt dat, zelfs wanneer er gecontroleerd wordt voor het effect van de organisatiecontext, leiderschap en cultuur een duidelijke invloed hebben op het bedrijfsresultaat. De uitkomsten van het onderzoek weerspiegelen echter ook het grote belang van de puur economische variabelen voor het bedrijfsresultaat.

In hoofdstuk 9 worden de uitkomsten van het empirisch onderzoek in een breder kader geplaatst. Twee argumenten staan in dit hoofdstuk centraal. Ten eerste ondersteunen de uitkomsten van het onderzoek de veronderstelling dat organisatiecultuur een belangrijke rol speelt in organisaties. De leiderschaps- en cultuurvariabelen die gerelateerd zijn aan bedrijfsresultaten wijzen in de richting van vertrouwen als kernvariabele in de organisatie: vertrouwen wat betreft motivatie en doelstellingen, taakuitvoering, en sociale interacties binnen de organisatie. Deze bevindingen zijn consistent met recente ideeën over de kwaliteiten van een lerende organisatie. Vertrouwen wordt vaak genoemd als randvoorwaarde voor kennisontwikkeling en empowerment van medewerkers in de organisatie. Ten tweede benadrukken de resultaten het belang van de formele organisatie en economische argumenten van rationaliteit en efficiency. De formele organisatie is het instrument bij uitstek om kennis te bowaren en te communiceren in de organisatie. Het combineren van de eisen die gesteld worden aan een organisatie die ruimte moet geven aan creativiteit en innovatie, maar ook moet zorgen dat de nieuwe kennis op een zo efficiënt mogelijke manier wordt gebruikt en vastgelegd, lijkt de uitdaging voor het management in hedendaagse organisaties. 


\section{Curriculum Vitae}

Bas A.S. Koene is op 19 augustus 1966 geboren te Maastricht. In 1984 slaagde hij voor het eindexamen Atheneum, waarna hij Economie ging studeren aan de Rijksuniversiteit Limburg. Van september tot december 1987 studeerde hij aan de Accounting and Finance Department van de London School of Economics and Political Science. $\mathrm{Na}$ het behalen van het doctoraaldiploma in mei 1989 trad hij als assistent in opleiding in dienst bij de sectie organisatie van de vakgroep Management Wetenschappen van de Rijksuniversiteit Limburg. Van januari tot april 1992 was hij als visiting scholar verbonden aan de Management Department van de Wharton School van de University of Pennsylvania in Philadelphia. Voor dit bezoek ontving hij een beurs van de Nederlandse Organisatie voor Wetenschappelijk Onderzoek. Sinds mei 1994 werkt hij als universitair docent bij de sectie organisatie van de Rijksuniversiteit Limburg.

Bas A.S. Koene, born August 19th 1966 in Maastricht, studied Business Administration at the University of Limburg in Maastricht from 1984 to 1989. From September to December 1987 he studied at the Accounting and Finance Department of the London School of Economics and Political Science. After receiving his Master's degree in Business Administration in May 1989 he joined the Department of Management Sciences of the University of Limburg, where he completed this doctoral dissertation. Between January and April 1992 he was a visiting scholar at the Management Department of the Wharton School of the University of Pennsylvania in Philadelphia. Since May 1994 he has worked as an Assistant Professor in the Department of Management Science at the University of Limburg. 


\section{LIST OF ABBREVIATIONS}

\section{Abbreviation}

Leadership

CHLDS

COLDS

ISLDS

Organizational culture

ECUL

OCUL

Organizational climate

GCOM

INNO

TCOM

Satisfaction

SATIS

Organizational context

STSIZE

NRMPROD

AAGE

COMTNR

STOTNR

CSTMRS

Performance variables

DCSTS

DNTRES

DPRODDIF

DSICKLV

DWAGE

MCSTS

MNTRES

MPRODDIF

MSICKLV

MWAGE

\section{Description}

Charismatic leadership

Consideration leadership

Initiating structure leadership

Employee orientation

Open culture

General communication

Readiness to innovate

Task communication

Satisfaction

Store size

Norm productivity

Average employee age

Years in company

Years in store

Social class customers

Development controllable costs:

Development net results

Development productivity difference

Development sick leave

Development wage costs

Mean controllable costs

Mean net results

Mean productivity difference

Mean sick leave

Mean wage costs 


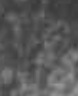

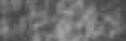

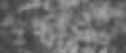

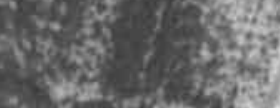

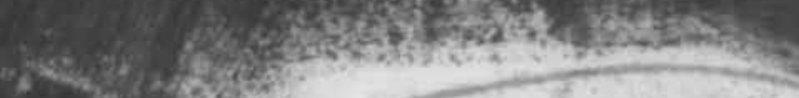

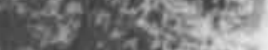

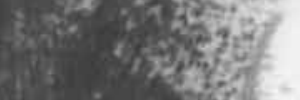

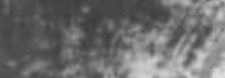

aton is

ovity
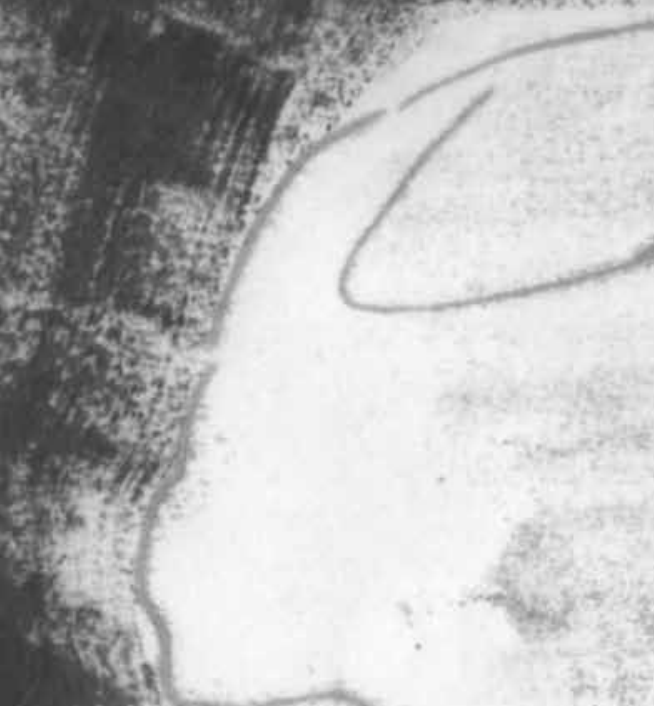